4.2.

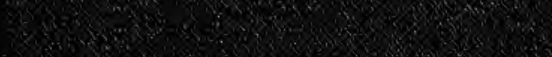

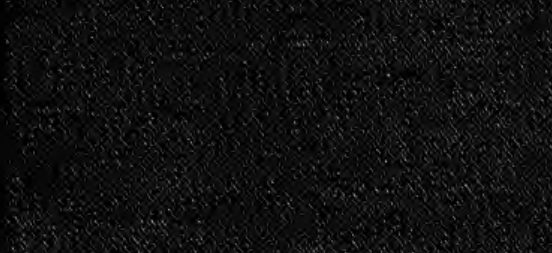

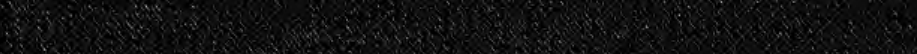

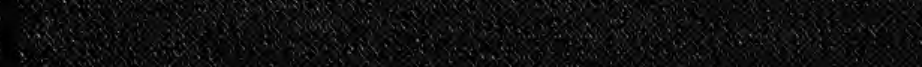
S.:

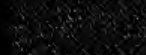

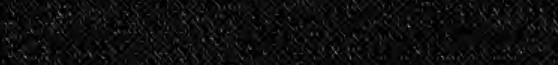




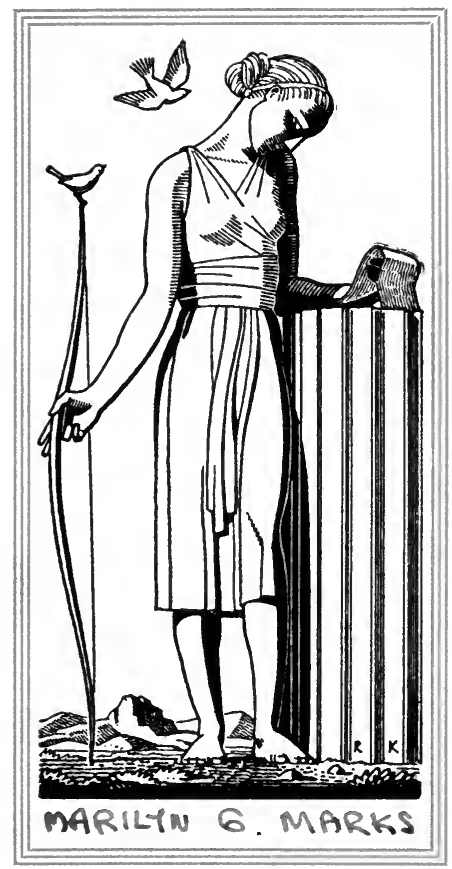


From the collection of the

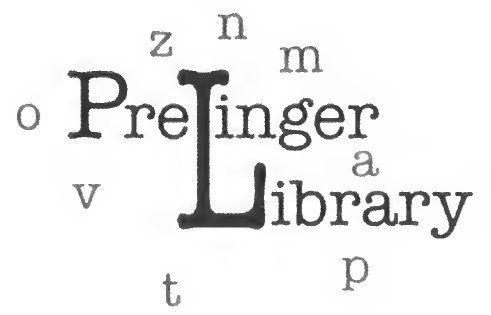

San Francisco, California 2006 
$$
\text { . }
$$ 


\section{RADIO AS AN ADVERTISING MEDIUM}





\section{RADIO AS AN}

\section{ADVERTISING MEDIUM}

BY

WARREN B. DYGERT, B.S., C.E.

Associate Professor of Marketing, New York University;

Secretary and Account Executive, F. J. Low Advertising Agency; Member of University Radio

Committee, New York University

First Edition

SeCONd Impression

McGRAW-HILL BOOK COMPANY, INC.

NEW YORK AND LONDON

1939 


\author{
Copyright, 1939, BY The \\ McGraw-Hill Book Company, Inc. \\ TRINTED IN THE UNITED STATES OF AMERICA \\ All rights reserved. This book, or \\ parts thereof, may not be reproduced \\ in any form without permission of \\ the publishers.
}




\section{PREFACE}

This book is written solely to give businessmen and advertising executives enough fundamental data about radio to weigh and evaluate the possibilities of radio as a carrier of advertising messages. It covers primarily what the businessman should know about this fast-growing advertising medium if he is to get the most out of it in sales and advertising results; in other words, if he is to make radio advertising pay dividends.

The author has endeavored to maintain a single viewpoint, that of the advertiser, the man who has a right to some kind of yardstick to measure the effectiveness of radio advertising and the efficiency of those who plan, build, and present the sponsored radio program which he pays for.

There are, of course, other worthy (many might say more worthy) viewpoints from which to study radio. The author is in no way belittling their importance. He does believe, however, that the advertiser has a right to consider advertising as the most important part of radio. For him, at least, it is.

The author wishes to extend his thanks in particular to: Mr. Richard W. Brown, College Editor of Orchestra World, for valued assistance on the chapter on music; Mr. C. E. Hooper, President of C. E. Hooper, Inc., and Mr. A. H. Lehman, Manager of Cooperative Analysis of Broadcasting, for valuable material on popularity ratings; Mr. E. P. H. James, Advertising and Sales Promotion Manager of National Broadcasting Company, Mr. J. J. Karol, Director of Market Research, Columbia Broadcasting System, and Mr. J. R. Poppele, Chief Engineer of the Mutual Broadcasting System, for their kindness in submitting to the author's lengthy verbal questionnaire and for permission to reproduce the fine charts and tables developed by their respective companies; and Advertising and Selling, Broadcasting, Printers' Ink, Radio \& Television Retailer, Sales Management, and Variety for permission to reproduce various charts and material appearing in their publications.

Warren B. Dygert.

New York,

September, 1939. 


\section{CONTENTS}

PREFACE. . . . . . . . . . . . . v v

CHAPTER I

Let's Go Dial Shopping. . . . . . . . . . . . . . . 1

CHAPTER II

ShOWMAN or AdVERTISER? . . . . . . . . . . . . . . . . . . . 13

CHAPTER III

The Key to Radio Success: Mr. John Q. Public . . . . 22

CHAPTER IV

Those Who Can Listen-and Those Who Will. . . . . 35

CHAPTER V

Broadcasting Tools-How to Use Them. . . . . . . 49

CHAPTER VI

What the Show World Has to Offer. . . . . . . . . 64

CHAPTER VII

What Type of Program. . . . . . . . . . . 71

CHAPTER VIII

If There Be Music. . . . . . . . . . . . . . . . . . 86

CHAPTER IX

Radio Time-When, How Much, and at What Price. . 99

CHAPTER X

The Competition-How to Handle It. . . . . . . . . . 109

CHAPTER XI

How the Program Is Bullt and Presented . . . . . . 115

CHAPTER XII

Writing the Advertising Script. . . . . . . . . 123 
viii CONTENTS

CHAPTER XIII

Censorship-Governmental and Otherwise. . . . . . 138

CHAPTER XIV

ANd Now-to Tell the World! . . . . . . . . . . . 155

CHAPTER XV

Contact—How to Get It. . . . . . . . . . . . . . . 162

CHAPTER XVI

Keeping the Dealer Interested . . . . . . . . . . . 168

CHAPTER XVII

Shall We Have a Contest? . . . . . . . . . . . . . 175

CHAPTER XVIII

Trial and ERror Testing. . . . . . . . . . . . . . . 187

CHAPTER XIX

Popularity Ratings . . . . . . . . . . . . . . 194

CHAPTER XX

The Advertising Agency and Radio. . . . . . . . . 209

CHAPTER XXI

Can Radio Do It All? . . . . . . . . . . . . . . 214

CHAPTER XXII

Tests and Surveys by Broadcasters. . . . . . . . . . 219

CHAPTER XXIII

Getting the Best Out of the Small Station. . . . . . 224

CHAPTER XXIV

Foreign Broadcasting . . . . . . . . . . . . . . . 229

CHAPTER XXV

Television, Facsimile, and Ultra High-frequency Broadcasting . . . . . . . . . . . . . 235

INDEX. . . . . . . . . . . . . . . . . . 247 


\section{RADIO AS AN ADVERTISING MEDIUM}

\section{CHAPTER I \\ LET'S GO DIAL SHOPPING}

When a merchant decides to open a store, if he is clever he plans every detail to fit the type of trade he wants to draw. His location, the lines he stocks, the type of salesgirls, the very color scheme of his interior decorating, all are carefully chosen to suit not the merchant or the merchant's wife, but the merchant's prospective customers.

When a businessman decides to go in for radio these days, he is not always so clever-generally because he is told that radio is something new, that nobody knows all about it, and that you have to take a chance. The Saturday Evening Post methods will not work-a new technique is in the making. It is high time the businessman himself, who after all is the one to pay the piper, is given enough fundamental rules (old and new) about this great business so that he does not have to follow blindly his "yes" and "no" men. His radio advertising program, whether it costs $\$ 10,000$ or $\$ 100,000$, will then be planned and executed to fit the type of prospects he wants to reach; will draw not the millions who merely want to be entertained, but the millions or even the thousands who are ready, able, and willing to buy and use his product.

This sounds simple in its fundamental form. But it is not. Few businessmen and a surprisingly small number of good advertising men are equipped with the facts to weigh and evaluate the radio possibilities presented to them. Some listen docilely to their advisers and, if the advisers have experience and are keen thinkers, succeed. Others, not so well advised or determined to bring to radio the unadjusted business acumen which has made them big businessmen, fail dismally. Then radio 
has to set up another tombstone in a graveyard of unnecessary failures where the other advertising media are only too pleased to keep memories alive with daily wreaths of condolence.

\section{Why Some Sponsored Shows Fail}

Only recently a great show went off the air-a failure. It had a good cast, an enthusiastic following, and a fair rating, but sales did not justify the cost of the program. Ninety-five per cent of the buyers and users of the product advertised were women, yet twice when the author sat among the studio audience over 65 per cent of those attending were men and boys, and these in a lower income bracket than that of the families who bought the product. A studio audience is not always a sample of the armchair audience, but one might well wonder in this instance what might have been the case history of this show if the businessman who paid the bill had said early in the game: "Say, I don't see any customers in this rabble. Maybe our show is drawing the wrong people."

The author has often wondered what the sponsors think about while they sit, in their correct evening attire, in the little glass-enclosed "sponsor's booth" and look down on the audience their money is making happy. Are their minds on this serious business of making a radio show pay or on the pleasure of taking the world-famous $\$ 5,000$-an-evening star up to the roof garden after the show?

\section{Dial Shopping - the Great American Pastime}

But let us start at the beginning. Perhaps there is no better way to get the "feel" of radio than to go dial shopping, for after all that is what a goodly percentage of our potential customers do. Radio listeners can be divided into three groups:

1. Those who shop for program values.

2. Those who consult the papers and know what they want.

3. Those who turn on a favorite station and keep tuned in regardless.

Twisting the dial, that great American pastime, will give the business and advertising man an astonishing picture of how unstandardized and complicated broadcast advertising procedure is. Of course, if we were Mr. Average Dial Shopper, we would shop only until we have found a program to fit our mood and 
then settle down in the armchair. We might also even read a book - for radio has developed a delightful group of people who can do two things at one and the same time. The advertiser might make a note that his program will be so compelling that the competing book shall be closed.

But we are after information and shall shop the entire dial and stop long enough at each station to see what it is all aboutparticularly the advertising.

\section{Soft Music-Harsh Sales Talk}

Here is stop number one: Soft music played by a famous orchestra. After a busy day at the office, we could well see ourselves soothed into a reverie. But what's this! The music ends. A voice, vibrant with the hammer and tongs of quickaction salesmanship is shouting at us. If we had been napping over the sweet music, the voice would have startled us out of our armchair and into a nasty frame of mind, like a sleeper suddenly shaken by the shoulder. The voice is using the good old advertising formula that ends with action and direct commands. Do this! Do that! We can see, in our mind's eye, the voice's owner, his coat off, sleeves rolled up, honest sweat on his forehead. "Accept nothing else," he shouts. "Have no regrets. Don't let another day go by without B_—. Get B at your dealer's now-today."

"My type of customers would never be influenced by this barrage," we say as we sadly tune it out.

\section{The Good-will Ambassador}

And here is stop number two: Music again! But the voice that follows is as soothing as the music. If this music had lulled us into a reverie, such a voice might not bring us out of it. They call this voice the ambassador of good will. He wants you to think kindly of his product. He may even suggest in a friendly, sincere voice and a few short words that you try S-_-sometime or he may say simply, "If you have enjoyed this program and care to show your appreciation, visit your neighborhood druggist, whose cooperation makes this program possible."

Once when the author asked the sales manager of a nationally known concern, which was using this type of program, whether 
he could check its sales value, he said proudly: "We don't want to. This is a good-will program-the icing on our advertising cake."

\section{Applause-at $\$ 17$ a Second}

And here is stop number three: We have heard of this program before. If surveys are correct, probably 20 per cent of all sets turned on are tuned to it. The total half hour on all the network stations presenting the program costs over $\$ 10,000$. Another $\$ 20,000$ goes into famous stars, orchestra, script writers, and master of ceremonies (m.c. to the profession). No money is spared here. They even let the studio audience applaud at $\$ 17$ a second. The show is good. The advertising is so closely integrated with the entertainment and so interestingly presented that we scarcely realize it is advertising.

Yet after all, we are coolheaded businessmen. We make a calculation. If the product being sold on this program has a gross margin of profit of 3 cents (and some popular low-priced commodities have less) then, in order to pay out, this program must sell one million packages a week. And well it might if the program is designed to attract, among its millions of listeners, enough millions who are ready, able, and willing to buy and use the product. There must, however, be few among them like the little old lady who listened regularly to the Chase \& Sanborn program and when asked whether she was sold yet on that particular brand of coffee remarked: "Oh, I can't drink coffee; it keeps me awake. But I do love Charlie McCarthy."

\section{The "Small-time" Show}

Just one more stop. Here on a small station is a valiant little program competing with the "supercolossal" we have just tuned out. No big names on the program, no famous orchestra, but withal an interesting performance. We wonder how it dares compete with such a famous show until we study its makeup, which is as different from the big show as day is from night. We can see how, if a person's mood or taste was not that of the big show, this one might be interesting. And on that one premise alone the show was built-to attract the few whose permanent taste or temporary mood craved something different. After all, no one show was ever built which could satisfy every 


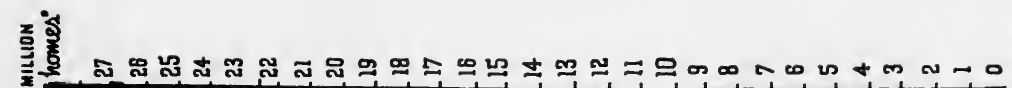

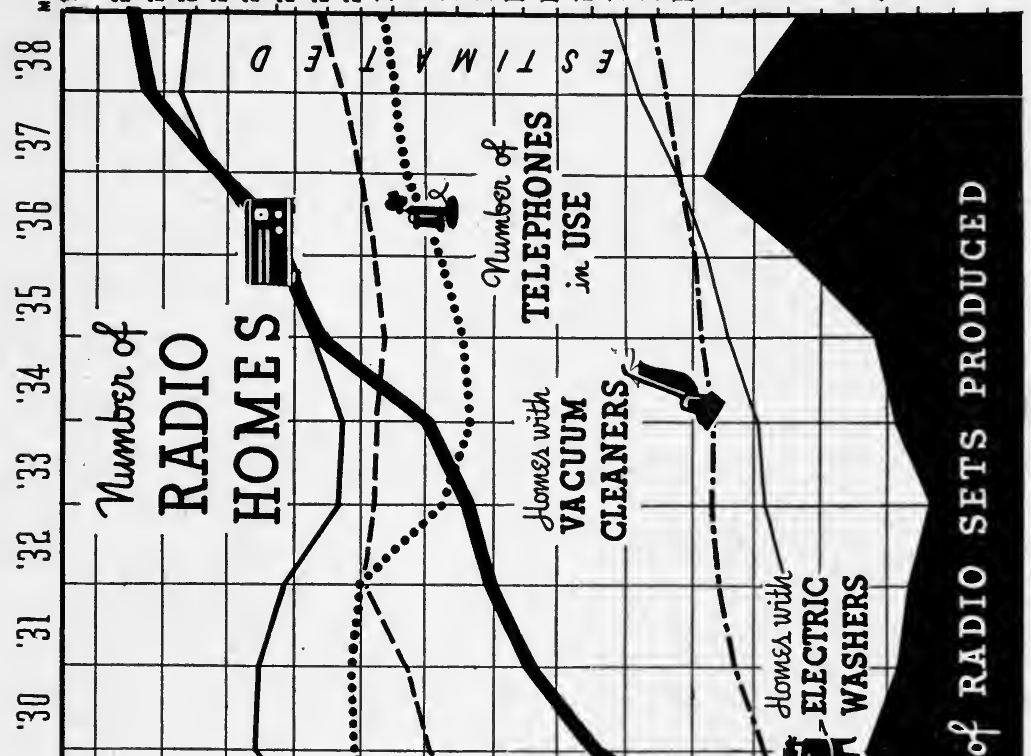

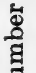
9
0
0
8
0 
listener. This show may attract only a scant 100,000 , but its cost may be so low that this modest circulation would make it pay.

And so we might shop on. Commentators whose views insult half the "sponsor's prospects; big stations and small; costly programs and cheap ones; good ones and bad; programs with too much advertising; programs with too little-and we can draw this one conclusion. The radio program today that pays its way is carefully built to fit the product it advertises and to appeal to the type of people who are the best potential prospects. Too many shows today are built to entertain millions rather than to sell the hundreds of thousands. Too many products are fitted to the program rather than the program fitted to the product, which after all is the only reason for the sponsored show's existence.

Admittedly, it is no easy task to select the ideal program and it cannot be done in every case. But this at least can be the objective-and the nearer it is reached, the greater the possibility that the program will pay out for the advertiser.

\section{Radio's Big Advertisers}

But before we discuss any plans for reaching this objective, it might be well to see what tried-and-true implements of the general-media field and what standard advertising tools the businessman can bring along to work in this new field. New field, because sponsored radio is less than 20 years old-yet in that short period of time it has developed over a $\$ 100,000,000$ annual income from advertising, not to mention an almost equal amount spent for talent and other advertising production costs. It has built up a sponsor following which includes at least 19 who spend a million or more annually. One of these, the Procter \& Gamble Company, spent in $1937 \$ 4,497,000$. The next runner-up was the General Foods Corporation, which spent, in the same year, $\$ 2,765,000$. Nor does the end seem to be in sight. All but four of the 1936 million-or-over sponsors increased their advertising during the next year. All of the 1936 advertisers repeated in 1937 .

Lest one gets the idea from this that radio is the big advertiser's field, records show many advertisers spending less than $\$ 50,000$ each, who have been consistent advertisers for several 
consecutive years. Many of these have consistently increased their appropriations each year. So rapidly has radio grown that in 1938 it actually outstripped some of the older advertising media. Printers' Ink gives the figures as follows:

Expenditures in Five Media,* 1928-1937

(In millions of dollars)

\begin{tabular}{r|r|r|r|r|r|r}
\hline & $\begin{array}{r}\text { News- } \\
\text { papers }\end{array}$ & $\begin{array}{c}\text { Maga- } \\
\text { zines }\end{array}$ & Radio & $\begin{array}{r}\text { Out- } \\
\text { door }\end{array}$ & $\begin{array}{r}\text { Farm } \\
\text { Paper }\end{array}$ & Total \\
\cline { 1 - 4 } 1928 & $\$ 720$ & $\$ 190$ & $\$ 20$ & $\$ 85$ & $\$ 30$ & $\$ 1,045$ \\
1929 & 760 & 210 & 35 & 80 & 30 & 1,115 \\
1930 & 670 & 180 & 50 & 65 & 25 & 990 \\
1931 & 590 & 150 & 70 & 50 & 20 & 880 \\
1932 & 470 & 110 & 75 & 35 & 10 & 700 \\
1933 & 430 & 100 & 65 & 30 & 10 & 635 \\
1934 & 470 & 125 & 90 & 30 & 13 & 728 \\
1935 & 500 & 130 & 110 & 35 & 14 & 789 \\
1936 & 550 & 150 & 135 & 45 & 17 & 897 \\
1937 & 570 & 165 & 165 & 50 & 18 & 968 \\
\hline
\end{tabular}

* Since the P. I. Index of Radio Advertising is based on billings of the two leading broadcasting companies, and since percentage that local and spot broadcasting is of total broadcasting has been increasing, a slight adjustment has been made for this fact in the earlier years. (Printers' Ink, June 16, 1938.)

\section{The "Supercolossal" Show}

Obviously not all of radio's advertisers - even the consistent ones-can definitely prove the sales value of their radio expenditures. Many use practically every medium of advertising, so coordinated that to pick out radio's share would be impossible. Some, like Lady Esther, Ltd., which have, at the present writing, the bulk of their advertising appropriation in radio, can check by sales. That they continue to be consistent radio advertisers year after year leads to its own conclusions. But some-we may as well be honest-have their radio horse by the tail and do not dare let go. It is a characteristic of radio-as it is of the show business - that bigger and better shows must be produced, more and more people glued to their radios.

Whether all these "supercolossals" are a paying proposition from a sales point may well be questioned. Every sane advertiser knows that, with space advertising, a place must be reached where to spend an extra $\$ 100,000$ will not bring the same per- 
centage of extra sales as the last $\$ 100,000$ expenditure did. Keen-thinking radio advertisers might well consider this, especially when tempted to rebuild a good half-hour program to a better full-hour one. It is reasonable to suspect that the new program will not double the sales or even add one-half more. Space advertising has gone through all this and some worth-while conclusions have been drawn. ${ }^{1}$ The advertising man cannot bring these figures to radio, but he can bring this principle.

\section{Applying Standard Advertising Procedure}

Other standard advertising practices which may be brought safely to this new field are research, testing (see Chap. XXII), the psychology of the consumer (including his radio habits), and circulation. A preliminary word about circulation, which will be discussed in detail in Chap. IV; this is one of the most confusing points of radio. The average businessman is pretty much tied up to the habit of buying tangible figures when he buys circulation. He looks - as he should-on an advertising medium as a simple carrier of his advertising message. If he buys an advertising page in The Saturday Evening Post for $\$ 8,000$, he knows over $3,000,000$ copies of his advertisement will be delivered. If he buys a full showing of outdoor advertising posters, he gets 16 or 640 billboards, each with a checked circulation of so many passers-by. In both cases the number of persons who receive or are exposed to his first advertisement are likely to be comparable to the number who receive or are exposed to the fifth or the tenth advertisement. Circulation figures are fairly constant for each issue.

But with radio, circulation is a very elastic affair. Unless, as pointed out in Chap. XIV, methods are taken to build up its circulation, the first advertisement is likely to have scant following. The tenth advertisement, if the program has been good, may even without methods of build-up have hundreds of thousands more listeners. One radio executive, referring to the increasing radio circulation without merchandising helps, has said that it takes 13 weeks for a program to build up a worthwhile audience and it is the next 13 weeks that bring paying

${ }^{1}$ Tipper, Hotchkiss, Hollesworth, Parsons, "Advertising, Its Principles and Practice," p. 115, Ronald Press Company, New York. 
sales returns. Unfortunately, the timid advertiser, having gone 13 weeks with scant results, has not the heart nor the backbone to continue. Some of radio's most unnecessary failures are in this class; just as with the printed media, some of the most pathetic failures are chalked up to the advertiser who expects a one-time advertisement to "pay out."

\section{Advertising Principles to Discard}

Now for some of the standard advertising precepts which must be cast aside. The first is that the advertising message can stand by itself unsupported by either entertainment or worth-while information, news, or service. This just is not done if you are taking your radio seriously. One might think the little commercial announcements which some stations sell on a 1-min. time basis (approximately 125 words) are an exception to this. Certainly they have no entertainment value unless it be the exaggerated and often humorous claims of the sponsor. Some sponsors have used them with fair success but these parasites on the structure of standard broadcasting procedure are successful not in themselves but because they precede or follow a program with a good listening audience. Certainly no saneminded radio listener would turn to a station whose policy was to run only these straight advertising messages.

Surveys show time and again that listeners abhor these spot announcements and tune them out unless they are waiting for the regular program which is to follow. The reason for this is the listener's attitude. He turns on his radio for the entertainment, information, news, and the like but not for the advertising. If he gets 90 per cent of this sought-after material on a sponsored program, he will tolerate the remaining 10 per cent advertising.

\section{The Weakness of Unsupported Advertising}

Because a goodly number of the radio audience are practically forced to listen to these independent advertising announcements, they pay, particularly if the spot announcement precedes or follows a program with a million or more listeners. As obnoxious as these "spots" are to the radio listener, they account for a goodly proportion of the advertising sales volume of small stations. From a media-buying standpoint they may be a very 
good buy if spotted at the right time. What would a shrewd advertiser give for just 20 words (let alone 120) of advertising preceding the Chase \& Sanborn program or the Jell-o program starring Jack Benny. Of course, on a big station he could not get it, for big stations frown on the practice. But the small stations have been known to sell spots in almost any desirable location.

It should be noted that not only does the listener frown on these small spot announcements but the big advertisers as well. They feel that the spot announcer is stealing circulation which they have spent thousands of dollars to build up. Such outstanding advertising agencies as N. W. Ayer \& Son and Young \& Rubicam, Inc. are on record as militantly against the practice. In Canada, the Canadian Broadcasting Corporation has ruled this type of announcement off the air between the hours of 7.30 and 10 P.M. and also ruled that no spot announcement shall exceed 100 words or shall total more than $3 \mathrm{~min}$. in any hour.

The popular time signals sponsored by the Bulova Watch Company, Longines-Wittnauer Company, and the like do give the listener a service and should in no way share the ill repute of the spot announcements just discussed.

\section{New Advertising Principles for Radio}

Now let us consider, in a preliminary way, some of radio's own precepts-precepts that run contrary to the accepted experience in other advertising media. One is the matter of entertainment. An advertiser in The Saturday Evening Post or Collier's spends his $\$ 8,000$ or $\$ 5,500$ for an advertising page, secure in the fact that the magazine itself will have spent many more thousands on story and editorial material so that reader interest will be guaranteed. There may even be an article so sensational that thousands of new readers will be added. Certainly the advertiser needs no entertainment (as such) in his advertisement. In radio, the advertiser has no such assurance. ${ }^{1}$ The advertiser must furnish his own entertainment and, like the midway pitchman's, it must be good if he expects people to

${ }^{1}$ Some might say that radio's sustaining programs, those put on by the station itself, are comparable to a publication's stories, but their value accrues more to radio as a whole than to the individual station or to a specific hour of listening. 
stay and listen to his sales message. In fact, his entire success will depend on how well he presents his entertainment.

Another startling difference between publications and radio is that sustaining features are for sale to advertisers. Practically any feature built by the station can be bought. In fact, most stations build their sustaining features with an eye to selling them to a sponsor. Note the sly jokes by the m. c.'s on many of these programs inviting sponsorship. Fancy buying the leading editorial in The New York Times and placing your advertising message between paragraphs 4 and 5 and 12 and 13. Yet this, if you please, is an accepted practice in radio, accepted by the mass of listeners, criticized only by the small class minority.

\section{Oddities of Radio}

Another oddity that handicaps the old-time advertising man is the matter of class and mass circulation. He knows if he buys advertising space in Redbook, True Story, Business Week, Country Life, he buys a ready-made type of reader. The publisher can tell him the reader's buying habits, income bracket, even the group age and sex. This solves a big problem in periodical advertising. In radio, with the exception of foreign-language stations, the advertiser has no such help. Rich and poor, employed and unemployed, educated and uneducated, moron and solon listen to the radio-and are no respecters of stations. The radio advertiser has the added task here of picking out the group he wants and building his program to attract and hold that group. If he wants both mass and class, he may do as the Ford Motor Company did in building a special custom-made program for each group. Or he may attempt to build one program for all, a difficult feat for, as already pointed out, no one program can possibly suit everyone.

\section{Popularity-How to Hold It}

One final caution to the businessman contemplating radio. This is a fast-moving business. If you are going along, decide to give it all you have in energy and ideas. Do not overlook what you have learned in your own business; the public is fickle, ever searching for something new, easily becoming deaf to anything said or done in the same old way, whether it be 
advertising appeal or entertainment. Your biggest radio headache will not be in getting a reputation with your listeners but in keeping it. Sponsors of top-rating shows are ever on the hunt for new material to keep their show at the top. The listening public tires of its radio shows as it tires of its movie heroes. One year, amateur shows are the vogue; the next, variety comedy hours. The next year will see listeners flocking to something else - an idea probably hitherto unknown. Clever is the sponsor who can keep his place in the spotlight; a study of the few who have done so will picture the ever-changing details and novelties which keep the same show always a new one.

There is an old line of Alexander Pope's which runs: "Be not the first by whom the new are tried, Nor yet the last to lay the old aside." The businessman can modify this for his radio efforts: Be the first to accept a new idea and far from the last to discard it. Watch the trends. If something new seems to be catching on, be ready to work fast. Skim the cream while the milk is fresh. But don't be left, as some of our big radio advertisers have been, with an idea that was new 6 months ago but today is as uninteresting as yesterday's newspaper. If your show is a well-accepted one, your ratings will warn you (see Chap.

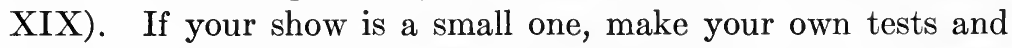
surveys. A few hundred dollars thus spent may dig up advance warnings which can save you thousands of dollars. 


\section{CHAPTER II}

\section{SHOWMAN OR ADVERTISER?}

One of the first surprises to confront the advertiser when he gets serious about the possibilities of radio advertising is the dual personality back of this radio business. He finds right from the start two radically different viewpoints-that of the advertiser and that of the showman. To an advertising manager experienced in all the intricacies of visual media, a failure to adjust himself to this dual personality may spell ruin. Inability to see both viewpoints has probably accounted for many of the failures of the air-the sponsored programs that are not handing the advertiser a profit on his investment.

\section{Two Different Viewpoints}

Admittedly, the advertiser's cold business view is important. His talk of markets, product distribution, advertising message, type of prospects, and actual sales must be considered. Business to stay in business must make a profit. "Box-office" attractions to the radio advertiser must be "box-selling"-boxes of his product. No sales-no program. That can be put down as fundamental.

Yet this other factor, the showman, is also vitally important to radio. He will talk of entertaining the public, of listener popularity, of glamour, glitter, and celebrities with a following. He will say and rightly; no good show, no listeners; no listeners, no sales. Where the businessman is geared to run on cold reason-why facts, the showman's machine is driven by emotion and enthusiasm. There never was a good showman yet who did not believe his ideas simply could not fail-who would not rather use a $\$ 5,000$ star even when the sponsor's margin of profit on his product could allow only a $\$ 1,000$ one.

\section{A Combined Viewpoint}

So long as radio must - in the $15 \mathrm{~min}$. or more sponsored program-furnish 90 per cent entertainment to 10 per cent sales 
effort, the show will come first. Nothing in this chapter should be construed to belittle the showman's importance or to make him a "necessary evil." What the author does want to point out is that often the advertiser's point of view is a fine governor to keep the great show engine from running so fast that it flies to pieces.

To the businessman and advertiser this sound advice: Get the showman's viewpoint but don't try to be a showman unless you always have been, and many good businessmen have been showmen from the day they sold their first bill of goods. Unfortunate is the businessman who, instead of trying to justify these two viewpoints, has tried to make himself over into a showman. If you are inhibited with the urge to put on a good entertainment for the world, if you think a radio program is a place to live vicariously in the world of tinsel and spotlights, don't risk your stockholders' earnings by demonstrating your showmanship. Take $\$ 50,000$ of your own money and be a "good angel" to a new Broadway show.

The advertiser will be more valuable to radio if he looks coldly upon the-show as nothing more than a means to carry a business message about his product or service. A glorified Christmas tree, if you will, on which he can hang his advertising messagesand not make them so heavy that they break the limbs or upset the tree. But he can insist that, no matter how successful the show, how vast the listening audience, he wants to know how many of these are potential sales prospects, ready and able to use his products, and so located geographically that they can procure them. The advertiser should continue to look at the radio show not only in terms of listeners, the showman's viewpoint, but in terms of the number of product packages it costs him, the advertiser. If he wants to stay in business, in the long run, he must get from radio better than a dollar back for every dollar he puts in it.

\section{Weakness of Advertiser's Viewpoint}

On the other hand, the advertiser should not let his prosaic grasping for dollar returns ruin his program's opportunity. If radio is suffering from anything today, it's not an overdose of showmanship but an overdose of the advertiser who in his anxiety to make sales, tramps with hobnailed shoes over the 
gossamer fabric of the entertainment-and consequently over the sensitive feelings of his listeners. We have him to thank for those dry-as-bones sponsored shows which Charles F. Gannon, radio director of Erwin, Wasey \& Company, said are "largely commercial copy, badly conceived, badly projected, obtrusive, inharmonious, braying of wares, deficient in grace and as unproductive as-unnecessary."

\section{Danger of Public Disapproval}

The advertiser must realize that this "braying of wares" in the radio market place is as pleasing to many listeners as the hawk of the itinerant huckster under a sickroom window. No one realizes this more than the broadcasting companies themselves. They know that the air belongs to the people, ${ }^{1}$ and that radio is regulated on a basis of public "interest, convenience, and necessity." They know their first job is to furnish the public with information, news, entertainment (hence the sustaining programs) and their second to let advertisers sell their goods over their stations.

They fear, as every other advertising medium does, public disapproval; for public disapproval means stringent government regulation at worst or smaller sales from advertising in that medium. Organized outdoor advertising was wise enough to see this years ago, yet in spite of bettering outdoor sign placement, there is a group of conscientious objectors whose concerted cries get into print more than occasionally. Radio, too, has its conscientious objectors, particularly against advertising, and it behooves the advertiser not to give them more to complain about than necessary. To the great mass of radio listeners the advertising message can be made effective and yet not obnoxious. It is a fairly safe axiom that the more educated (or intelligent) the radio listener, the more antagonistic he is to long and poorly placed advertising messages. When selling

1 "While the Commission recognizes the United States broadcast stations are for the most partially supported by advertising, nevertheless privileges granted said stations by the government are primarily for benefit of the public and benefit derived to advertisers must be incidental and secondary thereto." U. S. Broadcasting Corporation et al., 208 (224). ("Second Annual Report of the Federal Radio Commission to the U. S. Congress 1928," p. 168.) 
exclusively to this class, the less direct selling the better. Study the amount and placing of advertising in such programs as the Ford Sunday Evening Hour.

The advertiser, then, can sum up these foregoing paragraphs thus: "Don't kill the goose that lays the golden eggs." If you are the type that will put this down to plain calamity howling, note this case history. Only a few years ago a certain type of proprietary remedies found radio a highly profitable advertising medium. The golden goose laid profitable eggs for them until in their striving to get two eggs a day, they overstepped the bounds of public decency. "Burps" with sound effects for indigestion, intimate excursions into human anatomy (always at mealtime), commercials so intimate that a mixed listening audience dropped its eyes in embarrassment-all this led to an edict, not from the government but from some of the big networks that this type advertising must go. One chain is said to have "let out" $\$ 9,000,000$ worth of business. Result, the advertiser lost a profitable medium; the networks, a profitable advertiser. After all the "public interest" must be served, and no advertiser for a moment should forget it.

\section{How Radio Got Its Showmen}

Be it said to the showman's advantage he never forgets the public interest-unless it be occasionally to overdo the risqué type of entertainment. Radio comes honestly by its showmen. For while it was first simply a means of communication, radio was secondly a means of entertainment and a mass disseminator of news. Advertising as we know it today did not start until 1922, when in September, the Queensboro Corporation of Jackson Heights, New York, N. Y., broadcast over WEAF a 10-min. sponsored talk. At about the same time Browning, King \& Company of New York are said to have broadcast the first sponsored musical show.

But long before this, radio was entertaining the public. In 1916, Station $2 Z K$, New Rochelle, N. Y., operated by George C. Logwood, was broadcasting music betwęen 9 and 10 A.M., daily except Sunday. ${ }^{1}$ And on Nov. 2, 1920, when KDKA, Pittsburgh, Pa., the first commercial station of the air, was founded, it sold no advertising but furnished its limited public music

1 “Broadcasting Year Book, 1936," p. 30. 
via phonograph records and such news as the Harding election returns. Here one had in these early stations technical men with a new invention.

So long as hunching over a homemade set and hearing anything from the air was a novelty, nobody thought much of entertainment and showmen. But when the novelty wore off, good old John Q. Public, always demanding, insisted on better entertainment. It was then that the showman came into his own. Where a station could not develop its own show, it called in the professional. And he came gradually from the stage, the movies, the circus, until today radio boasts some of the country's greatest showmen.

\section{Types of Showmen}

Many of the radio showmen have learned the advertiser's point of view. A few, like Eddie Cantor and Major Bowes, are really doing much to help their sponsors sell goods. Some of the rest, unfortunately, have never learned the advertiser's view. Among their personal friends, they will refer to their sponsor as a kind of little old man of the sea-to be tolerated because they cannot get rid of him. The advertiser will find scant cooperation from this group, which is fortunately small.

Another unfortunate type of showman is the one who can stage a good show for the visual audience (the studio audience), but somehow fails to project his showmanship to the armchair listener in his home. After all, the studio audience as we know it today is probably less than $2 / 10$ of 1 per cent of the listening audience and its only justification is its use to project the show through to the listener. If your showman plays to the studio audience at the expense of the nationwide home-listening audience, get another one before you find radio advertising unprofitable. If you want to check on the success of your program, beware of studio audience reactions-go to the home listener.

Another type of showman who can well be curbed is the one who talks in millions of listeners when the appropriation is such that a few hundred thousand listeners will make the program pay. In this case, if the advertiser weakens, he is likely to find himself the father of a bouncing $\$ 35,000$-a-week show with enough fan mail to put him "in the red" answering it. 
Of course, if like the Procter \& Gamble Company, the advertiser can spend annually for his air shows $\$ 4,497,000$ or like Standard Brands, Inc., the General Foods Corporation, or American Home Products Corporation, over $\$ 2,500,000$ each, a few extra thousand on the show will be well spent and probably bring returns at the corner store. If interested in going after a radio audience in a big way, note the following figures which are reputed weekly, pay checks (mostly covering the supporting cast as well) of some of radio's headliners. Remember, too, that Rudy Vallee is said to have received for his first show on the air, a half hour for Herbert's Jewelry Store, New York City, the magnificent sum of $\$ 60$, out of which he paid his orchestra.

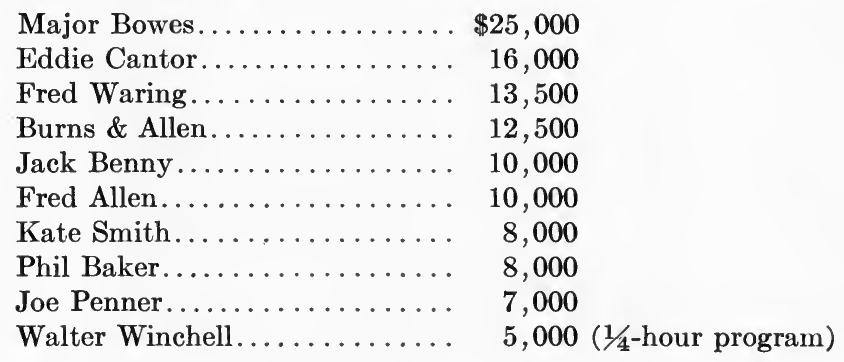

\section{No Sure Formula for Show Success}

It has already been said that the showman bases his efforts on emotion rather than on reason and because of that, so far as showmanship goes, there can be no sure formula for show success. The cold reasoning applied to advertising in other media cannot be applied to the showman's effort. There will almost always be a bit of a gamble on the show's success as such. What will "click" with the show public will ever be a mystery. Take examples of Broadway shows, of movies, and of books. The same master showman who builds a success quite often follows it with a failure. Such box-office hits as "Abie's Irish Rose" and "Over the Hills to the Poor House" were turned down by showmen who thought they knew.

To obtain a successful product-selling radio show, there must be a fine balance of good showmanship and carefully worked-out advertising. This can be possible only when showman and advertiser work together, when each realizes the other's importance and adjusts himself to the other's viewpoint. 


\section{Show Business and Showmanship}

The advertiser should not confuse the show itself with showmanship. Show producing is presenting entertainment to the public. It may be good entertainment or bad. Showmanship is presenting any proposition successfully to the public. The proposition may be entertainment, product, or advertising, but it is presented with that knack that emotionalizes, touches the heart as it were. The fresh-cut flowers on the restaurant table, the neatly pressed suit and shined shoes of the salesman, are each little emotional touches that make the actual selling of the proposition that much easier. Most successful businessmen who have never heard of "theatre" practice showmanship.

There is nothing cheap or tawdry about showmanship. It need not even be spectacular. Showmanship is merely presentation-impressive and expressive. It will be found practiced in the outstanding houses of worship, in great universities, by men in public office, and always it emotionalizes and impresses those to whom the presentation is made.

In business it may mean most anything; in radio it is likely to include adding a touch of entertainment to any presentationshow or advertising!

\section{An Example of Good Showmanship}

An example of good showmanship is well illustrated in one of the successful radio programs. The National Farm and Home Hour which recently gave its 3,000 th performance was first carried on only $18 \mathrm{NBC}$ stations, but today is a regular feature on over 90 stations. Its basic function was to supply the American farmer with the official summary of crop forecasts, weather reports, and other statistics pertinent to agriculture. If it had done only this, its listening audience not only would have been limited but a regular weekly following would have been impossible. The principles of showmanship were applied from the start. Everything was done to give the program an entertainment value that would compete favorably with the offerings of other stations. Nationally known speakers were invited to participate; music and famous guest writers were added; the women of the farm were enlisted through service talks on household budgets, cooking, and home management; human interest 
was added by picking up news and interviews on the spot. A farmer talked directly from the seat of his tractor in the field, a grand champion steer was "interviewed"-little touches of showmanship that raised the program from a mediocre farm service hour to a national program with probably millions of listeners in both country and city.

The moral that can be drawn here for the advertiser is this: a touch of entertainment and human interest can do wonders (1) for the advertising message itself, and (2) for the entire program if the program is of the service type, i.e., how to cook, how to run a home, how to stoke a coal furnace, how to fertilize a garden or lawn. These service or specialized programs, especially when presented during daytime hours, can be made particularly effective if good showmanship is applied to their building and presentation.

\section{Advice to Radio Advertisers}

To sum up the case of advertiser vs. showman, the advertiser will do well to leave the show itself to those who have spent years in the show business. But he can practice showmanship itself and he should know its principles well enough to know when his program lacks understanding showmanship. As to the show, the less the advertiser meddles with it, the better it probably will be. Don't suggest that your niece who brought down the house in the local Rotary Show be a featured soloist on your program. And don't think you can apply cold business tactics to hiring celebrities or telling them what to do after you have hired them. Temperament, moods, jealousy are all old stuff to stage and movie directors-and now to the professional radio program director as well. If he cannot handle the situation, no businessman can.

If the advertiser contemplates big programs with mass appeal and national audiences, he is, as they say, "going into the show business." He should let a showman handle it, but stay close enough to know what is going on. There is a lot of politics among showmen too-putting their "nieces," so to speak, in spotlight positions.

Finally the advertiser should not take all this comment too seriously. There are big shows that go on the air smoothly, that cost the advertiser just what they are worth, and that sell enough 
and sometimes much more than enough products to pay for themselves.

But if the reader does not believe showmanship is necessary, let him listen to a few of the so-called civic interest and educational programs of the air. That they can never develop a million listeners will be plainly evident and the reason is their basic dullness due, in many cases, to a lack of showmanship in presentation. 


\section{THE KEY TO RADIO SUCCESS: MR. JOHN Q. PUBLIC}

John Q. Public, a prince in person! A problem in the mass! The man every advertiser knows - until he comes to radio. The man who can be quite accurately catalogued by his reading habits, but who often defies classification as a radio listener.

Let us look at our radio potential consumers, Mr. John Q., Mrs., and the little Publics. Any advertiser who thinks he can make up one magic program to please the entire public should remember that he has never yet published a single advertisement to accomplish this same end. The advertisement he writes for the Ladies' Home Journal or Good Housekeeping is not the one he uses for the Pennsylvania Farmer, Time, Newsweek, or for the morning newspaper or the evening tabloid, or for Country Life or Spur or The American Boy.

In the magazine field, for example, the advertiser is satisfied to go after one type of John Q. Public and to know reasonably well what John Q. is thinking and feeling when he has his nose between the covers of any particular magazine, because each magazine is built on a definite reader interest.

\section{Comparison of Reading and Listening Habits}

No finer lesson for the radio advertiser is possible than to contrast this picture of his potential consumer at home with the picture of the same person listening to his radio. His reading habits: He probably has before him several magazines and his newspapers. If he wants news as it is, he selects the newspaper, if he wants news summarized, he picks some news weekly; if he wants fiction, beautiful pictures, stories in pictures, cheap melodrama, humor, he can pick from his collection a single publication to fit his mood of the moment.

Take the same consumer, laying a finger to his radio dial. An hour ago, he may have been in the mood for a good mystery story, or light humor, or the news, and satisfied his desire with the printed media. At this second he may definitely want restful 
music. When he read his magazines, page after page of advertisements bothered him not at all. Now, as his dial tunes in a long commercial, he turns again and again until he gets what he wants, music. Or it can be just the other way around; music may for the moment have no charm for him. He may not know what he wants. Fortunately for the radio advertiser, listener moods change rapidly. Many a radio dialer has struck an interesting spot in a program not in keeping with his moodand stayed with the program. The curiosity of the listener is still one of the advertiser's greatest helps.

\section{Radio Listener Difficult to Define}

The conclusion to be drawn, and one many advertisers have learned, is this: The radio listener is not one, but a thousand types. He (or she) is not the same person on Tuesday as on Sunday, nor at 6 P.M. as at 8:30 P.M. This should be considered in designing a program to reach a maximum number of listeners. For it is the design of the program that counts rather than the station. The advertiser can buy a million potential listeners if he selects the proper broadcasting station or stations. His work, however, has just begun. His cleverness in selecting and developing his program idea and that alone will determine how many of the million potential listeners become actual listeners. And the way he constructs and places his advertising will again determine how many of these listeners become actual buyers. It should be noted here that the sole purpose of radio entertainment is to create an audience to listen to the advertising message. The advertising and not the program sells goods, just as in the printed media the contents of the publication draw the readers while the advertisements sell them.

\section{Fitting the Program to the Listener}

As difficult as the problem may seem to interest a maximum number of the potential listeners, the procedure basically is fairly simple. Three fundamental rules can be applied:

1. Determine what class of the public has the biggest sales possibilities.

2. Design a program to interest this class.

3. Select a time of day and week best suited to reach the greatest number in this class. 
But to apply these three simple rules, one must be familiar with a vast amount of data covering not only the listening habits but also the daily habits of the potential consumer. For while radio has changed many of the public's habits, many of the fixed habits still stand. Consider for instance; certain groups definitely prefer musical programs to spoken ones. Surveys have shown that approximately 65 per cent of radio programs are musical. This may mean that a good musical program may draw more listeners. But how many will be lovers of music giving their undivided attention to the program and how many will have turned to music only because music can be an innocuous background for reading, talking, and playing games.

Consider the age of the listener. How does this affect his radio likes and dislikes? Certainly the 16-to-25 age group, at the present writing, leans toward popular music in a fast tempo, while the 45-to-60 age group seems to prefer familiar tunes or the semiclassics. Certainly an advertiser who wants to reach both groups with a musical program would be safer with two musical programs of decidedly different types. Or consider the juvenile programs and serials. Just what ages should they be planned for? A survey made a few years ago by Erwin, Wasey $\&$ Company using 10,000 letters sent in on a Hecker's program ${ }^{1}$ showed the peak interest on this program to be among followers 9 years of age and that 82 per cent of this following were between the ages of 8 and 13 years.

\section{The Listener's Activities Important}

The daily occupation of the listener is a factor that transcends radio's likes and dislikes. A survey made for NBC by Market Research Corporation (3,034 home interviews supplemented by 94,017 completed telephone calls) gives the various home occupations of housewives related to their listening habits during the day. ${ }^{2}$ Twice as much time, for example, was spent on general housework in the morning as in the afternoon. This is one reason why the morning hours are good hours to reach the housewife at home. Occupations as they affect the farmer, the businessman, the woman, or any group of listeners should be con-

${ }^{1}$ Variety, Oct. 23, 1935.

2 "A Nationwide Survey of Listening Habits," National Broadcasting Company, September, 1935. 

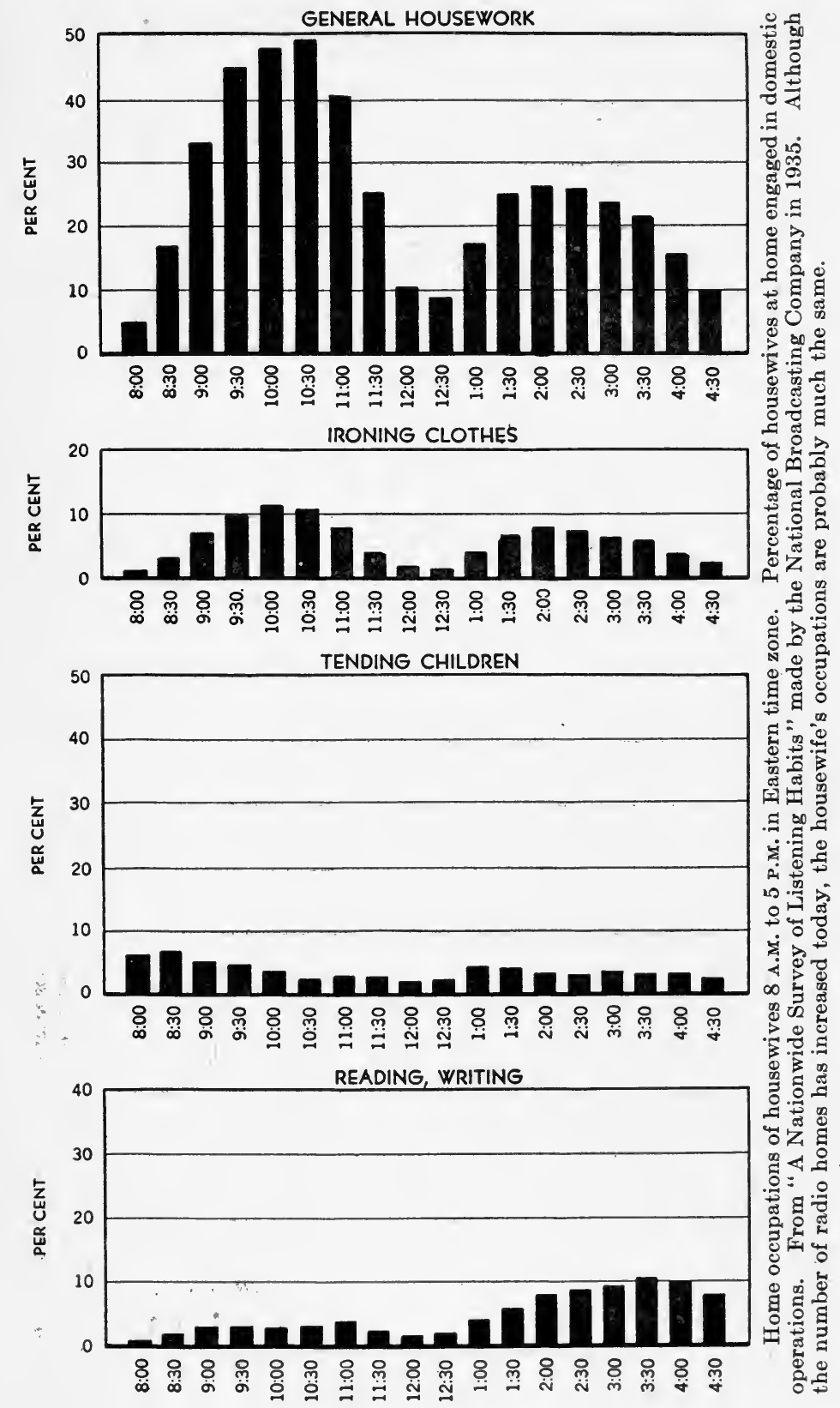

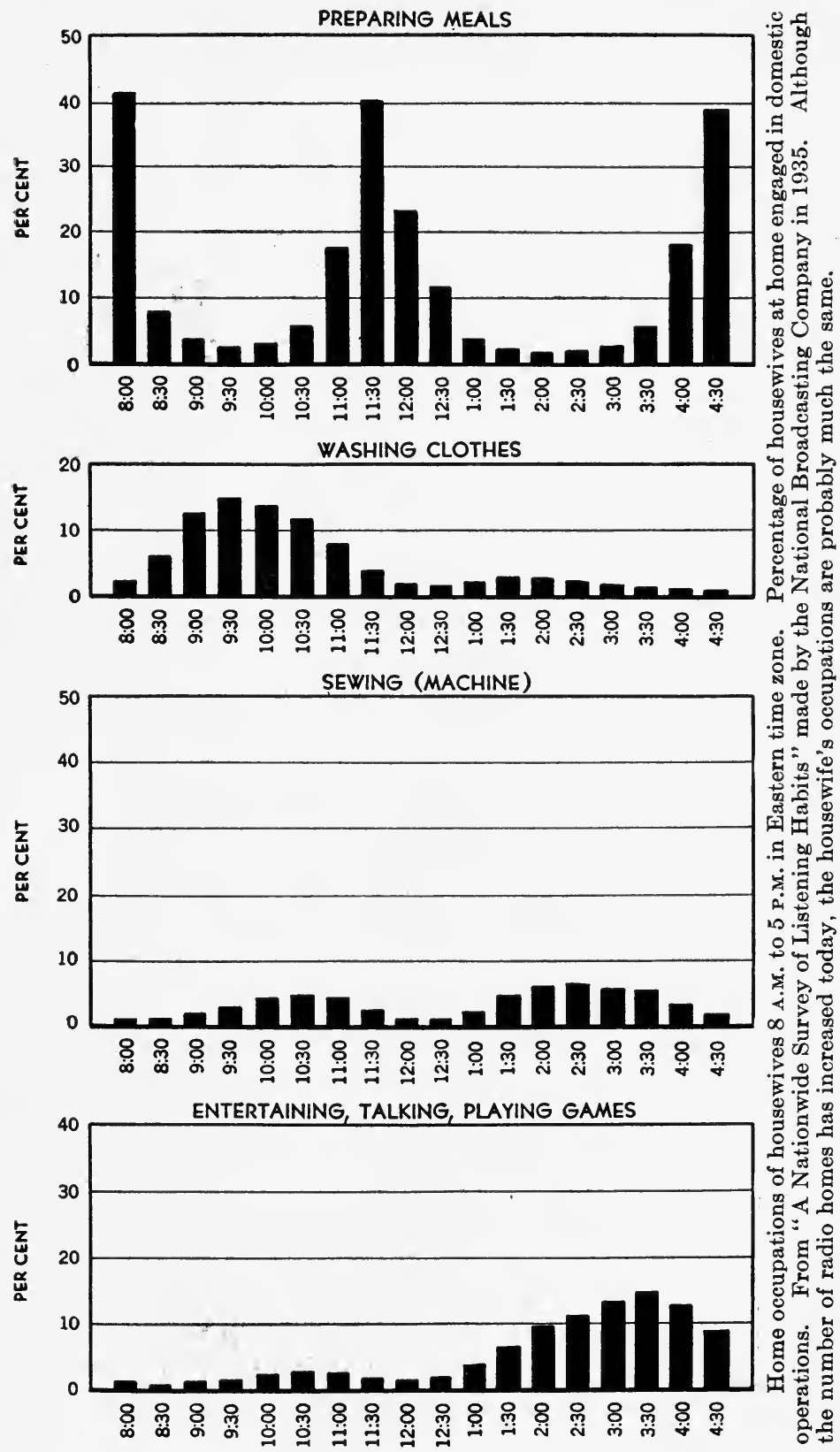


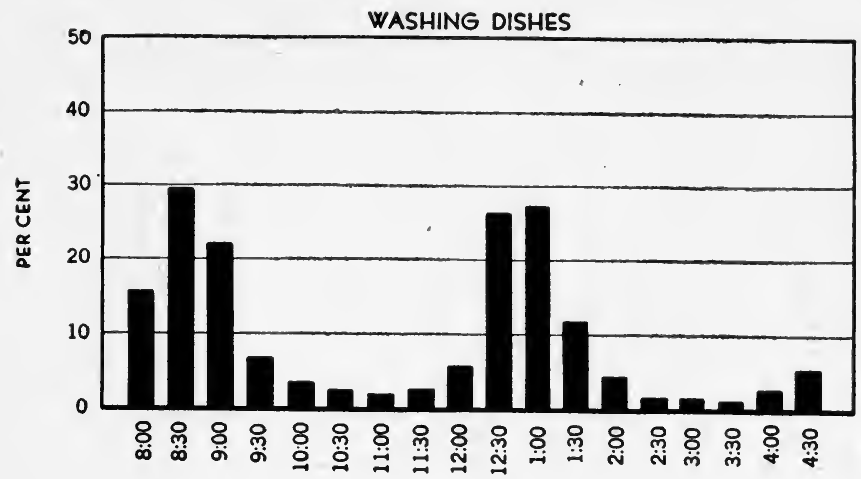

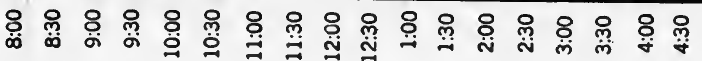

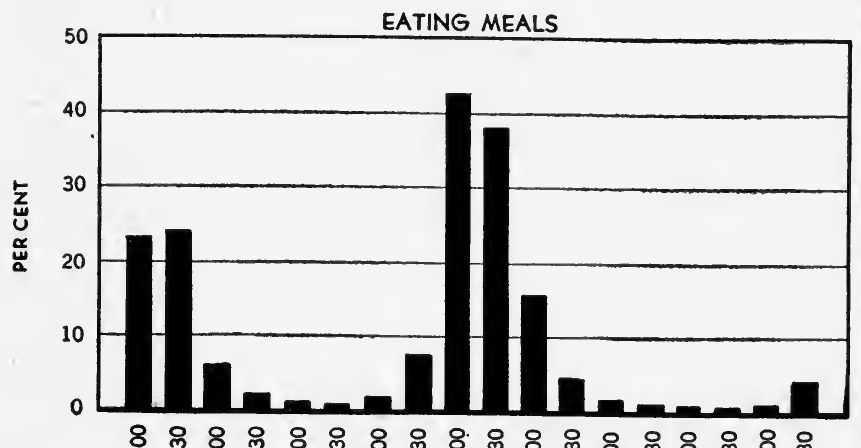

৪

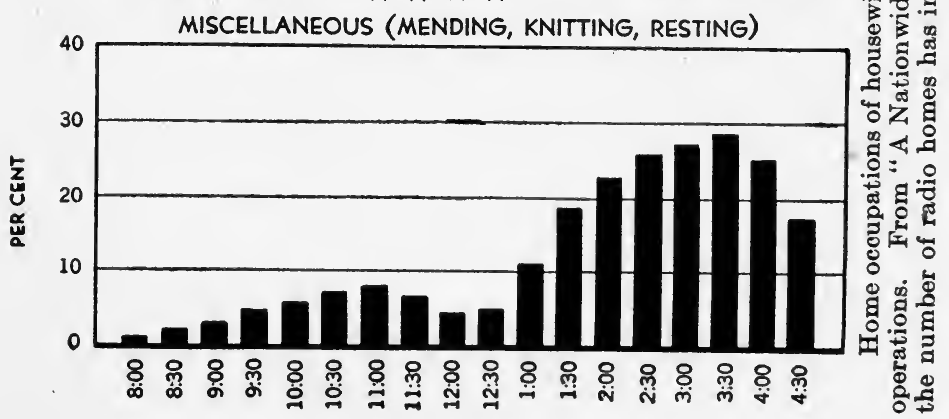


sidered. The small-town businessman, for instance, generally comes home to lunch. Noonday programs for him therefore have possibilities... The farmer has his standard set of listening habits built around the occupation of farming. Early morning and noonday programs reach him. A survey by the Joint Committee entitled: "Study of Rural Radio Ownership, and Use in the United States," published in February, 1939, gives detailed information on this. The following is typical:

Rural Adult Male Audience Available to Radio, Monday to Friday Average

\begin{tabular}{r|c|c|c|c}
\hline Time of day & $\begin{array}{c}\text { Eastern } \\
\text { time, } \\
\text { per cent }\end{array}$ & $\begin{array}{c}\text { Central } \\
\text { time, } \\
\text { per cent }\end{array}$ & $\begin{array}{c}\text { Mountain } \\
\text { time, } \\
\text { per cent }\end{array}$ & $\begin{array}{c}\text { Pacific } \\
\text { time, } \\
\text { per cent }\end{array}$ \\
\hline 6 to 7 A.M. & 60.7 & 71.1 & 75.9 & 52.7 \\
8 to 9 A.M. & 21.6 & 18.7 & 24.4 & 20.8 \\
12 to 1 P.M. & 63.4 & 64.6 & 65.6 & 53.9 \\
6 to 7 P.M. & 81.0 & 76.3 & 79.8 & 79.8 \\
7 to 8 P.м. & 78.5 & 78.3 & 85.0 & 80.3 \\
9 to 10 P.M. & 64.3 & 56.3 & 65.8 & 73.5 \\
10 to 11 P.м. & 31.5 & 24.3 & 21.1 & 23.2 \\
11 to 12 P.M. & 8.8 & 6.9 & 4.7 & 5.6 \\
\hline
\end{tabular}

Percentages shown are percentages of maximum possible male radio audience.

Local customs and habits, as well as the time of the year, have their effect on the listeners. In summer, the farmer will retire earlier; city listeners, particularly apartment-house dwellers, will be away from their radios in the evening; surburbanites will be busy in their flower gardens. There may be almost the same number of people available to radio in the summer with 7,000,000 radio-equipped automobiles and with almost every summer home and camp equipped with radio, but certainly summer occupations cut down the number of actual listeners to a certain extent. Surveys seem to show, however, that there are still a paying number listening in summer. But note that many large year-around advertisers cut down the cost of their programs during the summer on the premise that there are fewer radio listeners at that time. It has been well said by the broadcasting companies that better summer programs would 
mean more listeners. CBS in a statistical study released in 1936 showed the summer drop in listeners to be only about 3 per cent. ${ }^{1}$

There is an old adage in advertising: Put your message among your reader's interests and it will get attention. And so with the radio program. If your listener is a housewife who does her own housework, a helpful morning program on household problems should be effective. If she has servants, then style, fashion, and the like would be more effective. Take a tip from the editorial columns of women's favorite magazines. Subjects which she pays money to read about can be the same subjects that will interest her on the radio. If the listener is a man, he may be reached through sports-baseball, football, and prizefighting; through his hobbies or other interests.

\section{The Juvenile Listener}

If the listener is a child - and advertisers have found children to be the best little salesmen for their product that a manufacturer ever had-follow his interests. Good dramatic serials with red-blooded characters have appealed to boys from the beginning of time. The only difference today seems to be the attitude of the parents. A generation ago, red-blooded western stories were read secretly up in the attic; today America's young hopeful listens in the living room. Same stories, same characters, but mother and father, although they may not approve, accept the trend.

\section{Time of Day a Factor}

The time of day to reach different classes of listeners seems generally agreed upon, thanks to many surveys covering this subject. To reach the woman listener, morning is first, afternoon a weak second; late afternoon reaches the children; evening is best for the whole family, 7:30 to 10:30 P.M. being the most popular listening period, with 8 to 9 P.M. as the peak. A survey conducted by Crossley, Inc., consisting of 4,000 interviews in 11 large and 42 small cities, brought out the following in connection with the popularity of evening listening hours:2

1 "CBS Radio in 1936." Columbia Broadcasting System.

${ }^{2}$ Variety, Mar. 25, 1936. 
Percentages of Set Owners Using Sets in Evening Hours (January 15 and 22, 1936)

\begin{tabular}{ll|c|c}
\hline Time & $\begin{array}{c}\text { Station cities, } \\
\text { per cent }\end{array}$ & $\begin{array}{c}\text { Remote towns, } \\
\text { per cent }\end{array}$ \\
\hline $8 \quad$ to $8: 30$ P.M. & 32.3 & 36.3 \\
$8: 30$ to $9 \quad$ P.M. & 43.3 & 49.9 \\
$9 \quad$ to $9: 30$ & P.M. & 38.9 & 44.0 \\
$9: 30$ to $10 \quad$ P.M. & 37.5 & 42.5 \\
\hline
\end{tabular}

There was a time when an evening program just had to be of general interest. But the striking rise in the number of homes with two or more radios has influenced evening programs.

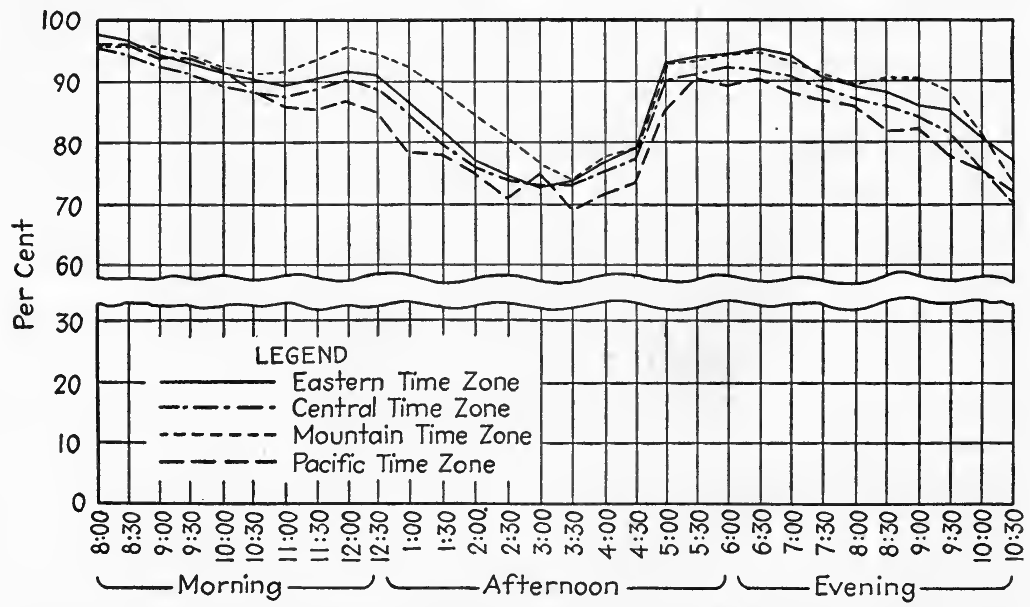

This chart, from "A Nationwide Survey of Listening Habits" made by the National Broadcasting Company in 1935, shows the percentage of radio homes with people present and awake (but not necessarily with their radios turned on) for the different hours of a radio day. Monday to Friday average for individual time zones.

Probably most homes in the income brackets above $\$ 2,500$ have two or even three radios. In the ideal American listening home today, one will find in the evening the children listening to their favorite program in their own rooms, father and mother listening on the family's best radio in the living room, and possibly grandmother in her own room listening to her favorite program.

At the present writing, Sunday evening has a high value for listeners. Part of this value is due to the fixed habits of the 
listener and part to the exceptionally popular offerings on Sunday night radio. Thursday evening has by survey been shown to have the highest number of radio listeners of any week night.

\section{Surveys on Listening Habits}

A word of caution about surveys. Beware of a survey even 6 months old if it covers changing habits. Beware of accepting the conclusions of a survey without some common-sense thinking. For instance, survey after survey places the hours of listening at 5 hours per day. The figures are beyond a question accurate. But just how many of these listeners are really listening. Undoubtedly the radio is turned on. But as Kenneth Goode says, ${ }^{1}$ the average listener may turn himself off rather than the radio. Also note the increasing number of radios with phonograph attachments. If any broadcasting company today were brave enough to make the survey, would it find in the radio homes previously reporting a 5-hour daily listening average that a certain percentage of this time must today be charged to phonograph radio listening and not to program radio listening?

Thus when it comes to judging the effectiveness of a program, how many radios turned on and how long they are on may not tell the whole story. Some listeners turn a radio on, leave it on, and go about household duties upstairs and down; others use the radio as a background for unrelated activities; others sit down before their radio and listen carefully. Some of the true radio fans can identify advertiser, are familiar with the product and its uses, can tell you why they like the program, and can give the routine of a dozen of their favorite programs. Thus many advertisers are not satisfied with a report on how many listeners their program has. They ask for the answer not just to the first, but to all these questions: (1) How many radios are turned on? (2) How many people are listening? (3) How many people are conscious of the identity of the sponsor? How many people who heard the program yesterday remember it today? (5) How many listeners are influenced by the program and its advertising message?

Only surveys can give this information. In fairness to radio there is no just reason why the broadcasting companies should be asked to furnish such information. No magazine is asked 1 "What about Radio?" p. 207, Harper \& Brothers, New York, 1937. 
to prove its value by telling how many people will see and act upon a given advertisement. Both magazines and radio have in cases obtained this information at their own expense not so much for an individual advertiser as to prove the advertising value of their medium to other advertisers.

Fortunate indeed is the advertiser who knows his prospect's listening habits, and can therefore select an interest-compelling program and place it on the air at the most profitable hour. Does this type of prospect go out to do her shopping from 10 to 11 in the morning? Then 10:30 A.M. is a poor hour for his program.

To know the prospect's listening and buying habits and to gear them for effective sales results is not a complicated matter. It merely calls for alert thinking and keen judgment in weighing the facts and data available. If an advertiser's own sales department cannot furnish data to make such decisions, there are countless dependable and unbiased research companies that can-for a consideration, of course.

\section{Value of Surveys}

More surveys before a program goes on the air mean fewer surveys later. If the advertiser is going to spend a million or even $\$ 10,000$ in radio, it is better to protect his investment by a sensible amount of keen research before he is "on the air" than after.

Common sense and a careful study of the immense amount of radio survey material available can give the prospective advertiser a fairly accurate picture of the radio listener and his listening habits. Certain radio habits are in general well fixed. Available data cover these. Other listening habits are ever changing. Continued surveys can keep the advertiser informed here (see Chaps. XVIII and XIX).

\section{Mass and Class Listening Habits}

Reference will later be made to the special-appeal program and the mass-appeal program. A thorough knowledge of the habits of the radio listener is particularly necessary in selecting the special-appeal program, i.e., the program designed to suit a known group with a common interest. The problem is simplified when the product is used only by this particular group, as, 
for instance, a garden and lawn fertilizer which is of interest only to those owning their own homes (apartment-house dwellers not invited), or a dog food which is of interest only to owners of dogs.

The more difficult type of program is the mass-appeal. Here the advertiser often fails because he chooses so wide a group of listeners that his program loses individuality, or he fails because he attempts to combine several class groups into a mass group. A variety program, one containing both music and spoken drama, is an example of the mass-appeal program. Such a program will by design have something for everybody: comedy, popular music, classical music, drama, and the like. The fallacy in this type of show is that in trying to suit everybody, no one is suited perfectly. The mass-appeal program is likely to have a less loyal group of listeners than the special-appeal program.

\section{Listeners' Reaction to Sales Talks}

There is another decision which involves the listener and his habits. Shall the program be simply for good will or for sales action? As already pointed out, the listener will not object to page after page of advertisements in his favorite magazine. He can skip them if he wishes. But line after line of sales talk in his favorite program annoy him. He has to listen if he wants to hear the rest of his favorite program and he resents the interruptions.

Because the listener is definitely antagonistic to long commercials and strong sales talk over the air, radio is at its best in the good-will program that does not demand action and that contains short and reserved commercials. The advertiser who is using other media to do his selling can well use radio as a good-will medium. Unquestionably, so used, it does increase the effectiveness of the other advertising.

But the advertiser who uses radio alone and who must have action, must through necessity use an action-compelling commercial. He must use longer commercials, more powerful sales talk. He will alienate many listeners, will develop little good will, but he will sell goods. Experience has shown that there are enough listeners who will buy even in the face of their own objections to "action" commercials. At one time Lady Esther, Ltd., had practically all their advertising in radio. Therefore 
the commercials had to sell goods and naturally were long. A survey made by Sales Management showed that the feminine announcer for their program was the most unpopular on the air. Yet she sold goods for the manufacturer. Enough chose to listen and be convinced to make the program a success. That was in 1931. Lady Esther, Ltd., have used the radio continuously since that time and at the present writing have two programs on the air, the Lady Esther Serenade, 10 to 10:30 P.M. Fridays over NBC's Red network, and Guy Lombardo and his orchestra, 10 to $10: 30$ P.M. Mondays over CBS network. The original long commercials have been shortened, however, and a switch made from feminine to masculine announcers.

It seems to be a fairly fixed rule that the higher the intelligence of the listener the more critical he is of long commercials and strong selling talks. The mass public accepts them, as it does almost everything else, with little annoyance and less comment.

\section{The Typical Listener}

For the reader who feels that the typical radio listener can be given a more concrete description than the author has offered, the following definition by Mr. Roy Durstine, ${ }^{1}$ well-known agency executive is given: "The typical listening audience for a radio program is a tired, bored middle-aged man and woman whose lives are empty and who have exhausted their sources of outside amusement when they have taken a quick look at an evening paper."

${ }^{1}$ Herman S. Hettinger, "Radio-The Fifth Estate," American Academy of Political and Social Science, 1935. 


\section{CHAPTER IV}

\section{THOSE WHO CAN LISTEN-AND THOSE WHO WILL}

When an advertiser buys a page in The Saturday Evening Post for $\$ 8,000$, he knows, at the present writing, that $3,168,170$ copies of his advertisement will be printed and delivered somewhere. How many of this "circulation" will see the advertisement, will read it, or will be influenced by it, how many extra readers over the $3,168,170$ will also see the magazine, all this is something of a guess to the advertiser. He may make surveys among readers, he may consider the factors of reader prestige and reader popularity, but the cold fact remains, the magazine has sold him 3,168,170 deliveries. It guarantees nothing else, although it may have tried to make its pages so interesting that every reader will at least open the magazine he has paid 5 cents to procure.

\section{Potential Circulation vs. Actual Circulation}

On the face of this it seems strange that so many advertisers, when they talk radio circulation, consider not those who can listen, but demand to know those who will listen. All that radio can guarantee the advertiser, in the way of circulation, is those who can listen. This potential circulation is defined as those radio-equipped homes within the listening area covered adequately by a given radio station. How many of these homes will be tuned into a given advertising program, how many people in each home will be listening, radio can no more guarantee than can a magazine tell how many people are going to look at an advertisement on page 33 of its publication.

An advertiser does not think it at all strange that he must spend hundreds of dollars extra for art, color, and copy to make his advertisement compelling enough to be seen and read by only a fair percentage of the subscribers. Yet when he is asked to spend hundreds of dollars extra for good entertainment on his advertisement of the air to get extra listeners, he often balks at the oddity of radio as an advertising medium. 
It seems extremely doubtful if radio circulation can ever be put on a comparable basis with the circulation of the printed word. With radio, the advertiser will always buy potential circulation and then out of his own pocket spend money to build up actual profitable circulation.

Radio's greatest misfortune, from an advertising standpoint, is that it has played up this potential circulation too much. It has sold too big a bill of goods. If an advertiser could get but 10 per cent of the potential circulation of radio as his very own (i.e., actual listeners tuned into his program), the price he pays for the actual time would still be a good buy. Take, for instance, radio's claim for potential coverage. The Joint Committee on Radio Research, sponsored by the American Association of Advertising Agencies, the Association of National Advertisers, and the National Association of Broadcasters, gives in its Jan. 1, 1938, report, the estimated number of families owning radio sets in the United States as 26,666,500. There are approximately $32,641,000$ families in the United States. This is a national coverage then of 82 per cent.

But the advertiser should not take this too seriously. If broadcasting stations could offer this stupendous coverage to the radio advertiser on the same basis that an $\mathrm{ABC}$ publication can offer its specified coverage, then radio rates should be boosted many times. This great radio circulation represents a potential 100 per cent audience, listeners which no advertiser, no president, nor hurricane could ever draw to the radio at a single given moment.

\section{Divisions of Potential Circulation}

This 100 per cent potential audience must be divided into three groups: (1) those not at home, (2) those at home but not listening to their radio, and (3) the real listeners. This last true radio audience is what the advertiser pays for and if he plans his campaign effectively, he does not pay too much for it.

Just how big is this true radio audience? Fortunately, we do not have to guess. Radio's various independent research organizations (discussed in Chap. XIX) are collecting for the advertiser, and generally at the advertiser's expense, invaluable statistics not only as to how large this audience is but also the programs to which they listen. A careful study of many evening- 
hour surveys by C. E. Hooper, Inc. and by the Cooperative Analysis of Broadcasting allows the author to advance the following figures:

That 16 to 25 per cent of the potential audience are not at home. ${ }^{1}$

That 30 to 50 per cent of the potential audience are not listening to their radios.

If we accept these figures which are drawn from telephone and personal interviews in many typical cities and towns, we narrow our true radio audience to 25 to 54 per cent of the 100 per cent potential radio audience. The radio advertiser should not be unduly alarmed at this shrinkage; the figures still represent from $7,500,000$ to $18,000,000$ homes or conservatively $30,000,000$ to $72,000,000$ people. It is reasonably claimed that President Roosevelt in his earlier fireside chats did have close to this number of listeners.

But no advertiser could reasonably expect to approximate this radio coverage unless he were tied into an event of national interest and could command national publicity to drive the people to their radios and, in addition, had selected stations, both network and independent, to cover the entire country.

\section{Competition of Program Cuts Circulation}

Therefore the wise radio advertiser again accepts a further shrinkage of this true radio audience. He must further divide these 7,500,000 and 18,000,000 radio homes into additional limited listening groups. There will be competing programs, either sponsored or sustaining, for today practically the poorest radio can pick up at least several stations. This matter of competing programs is a serious one and will be discussed in Chap. X. Further, the advertiser must consider that, although he may have an air show superior to all competition, there will be a goodly number of listeners who still will not like it and will turn from even a $\$ 20,000$ show with world-famous stars and comedians to a $\$ 100$ show of well-chosen electrically transcribed

1 There are approximately $7,000,000$ radio-equipped automobiles. This is 26 per cent of radio's total home coverage. In all fairness to radio, a percentage of these "not at home" will be listening on the road. Also a percentage of the rest of the "not at home" may be listening to the radio in someone else's home or to a portable radio in an automobile or elsewhere. 
music on some small station. The Chase \& Sanborn program starring Charlie McCarthy and the Jell-o program starring Jack Benny, which at the present writing are top-ranking shows, get only 80 per cent of the actual listeners. ${ }^{1}$

But here again 80 per cent of radio's true listening audience is counted in millions and when figured on a basis of cost to reach each thousand listeners compares favorably with that of many other media. It is said that the cost to reach 1,000 listeners on the Chase \& Sanborn program is about 43 cents.

\section{National Coverage}

It must be kept in mind that complete national radio coverage means placing a radio offering on enough stations that every worth-while radio home in the United States can, if its radio is in order, pick up the program. This is a goal few if any advertisers set for themselves. They talk rather of profitable market areas, where people can afford to buy their products and where the advertiser's distributing system is functioning to make purchase of the goods possible. Thus we have advertisers using a single radio chain of stations or confining their coverage to east of the Mississippi, north of Washington, D.C., to the Southwest, or to the Far West. And here again seldom could an advertiser expect complete coverage even in specified districts. The nearest complete coverage ever attained in a single market in the author's experience was in 1935 in the New York metropolitan district when Schaeffer Brewing Company tied into an actor's benefit show which was presented at the same time over practically every worth-while station in the metropolitan area. On that one evening, whether they liked it or not, Mr. John Q. Public and family; if they turned on the radio at all, heard about Schaeffer beer.

In other media, the advertiser in selecting coverage or circulation wisely divorces copy appeal from media selection, and looks at his medium merely as a means to carry the advertising message to market. He selects a newspaper of 100,000 circulation in a given geographical area or a magazine with $2,000,000$ circulation specifically located in certain states and cities and towns.

1 “C. E. Hooper Radio Report," March, 1939. 
And in radio, the advertiser can follow the same method in selecting his coverage - not forgetting that radio least of all can guarantee circulation. The effectiveness with which he follows the many coordinated procedures outlined in this entire volume will determine for the radio advertiser how many listeners he will have.

\section{Market Coverage}

First let us look at radio merely as a carrier of the advertising message. We ask it at this point only to carry our advertising message to those areas in which live people who have a need for the product, or service, the means to buy it, and the opportunity to purchase at stores in that area. The usual marketing procedures can be followed here, and areas selected where profitable sales can be made. Having selected the areas, the next thing to do is to select the stations that cover the areas. Often this task is doubly difficult because several stations may cover the same area.

\section{Station Coverage-The Concentric-Circle Method}

The coverage area of any single station can be said to consist of the number of radio homes capable of picking up satisfactorily

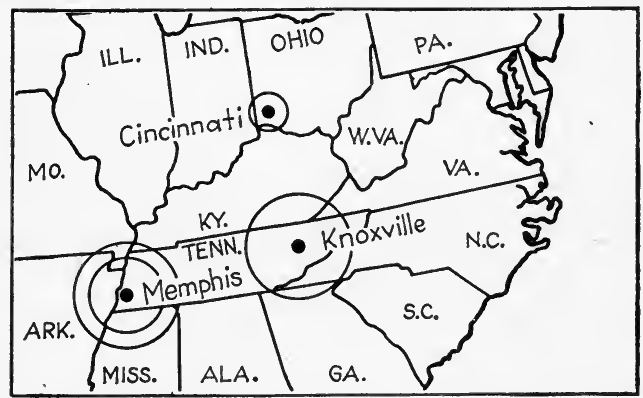

FIG. 1.- Listening areas plotted by the concentric-circle method.

the station's signal. This is radio's most simple problem and in the author's estimation should be the yardstick for comparing one radio station with another. Typical of radio, of course, the unusual always arises, which makes any comparison with other media, even as to coverage, uncertain.

For instance, the radio homes within a station's area must be divided into (1) homes that can pick up the station satis- 
factorily at all times of the day or night, called primary listening area, and (2) homes that generally can pick up the station, called secondary area. This would seem a simple enough premise and some stations so consider it. They say if a radio home 10 miles north can always pick up our program and one 30 miles north can often pick up our program, our primary area is within a circle of 10 miles radius from our station and our secondary area within a concentric circle of 30 miles radius (see Fig. 1). But this is a weak and proved makeshift. The author does not contend that a station using this method should automatically be discarded, but certainly any alert advertiser should demand other area checks before selecting such a station.

\section{Station Coverage-Field-Strength Method}

The reason this concentric-circle area method is inaccurate is that other important factors enter into calculating area cover-

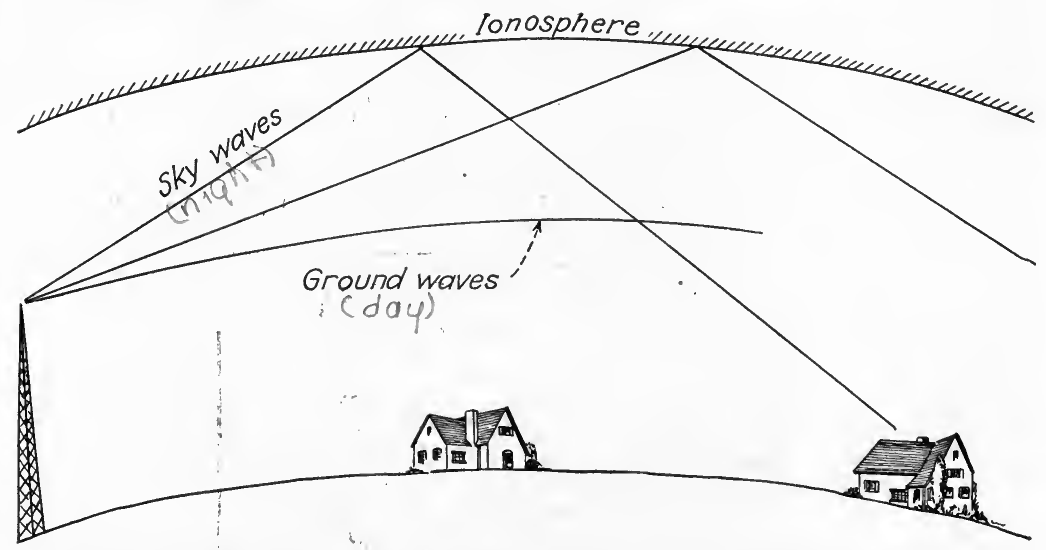

Frg. 2.-Showing how the ionosphere, which becomes active at night, reflects radio waves so that they often return to the earth at great distances from the sending station. During the day the ionosphere is not active, and radio depends entirely on ground waves.

age. There may be dead spots, where no reception can be obtained even within the primary area, mineral deposits, steel buildings, transmission lines, altitude, and many other littleknown factors which can change these two concentric circles into two very uneven and peculiar areas. A point 10 miles north may be in the primary area and a point 10 miles east not good enough to be considered even in the secondary area. 
Then, too, day and night coverage may be different. Engineers tell us of radio ground waves which travel parallel to the earth's surface with gradually weaking intensity, of radio sky waves which at night reflect from the ionosphere (see Fig, 2) and may reach a very distant radio home effectively.

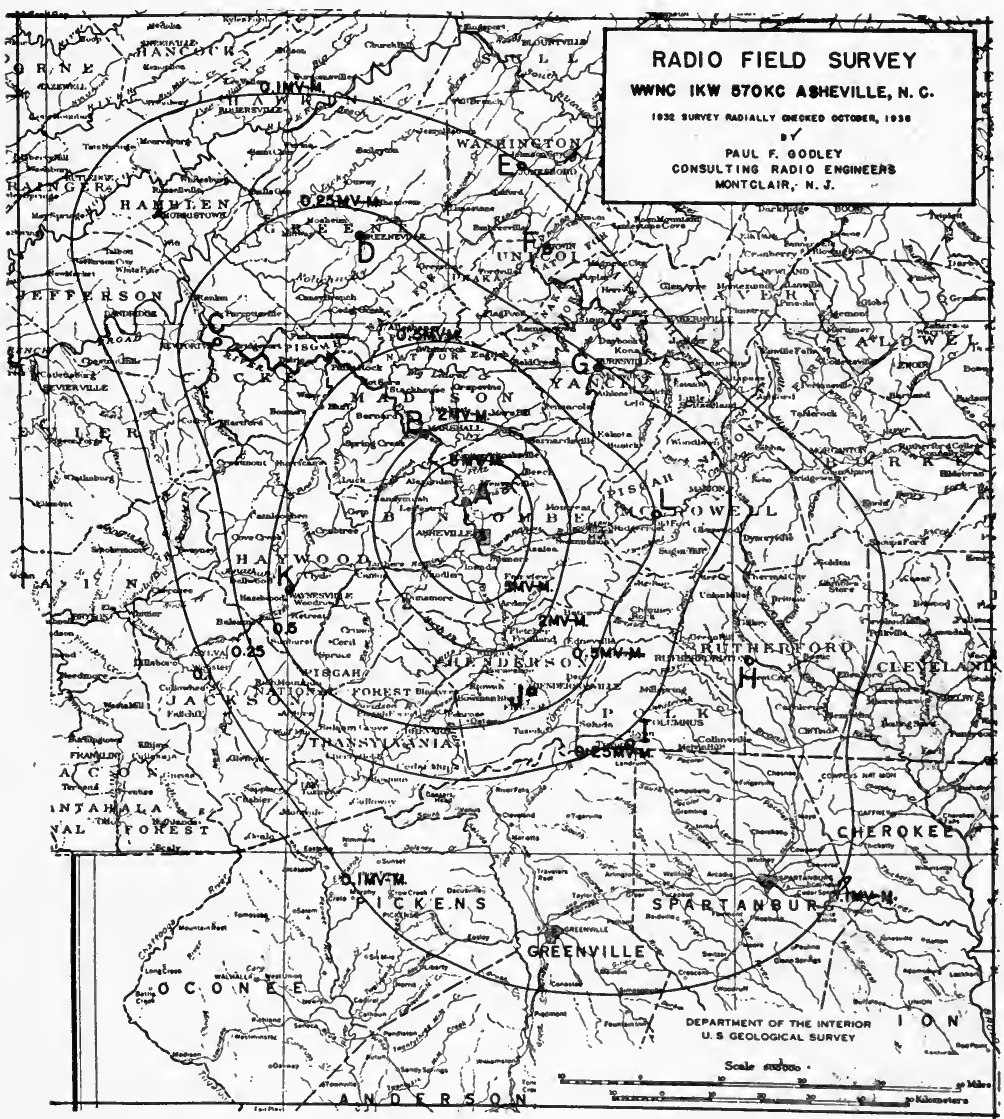

Fig. 3.-Listening areas plotted by the field-strength method. Station WWNC, 1,000 watts, Ashville, N. C.

Radio stations that have applied more engineering skill in determining their coverage areas will present the advertiser with a coverage map similar to Fig. 3, a map based on a careful field survey by competent engineers. They have determined just what points in all directions mark the limits of the primary area and the secondary area. This method may be more or less 
satisfactory but note that it may not locate dead spots within the area, spots which radio engineers admit are often present.

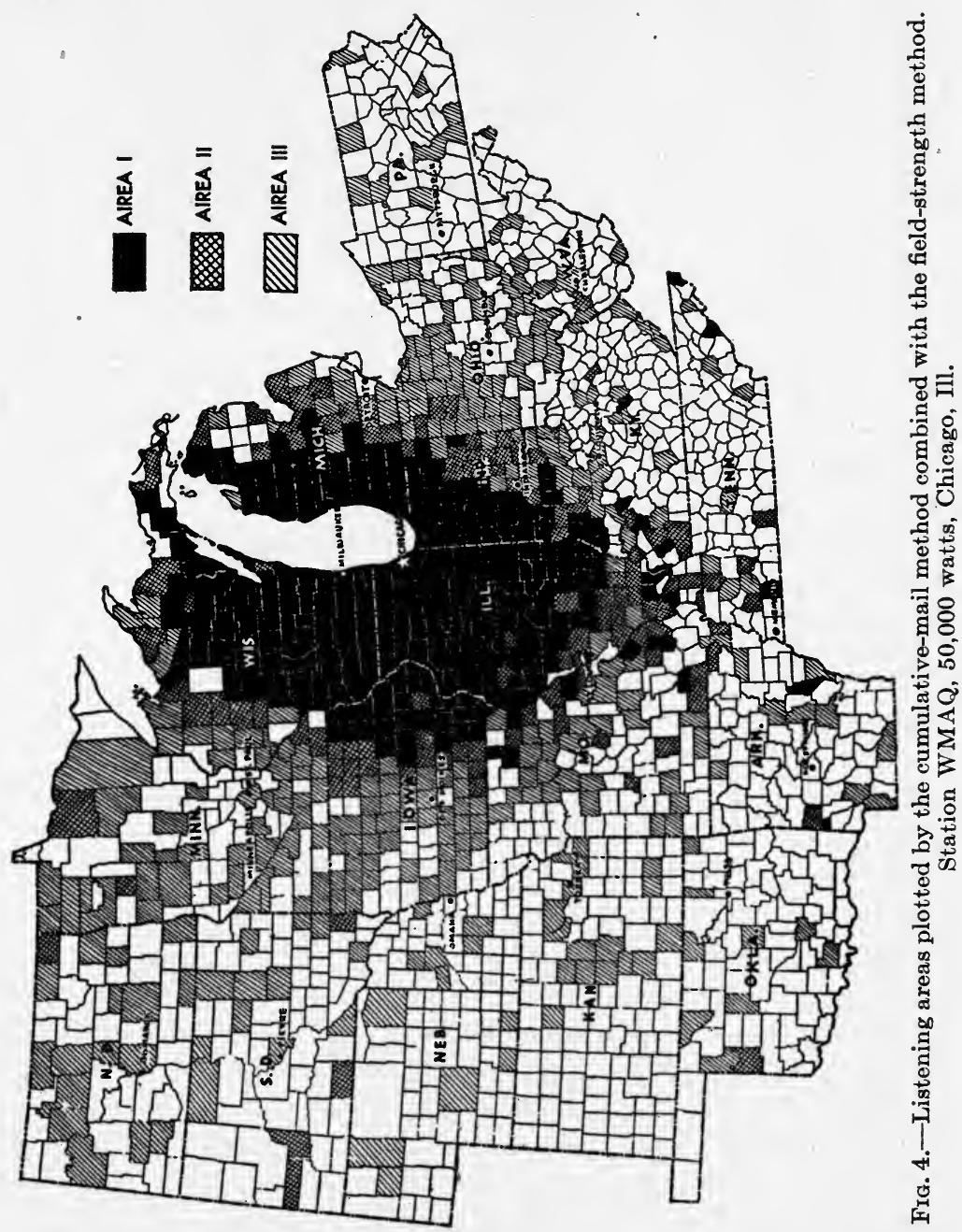

Station Coverage-Cumulative-Mail Method and ControlledResponse Method

To improve on this second, or field-strength method as it is called, many stations build their coverage maps with other methods included. These may be: to study the fan mail received 
by the station over a long period of time, which is called the cumulative-mail method; or it may be to get special mail response by making an offer of a free gift over the station and noting the locality from which the response comes, which is called the controlled-response method. It should be noted that in each of these two cases the actual number of responses is used to determine a ratio which is then applied to the total number of radio homes in each of the localities. These methods used either alone or combined with the field-strength method give a coverage map similar to the one shown in Fig. 4.

The National Broadcasting Company in mapping the coverage areas of its stations, ${ }^{1}$ used a combination of the field-strength method and the cumulative-mail response for each county in the different areas. The network is said to have spent more than $\$ 250,000$ and 2 years of time on this survey. Engineers trekked over the entire area of all the NBC stations; over 1,500,000 fan letters were studied. From these two factors ratios were determined to establish three areas of reachable audience: area 1 , representing 100 per cent of all potential radio homes; area 2, 50 to 99 per cent; area 3,5 to 49 per cent.

\section{Day and Night Coverage Different}

The Columbia Broadcasting System in mapping the coverage areas of their stations ${ }^{2}$ based their study on the premise that day and night areas are different, night generally, but not, always, covering a wider area. In order to establish ratios to determine listening areas, a special offer of a free novelty was made over each CBS station. In the 1935 survey, a souvenir radio game and a souvenir joke book were offered. Neither had an intrinsic value. The first was offered to day listeners, the second to night listeners. A 60-second announcement was made over each CBS station, for 7 days, at different times each day. Over 400,000 replies were received. In the 1938 survey a simple map of CBS stations was offered to evening listeners, a game form of the same map to the day listeners. The replies numbered 520,155.

1"NBC Coverage Areas, 1935."

2 "Dáy and Night CBS Listening Areas," 1935; "CBS Listeners and Dealers'," 2 vols., 1938, 
These replies were tabulated by counties for each station. Here again the ratio established was applied to the number of radio homes in each county and several areas worked out. The primary area included a zone of intense coverage, where 50 to 100 per cent as many requests per 1,000 population were received as were received in the county in which the station was located, and a second zone of very good coverage, 25 to 50 per cent. The secondary area included a zone of less than 25 per cent coverage on the basis of requests received, and other territories from which station mail was generally received but where the free offer had not been accepted.

The 1938 CBS report contains separate listening-area maps worked out on a new basis, the dealer zones of influence. To determine these, 100,000 questionnaires were mailed to dealers throughout the country. They were asked what stations they and their families listened to during the day and at night. The 11,894 replies received were then used to determine the maps of dealer zones of influence.

Obviously, although there is much good in both the CBS and the NBC methods of listening-area calculations, they are not on a comparable basis. Until all stations use the same method of computing their coverage areas, the radio advertiser will have to temper statistics with good judgment in selecting his stations.

\section{Other Factors Affecting Circulation}

Certainly the advertiser will not select his stations by coverage alone, as good a criterion as coverage is. There are other yardsticks he should use and these should include:

1. The Power of the Station's Transmitter. This is given in watts or in kilowatts (1,000 watts equal 1 kilowatt). A station of 100 to 500 watts, other things being equal, can be depended on for local coverage only; a station of 1,000 to 2,500 for regional coverage; a station of 50,000 watts for even greater coverage. Theoretically, a station of 50,000 watts can give national coverage, but actually, because of the intricate relation between the broadcasting of other stations and the mechanical make-up of the average set, it seldom does except in territories where few other stations are broadcasting. Also the regular radio fan does not shop for distance but prefers to use stations in his own locality 
provided they offer suitable programs. However, station WLW at Cincinnati, Ohio, when it operates on 500,000 watts power has been picked up over the entire country and claimed national coverage for its station. WLW's regular power, however, is 50,000 watts.

2. The Station Itself. Has it a cleared channel or does it share its wave length, or its time, with other stations? Does it have modern equipment to give the best reception? Stand-by equipment to assure continuous service in the event of a breakdown? Does it have remote-control equipment to bring in programs originating outside its studio? What type of electricaltranscription equipment does it have? Does it have studio facilities for a large studio audience?

3. The Station Personnel. What type of announcers and operating engineers does the station possess? Is its management governed by the accepted ethical code concerning advertising? Has it good program directors to produce worth-while sustaining programs?

4. Local Popularity. What is the station's standing in its community? Are its programs listed in the local newspapers?

5. Competing Stations. What is the number and general standing of competing stations, the type of programs carried by them, and the type of advertisers using these stations?

6. Rates. See Chap. IX.

\section{Network or Spot Station}

That many stations are hooked up to form national or regional networks, while other stations operate as independent or spot stations is, of course, general knowledge.

The principal advantage in using the networks is that the advertiser can put on one show and have it sent by special wire (as described in Chap. V) to every station on the network. He buys a ready-made coverage, generally in profitable market areas. Sometimes he is forced to buy a certain fixed number of stations, whether he can profitably use all of them or not. Sometimes he is allowed to buy regional networks or even individual stations. The largest networks are the National Broadcasting Company's Red and Blue with 173 stations, the Columbia Broadcasting System's network with 115 stations, and Mutual Broadcasting Company's system with 106 stations. Mutual's 
talking point recently has been that it will allow the advertiser to buy as many or as few stations on the network as he may require to cover his present market. The idea is good but too many such programs might make it difficult for an advertiser to select the entire network if he desired it.

\section{Time Zones Affect Circulation}

One of the difficulties of national network broadcasting from the advertiser's point of view is the change of time across the country. If he selects 8 P.M. in the Eastern standard time zone,

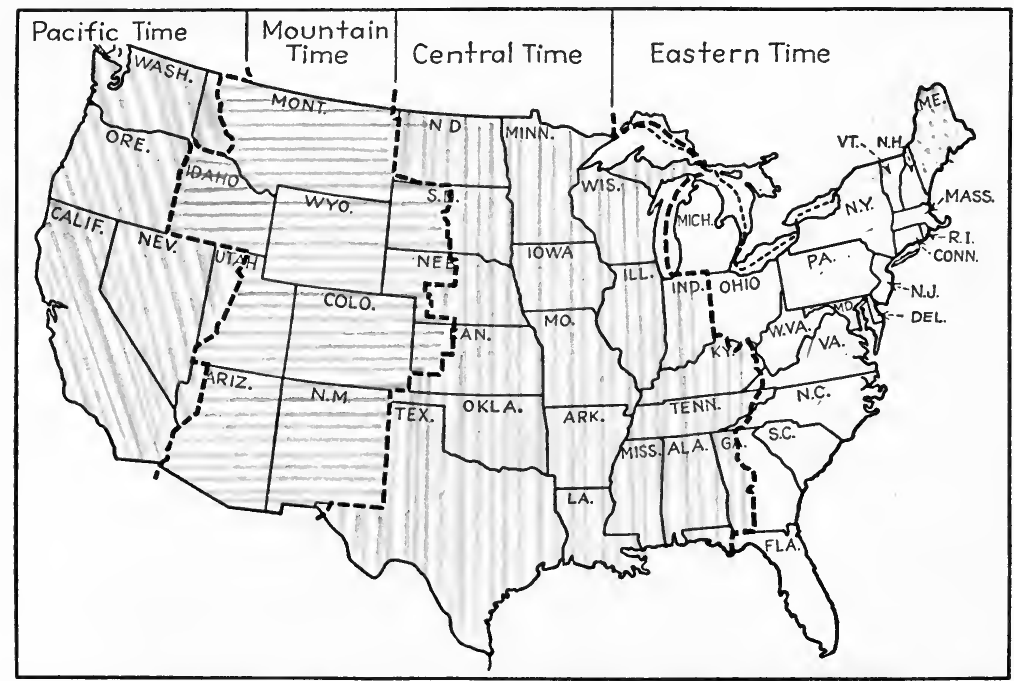

The four time zones across the United States, which must be considered in planning a coast-to-coast radio hookup.

he has 7 P.M. in the Central standard time zone, 6 P.M. in the Mountain standard time zone, and 5 P.M. in the Pacific standard time zone. Obviously the ideal selection here is to pick the best hours for the time zones that contain the greatest number of potential listeners. Thus most advertisers favor the Eastern and Central time zones. Other advertisers give two shows, 2 hours apart, one for the Eastern time and Central time zones and the other for the Mountain time and Pacific time zones. Thus a show at 8 P.M. in New York would reach Chicago at 7 P.M. If the same show were given 2 hours later in New York and sent to the Mountain and Pacific time zones, it still would 
arrive there at 8 P.M. and 7 P.M., respectively. Other advertisers where station rules allow, have an electrical transcription made of the first show and play it back later for the western time zones. A caution here. Many of the larger stations when on network time will not accept electrical transcriptions, particularly in the evening.

Where spot stations are selected, no single program can be given for all stations. Occasionally special wire arrangements may be made to tie several of these stations together. This, however, is costly. Most advertisers using spot stations depend on the electrical transcriptions described in Chap. V, and thus get the same show on all stations independent of time or talent difficulties.

The principal advantage of the spot station is that, where the advertiser. can find the right type of independent station, he can spot his programs in exactly the market he desires to reach, whether it be large or small. He also can supplement his advertising in other media or even on the radio networks in such spots as may be less intensively covered or where his competitors' standing make extra effort necessary.

\section{Big Stations or Small}

Before the advent of electrical transcription there seemed to be a concensus of opinion among advertising men that it should be big stations or none at all. Certainly in the old days the small station, with its inferior programs and its mediocre musical talent, offered little hope to the advertiser, especially if the small station was located in the primary area of a large and popular station.

But today the small station is coming into its own. Electrical transcription allows it to present the same shows sponsored on the big stations. A musical library of electrically transcribed numbers by the world's leading orchestras and vocal soloists give it an opportunity to build as delightful a musical program as that put on by the big station. For the advertiser with a limited appropriation and a limited market, often the small station is a salvation. Many nationally known manufacturers are today using small stations, either exclusively or to back up and supplement network programs. See Chap. XXIII for suggestions on getting the best out of the small stations. 
The World Broadcasting System should be mentioned in connection with the small stations. It is a network of smaller stations which accepts electrical transcriptions, and, although not tied together by wire lines as are the big networks, these stations can be used by an advertiser as a network for electrically transcribed sponsored programs. 


\section{CHAPTER V}

\section{BROADCASTING TOOLS-HOW TO USE THEM}

To get the best out of radio, the advertiser should have a general knowledge of the mechanics and organization of broadcasting. In no other medium is the advertiser so intimately connected with the production end of the business and in no other medium does a lack of the knowledge of the production technique so affect the success of the advertising. No publication would welcome the advertiser puttering around the editorial office and the composing room. Yet radio not only welcomes the advertiser or his representative, it almost demands his presence in the broadcasting studio. It is almost as if the publisher of a magazine said to his advertisers: "Not only must you write the articles, stories, and advertisements but you must come around and set up the type and also keep the reader sold on our magazine - even go out and get us new subscribers."

There is nothing more pathetic in the studio than the advertiser who does not know how all the gadgets add up to equal success in presenting the sponsored program. This book in no way intends to go into a technical discussion of radio, but it must cover such points of mechanics as the advertiser should know.

\section{The Broadcasting Studio and Control Room}

Let us first follow a sponsored program through from the broadcasting studio to the listener's armchair. The studio may be a small, intimate, soundproof room with walls treated so as to take care of echoes or it may be a much larger one capable of seating a studio audience of 1,500 and containing a stage for orchestra, stars, and announcers. Microphones are placed at various points to pick up separately orchestra, vocalists, announcers, even audience applause.

The sound waves created by the performers are transformed by the microphones into electrical impulses or "waves" and 
carried by wire to the glass-enclosed studio control room, where the control engineer sits at his control console. All the microphones in the studio are connected to this console which regulates and mixes the microphone output. Separate amplifiers, one for each microphone, allow the operator to bring up the volume or to make it softer. The control room also contains a loudspeaker of high quality.

In a well-equipped control room, the engineer has facilities for a number of functions. In addition to listening to the pro-
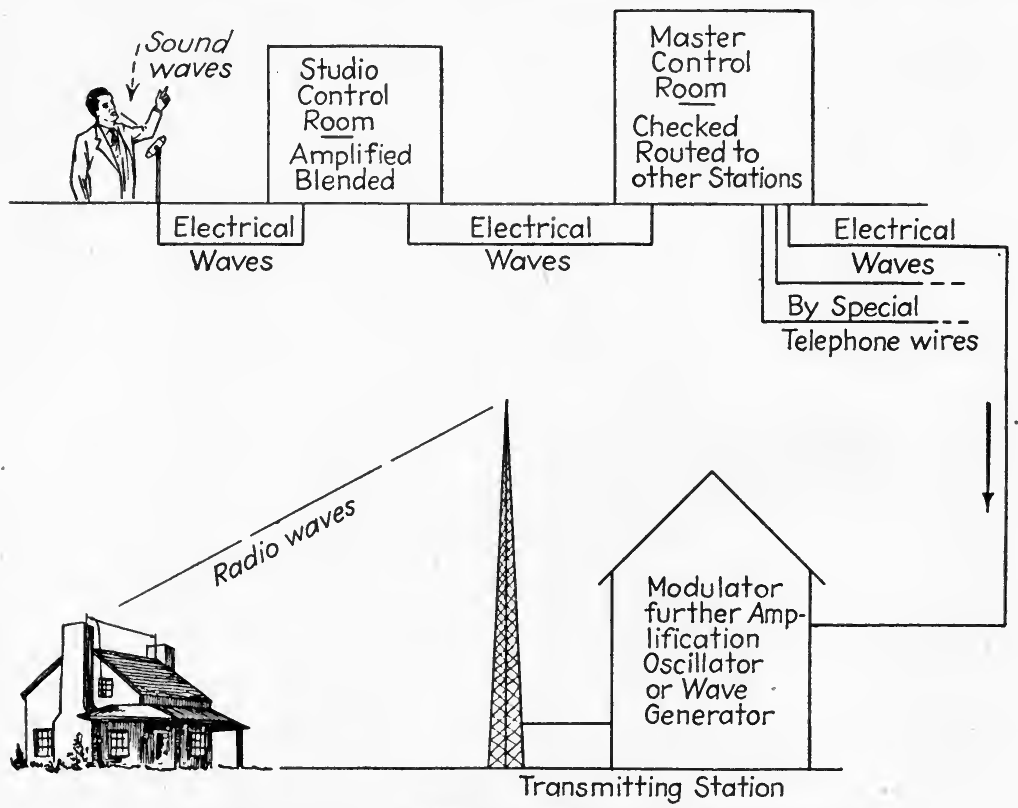

The course of a radio program from microphone to radio home.

gram in the studio and varying the volume on each microphone individually or collectively, he may speak to persons in the studio over a microphone on the control console by pressing a button in the microphone base. He may turn a key on the panel of the control console, and so allow anyone in the building provided with the proper monitoring facilities to listen to what is going on in the studio. He also may connect or disconnect the studio from the master control room; he may make local announcements at switching time; he may press a button which automatically sends the familiar "chimes" signal to the network. 


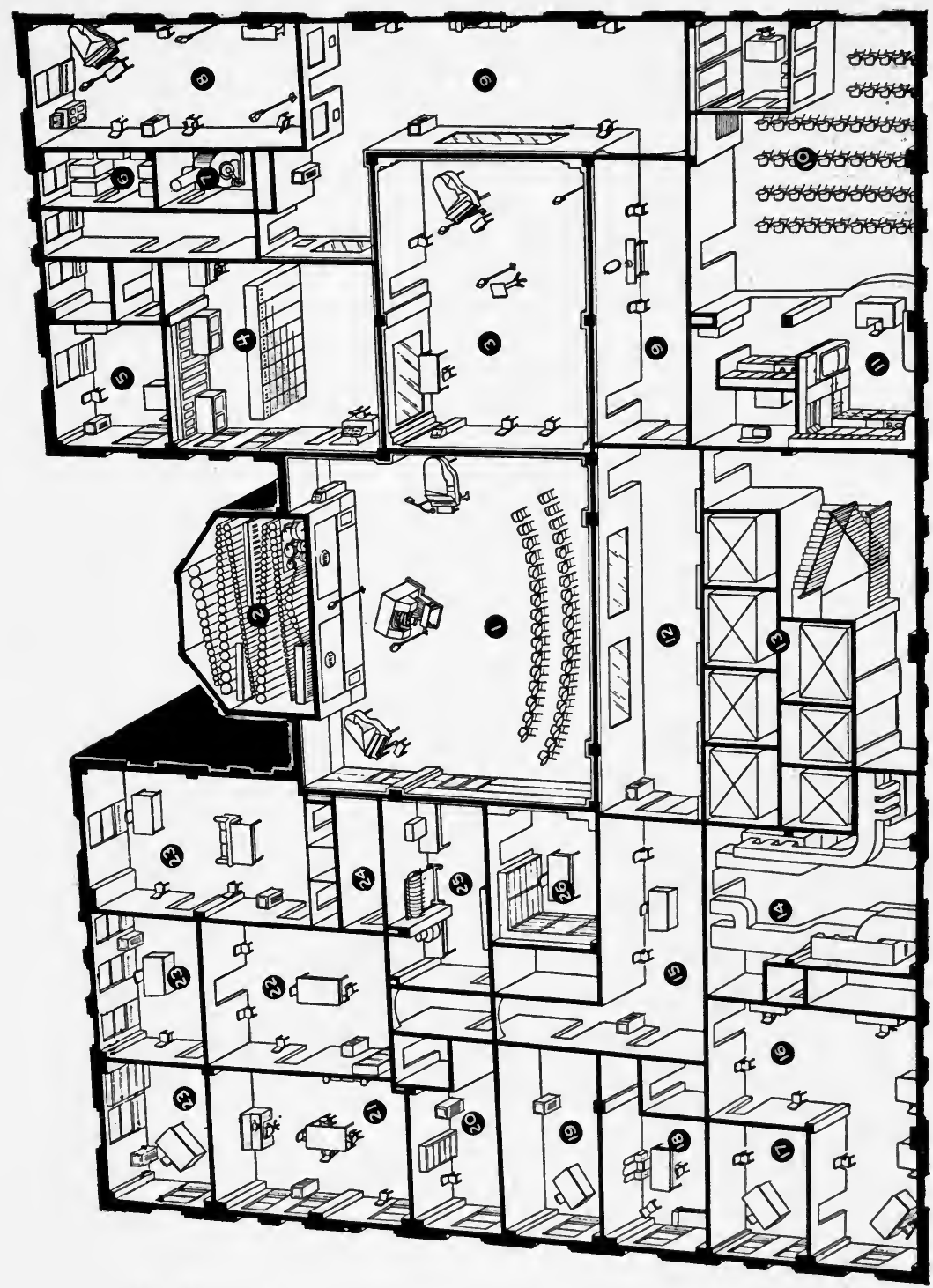

Broadcasting studios of station WKY, Oklahoma City, Okla.

\section{Studio "A."}

2. Organ chamber.

3. Studio "B."

4. Control room.

5. Engineer's office.

6. Battery room.

7. Organ blower.

8. Studio "D."

9. Corridor.

10. Home economics auditorium.

11. Aunt Susan's kitchen.

12. Elevator lobby.

13. Elevators.
14. Air conditioning equipment.

15. Reception lobby and information desk.

16. Advertising department.

17. Office, advertising manager.

18. Women's lounge.

19. Continuity dept.

20. Production dept.

21. Studio "C" and audition room.

22. Inner lobby.

23. Executives' offices.

24. Entrance to studio "A."

25. Sound-effects room.

26. Music library. 
Finally he may monitor any one of several so-called headset monitoring channels by means of a telephone headset and thus follow in another studio the program immediately preceding his. This last facility accounts for the split-second timing and smooth continuous flow of programs to which the American listener has been accustomed.

In short, the operating engineer, often almost unnoticed by the studio audience, is a very important link in broadcasting. He can make or break a show, keep the basses from dominating the orchestra, or the orchestra from drowning the vocalist whom it is accompanying.

\section{The Master Control Room}

Each control room is connected with the master control room, which is the next place to receive our program, it still being carried by wire as electrical impulses. Note that no radio waves have yet been used. In the master control room at a master control desk, the programs are routed, still by wire, to the transmitter of the home station and to various other stations on the network. Some of these stations are thousands of miles away from the station giving our program. Intricate equipment, knowledge of which is unnecessary for the advertiser, sorts out, cuts off, adds other stations, amplifies, checks programs for delivery to the other stations. The master control desk at Radio City is $27 \mathrm{ft}$. long and has approximately 3,700 indicator lamps and keys mounted on its face, a goodly portion of which is stand-by or duplicate equipment.

\section{The Transmitter}

Let us follow our program after it reaches the transmitter of the home station. Here it meets the radio wave-the carrier wave as it is called. At the transmitting station, the carrier wave is generated, and until it receives our program it is as blank as a white page. A special apparatus called the modulator places our program on the carrier wave and the program is off in every direction to deliver its message to the home radio sets in its area. Of course, our program has been magnified many times at the transmitter station, and the electrical impulses changed to radio frequency energy. 
All this takes a long time to describe but in actual time the program has traveled from the microphone to homes even 3,000 miles away so fast that these listeners are getting their radio program even before those in the rear seats of the studio are registering the sound waves from the stage-for sound waves travel about 12 miles a minute and electrical waves more than 11 million miles a minute.

\section{Microphone Technique; Rehearsing}

Few advertising men ever visit the transmitting station. If a sponsored program gets that far safely, it is purely a matter of engineering that it goes "on the air." It is in the studio and the studio control room, that the advertiser can do much to better his programs. The placing of the microphones in strategic spots, seeing to it that the actors stand just the right distance away-generally about $2 \mathrm{ft}$., farther if any loud shouting or sharp noises are going to be delivered to the sensitive "mike." Standing too far away gives a fuzzy presentation that even the operating engineer cannot entirely correct. The show also must be so well planned and rehearsed that there is no dragging, no dead spots of silence; everything must run with split-second precision. The advertiser's program director or stage manager sees to this. He has rehearsed his show, often 6 hours for every hour on the air. Rehearsal studios and studio control-room facilities are furnished so that the director can listen to just how his show will be expected to sound when it does go over the air. During these rehearsals, the numbers and commercials are carefully clocked so that at the final rehearsal the timing is within a few seconds or actually the same length as the final "air show."

Often, however, unforeseen circumstances arise. Actors may be at a more nervous tension when actually on the air and may speak more rapidly or musical numbers may slow up a few seconds. This accounts for the great showing of clocks and timepieces at a performance. Keeping to time schedules is a religion and a necessary one in radio; thus the sign language used in the studio. If a show is lagging it must be stepped up in tempo; if it is ahead of schedule it must be slowed down. It must at the end, hit its time "square on the nose," for another show just as important may be following it on split-second time. 
The reader should in no way infer from the foregoing that the broadcasting station could not successfully put on an advertiser's show without help from the advertiser. After all, radio does put on its own sustaining shows, many of which are better than the advertiser's. But no matter how small the radio show, the advertiser or his representative is always on hand. Large studios even have the sponsor's booth provided for his comfort. If he knows nothing about radio, he might better stay home. If he, like most advertising men in radio today, really understands broadcasting, his suggestions will improve the show. Many of our large advertising agencies claim to have in their radio departments, better showmen, production men, announcers, and idea men than the stations have.

\section{Remote-Control Programs}

It should be said in passing that not all shows, even sponsored ones, originate in the studio. An oil company may sponsor a football game; a breakfast food company, a baseball game. In these cases the microphone with amplifying equipment goes to the game. This is called a remote-control program, a "nemo" broadcast in popular parlance, the studio control room "nursing" the program as usual but getting it by special wire from the scene of action. It is also possible to substitute short-wave sending for the standard wires. This has been done by advertisers sponsoring distant happenings, as, for example, the Admiral Byrd Expedition to the South Pole and, a few years ago, Lucky Strike's bringing the music of leading orchestras of South America and Europe to its program by short wave. These programs are sent by a short-wave transmitter, received by short-wave receiver, translated into "long wave" for the listeners' 'sets, and then sent out in the usual way over the stations selected by the advertiser. The hazard here is that one can never be sure that conditions are good for the short-wave reception, and the advertiser may be called on to give the standard apology: "Owing to unfavorable conditions, the program cannot be broadcast at this time."

\section{The Announcer}

Another broadcasting tool vital to the advertiser is the announcer. There was a time when the announcer often acted as a program director and master of ceremonies as well 
as commercial announcer for the advertiser. Many of these past duties are taken over today by the program director, by the musical director, or by the master of ceremonies such as Don Ameche on the Chase \& Sanborn program. But big show or little, the announcer is still tremendously important to the advertiser, for he delivers the advertiser's. messages, the few minutes of golden sales talk for which the advertiser is willing to pay thousands of dollars on the entertainment build-up.

The announcer can well be said to be the advertiser's ambassador. His personality, his sincerity, his delivery technique, will in the ears of the listener be closely integrated with the advertiser's products and policies. Great care should be taken by the advertiser in the selection of the announcer, and by the script writer in adapting the script to the selected announcer. It has already been said that the advertising message is the only reason for the show; therefore, to the advertiser, the announcer should be more important than the star.

The rates for time on the air include the service of an announcer and it is assumed, with the chains at least, that a satisfactory announcer will be forthcoming. However, all announcers cannot have the ability of a John S. Young, a James Wallington, a Harry Von Zell, a Milton Cross, or a Don Wilson, not to attempt to list these in order of merit. Thus many large advertisers prefer to pick their own. The general broadcasting station policy is that if you demand a star announcer, you pay extra for him.

Some advertisers prefer to develop their own announcer; some advertising agencies have allied themselves to certain star announcers whom they retain and offer to prospective clients as a pièce de résistance. Harry Von Zell is one of these. On smaller programs, the advertiser will take the announcer assigned -and very fine announcers some of these are. But it might be well for the advertiser to have a check list of announcer qualifications to see if he is getting the best from his announcer; a poor announcer can lose an audience more quickly than a poorly constructed commercial announcement.

\section{Voice Qualifications}

To those who have been close to the sponsored radio program from its beginning, the development of the announcer has been interesting. Originally the announcer was practically anony- 
mous, known only by three letters, the first signifying announcer or operator, the second the man's name, the third the city of the program's origin. In those early days, he.was merely a mechanical part of the program, which was enough when the mere novelty of getting something over the air was all the listeners asked of radio. But as the audience became more critical, they demanded not only better shows but better announcers. In an effort to improve announcing, the Radio Voice Technique Committee was formed in Feb. 4, 1925, at the request of Radio Corporation of America and New York University "for the purpose of determining what characteristics constituted the perfect radio announcer." Professors Alvin C. Busse and Robert Borden, then instructors in public speech at New York University, had just produced a recording device by means of which the committee were able to study the factors affecting broadcast speech delivery. Their conclusions are as good today as they were then. A few of them follow:

1. That announcers could successfully deliver 175 words per minute, but that solemn announcements, stock quotations, etc., were better at 125 words per minute.

2. That rate of speed variation must correspond to thought rate.

3. That mechanically recurrent falling inflections were preferable to rising ones-but that both were objectionable.

4. That incorrect breathing caused painful panting which was very much amplified on the radio.

5. That arbitrary stress placement tended to misrepresentation of announcement.

6. That nasal and harsh qualities were amplified to a distasteful degree.

7. That mannerisms and lapses were particularly distressing.

8. That dialect, provincialisms, etc., were out of place.

9. That an even pitch was desirable and that a deep voice was preferable to a high-pitched one.

10. That formality, distinctness, and personality were important.

But they found voice personality most important of all, that telepathic power of thought transference which assures the announcer's immediate acceptance by the listening audience. The "voice with a smile" the telephone company calls it. And it is voice personality today that makes the successful announcer, radio artist, or news commentator. 
'The advertiser may well look at other qualifications besides voice, for his announcer must be able to get along well with the cast and the studio staff, must be able to think and act quickly in an emergency (for things do occasionally go wrong with the best rehearsed shows). The announcer must be punctual, calm in a crisis, and resourceful enough to get his program through on schedule, whether this means slowing down or speeding up.

\section{Delivering a' Sincere Advertising Message}

Nor should the advertiser overlook what is to him the most important of all points: the announcer's ability to deliver a convincing and sincere advertising message. Some of our best announcers with all their fine diction, tone, enunciation, and personality seem to miss that fine touch of convincing sales presentation for the product. It seems that any good announcer should be able to sell himself on his sponsor's product at least for 60 sec., long enough to convince his listeners. One of the reasons he does not is the inane claims which some advertisers let their script writers make for the product, claims at which any sane thinking listener can well smile. No wonder some announcers, tonguing the drivel, let a little of their resentment slip into the voice, like a school bully being forced to recite "Mary's Little Lamb."

If the advertiser is shortsighted enough to run this type of commercial, he probably will not be long-sighted enough to try to select a good announcer. No better summing up of the announcer's job can be given than to quote Roy S. Durstine, ${ }^{1}$ who in discussing the awarding of a cup given for good announcing by his agency, Batten, Barton, Durstine \& Osborn, said:

By good announcing, we mean sincerity, accurate diction, naturalness, persuasiveness, a lack of mannerisms and an absence of those curious inflections which belong to an unknown language in a world which doesn't exist.

Somehow there has grown up a technique in announcing which, we believe, is exasperating to the public, annoying to the sponsors of broadcasting programs, and detrimental to the future of radio. Many announcers have refused to let themselves be drawn into this style of announcing and it is to encourage them and to beguile others away from

${ }_{1}^{1}$ Printers' Ink, Oct. 25, 1934, p. 113. 
the stilted, hot-potato school of broadcasting that we are offering this cup as a modest protest.

\section{Women Announcers}

The question is often asked by an advertiser: How about a woman announcer? Radio listeners, even women, seem to have a sex complex here. As far back as July, 1926, Radio Corporation of America canvassed 5,000 listeners, both men and women, on this question. They were 100 to 1 in favor of men as announcers. For singers their preference was 50 to 50 . At that remote date radio sets did not reproduce high tones well, which might have been a factor in the decision. But the author has for several years taken a vote in his radio classes, which often run over 150 students, on the same question, and with men and women alike, the vote is still overwhelmingly for men announcers.

Probably the main reason for preferring male announcers is that women announcers have difficulty in maintaining reserve and dignity in their voices, and when they strive for these they lean over backward and their voices either sound patronizing like a schoolteacher talking to her children or become monotonous and colorless.

Announcing from a radio station point of view is no woman's job. The announcer may be called upon for any emergency day or night, may be asked to go anywhere from covering a riot to a shipwreck.

From the advertiser's standpoint the woman announcer is favored for only one type of program, and that is for products on which she is acknowledged an authority. Cooking schools of the air, beauty programs such as those sponsored by Elizabeth Arden or Lady Esther, Ltd., may have their possibilities, although in 1936 when a woman was announcing for Lady Esther, Ltd., as already noted, a Sales Management survey showed the announcing to be the "most obnoxious" on the air.

\section{Electrical Transcriptions}

Another broadcasting tool of ever-increasing importance to the advertiser is the electrical transcription, canned programs, disks, platters as they are often called. These are simply a permanent or a temporary record of a performance of the show 
transcribed in electrical impulses on disks similar to or the same as phonograph records for future reproduction. All stations today have electrical transcription apparatus, 78 or $331 \frac{1}{3}$ r.p.m. turntables, and are prepared to handle this type of show.

It should be noted that some stations have rulings prohibiting the use of transcriptions except for theme songs and sound effects. This was a point well taken when electrical transcriptions were in their infancy and when even the most ignorant listener could detect them over the air. But today with the high degree of accuracy in production of these records and their efficient handling in the studio, few listeners can distinguish them from a live show. Only the ruling by the Federal Communications Commission that electrical transcriptions must be announced as such over the air has kept them from an even wider acceptance. In spite of this, they are widely used by many advertisers.

The complete technique of making electrical transcriptions is not of vital interest to the advertiser. All he need know is that, in general, electrical transcriptions are of two kinds: (1) Those made for immediate playback and for record. These are available for use directly after they are recorded. Those made in the form of a more durable record, for spot programs, announcements, etc. These are available in 10 days or 2 weeks after the immediate recording. The recordings may be made on acetate-covered metal disks, on aluminum disks, or on thick special wax disks. Also recently a move has been made to record sounds on sound tracks, such as are used in talking pictures.

The wax method of recording as used by $\mathrm{RCA}$ Victor is among the older methods. The electrical impulses which make the program are first recorded by a stylus electrically operated on wax disks approximately $1 \frac{1}{2}$ in. thick, in special studios designed for wax recording. Here programs are rehearsed in the usual manner but the final show instead of going on the air goes to a special control room and is recorded on the wax disks (two are used in case one is broken later). The wax disks are timed carefully, timing and subject marked on them, and then they are sent to the plant where, somewhat along the lines of electroplating, a master pressing is made. Then as many copies as are necessary for the spot stations used are stamped from this master 
record. These when finished are approximately the same as a phonograph disk except that in some cases they are more carefully made and have a lower noise level. A 15-min. show can be encompassed comfortably on a 16 -in. record at $331 / 3$ r.p.m. Often three 5-min. (or less) shows are recorded on the same 16-in. record. These, unlike phonograph records, generally feed the needle from the center rather than from the outside edge. The company making the transcriptions will, if requested, ship the final copies to the stations on which they are to be used. In the case of advertisers using many stations, one show may need many copies. "Musical Moments," an electrically transcribed 15-min. program made in this manner for Chevrolet Motor Company, was shipped to more than 300 large and small spot stations throughout the country.

\section{The Acetate Method}

The acetate recording, a newer and increasingly popular method of making electrical transcriptions, substitutes an acetate-covered metal disk for the wax disk. The program is recorded in the same manner, the stylus cutting its impressions in the acetate. One advantage of this method is that the original acetate record is durable enough to be played over the air with no further treatment. Where many extra copies are required for spot stations, the original record is handled in the same way as the wax, and a master record made to stamp out as many extra copies as are required.

\section{A New Method, the Millerfilm}

There are, of course, other methods of electrical transcriptions, some of which may push aside the two methods just described. One method, which is receiving more and more recognition, is the Millerfilm method, originated in Holland. This method makes use of a narrow strip of film, on which a stylus cuts a record of the program. .Programs so produced have already appeared on the American air waves. An outstanding example is the rebroadcast over WOR at 8 o'clock on Thursday evenings of Kay Kyser College of Musical Knowledge which originates on Wednesday evening at 10 o'clock over NBC as a live show.

The claim for this new method, and a very important one from the advertiser's point of view, is that a Millerfilm transcribed 
program can be edited before going on the air, just as the "movie takes" at Hollywood are cut and condensed into a compact final movie film.

The reason editing cannot be done on an acetate or wax-made record is that the record made by the cutting stylus is in close parallel tracks, whereas in the Millerfilm the record made by the stylus runs along in a single line on the narrow tape. Thus the tape can be cut and patched, as in a movie film. Numbers and jokes that did not go over on the original program can be cut out and other material substituted. If a guest speaker inadvertently presents material that the F.C.C. would object to as unfit for the public ear, as occasionally happens on a question-bee program, this too can be deleted from the next program.

\section{When to Use Electrical Transcriptions}

But it is not the making of electrical transcriptions that should interest the advertiser; it is the effective use of them. Since their improvement in manufacturing and their more or less general acceptance by the listening public, electrical transcriptions are being widely used by advertisers. Certainly their use is almost essential when the advertiser selects for a 15-min. or more dramatic or musical program several stations not on a network hookup. Without electrical transcriptions this would mean a separate cast for each station or a special and overcostly wire hookup. On small stations it would mean an inferior cast. It should be noted, however, that some outlying stations have available efficient actors, good announcers, house bands, vocal singers, and quartets, which may be had by the advertiser for a consideration. According to the listings, dramatic actors run from $\$ 5$ to $\$ 25$ per program with rehearsals, tenors from $\$ 3$ to $\$ 15$, quartets from $\$ 10$ to $\$ 100$. To use these, even if they are good, is to invite extra work and extra expense. By using the transcription, the advertiser can employ the best of actors and directors, produce his show once and know that on each of the spot stations the show will be uniform and not one bit less effective than a live show-barring the fact that it will be announced as an electrical transcription.

Advertisers often use an electrical transcription for spot commercial announcements, if they want a uniform presentation. Or they may electrically transcribe their show and leave blank 
a place on the record for the local announcer to deliver a live commercial announcement. In such cases the complete script is generally sent with the disks. This method often adds a certain reality to the transcribed program. Its risk is that on the very small stations an inexperienced announcer may "butcher" the commercial.

Advertisers, too, use the electrical transcriptions as examples for the local announcer. One company sent out a record asking the local announcer in his live broadcasting of their commercial to approximate as closely as possible the tempo, stress, and voice quality of the records. Other uses of records are for special sound effects, for theme songs, and for file records of a program.

The immediate playback type of electrical recording may be made for a repeat on another local station later in the day. In New York recently, the Hobby Lobby program was transcribed from the live show on WJZ and played later in the evening on WOR, the advertiser buying another audience at a later hour and on another station.

\section{Cost of Electrical Transcriptions}

In the larger cities, there are special recording companies equipped to make records at very attractive prices, sometimes as low as $\$ 3$, exclusive of talent and rehearsal time. Some of these companies will even plan and rehearse the show. Others like RCA Victor, WOR, and World Broadcasting have several large studios specially equipped for transcriptions and do a very worth-while job.

\section{Sound Effects}

Sound effect is another typical broadcasting tool which the efficient advertiser can often use to good advantage in his advertising script. Sound effects frequently provide fine background and atmosphere, particularly for a dramatic script; one well-placed sound effect can often save 20 words of script and convey a more vivid and interesting ear picture to the listener than is possible with mere words.

Practically every station has some kind of sound-effect equipment. Many of the large stations have a sound engineer in charge and a collection of gadgets to imitate any possible sound desired. If they do not have the effect in stock or know its 
method, they will experiment until they can successfully reproduce it. It should be noted that when the show is on the air in a well-regulated studio, all sound effects are handled by the sound engineer and not by the actors. Even so romantic a thing as a kiss is said to be most effectively reproduced for air purposes by the sound engineer kissing the back of his hand. Any sound engineer can give an effective representation of horses at a gallop on a soft dirt road by pounding his own chest before the microphone to the same rhythm as the rhythm of the horses' hoofs. Sound effects of fires, big and little, are effectively produced by crinkling a few strips of cellophane or crushing strawberry boxes.

It is always a risk to list methods for sound effects for clever sound engineers are effecting better methods almost daily. Some improvements are discovered quite by accident. Enough for the advertiser to know that he can have by a recording of the actual sound, such sound effects as traffic sounds, laughter, mumbling records of voices of men, women, etc. Or by the actual imitation of sounds by mechanical effect, he can have such sounds as rain on a tin roof, wind, waves, etc. The latter sounds are more effective when made by special mechanical means than when actually recorded. Whatever sound is wanted from the felling of a tree to the sound of wagon wheels on a snowcovered road $20^{\circ}$ below zero, it will be forthcoming and effectiveat least in the big studios where sound-effect creation is an art.

All that the advertiser's script writer needs to do is to call for his sound effect in the script. This is generally done by making a bracket insertion thus: [trumpet blare in distance] [distant crash] [groans] [rattle of door knob] [background of traffic sounds]. 


\section{CHAPTER VI}

\section{WHAT THE SHOW WORLD HAS TO OFFER}

The advertiser may ignore the show world when he is planning the marketing and advertising end of his radio campaign; selecting the stations, the time for the program, and planning the dealer tie-ups is the advertising man's own special job. But when it comes to planning the entertainment and building the program, then the advertiser will find himself strictly within the province of the show world. Those radio authorities who lay down the axiom: "When you are in radio, you are in the show business" refer generally-and correctly-to this phase of the sponsored radio program.

\section{Importance of Program Selection}

So important, in fact, is the show world in this unusual business that the shrewd advertiser will not try to differentiate too closely between radio as an advertising medium and radio as an entertainment medium. As has already been pointed out, the selection of the program is more important than the selection of the network, granting of course that the networks considered all cover the advertiser's market. When it comes to counting real circulation (actual listeners), the show itself is the circulation builder. There have been small stations with real shows that have pulled more listeners than big stations with poor shows.

The popular Professor Quiz program started its radio career on a local station in Washington, D. C., as a sustaining feature. So popular did the program become with the listeners that soon it had a sponsor, then a few additional stations. Next the Nash-Kelvinator Corporation picked the program for a network feature, and then it was chosen by the Noxzema Chemical Company. More stations and more listeners resulted. Many of radio's finest shows have been born on radio's small stations and have carried their listeners with them from station to station, from network to network. 
If the radio advertiser, then, wants to turn potential radio circulation, which is at best an intangible, into actual circulation, which is the goal of every advertiser in any medium, let him study the show world. And that includes the stage, the screen, the musical world, vaudeville, the night clubs, the circus, and even sports-anything, in fact, that makes a business of entertaining the people. Certainly the drawing power of sports, baseball and football in particular, can be studied to advantage. Any football game that can draw 75,000 paying spectators, as our big games do today, is a major show.

The advertiser and advertising manager, unless they have had show experience, will do well to leave the presenting of their entertainment to those professionals who have spent their lives in this kind of work. The selection of a program director who knows the technique of radio presentation and the niceties of adapting the stage and screen presentation to radio must be made by the advertiser or his agency. Such selection may well be vital to the success of the entire advertising campaign. Past performance and former experience plus that rare gift of getting along with the many temperamental folks of the showworld can well be used in a checkup here. Having selected a good program director, the advertiser should not handicap him with too many suggestions.

Few advertisers actually interfere with the presentation of the show, but to most of them the actual selection of the actors holds a fatal fascination. The advertiser should be familiar with what is going on but should be cautious about depending entirely on his own judgment here. He should know, however, that there is much politics in the show business. It is a "friend of a friend" business-but after all what business is not. Undoubtedly many selections of talent are made upon other factors than the ability to act. Some actors do a better jobimpressing the sponsor and his agent than they do impressing the people who are to buy the advertised goods. Some sponsors think more of getting their wife's charming niece before the microphone than they do of getting their product before the dealer. Certainly if a sponsor is spending $\$ 20,000$ a week for his radio program, he should think many times before risking the show's success on untried and often inferior actors-whether of his selection or his showman adviser's. 
The advertiser should, of course, at least be familiar with the methods used to procure talent and with the rather complicated system of commissions which exist in the show business.

\section{Sources of Radio Talent}

Talent may be procured from: (1) the artist service bureaus of the broadcasting stations, which have listed most available professional and amateur talent, (2) the outside agency specializing in building radio programs, (3) the theatrical agency which has functioned for years in the show business and now has added radio talent to its list, (4) the advertising agencies, many of the larger of which have quite complete talent bureaus, (5) the managers of the artists themselves, (6) talent scouts who make a business of following radio shows large and small and often know the possibility of coming radio talent.

It is not impossible for an artist to be handled by several of these agencies or by outside brokers who sometimes have arrangements covering a commission on placing, in addition to the regular 10 per cent commission demanded by the usual agency. Thus we sometimes find an advertiser buying talent at a goodly price, while the talent itself may lose from 15 to 30 per cent of the price in commissions.

There is, too, the legal side of the actors' contracts to be watched. Some artists are tied up exclusively by contracts to one organization. Others with existing contracts cannot be hired exclusively for one advertiser. If the advertiser wants a star exclusively, he will pay high for the privilege. If he does not want exclusive rights, he may find his star appearing on other sponsored programs. A few years ago a well-known tenor played at least two sponsored programs on the same night and on different networks. The arrangement reduced his value to both of his sponsors.

\section{Value of Famous Names}

There is, too, another decision the advertiser is called upon to make early in his plans. Should he retain "name" stars and famous bands at high prices for his program or should he build up the fame of good but comparatively unknown talent? Here the advertiser must weigh the following factors. A well-known star or band has a listener following which will accrue to his program. A famous name also has a tremendous publicity 
value, is sure-fire in a radio column or a fan magazine. This publicity will come to the advertiser indirectly for the publicity is always given to the star, seldom if ever to the product the star represents. One direct advantage comes from the show listing in the newspaper radio log. Here talent names are listed but never products. The jaded listener thumbing his newspaper for new radio shows almost invariably picks his shows by talent names. "Name" talent is often well worth the price paid for it.

On the other hand, there is a certain value to unknown but good talent. It can often be tied up exclusively at a reasonable figure. The public enjoys novelty and new names if they are good performers. The advertiser will find, however, as soon as new talent becomes famous that with the expiration of its contract, it will forget who made it famous and demand the prevailing rates for a "name" star. Gratitude is a rare trait in the show business.

\section{The Studio Audience}

Another show-world necessity carried over to radio is the studio audience and its prerequisite, the stage presentation. There is much to be said pro and con for this popular but expensive procedure. First, the advertiser must have a clear picture of the difference between the psychological reaction of an assembled audience to a stage show or a movie and of the scattered radio audience. When people are together, there is a certain spontaneous approval. One hearty laugh may set off an entire assembly. The radio listener, being by himself, has no such yardstick with which to judge a radio program unless he can hear the reaction of a studio audience. If they applaud, if they laugh at a joke, the radio listener thinks it must be good and chuckles to himself, this in spite of the fact that he may know that the guinea-pig studio audience may have been asked to applaud or even asked to laugh. As already pointed out, the applause of the studio audience may run high in cost, but its effect on the lone listener is often worth the price.

Another advantage of studio audiences is their effect on the actors themselves. Radio actors who have been trained on the stage have come to depend on an audience reaction. It gives them an indication of how well they are going over; it acts as 
a stimulant to make them do their best. Eddie Cantor, an ardent advocate of studio audiences, often uses his rehearsal studio audience to try out his gags. If they "click" with the audience, he uses them on the regular air show. If they fall short of his expectations, he drops them.

Still another advantage of studio audiences little exploited at present is the possibility for merchandising the actual audience, selling them on the product, sampling, etc. The weakness of this recommendation is that most studios are limited in capacity. National Broadcasting Company's largest Radio City studio holds about 1,300. Columbia's New York radio theatres in no case seat more than this number. ${ }^{1}$ The studio audience for the Ford Sunday Evening Hour has a maximum limit of 5,000 . Whether these groups are worth the effort and cost of merchandising may well be questioned. There have been cases in some cities where a studio audience of as many as 10,000 have been assembled. To have even 5,000 people in a friendly mood and willing to listen to a sales talk is worth real money to any advertiser.

The use of a studio audience as an indicator of the popularity of the show has been pointed out. Certainly the demand for studio tickets is a very good indication of a show's popularity. But the enthusiasm of the assembled audience itself should be discounted. Their reaction is never the same as that of a real stage-play audience who have paid their admission. These studio audiences are free guests; they feel obligated and are likely to be overenthusiastic. The fact that they will blindly applaud when requested to by the announcer is proof of this.

To sum up: radio studio audiences may be advantageously used if the actors need their visual support; if the psychology of mass laughter and applause is a necessary part of the show presentation; and lastly, if the audience is worth merchandisingor can be used for their effect on the dealer. (See Chaps. XV, XVI, and XVII on merchandising.)

\section{Disadvantages of Studio Audience}

There are types of radio shows that either do not need the studio audience or that can actually be ruined by such an

${ }^{1}$ CBS Radio Theatre No. 1, capacity 973 ; No. 2, eapacity 720 ; No. 3 , capacity 1,225 ; No. 4 , capacity 1,156 . 
audience. Musical radio shows made up of orchestra numbers are an example of the first; dramatic presentations are examples of the second. Here, often because of the sound-effect technique, the audience never have the same reactions as the listeners. When a highly dramatic moment in the show is interrupted by the sound engineer tiptoeing to the microphone with his sometimes ludicrous-looking sound contraptions, it of ten has brought an audible audience laugh-sometimes loud enough to go over the microphone and ruin a highly dramatic sequence for the distant listener.

Where the stars are entirely radio trained, a studio audience is a hinderance, for this type of actor has never learned well to "play to his visible audience." He has his entire heart and soul on the vaster audience, the listeners at home before their radios. The author has in mind a radio singer trained entirely to radio who appeared a few years ago in a sponsored radio show with a studio audience. The actor sang too low for the audience, he ignored them, he almost caressed the microphone for his love songs. The studio audience voted him a failure, even tittered at some of his gestures. But a poll of the listeners at home showed this singer to be the most popular spot on the whole program. He had put his personality over the air but failed to deliver it to the studio audience.

\section{Actors-Stage or Radio Trained?}

Should actors be radio or stage trained? In ever-increasing numbers, there is a rising generation of actors who have had all their training over the radio. Much has been written as to which is better, the radio or stage actor. At present there are more famous names among the stage trained, but the stage is a far older institution. Certainly the technique of radio presentation is a business in itself and must be learned. It is often said that those trained exclusively to radio can best appreciate this technique in a medium of stop watches and invisible audiences; are better able to put everything in the voice and lose nothing by gestures.

Rosaline Greene,${ }^{1}$ the Mary Lou of "Showboat," herself an exclusively radio-trained star, says for the radio-trained artist:

${ }^{1}$ Radio Art. June 1, 1934, p. 24. 
Radio actors are likely to be more versatile than stage actorsaudibly. Instead of playing a role for a whole season, they play several radically different shows a week. They learn, too, a definite trick of characterizing by voice, not depending on make-up or "business" such as walk, movements, for effect.

Timing, too, is most vital. Do you realize that very often a show is cut and rehashed a few minutes before going on the air? A radio player must pick up the loose threads and instantly revise values. I have seen veteran troupers of the stage get positively panicky in such situations.

Think, too, of the distractions of the studio, the lack of costumes and settings to create the proper atmosphere for your drama. It takes a specially trained imagination to transcend evening clothes and stop watches to play a mountaineer woman!

Also the difficulty of getting into the mood of a situation after a commercial has thrust stern merchandising upon your glamorous romance. Or, the abrupt musical selection to change, as I have had to do, from a giggling girl into a grief-torn woman, bridging a gap of ten years with a few bars of music. Does stage training prepare one for that?

It must be said in credit to our many fine stage-trained actors on the radio, that many of them have learned to do these things and do them well.

A caution the advertiser might take from this is to question how effectively a stage star might be on the radio if he has had no considerable amount of radio training.

\section{"Doubling in Brass"}

Radio has been able to improve on the show-world practice of "doubling." From the early circus days when the performers often played in the band-"doubled in brass"-to today when two small parts are played by one stage actor, doubling has been an economic factor in the show world. But it has had its limits because of make-up and timing.

Not so in radio. A good character actor can change his voice at a moment's notice and in radio performance it is not uncommon to find one actor taking three or even more partsat a fine saving in talent charges to the sponsors. The Amos ' $n$ ' Andy program is an outstanding example where the dozens of radio characters on the program are all played by only two characters. 


\section{CHAPTER VII \\ WHAT TYPE OF PROGRAM?}

At any given time of the day or evening, on radio's over 700 stations there are literally hundreds of different programsmost of them carefully worked out to attain a given objective. Fortunately these fall conveniently into a dozen or more types of radio programs.

The advertiser might well ask: Is there any one magic type in this mass that can furnish a solution to my particular problem? There is sometimes in radio such a magic solution. In popular parlance it is called a "natural" and simply means that product, program, and time are all in perfect accord-that the product and the program are integral. The chances of a natural turning up, however, are about one in a 100.

A natural is not necessary for radio success, but a carefully selected type of program is. It must be remembered first that no program in itself sells goods. At best the program can attract and hold the audience long enough to tell them the advertising story, which is all the more reason why the advertising message should be a natural part of the program, smoothly delivered and strategically placed.

The next point is that no type of program can be devised to suit everyone every day. Today the radio fan selects his programs according to his likes and his moods. His moods are not predictive, but his likes are quite definitely known.

\section{Recognized Types of Listeners}

For instance, the theatre recognizes definite groups motivated by their entertainment likes. Among these are the lovers of good music, symphonic or operatic; those interested in comedy; in pictures; or in vaudeville. ${ }^{1}$ We might add to these for radio:

${ }^{1}$ R. L. Harlow, "Radio Audiences Form Class Tastes," Broadcasting, Jan. 15, 1934. 
lovers of sports, and those interested in news, education, and other informative items. Or we can divide the public, as the magazines do, into groups interested in specific subjects such as dogs, gardens, boats. One might conceive of one single program to reach all these types of listeners once, but to expect to hold them week in and week out is to hold a World's Fair for 4 years.

Rather than attempt to reach and hold radio's millions with one program, it is generally more effective and more economical to select a specific group. The advertiser can wisely ask himself: (1) Can my prospects be put in one of these "interest" groups? (2) If not, what group contains the most prospects? It has always been good advertising procedure to sell 100,000 well rather than to half sell 200,000 .

\section{The Special-Interest Program}

Fortunate is the advertiser, from a radio program standpoint, whose product is bought only by a specific group such as owners of dogs, or gardens, or sailboats. A special-interest program which automatically holds his prospects and politely drives away others is ideal here. And one big advantage of this type of program is that it can be inexpensive. It needs no great name bands, no $\$ 5,000$ movie stars, no great cast, but just a good authority on his subject who can present that subject according to the best practice of showmanship. And strangely enough good authorities on almost any subject come far cheaper than the top entertainers.

An outstanding example of the special-interest program appeared a few years ago. A fertilizer company wanted to reach garden and lawn owners. Its program consisted of informative talks on better gardens and lawns, which stressed the value of fertilizers. The selling talk for the fertilizer company was in separate commercials. Obviously the apartmenthouse dweller and probably the suburban renter tuned this program out, but the homeowner and especially the garden lover stayed to listen and, in paying percentages, to buy the product advertised.

A recent series of dog stories and talks for a manufacturer of $\operatorname{dog}$ food is another example of the specialized-appeal program. Advertisers have found these special-interest groups small in number but extremely loyal in spirit. 


\section{The Mass-Appeal Program}

But the advertiser might well say: "But my potential prospects include every man, woman, and child in America." Here the advertiser may take one or more special-appeal programs to cover the best of his prospects or he may use the mass-appeal program which is designed to include every listener. The present Chase \& Sanborn program, or any good variety hour or half hour, is an example of the mass-appeal program. Music, classical and popular, drama and comedy, laughs and thrills, something for everyone-and often not much for each one. These mass- or universal-appeal programs can never interest all groups for any length of time. Novelty soon wears off. It is only by the bigness of the offering, the fame of the stars, the surprises on each consecutive show that such programs keep as large an audience as they do. And such an audience is seldom loyal, is always shifting. To compete today in this field the advertiser must be willing to spend a large amount of money. Beyond a doubt there is a point even in mass program presentation where the cost of performance is not in keeping with the sales possibilities of the listeners.

Other advertisers prefer to put on several programs, one for each group, which may mean one for children, one for housewives, one for farmers. Still other advertisers with massappeal products have found it more profitable to go after a single "interest" group, and when they have thoroughly sold this group, to change their program to interest another group. If a group of listeners are not sold on an advertised product after 6 months of listening, they never will be. Better to drop them and go after a fresh group.

The devotees to direct-mail advertising have demonstrated this principle. A mass mailing list after a certain point yields an ever-decreasing amount of sales. When the sales drop below a profitable point, the list is said to be worked out and is discarded for a new one. Radio advertisers can profit by this and by many other standard advertising principles which have proved their worth in other media.

\section{Good-will and Sales-action Programs}

Before the type of program is selected, the radio advertiser should settle another fundamental question, the objective of 
the campaign. Is the program to secure good will or sales action? Radio will always be at its best as a good-will medium. Advertisers who have sufficient resources often use newspapers, magazines, and outdoor advertising to do their selling work and radio to bring them good will. They believe that the good-will radio program makes the other advertising more effective.

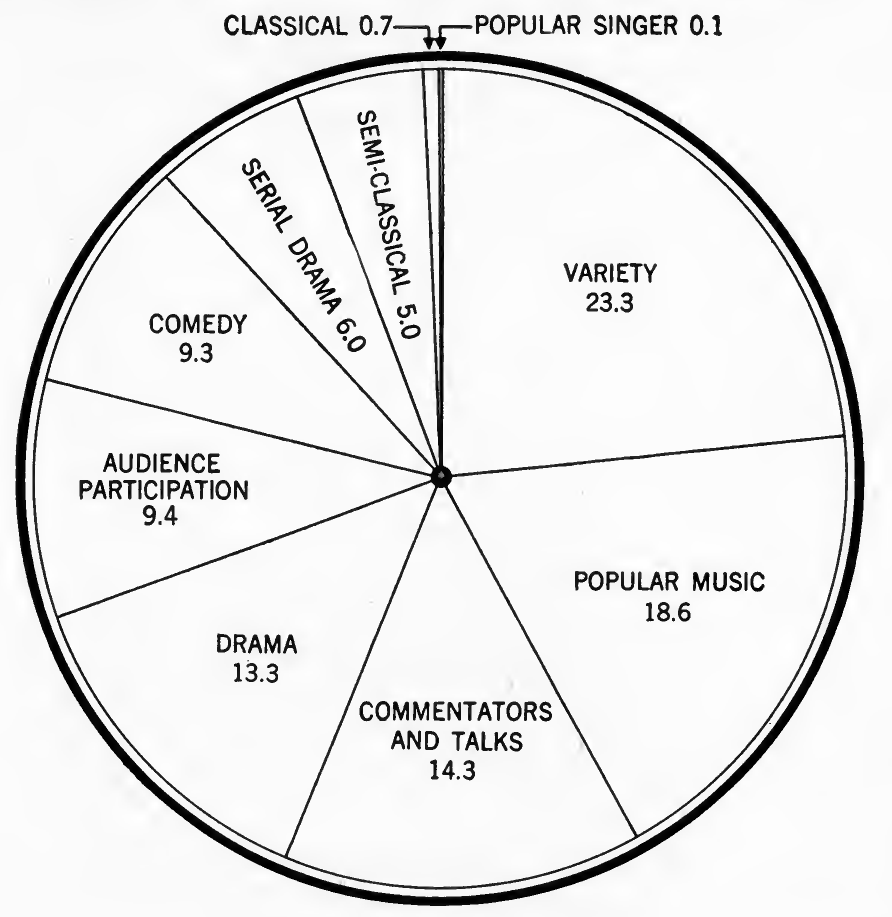

EVENING TIME PERIOD 1938

Division of commercial network time by program types, evening programs. (Courtesy of Cooperative Analysis of Broadcasting.)

But radio can do a good selling job and for the advertiser who can afford no other collateral advertising media, the sales-action program can be made effective and palatable. Its commercials will be longer and more powerful; they will annoy a few, but they will sell many.

\section{Recognized Types of Programs}

The selection of the proper type of program for any of the above cases will depend on the product, the time, and the listening 
group. Many types of programs are available. Novelty types always are an asset, but it should be kept in mind that novelty is short-lived. Advertisers have combed the world for a program with listening possibilities. Seemingly every possible type of program has been sponsored: church service (formerly Adams Hats) to prize fights (Buick); quiz bees (Noxzema) to

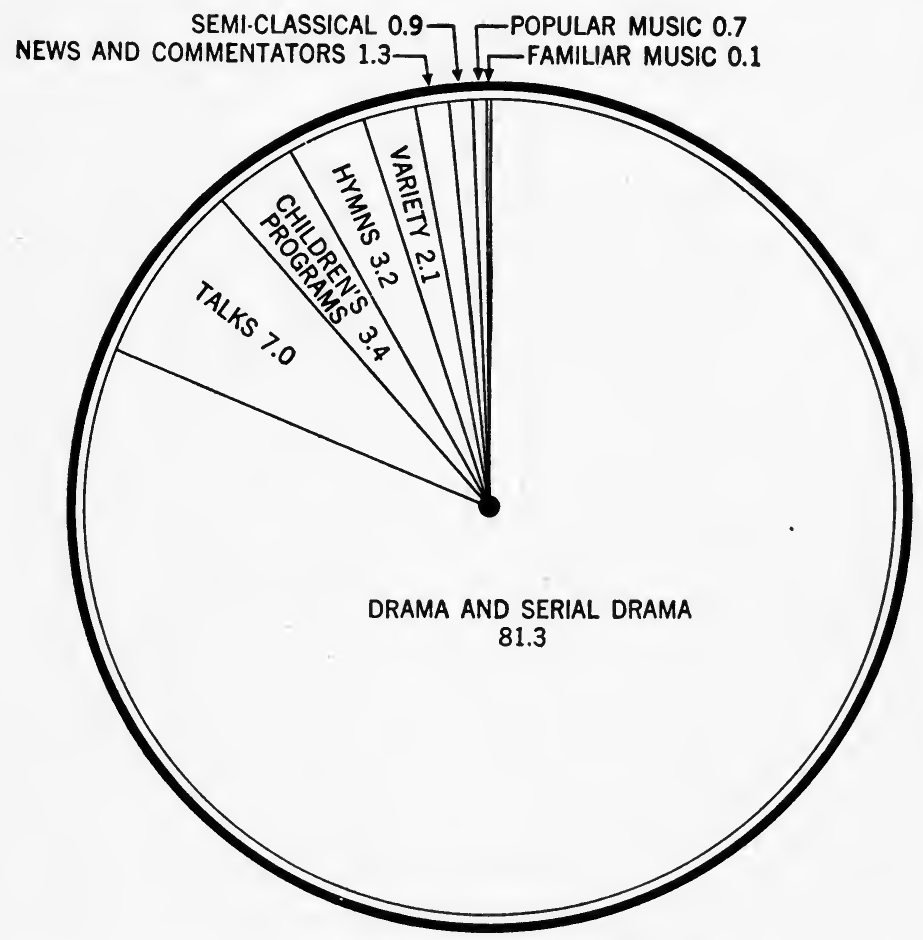

DAYLIGHT TIME PERIOD 1938

Division of commercial network time by program types, daytime programs. (Courtesy of Cooperative Analysis of Broadcasting.)

football games (Atlantic Refining); symphonies (Ford) to swing (Camel). Yet almost all these offerings fall into a few definite types of programs. Broadcasting companies recognize seven: dramatic, variety, music, service, news, commentators, and announcements. The Cooperative Analysis of Broadcasting (CAB) lists the following types of programs: variety, audience participation, serial drama, classical, semiclassical, comedy, popu- 
lar music, bands, commentators and talks, popular singers. The advertiser, however, will do well for his purposes to make a more detailed list with music at one end, spoken programs at the other, and variety programs in the middle.

The following list is meant to be a suggestion for a general classification, and is not an attempt to classify all programs into definite types:

\section{Possible Types of Sponsored Programs}

I. Musical.

Symphony, opera, operettas, popular dance, musical comedies, choruses, soloists, folk songs, presented by orchestras, bands, individual instruments, voice.

II. Variety.

Balanced programs of music and speech, variety hours with masters of ceremonies, amateur hours (both adult and child), farm and home hours combining music with informative talks.

III. Straight Dramatics.

Plays, comedy and dramatic sketches, serials (mystery, romance, adventure).

IV. Talks.

Educational lectures, speeches by famous people, reviews of theatres, movies, books, sermons.

V. News.

Straight news, dramatized news, news by commentators.

VI. Special Events.

Parades, prize fights, baseball games, football games, and the like. VII. Service.

Advice on such topics as cooking, health, home decoration, style, and beauty; weather, time, stock reports.

VIII. Information.

Do-you-know programs, interesting facts of history, movies, radio science-anything that appeals to the ever-growing group of adults who strive to increase their knowledge.

IX. Participation.

Spelling bees, quizzes, community sings, guessing programs-any program in which the armchair listener can take part-actually or vicariously.

\section{Selecting the Type of Program}

A formidable array of possibilities exists for the advertiser who is selecting his radio offering. In choosing the type of program he will use, let him consider the number of possible listeners who are interested; the number of prospects in the "interest" group; adaptability of the program to the product or 
service; the number of similar programs on the air (novelty); the cost of talent; and the practicability, i.e., whether the type selected can be presented on the stations used. Spot stations, for example, may not be able to furnish the proper type of talent; and although electrical transcriptions can be used in some cases, if the program is a timely one, even these may not be practical. A "natural" program would be one answering favorably to every one of these points.

Another line of approach in selecting the program type may be this. List the type (or types) of prospects first. Example: housewives, children, business women, young people (ages 17 to 27), businessmen, farmers, small-town folks, city folks, etc. Then select a type of program which might interest that group or groups. Where more than one type is listed, the really successful radio advertiser seldom is satisfied with one program. He may select two or several: a morning program for the housewives, a late afternoon program for the children, an evening program for the men or young people, perhaps a late program for the sophisticates.

It should be noted that the type of program will determine the type of listeners just as the type of magazine or newspaper - definitely determines its type of reader. True Story or Redbook, National Geographic or Crime Stories, The New York Times or the New York Daily News, all have definite reader groups, all good prospects for some advertisers, often all good prospects for one advertiser, but rarely if ever can they all be sold by the same appeal.

\section{Trends in Programs}

Certain types of radio programs have a tendency to rise in listening popularity, reach a zenith, and then fall rapidly. This is due in part to the public's unending search for novelty, in part to the shameless imitating of popular programs, and in part to the public's ever-changing taste. The advertiser before deciding on a type of show will do well to study at least a year's series of ratings on similar shows and also on the public's taste.

There seem to be certain public tastes that do remain constant. One is the liking for musical programs. Tests made by broadcasters and advertisers show this liking to be practically fixed. Note, however, that the type of music does change. Symphonic 
offerings are on the ascent at present, hillbilly music far on the descent, swing music just passed its zenith.

A criterion the advertiser can use in this connection is the average number of sustaining programs being offered by the leading broadcasting stations. Sustaining shows are obviously a bid for listener interest; they are the station's "editorial" matter in contrast to its "advertising" matter. They are chosen always to answer the question: "What do the listeners want?" just as a periodical's editorial content answers the question: "What do readers want?"

Recently the Federal Communications Commission diagnosed a typical radio week (Mar. 6, 1938) on 633 stations and furnished the first thorough index to program trends in American broadcasting ever made available. ${ }^{1}$ These figures give the advertiser not only a comparison of sustaining and sponsored programs, but also the percentages of each type of program actually on the 633 stations (both chain and spot stations).

Following is a summary of F.C.C. Table 39A, covering the week of Mar. 6, 1938.

\begin{tabular}{|c|c|c|c|}
\hline Type of program & $\begin{array}{c}\text { Sustaining, } \\
\text { per cent }\end{array}$ & $\begin{array}{c}\text { Commercial, } \\
\text { per cent }\end{array}$ & $\begin{array}{l}\text { Total, } \\
\text { per cent }\end{array}$ \\
\hline 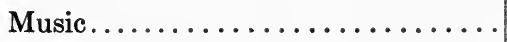 & 40.03 & 12.42 & 52.45 \\
\hline 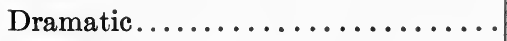 & 3.06 & 6.05 & 9.11 \\
\hline 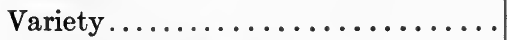 & 4.24 & 4.60 & 8.84 \\
\hline Talks and dialogues.............. & 7.56 & 3.85 & 11.41 \\
\hline 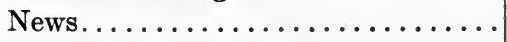 & 5.36 & 3.19 & 8.55 \\
\hline Religious and devotional.......... & 3.15 & 2.00 & 5.15 \\
\hline Special events........... & 1.44 & .77 & 2.21 \\
\hline 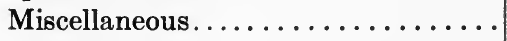 & .61 & 1.67 & 2.28 \\
\hline 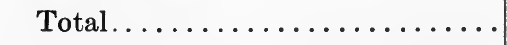 & 65.45 & 34.55 & 100.00 \\
\hline
\end{tabular}

In commenting on the above, Broadcasting ${ }^{2}$ says:

Significant is the fact that sponsored musical offerings were not quite one-third of sustaining musical offerings; that twice as many dramatic programs are sponsored as sustaining; that variety shows run evenly between commercials and sustaining; that talks and dialogues, which

${ }^{1}$ See Broadcasting, July 1, 1938, pp. 18-19, for a fine summary of this F.C.C. report.

${ }^{2}$ Broadcasting, July 1, 1938, pp. 18-19. 
include politics, educational forum subjects, etc., run two-to-one sustaining, that only about three out of eight news programs are sponsored; that one out of three special events is sponsored.

From the advertiser's viewpoint, a musical program is always a safe one. Yet its weakness is that, while it is popular with a large group of listeners, the popularity, as already pointed out, is divided between those who really like music and those who want a harmless program which they can use as a background for reading, talking-everything except conscious listening. (See Chap. VIII for a further discussion of the musical program.)

In favor of the spoken radio program is the fact that, although the average spoken program may draw fewer listeners, these listeners on the whole will be more attentive listeners both to the program and to the commercial message. One can listen to a musical program with divided attention, but a spoken program must be given complete attention-or none.

An analysis of over 200 sponsored programs over the NBC and CBS networks in March, 1939, shows the following division of types of programs: 18 per cent musical; 16 per cent variety; and 66 per cent spoken. Foods, drugs, and toilet goods and soaps accounted for the largest number of programs; the majority of these were of the spoken type given in the daytime to reach the housewife. Cigarettes and tobacco accounted for the next largest number of programs, the majority here being of the musical and variety type given in the evening for the whole family. The American Tobacco Company and Philip Morris \& Company, Ltd., both had programs on each of the networks.

\section{Children's Programs}

Exploiting Young America via radio has become for the advertisers, the great American pastime. So great has it become in fact that some of the networks have had to curb the advertiser's enthusiasm, have had to assure irate parents, ParentTeacher Associations, and Women's Civic Clubs, that little Junior's youthful enthusiasm was not being unduly exploited.

Certainly there is no more enthusiastic and loyal market in the world than youth and in America there are approximately $40,000,000$ under 18 years of age. Probably close to $20,000,000$ of these are at the height of their enjoyment when 
belonging to a radio club. A feather, a badge, or a gilt button makes a boy an enthusiastic salesman and personal user, for a time, of any product that fits halfway into his daily life.

No wonder that shortsighted advertisers have overdone it, and have given doting parents "box-top jitters" and their children "radio tantrums." No wonder that, within the past few years, sensible advertisers have listened to reason and taken the "blood" out of their blood-and-thunder offerings and cooperated with parents in not overloading little Junior's stomach by asking him to eat "Munchies" not only at breakfast but at lunch and dinner and bedtime.

The radio advertiser who wants to reach this juvenile market will do well today to select a type of program that has the parents' approval-if not their enthusiastic endorsement. Otherwise tremendous ill will and downright antagonism to the advertiser's product will ensue. It is characteristic of children that their interest soon wanes. If a product is to hold its position in a household, it needs a parent's endorsement after the child has introduced it.

There are several successful types of children's programs. Some of them actually meet with both parents' and teachers' endorsements. The first consideration in determining the type of program should be suitability to the age of the listeners. A simple type of program is needed for children under 8 years; a more adventurous type appeals to children from 9 to 12 years, which group, surveys and sponsor's fan mail show, contains the larger number of enthusiastic listeners. For the younger group fairy tales, dramatized comic strips, musical programs such as the former Kellogg's Singing Lady program, can be used successfully. For the older group stories of adventure, sketches, programs built around clubs, have been widely used. Some of these clubs, when the proper paraphernalia has been offered, have amassed more than 1,000,000 members. In a membership drive for Swift \& Company's Junior Nurse Corps (Monday to Friday 5 to 5:15 P.M., Feb. 14-18, 1938), an offer of a signlanguage manual for names and addresses of two new members written on the back of Sunbrite labels brought in 75,000 in one day. For the Reporter's Club of the former Bond Bread program, over 700,000 reporters' badges were distributed. The serial motif is a powerful one for this type of listener as it gets 
the child into the habit of daily listening. Some of these programs appear 5 days a week- "across the board," to use radio's lingo.

\section{Women's Programs}

Program types appealing directly to women have been particularly successful on the air. Because women buy or influence probably 87 per cent of all commodities sold, here is an ideal market for the advertiser. Any of the standard types of programs that will appeal directly to women can be used. Music, story, serial played "across the board" mornings, or possibly afternoons, will have a good following if well done. Service programs on cooking, domestic economics, home decoration, health, and beauty have been successfully used by leading radio advertisers. Lever Brothers Company's Big Sister program, Monday through Friday 11:30 to 11:45 A.M., is said to have given out over 800,000 sewing kits at 10 cents each plus a Rinso box top, after only 18 announcements covering 3 weeks' time. Regional Advertisers, Inc. Cooking Talks, Tuesdays and Fridays 11:45 A.M. to $12 \mathrm{M}$. and 2:45 to 3 P.M., is said to have given out from stores 2,909,000 copies of the Mystery Chef's Cook Book during 2 years and 10 months.

No matter what type of program the advertiser selects nor what group he wants to reach he must see that the program has continuity to hold its listeners over a given period of time and freshness to keep the listeners enthusiastic. Kenneth Goode says $^{1}$ in discussing this:

Never let your radio show stand still! Be always eager to improve! Test constantly for more popular features, for more effective ways to do things! Work your heart out to get just the right amount of variety. Sit up nights finding a touch of freshness. But don't risk too much newness until you are convinced your show is so unpopular you couldn't possibly be worse off.

\section{Program Types for Small Stations}

Many of the types of programs thus far discussed are much more suitable for network broadcast than for presentation by 1 "What about Radio?" p. 212, Harper \& Brothers, 1937. 
small stations. The advertiser is often faced with this situation: 5 or 50 small independent stations have been selected for the campaign. What type of program is most practical? Obviously the expensive mass-appeal program is not practical here. Its cost is too high-even if the presentation is made for the spot stations by electrical transcription. Much of the program's attractiveness depends on the fact that it is a live show, that great stars are speaking or performing at the moment. Electrical transcription for such programs lessens listener following.

Thus to select the small spot station is to discard almost automatically certain types of programs. For drama, for certain types of musical shows where electrical transcription does not greatly lessen listening appeal, the small station may use a good electrical transcription. Other types of programs admirably suited to the small station are those that do not require top-ranking talent and those where a fair announcer with the proper script can conduct a fair show. News programs, service talks, certain types of quiz and information programs can be presented with live talent on small stations. The checkup here should be to see that the small station has the type of announcer desired.

More and more, the advertiser is turning to electrical transcription (either the whole show or parts of it) for acceptable presentation on the small station. For building shows especially adapted to small stations, see Chap. XXIII.

\section{Traveling Shows}

There is also a type of show called the traveling show or the road-radio show. It travels from city to city, may include vaudeville or stage engagements in its itinerary, but can be booked also for presentation by radio stations, if they are not too small. There is the danger here that the week-in, week-out continuity of the radio program will be jeopardized by this type of offering. Of course, even on the mass-appeal shows on the large networks, the stars may go to Hollywood or on the road for stage engagements. But here the problem is simple for each station of the network is equipped to pick them up and by way of special wires, fit their performances into the regular network of the show. There are cases on record where as many as three of the star performers have been in different cities, have through 
the network station in their city been connected with the network program, have been able to "talk back" and thus take part smoothly in the national network program.

\section{Rural vs. Urban Program Preferences}

That rural and urban tastes differ, every advertiser knows. How much does this difference affect the type of radio program selected? Certainly a type of program can be selected to suit

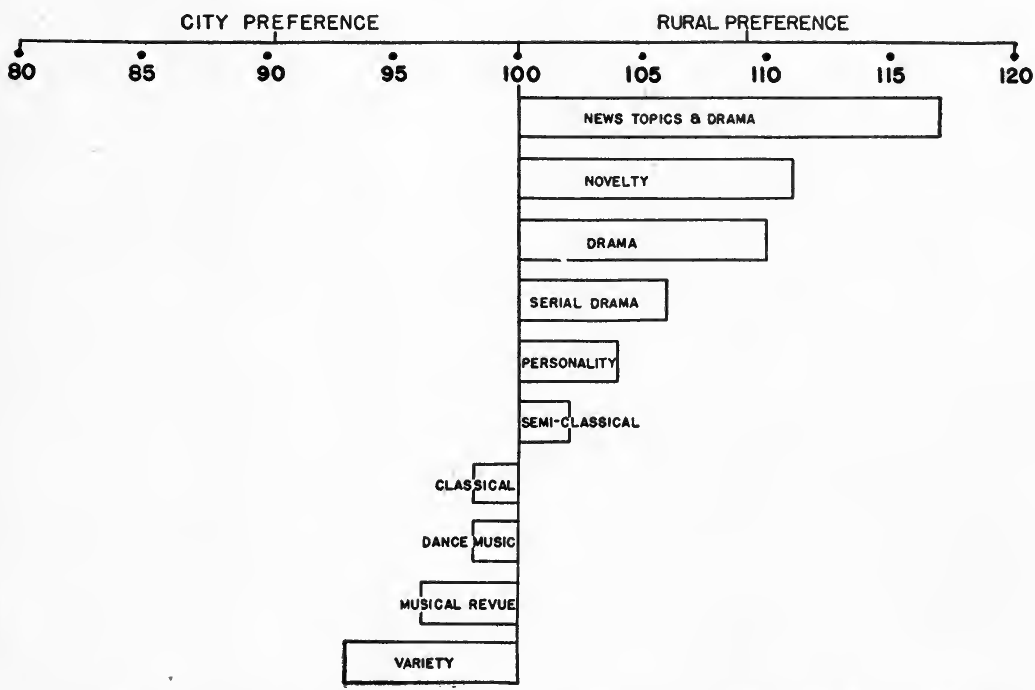

Indicated preferences of listeners in rural areas and large cities by program types. 100.0 = large cities average for each type. (Courtesy of Cooperative Analysis of Broadcasting.)

both city and country. The Chase \& Sanborn and the Jell-o variety programs prove this because they are top ranking both with urban and rural listeners. Other ranking programs have not so successfully catered to both groups. Oversophistication will be appreciated by the urban listener but will not appeal to the rural one. Simple homey programs, on the other hand, are more appreciated by the rural group.

The following comparison of the Cooperative Analysis of Broadcasting rating of several leading evening programs are worth the advertiser's careful study before selecting a type of program for either urban or rural presentation. 
Rankings of the 10 Leading Evening Programs in Rural Areas Compared with Their Large City Rankings

\begin{tabular}{|c|c|c|}
\hline Program & $\begin{array}{l}\text { Rural areas } \\
\text { ranking }\end{array}$ & $\begin{array}{l}\text { Large cities } \\
\text { ranking }\end{array}$ \\
\hline Chase \& Sanborn . . . . . . . . . & 1 & 1 \\
\hline Jack Benny . . . . . . . . . . . . & 2 & 2 \\
\hline Major Bowes.............. & 3 & 9 \\
\hline Lowell Thomas.............. & 4 & 21 \\
\hline National Barn Dance.......... & 5 & 30 \\
\hline Burns and Allen............ & 6 & 6 \\
\hline Town Hall-Allen............ & 7 & 4 \\
\hline Lux Radio Theatre............ & 8 & 3 \\
\hline One Man's Family............ & 9 & 16 \\
\hline Phil Baker............... & 10 & 10 \\
\hline
\end{tabular}

Rankings of the 10 Leading Evening Programs in Large Cities Compared with Their Rural Rankings

\begin{tabular}{|c|c|c|}
\hline Program & $\begin{array}{l}\text { Large cities } \\
\text { ranking }\end{array}$ & $\begin{array}{c}\text { Rural areas } \\
\text { ranking }\end{array}$ \\
\hline Chase \& Sanborn. ........... & 1 & 1 \\
\hline Jack Benny............... . & 2 & 2 \\
\hline Lux Radio Theatre............ & 3 & 8 \\
\hline Town Hall-Allen............. & 4 & 7 \\
\hline Kraft Music Hall.... . . . . . . . & 5 & 18 \\
\hline Burns and Allen............ & 6 & 6 \\
\hline Rudy Vallee................ & 7 & 11 \\
\hline Al Jolson. . . . . . . . . . . . . . & 8 & 15 \\
\hline Major Bowes............... & 9 & 3 \\
\hline Phil Baker............... & 10 & 10 \\
\hline
\end{tabular}


Rankings of the 10 Leading Daytime Programs in Rural Areas Compared with Their Large City Rankings

\begin{tabular}{|c|c|c|}
\hline Program & $\begin{array}{c}\text { Rural areas } \\
\text { ranking }\end{array}$ & $\begin{array}{l}\text { Large cities } \\
\text { ranking }\end{array}$ \\
\hline Guy Lombardo.... & 1 & 1 \\
\hline Dick Tracy $\ldots \ldots \ldots \ldots \ldots$ & 2 & 27 \\
\hline The Woman in White......... & 3 & 2 \\
\hline Gospel Singer............... & 4 & 24 \\
\hline David Harum............ & 5 & 7 \\
\hline Hilltop House............. & 6 & 36 \\
\hline Bachelor's Children........... & 7 & 14 \\
\hline Just Plain Bill.............. & 8 & 9 \\
\hline Pretty Kitty Kelly ........... & 9 & 28 \\
\hline John's Other Wife $\ldots . \ldots \ldots \ldots \ldots$ & 10 & 22 \\
\hline
\end{tabular}

Rankings of the 10 Leading Daytime Programs in Large Cities Compared with Their Rural Rankings

\begin{tabular}{|c|c|c|}
\hline Program & $\begin{array}{l}\text { Large cities } \\
\text { rankings }\end{array}$ & $\begin{array}{l}\text { Rural areas } \\
\text { rankings }\end{array}$ \\
\hline Guy Lombardo...... & 1 & 1 \\
\hline The Woman in White......... & 2 & 3 \\
\hline Guiding Light. $\ldots \ldots \ldots \ldots \ldots$ & 3 & 12 \\
\hline Vic and Sade.............. & 3 & 20 \\
\hline Aunt Jenny Real Life Stories.... & 5 & 23 \\
\hline Terry and the Pirates......... & 5 & 34 \\
\hline David Harum.............. & 7 & 5 \\
\hline Mary Marlin.............. & 7 & 12 \\
\hline Just Plain Bill.......... & 9 & 8 \\
\hline The Big Sister........ & 10 & 18 \\
\hline
\end{tabular}




\section{CHAPTER VIII \\ IF THERE BE MUSIC!}

For the advertiser who did not play a saxophone in the high school band and who does not belong to the local civic chorus, this chapter is written. He may feel as out of place in the presence of his radio program director and his musical director as an office boy at a directors' meeting. He may think Debussy wrote a naughty French book and that César Franck invented a railroad coupling rather than composed the difficult "Sonata in A." But none better than he knows why the sponsored radio show is on the air. In other words, there is much he can do to integrate the rhythm of radio's music to the rhythm of the cash register's song.

While music has an emotional appeal, a lot of cold reasoning should go into its selection if the sponsored program is to accomplish its end. And quite often a tone-deaf advertising man can reason better than a musical director with an aptitude for harmonic acrobatics.

Almost two-thirds of the radio shows presented today, as already pointed out, are basically musical. Over 8 per cent more are of the so-called variety type containing a goodly proportion of musical numbers. Of the balance, many of the shows use music for background, for musical bridges between the dramatic acts of the show, and for theme songs. As important then to know how and why music is used as to know how and why the very show itself is put together.

\section{The Different Classes of Music Lovers}

Let's start with the radio listener himself. Just because twothirds of all programs are musical does not mean that twothirds of the listeners are music lovers. A musical radio show is a comparatively easy thing to put on the air. At least the sustaining ones are. A wire to a leading night club where a famous orchestra leader is playing an engagement and the job 
is done. On the small station, select carefully five or six good electrical transcriptions by famous orchestras and a 15-min. program is created. Musical shows are probably overdone on the air because the mediocre ones are so easy to handle. And then the public itself has fooled the radio advertiser on the popularity of music. Surveys show the public to be predominately partial to musical programs. If the public honestly answered the question "Why?" they probably would say because music is easy to listen to, because work can be done, books read, and conversation carried on during the musical program. Although people listen more carefully to the spoken show, probably countless thousands turn off the spoken show because they are not prepared to concentrate on its context.

The music-loving public can be divided into two classes: those who know music and those who do not. Both have pocketbooks and stomachs, but there are far more of each in the great musically uneducated class, those who cannot recognize rhythm as such but who feel that there is something missing when it is absent and who cannot interpret the symphonies. Thanks to the fine radio educational work of Dr. Walter Damrosch and the presentation of sustaining symphonic and operatic offerings on the air both by station and sponsor, this "know-not" class is becoming smaller. But it still represents the mass listening public. People are interested in music because they like to listen, because they like to play or sing, or because they like to create or compose it. Everyone, the artist, the craftsman, the factory worker, is as conscious of the rhythmic pattern as they are of symmetry or sheer beauty. Rhythm is the basis of song and of everything we do accurately and accounts for the fact that so many people like musical programs. Experiments in factories where routine work is done show that the workers tire less quickly and do more and better work when radio musical programs are offered. A chance to get a commercial message on such musical programs to from 10 to 50 workers in thousands of factories is not to be treated lightly.

\section{Mass-appeal Music}

Phil Spitalny, ${ }^{1}$ who directs the well-known Hour of Charm for the General Electric Company, says:

${ }^{1}$ Phil Spitalny, "The Hour of Charm," The Etude, October, 1938. 
Thirty-five All-time Best Selling Songs

\begin{tabular}{|c|c|c|}
\hline Year & Title & Publisher \\
\hline 1892 & "After the Ball"... & Chas. K. Harris \\
\hline 1901 & 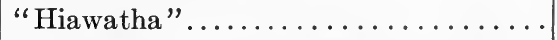 & Whitney-Warner \\
\hline 1905 & "In the Shade of the Old Apple Tree".. & Remick \\
\hline 1906 & "Love Me and the World Is Mine".... & Witmark \\
\hline 1907 & "I Wish I Had a Girl" ............. & Remick \\
\hline 1907 & "School Days".................. & $\begin{array}{l}\text { Gus Edwards Publishing } \\
\text { Company; Mills }\end{array}$ \\
\hline 1910 & "Down by the Old Mill Stream"...... & Tell Taylor; Forster \\
\hline 1912 & "That's How I Need You".......... & Feist \\
\hline 1913 & "Marcheta"............ & $\begin{array}{l}\text { John Franklin Music Com- } \\
\text { pany }\end{array}$ \\
\hline 1913 & "The Trail of the Lonesome Pine". & Shapiro-Berstein \\
\hline 1913 & “There's a Long, Long Trail" ........ . & Witmark \\
\hline 1914 & "Missouri Waltz"............ & Forster \\
\hline 1915 & "Keep the Home Fires Burning". . & Chappell \\
\hline 1915 & "Memories".............. & Remick \\
\hline 1917 & "For Me and My Gal"........... & Waterson; Mills \\
\hline 1917 & "Joan of Arc, They Are Calling You".. & Waterson; Mills \\
\hline 1917 & "Smiles" & Remick \\
\hline 1918 & "Beautiful Ohio" ............... & Shapiro-Berstein \\
\hline 1918 & "Just a Baby's Prayer at Twilight"... . & Waterson; Mills \\
\hline 1918 & "Till We Meet Again"............. & Remick \\
\hline 1919 & "I'm Forever Blowing Bubbles"....... & Remick \\
\hline 1919 & "Oh! What a Pal Was Mary"........ & Waterson; Mills \\
\hline 1920 & "Whispering" ................ & Sherman-Clay \\
\hline 1921 & 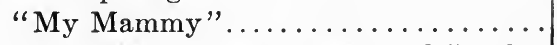 & Irving Berlin, Inc. \\
\hline 1921 & "Tuck Me to Sleep in My Old 'Tucky & \\
\hline & 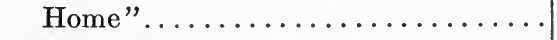 & Irving Berlin, Inc. \\
\hline 1922 & "My Buddy" .................... & Remick \\
\hline 1922 & "Three O'Clock in the Morning" & $\left\{\begin{array}{l}\text { Leo Feist, Inc. } \\
\text { West's Ltd., (London) }\end{array}\right.$ \\
\hline 1924 & "I Wonder What's Become of Sally?". & Ager-Yellen \\
\hline 1925 & 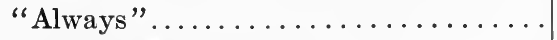 & Irving Berlin, Inc. \\
\hline 1927 & "Among My Souvenirs"......... & DeSylva; Crawford \\
\hline 1927 & "My Blue Heaven"............ & Feist \\
\hline 1927 & "Ramona"........ & Feist \\
\hline 1928 & "Carolina Moon". . & Joe Morris \\
\hline 1928 & "Sonny Boy" ................. & DeSylva; Crawford \\
\hline 1929 & "When It's Springtime in the Rockies". & Villa Moret, Inc. \\
\hline
\end{tabular}

Noncopyright Best-selling Songs

"Aloha"

"Blue Danube"

"Silver Threads among the Gold"
"Merry Widow Waltz" "Home on the Range" 
Experience shows that the vast majority of our people are music lovers at heart, provided they can be given music which means something to them. . . . To my mind, the answer is light music, melodic, rhythmic, well-played tunes which will satisfy the ear and the emotions, without overtaxing an intellect which has not been trained so that it may grasp the beauties of the greater classics.

And there you have the millions, the mass-appeal music lovers. If the advertiser wants the class appeal, those who really appreciate good music and generally know why, there are hundreds of thousands of worth-while radio prospects who will be responsive to symphonic and operatic offerings. Ford's Sunday Evening Hour is an example of a radio program designed to select this limited but profitable audience. When an advertiser can definitely locate all his prospects among either of these groups, the type of musical show to use selects itself. Otherwise the only rule the advertiser can use is: the faster the tempo, the younger (and probably larger) the group of listeners. Certain large groups of middle-aged people who have acquired a large number of musical associations will enjoy and follow closely programs of familiar music.

\section{Old Songs vs. New}

If the advertiser feels that the old songs are not good pullers, let him consult the table on p. 88 taken from the Sept. 21, 1938, issue of Variety. All these old-timers have sold well in excess of 1,000,000 copies. "Till We Meet Again" had sold over $6,500,000$ copies several years ago.

The advertiser who follows his radio programs will hear many of these old-timers played again and again on present programs. Most of them have a simple melody which carries through the years and adds them to that ageless group, the American folk songs.

Now compare these songs with the following 15 best sheetmusic sellers as listed in the same issue of Variety.

Fifteen Best Sheet-Music Sellers Title Publisher

*,†Alexander's Ragtime Band.......... ABC

*I've Got a Pocketful of Dreams....... Santly-Joy

A-Tisket, A-Tasket.............. Robbins

*Now It Can Be Told............. Irving Berlin, Inc.

When Mother Nature Sings Her Lullaby Santly-Joy 
Title

You Go to My Head............. Remick

So Help Me................... Remick

I'm Gonna Lock My Heart.......... Shapiro

Music, Maestro, Please........... Irving Berlin, Inc.

*Small Fry.................. Famous

Stop Beating Around the Mulberry

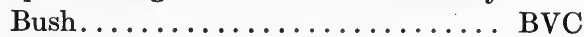

${ }^{*}$ Change Partners............... Irving Berlin, Inc.

*I've Got a Date with a Dream....... Feist

*Garden of the Moon............. Harms

What Goes on Here in My Heart..... Paramount

* Indicates song featured in a film musical; the others are popular tunes.

$\dagger$ A revival of an old song.

Of the 15 most popular songs of September, 1938, how many are played on the radio today? To show how quickly the modern song loses its popularity, not a single one of these songs was listed among the 15 best sheet-music sellers for February, 1939. And only 5 of the February list were on the March list, a month later.

The moral to be drawn here is that when musical programs are planned well in advance, or when electrical transcriptions are being made of several musical programs at one time, considerable skill will be required to pick modern songs which will still be popular when the program is put on the air.

As a matter of fact, the selection of any type of music for a radio program should be made with the same care and judgment that the advertiser uses in selecting illustrations and typography for a printed advertisement. Just as the printed advertisements determine the seeing audience by their artistic presentation, general appearance, and pleasant feeling tone, so does the proper selection of music determine the listening audience.

Before the problem of program planning can be profitably discussed, let us make a brief survey of the musical material which can be used in both the musical type of program, the variety, and in those spoken radio shows which include musical backgrounds. Note that musical backgrounds, if not too long, and theme songs can often be profitably recorded and used as transcriptions because the F.C.C. rules that this type of music when presented in electrically transcribed form, need not be announced as an electrical transcription. All full-length records must, of course, be announced as such. 


\section{Types of Programs in Which Music Takes Part}

Music is important in three main types of shows: the allmusical show, the variety show, and the dramatic show. The all-musical show can be supplied by a house band, a symphony orchestra, a vocal soloist, an instrumental soloist, a vocal chorus, or one of many different combinations of vocal and instrumental soloists and ensembles. This program, as the name implies, consists basically of musical entertainment. The quality of the all-musical shows presented by a radio station does much to win listeners and sponsors to the station. WQXR, a small station in New York City, uses a large part of its air time in playing electrical transcriptions of symphonic and operatic music and by doing so has developed a definite following of lovers of music of this type.

Music plays an important part in keeping up the tempo of the show. In the dramatic program, music sets the scene and retains tempo and feeling tone. The term "tempo" may be defined as the speed which a show must achieve and retain in order to keep the listener interested in the program. The tempo is usually set by the opening musical number of the show, just as the tone and style of a written piece of copy is set in the opening paragraph. The tempo may be accelerated as the show continues in order to increase the intensity of the listener's attention but tempo should seldom be diminished if results are to be obtained in holding listeners for the radio advertising.

Feeling tone in visible advertisements is the aesthetic quality which makes the appearance of the advertisement appealing to those for whom it is intended. Feeling tone in radio musical selections (closely associated with good will) follows this same principle. The program should be designed to appeal to potential consumers and the general listening public so that word-ofmouth advertising can supplement the commercial announcement long after the show has completed its radio time. The feeling tone should be maintained week after week. It can be achieved by perfect blending of music, commercials, and the proper show theme. The music should create and maintain the feeling tone and make up for whatever the show theme may lack. It is the program director's job to decide what tempo the show should have in order to achieve the proper feeling tone to obtain and maintain an audience. It is his job to obtain the 
proper cooperation from the musical director by offering suggestions of what he considers appropriate. Unless the advertising manager has a thorough musical background, the less he interferes here, the better.

\section{Planning the Program}

In order to have the best music for the needs of a show a good musical program must be carefully planned, the selections must be appropriately arranged, the talent must be tastefully selected, and the instrumentation of the orchestra must balance and reinforce the program, and meet the budget of the advertiser.

\section{Selection of Artists}

In radio as in show business, an artist (or group of artists) is selected for popularity or box-office power, as well as for musical merit. In selecting an artist for a radio show the advertiser should seriously consider both musical and publicity qualities of the artist and make sure that these balance each other. If the popularity merits overshadow the musical merits of an entertainer, his value to a program will be small after the first few broadcasts. Often artists who are successful guest stars do not do so well under the stress of the continuous weekly appearances on a regular program. Some are highly successful on the stage or in the movies, but only fair on the radio. Stars who were big names yesterday, like meteors, may be gone today. Many times good artists are put on a program where their talents are hidden; unless some wise showman can discover these hidden gems, they are never recognized. This is unfortunate because the public really wants to hear new artists and new interpretations of music; a change of flavor adds interest to a program.

In preparing musical entertainment, the advertiser should strive to have a balance in types of music presented as well as in the types of entertainers. It would be unwise, for example, to have a singer with a tenor voice, a lyric soprano, and an orchestra of high-pitched instruments all on one musical program. The effect would be shrill and annoying to the listener. It would be far better to have a balance of high- and low-register vocalists and instrumentalists.

Although male voices are musically classified as tenor, baritone, bass, according to their voice range, it might be more 
effective if they were classified as to the emotional quality of their voices because the talent of a radio show, so far as the advertiser is concerned, is simply the emotional background for his radio advertisement. Types such as romantic tenor, balladist, crooner, operatic baritone, and standard or regular would seem to be a better radio classification. Female voices could be classified in a similar manner.

More than timbre or tone quality must be considered in selecting a vocalist. A singer must have dramatic qualities which enable him to make his own interpretation of the composer's idea. A singer with this inborn dramatic quality usually can interpret a wide variety of types of songs. Thus, as a general rule, the most effective vocalists are those who have a prodigious repertoire.

\section{Selecting an Orchestra}

The orchestra is as important to a good radio show as the paper is to the printed advertisement. The orchestra is the most obvious part of a musical show. If the orchestra is not selected to fit the needs of the show, the program obviously will not "click."

Most of the radio stations can supply the advertiser with an instrumental ensemble, but most advertisers when they can afford it, prefer to use popular name bands on their programs. The size of house bands varies according to the size of the station. A station the size of WTHT, Hartford, Conn., may employ only one man as its basic music staff. WOR employs a basic staff of 42 musicians; WENR-WMAQ (Chicago) engages 70 musicians. The average number of musicians per station is $12 .^{1}$

In selecting a band, advertisers are usually influenced by the results of shows of other sponsors which featured famous bands. The advertiser can build his own band or select a still unknown band and build it up. For some unknown reason sponsors do not seem to investigate the sustaining programs of remote broadcasts of dance orchestras from 10 P.M. until 2 A.M. Record sales and fan mail give ample proof of popularity of many of these dance bands. There are many dance orchestras with distinctive styles which are being overlooked by sponsors and agencies who could profit in many cases by building their musical shows

${ }^{1}$ Variety, Dec. 14, 1939, p. 34. 
around these individual styles. Kay Kyser's College of Musical Knowledge got its start during the midnight dance hours. There are other radio box-office possibilities that have not yet been discovered by sponsors.

Although dance orchestras have large followings, they are not the correct instrumental ensembles for all programs. Tempo, it has been mentioned, must be maintained if a program is to hold its audience. Often the tempo of the show is more rapid or less rapid than the dance tempo usually maintained by the orchestra. It is usually necessary, therefore, to make special arrangement for radio shows.

Sometimes well-organized house bands under a capable conductor will offer better accompaniment than a dance band. Although a dance band may be successful in maintaining tempo, it may not be so successful in maintaining or creating "feeling tone." A studio orchestra which can play any kind of music because of its extensive library is often better for a variety type of program.

Radio allows many more types of instrumental combinations than the concert hall or vaudeville stage, owing to the amplifying qualities which can be obtained through microphone technique. Instrumental combinations now include orchestras composed entirely of stringed instruments, orchestras largely of brass - instruments with a few necessary percussion instruments, and various other combinations too numerous to mention here.

\section{Selection of Music}

After the program director and the advertiser or his agency have planned the form of the program, the musical director selects the music for the show.

Radio musical programs are now mainly of two diverse types: the type of program most frequently heard presenting popular ballads (dance tunes) in various styles; the type which has become overwhelmingly popular during the past few years, the symphony concert program. There has been no proof offered that the public demands or has demanded an overabundance of either type of music. Most people like to hear music that is familiar to them-music that they themselves can sing, whistle, or play. It is natural for people to be familiar with folk songs of their ancestors, or the American folk tunes they sang at school or 
Sunday school. One does not get much opportunity to learn a modern popular song, unless the tune is "plugged" to death. Some songs have received as many as 56 plugs (performances) in one week over the three leading network stations in New York City (WJZ, WABC, WEAF) from 8 A.M. to 1 A.M. It should be kept in mind that mere radio plugging does not necessarily make a popular song.

There has been a tendency among band leaders to feature the new songs that lead on the network plug list. Thus, by the time a listener learns the words and music of a popular tune, he finds the radio shows to which he ordinarily listens pushing brand-new tunes to his ears. Many people like tunes for sentimental reasons. The rendition of an old tune brings back old memories to many listeners. This usually means these listeners will enjoy such presentations well enough to listen in again the following week. There are two or three leading dance bands which have built up their reputations by playing old numbers that are constantly being requested by dancers and listeners. A program which offers a combination of old numbers and numbers that are presently popular and which introduces one brand-new number, i.e., a hit of tomorrow, seems to please the greatest number of listeners.

At present there seems to be a lack of light concert and light opera programs. The late Roxy (S. L. Rothafel) made this type of program popular when the radio was in its infancy; "The Glow Worm" and "Blue Danube Waltz" were heard almost as often as one now hears some of the popular show tunes. The general public will be glad to hear more Victor Herbert, Romberg, Schubert, Chopin, Strauss waltzes, Brahms Hungarian dances, Liszt Hungarian rhapsodies, and light symphonic works when some clever program producer can find a sponsor.

\section{Arrangements}

Beautiful melodic patterns are more beautiful when they are properly trimmed and tailored. It is the work of the arranger to trim and tailor a song for vocalists, instrumentalists, or combinations of both in the desired and accepted style. Just as the tailor takes the size and proportions of a person into consideration in designing and making a garment, so does the arranger consider the size and instrumentation proportions of 
an orchestra in preparing the arrangement of a song for an audience.

Musical arrangements, like sartorial arrangements, must show excellence in taste and must meet contemporary styles. Although style change in arrangements may be slow, one is as conscious of it as of style changes in other fields. In preparing old songs for a modern radio show, it is best to prepare a modern arrangement, but the wise arranger will not be too radically modern in his score. Moderism, i.e., extremism, is offensive to many listeners. Good taste on the part of the musical director who is in charge of arranging will lead to a larger radio audience and a more satisfied sponsor.

An arrangement should be short, for unless it is extremely clever the listener will tire of the music about the middle of the third chorus. It might be safe to set a rule for an arrangement length of not more than two choruses unless each is presented in strikingly different contrast. The length of the melody and the tempo at which it is to be presented should also be considered in determining the length of an arrangement.

\section{Theme Songs}

Theme songs are the symbols of product identification on the radio. An artist, an orchestra, or sponsored program is identified by its theme song.

A theme song is a better theme song when it is composed especially for the show. The use of a popular song, unless there are special lyrics which are sung at various points in the program, does not seem so effective as a specially composed song. Although original theme songs are not used for radio shows so much as formerly, the success of this type is proved by the successful sales of Tasteyeast and the resulting popularity of the theme song used on that radio program. Many requests for copies of the tune were received; some dance bands played it as the result of requests from dancing patrons.

The American Society of Composers, Authors, and Publishers ${ }^{1}$

1 ASCAP, as this organization is known in the musical profession, is a voluntary nonprofit association of qualified and recognized composers, authors, and publishers of musical compositions. It was organized in 1914 by the late Victor Herbert and others who found themselves unable as individuals to protect their compositions against infringement by unauthor- 
has recently published the first issue of "The ASCAP Register of Theme Songs and Musical Signatures." This publication should be a help to advertisers and their agencies in avoiding duplication of radio theme songs. As it is, the present volume lists a surprisingly large number of duplications.

\section{Clearing the Copyright - the ASCAP}

The advertiser should keep in mind that copyright protection of songs is just as effective as copyright protection of any printed material. The federal copyright law grants to composers an exclusive property right in their own works for 56 years and provides a minimum penalty of $\$ 250$ for every unauthorized public performance for profit. Thus before a song can be played over the air, permission must be obtained from the copyright owner. There are few noncopyright songs today and broadcasting companies are very careful to "clear" all song titles before the songs are played over the air. In cases where an orchestra at a night club is playing a number which has not been cleared for performance, the broadcasting company will shut the number off the air and fill in with a stand-by studio number.

Today most song copyrights are in the hands of the American Society of Composers, Authors, and Publishers, which was formed to protect composers from infringement. This organization now controls the exclusive right to license the public performance, radio, movies, or otherwise, for profit of some 5,000,000 of the world's most popular musical compositions. ${ }^{1}$ The broadcasting companies pay the ASCAP more than $\$ 4,000,000$ a year for the privilege of playing these songs over the air. This copyright payment is included in the regular time charges of broadcasting stations. Radio stations operating under ASCAP

ized and unlicensed public performance for profit. Suit after suit against the willful and deliberate infringers was carried through the courts until it reached the Supreme Court of the United States, where a unanimous decision was rendered which upheld the copyright owners in their claims.

The Society now issues licenses in behalf of its collective membership to all types of public amusement enterprises which use music, authorizing the performance for profit of compositions copyrighted by its members. The membership of the entire group, including affiliated foreign societies, is said to exceed 45,000 and includes those who write most of the music which the world enjoys.

${ }^{1}$ Fred J. Ringel, "Pay for the Piper," Collier's, Apr. 8, 1939. 
license pay a fixed fee, ranging from $\$ 250$ upward per year for sustaining programs and 5 per cent of their net receipts from sales of "time on the air" to advertisers and sponsors.

In making electrical transcriptions of copyright songs, the advertiser must keep in mind that here again there is a small charge per record, generally absorbed by the transcription company. This branch of copyright protection is under the supervision of the Music Publishers' Protective Association. 


\section{CHAPTER IX}

\section{RADIO TIME-WHEN, HOW MUCH AND AT WHAT COST!}

The average broadcasting station offers the advertiser for sponsoring 16 hours out of the 24, 7 days a week, 52 weeks a year-from 8 A.M. to 11 P.M. daily including Christmas and the Fourth of July. It offers the radio fan even more listening hours than that-some stations from 6 to 2 A.M. At least one station advertises its service as continuous " 24 hours daily." To give the listener such special events as a Pope's blessing or a dictator's warning, a broadcasting station may throw open its service even at 4 o'clock in the morning. So far as the sponsored hours between 12 P.M. and 8 A.M. are concerned, as long as a regularly scheduled program precedes or follows the hour desired, it is for sale.

American listening habits, however, are nearly enough fixed to make some of these hours golden ones for the advertiser and others of far less value. Advertisers have long known this and covet the golden hours; covet them so much in fact that many of them are willing to enter yearly contracts to hold what they consider the best listening hours even though at some times of the year they could profitably shut off their radio program.

\section{The Golden Evening Hours}

From a standpoint of sheer number of listeners the evening hours are best. Thus broadcasting stations generally charge twice as much for them as daytime hours; very early morning hours sometimes sell at even less than half of the night rates. Most stations consider night rates as covering from 6 to 11 P.M., day rates from 8 A.M. to 6 P.M. and 11 to 12 P.M., with transition rates (two-thirds of night rates) from 6 to $6: 30$ P.M. Sunday afternoon rates (two-thirds of night rates) are in effect from 12 м. to 6 P.м., and rates one-third of night rates are available from 12 P.M. to 8 A.M. 
Surveys show that, of the evening hours, $7: 30$ to $10: 30,8: 30$ to 9:30 have the highest number of listeners. A careful study of many of the surveys made by the Cooperative Analysis of Broadcasting $(\mathrm{CAB})$ and $\mathrm{C}$. E. Hooper, Inc. seems to show 8 to 9 as high for Tuesday, Wednesday, and Friday evenings; 9 to $9: 30$ as high for Monday and Wednesday evenings. The type of program offered can shift this high at least 30 minutes either way. Also more listeners seem to be at their radios on Monday and Thursday evenings, which can be accounted for by the fact that Tuesday, Wednesday, and Friday have always been good moviegoing nights. The second show starting at 8:30 or so might account for an early high on these nights. These figures are for urban listening. Surveys of rural listening show the maximum number of listeners at their radios at 7 to $7: 30$ P.M. unless some outstanding radio offer comes later in the evening. It should be kept in mind that a really good radio offering can shift the maximum listening peak as much as an hour. Surveys also show Sunday to be good for a large number of listeners both day and evening and Saturday evening, as compared with the other days of the week, poor for urban but good for rural listening.

\section{The Shining Daytime Hours}

The advertiser, however, should not be carried away by the listening possibilities of these popular hours. They are best for mass listening but not for reaching special groups such as the housewife, for example, when she is interested in her housework and uninfluenced in her radio listening by the rest of the family. The day hours, particularly the morning ones, are best for her. Nor are the evening hours best for reaching the farmer, tired after a day in the fields and with a 4:30 A.M. breakfast staring him in the face. The day hours again can be used for reaching him. When we add the factor of the lower price of the day hours, the decision in many cases is greatly in their favor.

Thus the "when" of radio time can be summed up to mean: When are the best prospects able and willing to listen? How much will it cost per 1,000 listeners to reach them? How much will a program cost which will be comparable with competition? If the advertiser is bidding for large numbers of listeners, for example, during the 8:30 evening hour, his program cost is likely to run high, for he is competing with the "big-money" advertisers 
on the air. The really clever small advertiser is the one who does not shoot his modest fireworks at the same hour that the spectacular pyrotechnic displays are coloring the sky.

\section{How Time Is Sold}

The problem of how much time to use is far more simple. Broadcasting companies offer time in all sorts of attractive packages: 1-min. announcements, 5-min. units, 15-, 30-, 60-min. periods, or any 15-min. multiple thereof. By special arrangement, the advertiser may purchase even less, 20 sec. or a few words, as illustrated by the famous "time announcements."

Broadcasting chains and spot stations differ in practice in this respect. Some of the small spot stations will sell fifty or fewer words of advertising at any time of the day or night. The reputable chains either will not sell a 1-min. or even a 5-min. announcement or will sell it only at certain times of the day, with the exception of time-signal announcements. As already pointed out, the "ordinary spot commercial which offers the listener no service, is frowned upon both by the advertiser and the listener. Any listeners contacted are caught off their guard. However, there is plenty of evidence that this type of announcement will bring results, especially if it is well placed. The radio advertiser with very limited means sometimes can afford nothing else. In this case, however, the station should be checked up to see that its sustaining programs have developed a station following.

\section{When to Use a 15-min. Program}

When it comes to the longer program-15 min. and increments of $15 \mathrm{~min}$. up to an hour or more-the advertiser is confronted with another decision. Shall he play his program at $15 \mathrm{~min}$. and "across the board," i.e., a 15-min. program every day or two or three times a week, or shall he select a half-hour or an hour program and play it once a week? The time of day and the type of program are important considerations here. Daytime service programs, news services, and the so-called strip programs ${ }^{1}$ are very effective when played "across the board." Nighttime news programs and comedy sketches such as Amos 'n' Andy are at their best when played five times a week. Certainly a

${ }^{1}$ Continued dramatic sketches or serials which present a strip a day. 
15-min. program played only once a week must have a tremendous amount of interest and individuality to call a listener back the next week. Played twice or three times a week, the 15-min. program of even mediocre grade will develop a following.

\section{When to Use a Half- or a 1-hour Program}

A good half-hour show once a week can make a strong enough impression to call back its listeners the following week. Most of the evening shows now on the air fall in this class.

The full-hour show is rarely twice as effective as the good halfhour show. Many of the present hour shows are more the result of sponsor pride than of carefully worked-out effectiveness. This is, unfortunately, both in radio and other media, the day of the spectacular. If an advertiser plans single pages in a magazine, his powerful competitor will run to two-page spreads, not because they are twice as effective but because they are at least twice as spectacular. If a radio advertiser is running half-hour programs, a powerful competitor will start with hour programs for the same reason. If such an advertiser wants to charge up some of the cost to personal vanity or prestige, this can still be a paying investment.

Of course, the exception to this is the hour program of the type that demands an hour's time. Thus dramatic plays, symphonies, and operas (which could not be effectively condensed to a half hour) might well be as hour programs more than twice as effective as similar half-hour programs.

There is another objection to the hour program. Many listeners do not care to tie up an hour's time on one type of program. Paradoxically, they may, if their radio mood holds, listen to two similar half-hour programs.

\section{How Long a Contract?}

Two other questions involving time must also be settled. How many weeks and how many stations should be used? Most broadcasting stations offer their time on a 13-, 26-, 39-, and 52-week basis, no contract being taken for less than 13 weeks except in cases of seasonal products, -store sales, or irregular campaigns. For how long the contract shall run depends on the objective of the campaign and can be worked out according to fundamental advertising principles. Good-will programs might 
run on successfully for years. A special program to introduce a new product might end successfully after 13 or 26 weeks. Radio has advertisers who have been on the air continuously for over ten years, but seldom have these companies used the same type of program year after year. A careful study of the number of listeners to a good program generally shows a gradual increase for the first 13 weeks, a maximum reached after that and sustained as long as the program continues to add novelty and surprise interest. But the best of programs eventually begin to lose their following. When this trend is definitely down, a new program or a new handling of the old is in order.

\section{How Many Stations?}

The other question-How many stations?-basically depends on the marketing objective and the distribution of the product just as it does in any other advertising medium. But here again, broadcasting practice differs. Such national networks as NBC and CBS offer a basic number of stations which must be used regardless of marketing objective or distribution. To the basic network may be added optional groups and supplementary stations. Columbia's basic network consists of 28 stations. National Broadcasting Company's consists of 24 for the basic Red network and 25 for the basic Blue. To these, other strings of stations may be added until the advertising Christmas tree can be lit up to its farthermost branch. (For networks of leading broadcasting systems, see maps on pages 134 to 137.)

Another national network, the Mutual Broadcasting System, works on another premise. No definite number of basic network stations is insisted on; to start with, an advertiser may select one or two stations and add others as his marketing efforts spread into other territory. Or he may take one station for a concentrated market drive in a single district. This is a talking point indeed, but the other networks might well counter with the thought that an advertiser can buy separate time on any of their stations locally, provided no network program is operating. Some very fine hours can be picked up this way but such hours are subject generally to a 28-day cancellation clause to make way for future network sponsored programs. Of course, independent stations have no such restrictions and some advertisers prefer to pick such stations to cover the specific territory they 


\begin{tabular}{|c|c|c|c|c|}
\hline $\begin{array}{l}\text { Geographic } \\
\text { Divisions }\end{array}$ & $\begin{array}{l}\text { Tolal } \\
\text { Families }\end{array}$ & $\begin{array}{l}\text { \%:Owning } \\
\text { Radios }\end{array}$ & $\begin{array}{l}\text { Total } \\
\text { RADIO Families }\end{array}$ & $\begin{array}{l}\% \text { of Total U. S. } \\
\text { Radio Families }\end{array}$ \\
\hline New Englond & $2,166,000$ & $92 \%$ & $1.990,900$ & $7 \%$ \\
\hline Middle Atlantic & $6,922,000$ & 92 & $6,361,200$ & 24 \\
\hline E. North Central & $6,729,000$ & 90 & 6.050 .300 & 23 \\
\hline W. North Central & $3,580,000$ & 80 & $2,861,900$ & 11 \\
\hline South Atlantic & 3.977 .000 & 65 & $2,598,700$ & 10 \\
\hline E. South Central & $2,561,000$ & 60 & $1,537.000$ & 6 \\
\hline W. South Central & $3,146,000$ & 65 & $2,040,000$ & 7 \\
\hline Mountoin & 975,000 & 80 & 778,000 & 3 \\
\hline Pocifie & $2,585,000$ & 95 & 2.448 .500 & , \\
\hline U. S. TOTAL & $32.641,000$ & 82 & $26.666,500$ & $100 \%$ \\
\hline \multicolumn{5}{|c|}{ RADIO FAMILIES B } \\
\hline \multicolumn{2}{|l|}{ Population } & $\begin{array}{l}\% \text { of Tolal Fam } \\
\text { Owning Radi }\end{array}$ & \multicolumn{2}{|c|}{ Total RADIO Families } \\
\hline \multicolumn{2}{|l|}{ Over 500,000} & \multicolumn{2}{|c|}{$88.5 \%$} & \\
\hline \multicolumn{2}{|l|}{100,000 to 500,000} & \multicolumn{2}{|l|}{93.4} & $\begin{array}{l}5,000,000 \\
4,030,000\end{array}$ \\
\hline \multicolumn{2}{|l|}{25,000 to 100,000} & \multicolumn{2}{|l|}{95.0} & 3.380 .000 \\
\hline \multicolumn{2}{|l|}{10,000 to 25,000} & \multicolumn{2}{|l|}{913} & $2.215,000$ \\
\hline \multicolumn{2}{|l|}{2,500 to 10.000} & \multicolumn{2}{|l|}{86.4} & $2,571,000$ \\
\hline \multicolumn{2}{|l|}{ RURAL-Non-Farm } & \multicolumn{2}{|l|}{803} & \\
\hline \multicolumn{2}{|l|}{ RURAL-Farm } & \multicolumn{3}{|r|}{4.261 .000} \\
\hline \multicolumn{2}{|c|}{ RADIO FAMILIES } & \multicolumn{3}{|c|}{ BY INCOME GROUPS $\star \star$} \\
\hline \multicolumn{2}{|l|}{ Income } & \multicolumn{3}{|c|}{$\begin{array}{l}\text { \% of Total Famulies } \\
\text { Owning Radios } \quad \text { Tolal RADIO Families }\end{array}$} \\
\hline \multicolumn{2}{|l|}{ Over $\$ 10.000$} & \multicolumn{2}{|c|}{$99.9 \%$} & 400.000 \\
\hline$\$ 5.000$ to $\$ 10.000$ & & 997 & & $1.495,000$ \\
\hline$\$ 3.000$ to $\$ 5.000$ & & 98.2 & & $3.730,000$ \\
\hline$\$ 2.000$ to $\$ 3.000$ & & 95.6 & & 4.780 .000 \\
\hline$\$ 1.000$ to $\$ 2.000$ & & 883 & & $10,600,000$ \\
\hline Under $\$ 1.000$ & & 570 & & 5.662 .000 \\
\hline & & $<$ & & \\
\hline $\begin{array}{l}\star \star \text { These fid } \\
\text { on radio } \\
\text { Statistical }\end{array}$ & $\begin{array}{l}\text { res cotima } \\
\text { Denilles an } \\
\text { Deportiner: }\end{array}$ & $\begin{array}{l}\text { ated by NBC } \\
\text { ad speciallze } \\
\text { nt. }\end{array}$ & $\begin{array}{l}\text { For more de } \\
\text { d tabulations, }\end{array}$ & $\begin{array}{l}\text { letailed figurea } \\
\text { call the NBC }\end{array}$ \\
\hline $\begin{array}{l}\star \star \\
\star \text { These fig } \\
\text { on radio } \\
\text { Statistical }\end{array}$ & $\begin{array}{l}\text { res estima } \\
\text { Depilies on } \\
\text { Departmen }\end{array}$ & $\begin{array}{l}\text { ated by NBC } \\
\text { ad specialize } \\
\text { nt. }\end{array}$ & $\begin{array}{l}\text { For more de } \\
\text { d tabulations, }\end{array}$ & $\begin{array}{l}\text { letailed figures } \\
\text { call the NBC }\end{array}$ \\
\hline
\end{tabular}

For descriptive legend see p. 105. 


\section{RADIO OWNERSHIP BY GEOGRAPHIC DIVISIONS OF $\mathrm{U} \cdot \mathrm{S} \cdot \mathrm{A}$}

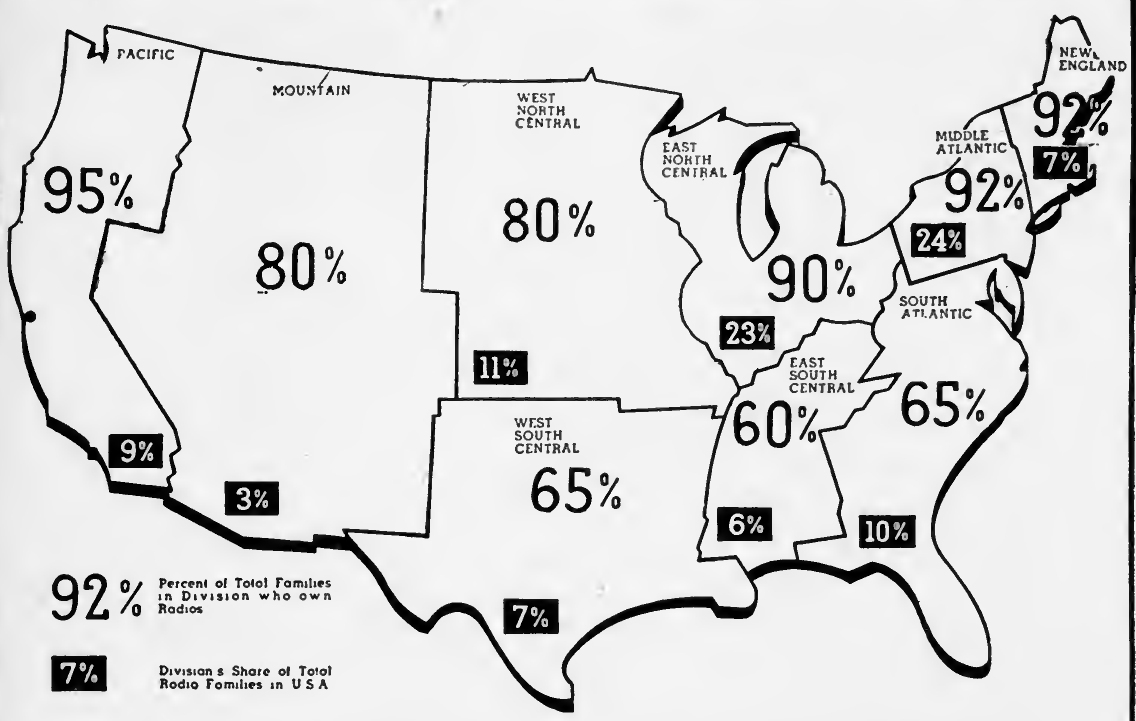

\section{RADIO FAMILIES BY STANDARD TIME ZONES}

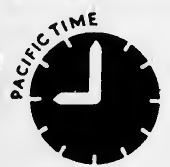

2,475,010

$9 \%$ of Tetel

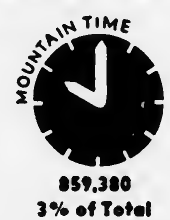

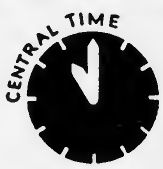

$9.794,420$

$37 \%$ of Totel

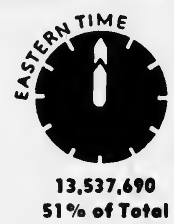

URBAN AND RURAL RADIO FAMILIES

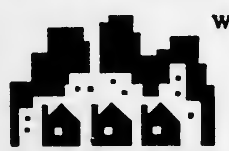

URBAN

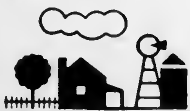

RURAL

WITHOUT RADIOS | WITH RADIOS
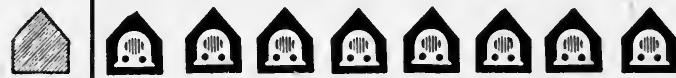

17.195 .600 (91\% of Tolal Urban Families)
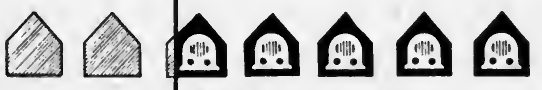

$\mathbf{9 . 4 7 0 , 9 0 0 ~ ( 6 9 \% ~ o f ~ T o t a l ~ R u r a l ~ F a m i l i e s ) ~}$

The Radio Market Place

The number and location of stations is basically a marketing problem. This chart and the one opposite show the intensity of the radio market $(26,666,500$ radio families) by geographical divisions, city size, income groups, as well as urban and rural coverage. (Courtesy of National Broadcasting Company.) 
wish to reach. Other advertisers supplement their network programs by spot selection of independent stations, either in territories not thoroughly covered by their network program or to reach network listeners at various other periods of the day or week.

\section{Urban or Rural Coverage}

Another point should not be overlooked in selecting stations on a network and that is the percentage of rural, of suburban, and of city coverage. The coverage must be fitted to the product's market and the type of program to the various types of listeners. Some advertisers want large-city coverage in preference to smalltown coverage. This can be accomplished partly by the choice of stations. It was originally one of the Mutual Broadcasting System's talking points that, with such key stations as those in Chicago, Cincinnati, Newark (New York area), and Detroit, they specialized in fine city coverage. With the many smalltown Mutual stations now on the chain, this does not apply today.

\section{The Cost of Broadcasting Time}

But the businessman asks: What is all this going to cost? How does radio compare in cost with other media? Is radio a business only for the "big-money" advertiser? Let us answer the last question first. There are probably three general types of radio advertisers from a financial point of view: the nationally known manufacturer with millions dripping from his overflowing advertising appropriation; the small manufacturer with an equally small appropriation; and the local retail merchant. Some of the first group are spending several millions a year in radio; some of the third group are using the 100-word limit spot advertising message at, in some cases, as little as $\$ 2.65$ per station. Strangely enough they both are getting results.

For cost comparisons consider the following figures, which are approximate, for radio rate cards like all advertising rate cards change all too often. A full-hour program over 95 key cities $^{1}$ will cost $\$ 15,783.75$ night, $\$ 7,977.75$ day; a half-hour program $\$ 9,792.13$ night, $\$ 4,953.03$ day; a quarter-hour program $\$ 6,744$ night, $\$ 3,404$ day. Consider the half-hour evening program at $\$ 9,792.13$. Add $\$ 10,000$ more for Grade A talent

${ }^{1}$ CBS Rate Card No. 25, April 1, 1939, station-hour discounts and annual $12 \frac{1}{2}$ per cent discount deducted. 
and a little merchandising. Total, $\$ 20,000$ for a single week's coverage of 95 key cities. High? Less than a four-color center spread in a single issue of one of the famous national weeklies and only about one-third more than the back cover of one of the same group. Cost alone is no yardstick for comparison of media and the author here is not trying to bring up the point of effectiveness of the two purchases. The point emphasized is that costs are comparable.

\section{The Small Advertiser's Problem}

Consider next the case of the smaller advertiser who may consider himself fortunate to conquer a single city in one campaign. He can cover a large metropolis, such as New York or Chicago, on a single popular station at $\$ 500$ to $\$ 750$ night or $\$ 250$ to $\$ 500$ day for a half-hour program. If the advertiser wants to be economical, by his choice of program he may get by with not over $\$ 500$ for talent and accessories. Total, $\$ 1,000$ to $\$ 1,250$ per week. This translated to newspaper rates, to give approximate equal city coverage, is about 500 to 1,000 lines, or a single 4-column by 10-in. advertisement in the city newspaper with the largest circulation or two such advertisements in one of the other leading newspapers. A daytime radio program which would cost about half this much could be compared to only half as much newspaper space.

Next consider the really small advertiser or the local retail merchant. If his local station has any size following at all, by selecting the time carefully (not against network competition) and by use of Grade B talent or by electrical transcriptions, he may purchase his half hour for as little as $\$ 50$ plus talent cost or his spot announcements at $\$ 2.65$ a piece, as already pointed out.

All figures given here are naturally approximate and it is suggested that the advertising man make his own set of figures from station rate cards or the Standard Rate and Data Service. For his particular type of program and the specific coverage desired, he may be able to reduce the above figures considerably.

\section{The Advertiser's Discounts}

Radio's system of discounts should interest the advertising and businessman. There is the usual 15 per cent discount to advertising agents, Then a series of earned discounts to the 
advertiser from 2 to $121 / 2$ per cent approximately for an increasing number of station hours used during the week on a 13-week contract; or in the case of NBC Blue network, 20 per cent for using all four groups. Another discount, about 10 per cent, is allowed for running through a 52-week contract. Note both the weekly and annual discounts must be first earned. In other words, the radio station will hold the extra money until earned, not the advertiser or his agent, as in the case of most publications. Clever people run these radio stations-the short-rate bugaboo will never enter their accounting system.

Note that this matter of station-hour discounts may be an important economic factor. Recently the Campbell Soup Company had one program (Amos ' $n$ ' Andy) on the NBC network and two other programs on the CBS network. At the expiration of the NBC contract, the Campbell Soup Company switched Amos 'n' Andy to the CBS network. This move in no way was a comparison of the value of two fine networks, but rather a chance to increase their station-hour discount and thus decrease their broadcasting cost.

\section{How Big Advertisers Use Their Radio Time}

A study of 155 programs by well-known advertisers of drug, cosmetic, and toilet goods on both CBS and NBC in 1935 gives the following information as to length and frequency of programs, with the total amount of time used during both day and evening.

Analysis of 155 Drug, Cosmetic, and Toilet-goods Programs

\begin{tabular}{l|r|r}
\hline $\begin{array}{c}\text { Length and frequency } \\
\text { of programs }\end{array}$ & $\begin{array}{r}\text { Num- } \\
\text { ber of } \\
\text { pro- } \\
\text { grams }\end{array}$ & Total \\
\hline 15 min. once a week & 40 & \\
15 min. twice a week & 24 & \\
15 min. 3 times a week & 18 & \\
15 min. 4 times a week & 3 & \multirow{2}{*}{91} \\
15 min. 5 times a week & 59 & \\
\hline 30 min. once a week & 1 & 60 \\
30 min. three times a week & 4 & 4 \\
\hline 60 min. once a week & & \\
\hline
\end{tabular}




\section{CHAPTER X \\ THE COMPETITION-HOW TO HANDLE IT}

Competition in radio does not mean merely what your competitor with a similar product is doing; it means what every advertiser with any product is doing when your program is on the air. Even a simultaneously presented sustaining program may give serious competition. Because the radio listener can listen to only one program at a time, competition has become one of the radio advertiser's "great headaches." It accounts for the fact that an 8 o'clock evening hour at a specified station rate may be worth three times that rate with no competition, and worth only half or a third that rate with severe competition.

\section{The Effect of Competition}

An outstanding example of the effect of competition, at the present writing, is the Sunday evening 8 o'clock situation. Here a single show, the Chase \& Sanborn program, has actually driven competition off the air, and thus increased the value of its time several hundred per cent. Instead of sharing equally with other good sponsored shows the 33 per cent of the potential listening audience ${ }^{1}$ (approximately 8,000,000 homes), it has kept approximately 80 per cent of this audience for itself. The reason? A popular mass-appeal show partly; but also because no competitor is bold enough to put a really powerful show against the Chase \& Sanborn program. The remaining 20 per cent of the actual listening audience is divided among the other networks, whose "great headache" is that this usually valuable sponsoring hour on their networks just cannot be sold at the regular evening rate.

On the other hand, the 7:30 hour just preceding the Chase \& Sanborn program shows the results of keen competition. Fitch's Bandwagon, Gulf's Passing Parade, and Vick's Seth Parker, all good sponsored shows, divide 77 per cent of the listeners

${ }^{1}$ C. E. Hooper, Inc., "Radio Report," October, 1938. 
among themselves, Fitch getting approximately 38 per cent, Gulf approximately 20 per cent, and Vick's 19 per cent (Oct. 2, 1938).

This situation is probably radio's most outstanding peculiarity. These same three advertisers could have advertisements of equal size in a publication and the same readers might see all three advertisements. In radio the listeners can "see" only the one advertiser. Competition here is indeed deadly.

Therefore the alert radio advertiser who is contemplating an 8 P.M. hour on the radio, or any other hour, will do well to know the ratings, the type of program, and the possibilities of every simultaneously presented show within his listening area, both on the networks and on independent stations. There are cases on record of small-station programs with a strong local flavor and some special interest that have appreciably cut down the listening audience of big network programs in that area. Air advertisers will also want to know the big attractions immediately preceding and following their contemplated hour. A really big show on a competing network may mean that a goodly percentage of the listeners are tuned into that station and, being tuned in, may stay for the next show as well. The unfortunate part of it is that the radio chessboard never stays the same. An ideal no-competition-of-note situation today may be a different and a complicated situation 3 months from today, when shifts in other station setups have occurred.

\section{More Than Enough Listeners for All}

Fortunately for the radio advertiser there are more than enough listeners for one program at any popular hour no matter how highly favored that program is. Even the Chase \& Sanborn program leaves 20 per cent (over $4,000,000$ homes) unaccounted for. Many highly rated shows play at a same hour and draw enough listeners to be considered successful. At the present writing, Maxwell House plays opposite Major Bowes Thursday evenings 9 to 10 P.M. and the two programs divide almost equally approximately 90 per cent of the listening audience. Against that figure, the popular Kraft Music Hall, playing the same evening 10 to 11 o'clock and against no real competition, gets only 70 per cent of the listening audience. On Friday evenings 9 to 10 P.M., Campbell's Hollywood Hotel draws less than 60 per cent of the listening audience and its nearest competitor, 


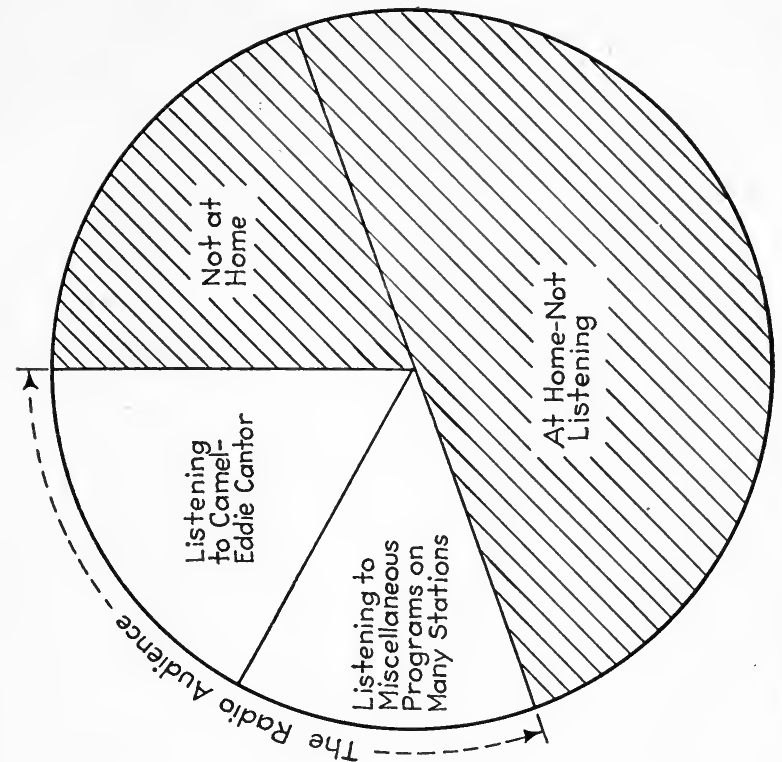

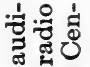

战吾

里告

.

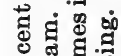

包,

กิ

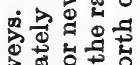

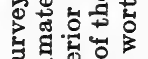

की

융 영

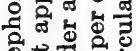

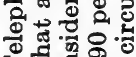

궁

요융유.

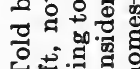

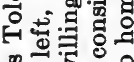

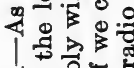

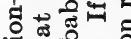

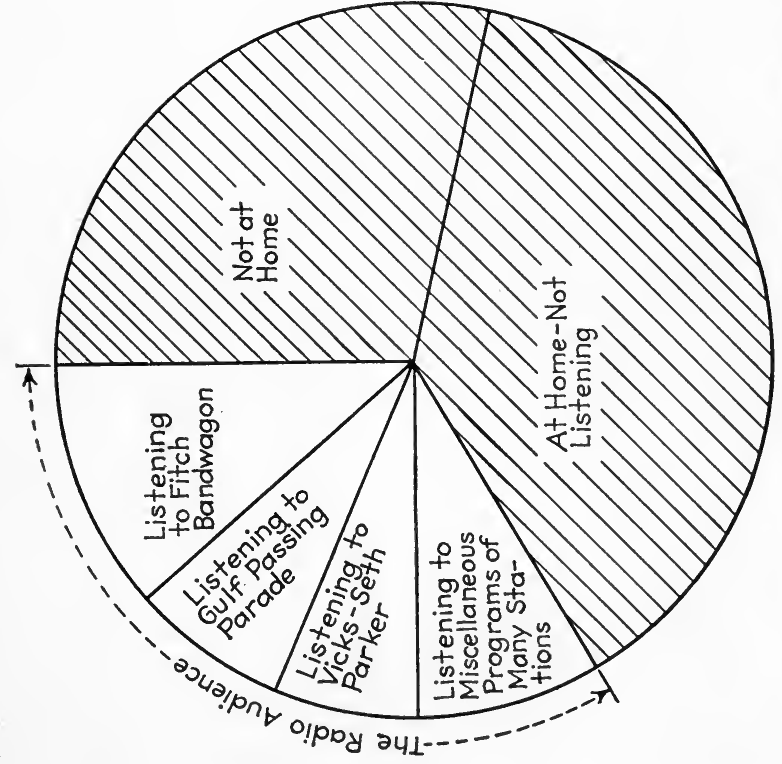

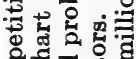

융 궁

ㅇํ สี

ऽ

느.렁 है

용

进

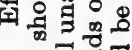

무굼무

엏 范

.웜임

융 क्ष

루융

들. 잉

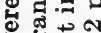

药 速

कั

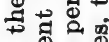

농 ง ำ

농요

이

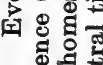


Phillips Milk of Magnesia Waltz Time, gets not over 15 per cent of the balance. These figures are from ratings prior to November, 1938. Radio is such a fast-moving business that even 4 weeks can basically change these percentages; 4 months can even remove some of the programs from the air.

The timid radio advertiser often-and erroneously-settles the competition question by refusing to play opposite any wellestablished sponsored attraction. This may be a wise procedure if other profitable radio hours are available. But the best hours of radio are pretty well taken up by alert radio advertisers. A newcomer in the field may be faced with the selection of a poor listening hour or with bucking the competition. The first question to ask here is: Shall I get more listeners with the proper type of show playing opposite the big show or shall I get more listeners on a less popular hour with no appreciable competition? To arrive at a sensible answer requires the weighing of many figures and a thorough study of listening tastes. Eight o'clock is a peak hour for listeners. If Chase \& Sanborn get 80 per cent of the listening audience (by survey), how big is the 20 per cent that is left? In some cases this 20 per cent may be more than 100 per cent of such an hour as 6:30 or 10:30 P.M. Listening moods are also a factor.

\section{The Marginal Listener}

Of the million of listeners to a top-rating program, there is always a percentage, small but worth cultivating, who refuse to be slaves of habit. Their mood sometimes is not up to the offering of their favorite show and they are likely to shop at any moment. Others too-and a goodly number-will not like the type of even the most popular program. These listeners are worth cultivating if the cultivating can be done with a not tooexpensive type of show. It should be noted that the popular showman idea of beating competition by putting out something bigger and better-the stupendous colossal-is effective for those advertisers only who have a fortune to spend and a margin of profit on their product great enough to make sales pay the bill.

That the best show in the world cannot attract nor hold every radio listener was startlingly and unfortunately illustrated in November, 1938, in the much-publicized Orson Welles's War 
of the Worlds show playing opposite Chase \& Sanborn's Charlie McCarthy. That the lost 20 per cent was an appreciable figure seems to be proved by the number of people all over the United States who thought the Welles version of the H. G. Wells drama was really a news program and promptly stampeded. Certainly such a large and credulous audience should be worth any advertiser's cultivation. It should be noted that Orson Welles's sponsoring by the Campbell Soup Company at about this same time was not a result of the Mars incident. The decision had been made before the fated broadcast.

\section{Mass vs. Class Programs in Competition}

In the event that an advertiser does not have the resources and the stamina to fight competition with an equally good or a better show, he has an alternative which in many cases has proved amazingly successful from the advertiser's standpoint. That alternative is to plan a show with a strikingly different appeal. If the competition is music, select drama; if the competition is slapstick comedy, be serious. Very often a passably good program of this type can be built for far less money than the popular mass-appeal show. Such a show may not draw an appreciable number away from the competition immediately, but it will draw a large enough audience from the total listening audience to make advertising pay. It also may wean back to the radio those former listeners who have shut off the popular program because they did not like it. After all, it is radio's

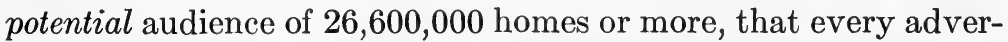
tiser should consider. There are even on a popular Sunday night literally millions of people who have radios, who could listen, but won't-sometimes merely because radio offers nothing at the moment for their particularly discriminating taste. This vast potential audience is sometimes not worth going after for itself, but it is worth considering as an increment to the regular listening audience.

\section{Importance of Popularity Ratings}

In planning a show from the competition standpoint, the advertiser is directed to such popularity ratings as furnished by the Cooperative Analysis of Broadcasting (CAB) and C. E. Hooper, Inc. (see Chap. XIX). The advertiser should keep in 
mind in studying the percentage figures offered that they represent mostly large or fairly large city reactions. While the rural listener may concur with the city listener in a liking for many shows of the popular type, he does have characteristic likes and dislikes. If he is the advertiser's market, the advertiser should not depend too much on city ratings. Note that $\mathrm{CAB}$ makes periodic rural surveys for comparison with urban ratings. It is possible that a program too low to rate with the city dweller might be very popular in small towns and rural areas.

Furthermore, no radio advertiser should consider his competition situation as ever being definitely settled. Survey and rating checks should be continued. Competing programs should be studied weekly and their ratings checked with his own. If the competitor's rating drops, the figures should tell a profitable story to every competing advertiser.

There is a long-range type of competition which has particularly to do with the type of show. Too many shows of a given type on the air compete in listener interest whether they are on simultaneous hours or not. The average listener has only about so much time and interest for any one type of program. He probably would soon tire of listening every evening in the week to the same type of program no matter how well it was presented. If Sunday night is his comedy night, Monday may well be his night for serious music. 


\section{CHAPTER XI}

\section{HOW THE PROGRAM IS BUILT AND PRESENTED}

Where do they come from, these programs of the air, the choice of which may spell success or failure for the advertiser? A few like Topsy just happen. They may be a spur-of-the-moment idea tossed off by a harassed program director on a small station to fill in an open spot on a day's schedule. There have been cases of such shows catching on with the public and growing from sustaining to sponsored programs, from one small station to a network.

But by far most shows of the air, particularly the sponsored ones, are carefully planned from the idea to the final rehearsal. The best sponsored shows are definitely built around the products they advertise; the advertising is considered an integral part of the program and planned for from the very beginning. Even that important branch of sponsored radio, merchandising (discussed in Chaps. XV, XVI, XVII), is often considered, as it should be, from the beginning. Censorship too, i.e., what the government and what the stations will allow (see Chap. XIII), must, from the first, stand behind the council chair and murmur into the ear of the planner: "But you can't do this.".

\section{Program Points to Consider}

Other basic situations which may affect the early planning of a sponsored program are such points as these: Will the program be on a network or on a spot station? Shall we use live talent or electrical transcriptions? Will it be a mass-appeal program or a special-interest one? Will it be five min. long or 15,30 , or 60 min.? Certain types of programs, dramatic plays, and operas, for instance, may require for good presentation at least 30 min. Other types, such as news broadcasts, can seldom be successfully stretched to more than $15 \mathrm{~min}$. unless dramatized like the March of Time program. Still other types can easily be expanded or condensed to fill any given time limit. 
Occasionally the sponsor for impressiveness will decide on an hour program, which automatically shuts out certain types of programs. The same may be the case when a sponsor decides to play a 15-min. program daily "across the board." On the other hand, the occasion might well arise where the program idea is so good that the time can be a secondary consideration. This situation, however, seldom occurs for it is well to option a time beforehand for a sponsored show, because the time of day or night and often the stations affect the presentation and idea of the proposed show.

Obviously the type of listener to be reached, with his habits, likes, and dislikes, is a factor in selecting the program ideas. Nor should one overlook the objective of the radio campaign. Good-will and action-getting programs are not entirely a matter of merely how much advertising the program contains but also a matter of the program idea itself.

Let us follow a program idea through the broadcasting mill. Assume that we have the points thus far covered at our finger tips; that we shall see to it that our selection of the program in no way conflicts with them.

\section{The Danger of Free-lance Ideas}

First the idea. It would seem that everybody but the advertiser has just the right idea for a successful radio program. There was a time not so many years ago, when the man with an idea could knock on any advertiser's door and receive a hearty welcome. Ideas for advertisements, ideas for radio shows, ideas for sales promotion, the most illusive things in advertising, were often brought in by the free-lance worker. Although some of them were million-dollar ideas, the advertiser has learned his lesson. A few lost lawsuits where the ownership of the idea has been in question have convinced many advertisers and most advertising agencies that an idea can be dynamite. Today the practice is to look at "new ideas" when submitted by the great army of free-lance creators only when the originator will sign a release beforehand. So many ideas submitted are so close to "what the advertiser has already been considering" that even to know they exist in someone else's mind is a liability often settled out of court for $\$ 500$ or $\$ 5,000$. The trouble with most of these ideas submitted from the outside is that they are not 
original. There is an old saying in the show business that "there is nothing new under the sun" and when one traces back the ancestors of some of the so-called "new" programs of the air, there will be found in the family, a P. T. Barnum or some other master showman.

Most advertisers will do well to let their advertising agency or the broadcasting station suggest radio program ideas, or the special type of service companies that make a business of creating, writing, and producing radio programs. Some of these have experienced writers and producers on their staff and work with agencies or advertisers. Some of the larger advertising agencies have equal facilities for doing the same thing.

\section{The Basic Program Idea}

The word "idea" as used in radio is all-encompassing. It may mean a really new approach to a radio program. It is more likely to mean an original twist to an existing type of program. The principles used by many program builders to produce the second type are simple. First, they ask, shall we have a timely program? Will it be events, races, sports, prizefights? And then develops the idea: why not sponsor football games or baseball games? And we have the Atlantic Gasoline Series of 1938 or the Ford Series of 1937. Or the question may be asked, shall we feature personalities, celebrities, aviators, movie stars, baseball heroes? And we have another type of show. Then there is the question of considering famous orchestras with a profitable following and we decide perhaps on Guy Lombardo, Horace Heidt, or Paul Whiteman. Or the question might be asked, how can we tie into the public taste; and then music, drama, symphony, swing, movie and stage stars, news, and the like suggest themselves. Or the advertiser can tie into a hobby or a fad; he may consider the special-service type of program-how to be beautiful, how to save money on the food budget, how to decorate the home.

If these program ideas are close enough to the product, do not cost too much, and seem to reach the type of audience (market) the advertiser wants, they may be successfully used. With the idea of the type settled, the idea of presentation is next. Script writers will set to work to get something on paper. To put an original slant into the presentation of these sometimes 
prosaic ideas, to add that certain something that will allow 13 or 26 or even 52 presentations that will each be different to the listener yet all be tied to the fundamental idea. A good example of such continuity is the present Fitch Band Wagon. Presumably the original basic idea was to present the "name" orchestras. The simple idea of these orchestras getting onto the band wagon each week, the chance to sell the listener on next week's wagonload, adds a continuity and freshness to what might have otherwise been a very commonplace procedure.

When the script writers have completed their job, actors are chosen, preliminary readings start; actors are shifted; voice character actors who can successfully play several parts will be considered to "double in brass"; final rehearsals will be scheduled and under expert supervision a hodgepodge start will result in a closely knit, effective show.

\section{Placing the Advertising}

From the very beginning, the placing of the advertising and the type to be used should be considered. The building of the ideal sponsored radio program is not a case of building the show and then tossing in a commercial in the opening, one in the middle, and one at the end The ideal plan is to have the show itself build up to the advertising. Even so simple a thing as the selection of a particular type of musical number to precede the announcement can be surprisingly effective. Also the listener mood developed by the show can affect the commercial. One technique developed by Jack Benny on the Jell-o program and by other comedians has been very favorably received by the listening public. This consists in creating a cue scene for the advertising, so that the advertising is practically an integral part of the program itself. The treatment may be either humorous or serious.

Not to be overlooked is the selection of unusual but basically appropriate places for the advertising. A surprise entrance, when cleverly done, does not seem to annoy the mass type of listeners. The class type, as a group, will probably be annoyed at any entrance of advertising. The idea of mixing entertainment and advertising seems to annoy particularly the "intellectual 600." If the advertiser is after this group, he will probably do well to change his tempo, deliver a short con- 
servative advertising message and have done with it. The Ford Sunday Evening Hour which contains practically no advertising is a good example of this type of presentation.

\section{The Work-sheet Time Schedule}

As pointed out radio operates on a split-second basis. If the advertiser buys 15 min., he gets exactly that-less, of course, approximately $30 \mathrm{sec}$. for the station break announcementand he is expected to fill exactly that time. For this reason, timing is important from the very start. Rarely is the script written exactly to the schedule. The first rehearsals generally have to be cut or added to. But as rehearsing progresses, the timing becomes more exact. The program planner should have a rough work-sheet time schedule, and should know about how long each part of the program is, particularly the advertising commercials. Then in rehearsal, he can clock the various parts and check them against his schedule. By final rehearsal the timing will be almost perfect, although it is not unusual to find the actual show of the air varying slightly from its clocked performance at dress rehearsal. Actors under the strain of the "air performance" sometimes speak faster than in rehearsal. But these differences are rarely great and can be taken care of by repeating a few bars of the theme song, or even an entire chorus of a song, or by merely stepping up or slowing down the tempo of the show.

\section{The Value of Constructive Criticism}

The advertiser or the advertising manager, as already pointed out, should not attempt to help too much in the building of the program unless he has had show experience. When it comes to the program idea itself and its development into a dramatic, musical, or novelty type of entertainment to appeal to the greatest number of his prospects, he can often be of service. $\mathrm{He}$ can see that the advertising itself is considered from the very start, is handled with respect, and given the placing that brings results.

$\mathrm{He}$ should at least be familiar with the essential elements that make a show effective. Knowing them, he can evaluate his program as the rehearsals progress. And he will not have to 
depend on that weakest of all objections to a program: "I don't like it personally-I don't know why, but I just don't like it."

Mr. R. Calvert Haws, who directed for the Selby Shoe Company 3 years ago the series of radio programs featuring Mrs. Roosevelt, wife of the President, has worked out a formula of these essential elements of an effective broadcast. ${ }^{1}$ It lists points which any advertising man can lean against in criticizing a proposed or existing program. Mr. Haws lists: Form, action, progression, good taste, balance, variety, tempo, and length. Briefly summing up Mr. Haws's article in explanation of his "formula," the following will suffice for the advertising man who should keep in mind that his province around the studio covers constructive criticism, not creative planning.

Form. Successful radio programs should have a basic appeal and while the variations are numerous, for success the script writer and producer should have in mind a form as the basis upon which to build. In radio there are three distinct forms: Comic, straight (sex in its broadcast sense), tragic.

Action. A successful program consists of three major actions: Introduction, happening, a clearing up.

Progression. A successful radio show must build up to a climax. Anticlimaxes tire an audience and lose their interest. The same law of progression applies to talks and strip shows.

Good Taste. In radio you cannot select your audience"for adult only" does not apply. Nor does the time of day help. Therefore a radio program to be successful must always in every detail be in good taste. It must not be offensive to any creed, or section or a race, or age.

Balance. This is something that only instinct can distinguish. Many a play has been a flop because of too much of the leading man or leading lady. Script writers and producers "feel" the right spot in which to place the commercial, the music, or to introduce a great artist, to cut dialogue, to introduce new characters, etc.

Variety. Variety is the law of interest. A good speaker injects a joke every so often into his talk, or varies it with a personal reminiscence. A successful radio program, therefore, must have variety to hold and retain interest.

${ }^{1}$ Broadcasting, May 1, 1935, p. 11. 
Tempo. Thoughts must be presented so that the audience can catch each one, assimilate it, and be ready for the next one. Otherwise they stop mentally and lose part of the speech trying to get the part they missed. This applies to all sounds coming over the radio. Composers repeat bar after bar, sometimes the exact thoughts, sometimes the melody with variations but the central melody or theme is there. If people come in and out of a scene too quickly, if they are not properly introduced, if a speaker rushes from one thought to another without being sure that his radio audience has thoroughly understood what he is driving at, a feeling of dissatisfaction is built up in the listener's mind.

Length. No scene, no musical number, no speech, no commercial should be longer than is necessary adequately to put across the thought you wish to convey. The last word is of great advantage. Copy writers of advertisements invariably end their copy with an urge to act. So in radio continuities the length should be sufficient to tell the story, driving home the most important point at the end of the speech or production.

\section{The Last 3 Minutes}

A caution in taking Mr. Haws's last statement too literally. A radio audience-excepting the studio audience-is something like a theatre audience. A goodly percentage may never wait until the actual end of the show. They may be tuning out or turning off any time during the last $3 \mathrm{~min}$. of the program. For this reason, the present trend of placing the most important point (the final advertising message) about $5 \mathrm{~min}$. before the end of the program seems a good one. This spot is the end of the show for the advertiser, although it is followed by a closing number or a last word from the star. Then if the audience, figuratively speaking, are putting on their coats and hats or are perched on the edge of their seats ready to go, no harm is done. The one exception is when a popular program is following the advertiser's show on the same network. In this case, many thousands of new listeners will be tuning into the station during the last $3 \mathrm{~min}$. of the advertiser's broadcast.

\section{Beware of Dead Spots}

Among other cautions the advertiser should observe is the important one: beware of dead spots in a radio program. These 
occur seldom with the wealth of good program directors radio has, but occasionally even the listener will feel an unnecessary slowing up of the tempo, a too-long pause between the end of one number and the announcement of another. Normally in a well-arranged program there should never be a moment when some sound is not coming out of the listener's radio. The exception is when a very short dead pause is made for impressiveness.

While the foregoing has referred to live shows, the technique is practically the same for transcribed shows which must be rehearsed and presented in the same manner as live shows. Instead of going over the air, however, they go to the soundrecording department for record. One advantage in program building made possible by transcriptions is that where a series of shows is planned, several shows in the series can be rehearsed and recorded at one time. This saves talent cost and studio time.

When the show is planned for an independent station instead of a network, the sales possibilities of a single station, except in large cities, will seldom be great enough to justify excessive costs in famous talent and orchestras. Also depending upon the city and size of stations, wide variety of talent may not be available. For building small-station programs, see Chap. XXIII. 


\section{CHAPTER XII}

\section{WRITING THE ADVERTISING SCRIPT}

Radio has suffered more from inferior advertising script and the poor timing of advertising messages than from anything else in its brilliant 19-year career. It is not unusual for the gag writer on an important sponsored show to receive $\$ 1,000$ for his script. He devotes all his waking and half his sleeping hours of the week to this single program. The advertising script writer, however, is not paid on the same scale for his work. For him, the commercials on this same program may be mere incidents in a week crowded with commercials for other programs.

\section{Script Writing vs. Advertising Copy}

Probably the biggest reason for inadequate broadcasting commercials is the attitude of the average advertising man who has been reared in the school of writing advertising copy for the printed media. With a brilliant record of smash hits in the black and white pages of The Saturday Evening Post or Collier's, he is cocksure he can repeat the performance in radio. But it is not that easy. It is not simply a matter of adapting "eye" copy to "ear" copy. The technique is different; the qualifications of the writer are different. There is no reason, of course, why an advertising copy writer cannot succeed in writing acceptable commercial radio script. It is being done every day. But the successful ones are those who start over again; who, like the artist who has worked half his life in pen and ink and then turns to oils or water colors, use painstaking care to learn the technique of the new medium; who strive to appreciate the fine possibilities of a different medium of expression.

\section{Getting the Broadcasting Viewpoint}

True, most of the rules of advertising copy apply with modifications to radio. One must be first a copy writer, but he must add to the standard tools of his trade new and sometimes strange implements. He must also do several other things. 
He must develop tact and delicacy of presentation. He must realize that a goodly proportion of radio listeners resent advertising on the air. The higher the mentality, the greater the resentment. Years may soften this attitude as it has done in the printed media, but we are writing for today. Fortunate is the script writer who can present a telling advertising message effectively and yet hold the respect of his listening audience.

He must develop an appreciation for rhythmic prose. His copy should flow as smoothly as well-executed poetry, pleasing and soothing to the ear. The feeling tone of a beautiful picture in the printed advertisement he must translate into words, words which can thunder or whisper but they must do it smoothly, words which avoid harsh combinations of consonants, cumbersome or tongue-twisting phrases, too much alliteration, s's in particular.

He must definitely translate his "eye" pictures to "ear" pictures. He must remember that until television is open to the advertiser his audience is "seeing through their ears." His copy must be rich in vivid word pictures. The good old copy rule of being specific rather than general applies well here. The listener must "see" the product itself. Note the package identification used on some programs: the package with the big red letters spelling Jell-o, Dill's bright yellow tin, and the like. Lucky in radio work is the copy writer who has a mind that sees pictures first and words second, i.e., one who is visual-minded.

He must appreciate the mental limitations to listening. $\mathrm{He}$ must present his thoughts in small parcels that can be readily comprehended. A reader of a magazine or newspaper can backtrack if he does not get the thought the first time. A listener to radio has no such chance. Therefore, complicated sentences, particularly of the complex type, should generally be avoided. This does not necessarily mean that all sentences should be short, although short sentences are always effective; they may be the type of sentences that add their ideas like a string of pearls, each pearl complete in itself.

He must appreciate the personal and intimate presentation of radio. The forensic presentation of the lecture platform is ludicrous in the front parlor. Adopt the conversational tone of the personal interview. It can be dignified, chatty, even 
whimsical, but it must be keyed to a 12 - by 20 -ft. room, to the family in the intimacy of its own home. Understand perfectly that goods can be sold in a $12-$ by 20 -ft. room; any insurance or vacuum cleaner salesman knows that. But one cannot successfully use the sweating brow, red-of-face dynamic presentation of a great evangelist shouting before an audience of 2,000 people.

\section{New Forms of Presentation Possible}

With these five precepts well in mind, any good copy writer is on the road to becoming a good script writer. He should study further the mechanics of radio, which were discussed in a previous chapter, and the accepted forms of script presentation, which will be discussed in this chapter. As a matter of fact there is no definite reason why a script writer should be governed by the accepted forms of radio advertising presentation. Someday a clever script writer will set up an entirely new and more acceptable form of commercial.

Jack Benny's interesting and amusing little sallies about Jell-o originally marked a new form of presentation that many listeners actually enjoy. These short, apt asides are a natural part of the sequence of the show. They have become quite a standard procedure in many air shows today.

- Another new type being experimented with is the slow tempo, face-to-face commercial as presented by Procter \& Gamble on some of their morning shows, a tempo as conversational as if the speaker were sitting opposite you in an armchair, stopping, hesitating as an ordinary visitor might do, a visitor who is doing his thinking and talking at the same time. Only research among listeners can prove the worth of such new ventures.

\section{The Opening and Closing Announcement}

But getting down to today's accepted radio practice which will probably last for many years to come, let us look at some of the precepts, strictly from the advertiser's viewpoint. We have the standard opening and closing announcements which may or may not include advertising. These must between them announce the show and its sponsor. The only apology for lengthy advertising in the opening announcement is where a 
show is so popular that one can be sure the listener will keep tuned in, in spite of the long advertising message. There is some excuse, too, for an opening commercial when the show is a dramatic play with a star cast which will leave the listener in a tense emotional state not suitable for receiving the presentation of a selling talk. Even in this case, many listeners will be unduly annoyed at the delay caused by an opening commercial. The closing announcement, on the other hand, is a harmless place for the advertising message but it is likely to find the listener packing up to leave, like the suburbanite at the theatre who is in the aisle with one arm in his overcoat before the final curtain.

\section{The Straight Commercial}

The straight commercial and the dramatic commercial may be placed anywhere in the program, but they should be placed as carefully as any other feature. In fact, they should be placed so expertly, or led up to so smoothly, that the listener looks on the commercial as a natural part of the program.

There seems to be much difference of opinion as to the definitions of a straight and a dramatic commercial. Obviously there can be much overlapping. For working purposes, let us consider a straight commercial as one which does not disguise its advertising message. It is generally a straight advertising or sales talk, a counterpart to the average printed advertisement. It will be delivered by the program announcer, a special announcer, or by two or more announcers (multiple announcing). But there should be no doubt on the listener's part from the very first that this is the sponsor's advertising message. Such a straight commercial may even have sound effects and a musical background.

\section{The Dramatic Commercial}

The dramatic commercial, on the other hand, has its counterpart in the dramatic strip printed advertisement or in story copy that has high dramatic interest. One is halfway through it before he remembers that, after all, this is only an advertisement. This type of commercial may be delivered as a monologue with one character, or a dialogue with several speakers. The fewer the characters, the more effective the dialogue will be. 
Never lose sight of the fact that simplicity pays big dividends on radio programs.

Many radio listeners call the dramatic commercial trickery, but they have no objection to the same practice in their favorite magazine. The determining factor is how cleverly the drama is presented. In other words, the dramatic situation must have entertainment value in itself. For example, here is one that does not measure up to the standard. It was given over a small local station and such programs probably account for the unpopularity of so many small stations:

Sound effect. Laughter, many voices: "Good Night." "A wonderful party." "Had a swell time." Departing guests. Silence.

Man's Voice: "Well, honey, you were a swell success."

Girl's Voice: "It wasn't I, dear. It was the big sparkling white diamond you bought me at A-_."

Then followed a hammer and tongs salestalk by the station announcer on A- 's sparkling white diamonds and your opportunity to buy them for as little as a dollar a week.

This "dramatic" commercial probably brought in some customers but a more cleverly done job could have brought in more and created less ill will among the more discerning listeners.

For the rules for writing good dramatic advertising copy refer to any good textbook on copy writing. ${ }^{1}$

\section{The Tone of Advertising Script}

One of these standard advertising copy rules which is not handled so well in radio as in printed copy is: adapt your copy to your product and to your audience. Adapting copy to the audience might be translated to tone for radio copy. Here are two examples of recent script. The first, for Pillsbury, is adapted to an intelligent group. Its smooth, even tempo should offend few listeners even though it does contain direct commands. The second, for Pinoleum, in a much faster tempo is adapted to a low mass level, the famous 10-year-old mind that advertising

1 George B. Hotchkiss, "Advertising Copy," Harper \& Brothers, 1936, is recommended. 
authorities so often mention, the mind that is not a mind at all because it is not allowed to think, even in an advertisement. The intelligent listener either strongly resents this tone or indulgently pokes fun at it.

\section{First Commercial in “Today's Children" Program, DeCember, 1936}

"Isn't it fun when . . a after a particularly successful luncheon or dinner . . your guests crowd around and demand 'your recipe for that perfectly delicious cake.' Although Pillsbury's Sno Sheen Cake Flour has been on the market only a few years - already thousands and thousands of women have learned the secret of making cakes lighter, finer, and more delicious than they have ever made them before-by using this better flour. Resolve now that in the new year ahead you will enjoy your share of compliments on the cake you bake. Start today by ordering from your grocer," etc.

\section{A 1-min. Spot Announcement}

"Friends! Attention to a free offer! An offer that asks no box tops ... no money ... only your name and address! This is what we're giving away: A trial bottle of the famous product, specially made for the supplementary treatment of head colds and accompanying throat irritation, Pineoleum, P-I-N-E-O-L-E-U-M, Pineoleum. Now you hear lots of claims over the radio in behalf of various treatments for colds. We believe that Pineoleum has a lot of merit. But we add: 'Here's a free trial bottle. Try it . . . and judge Pineoleum for yourself.' Listen carefully now and I'll tell you how simple and easy it is to get your very own free trial bottle of Pineoleum. All you have to do is send your name and address to the Pineoleum Company, care of this station. Now isn't that easy! And confidentially . . . we believe that once you try Pineoleum you'll always have Pineoleum on hand when... B But you just send for your free bottle and judge Pineoleum for yourself! Address the Pineoleum Company, care of this station."

It may well be maintained that there are enough mass minds to make a powerful exhortation such as this pay. The real question is whether the number of trial bottles sent out com- 
pensate for the ill will aroused in the minds of many listeners even in the mass-mind group. The same might be said for the 11 mentions of Pineoleum in a scant 172 words.

It should also be said in justice to the Pineoleum spot announcement, that tempo and sales talk are customarily stepped up in a spot announcement on the premise that few listen to a spot announcement unless they have to and if they have to, the advertiser has nothing to lose in blaring his wares, nothing to lose, that is, except good will for his product.

\section{The Placing of the Advertising Message}

As serious as the matter of poorly written script is, probably poorly placed or timed script is worse. Commercial announcements, dramatic or straight, should never be just "dropped" into the program on the hour and half hour like suburban buses. The program should be designed for the commercials. There should be a logical and sensible spot for each announcement. In other words, announcements should as nearly as possible be an integral part of the program, so adroitly led up to, so naturally placed, that the listener has no occasion to resent their introduction. Sometimes a properly placed musical number accomplishes this; sometimes an apropos turn by the m.c. (master of ceremonies). More and more in radio presentations the leading characters are introducing the commercial announcer, introducing him as if he were an accepted part of the show, a welcome guest on the program-not a pest.

Avoid violation of placement. A sponsored program on the air featuring the trials and tribulations of a very human family closed the story for the evening recently with one of the members ill in the hospital. The interested listener was as grief-stricken as the radio family. But, horror! The set plan of the program called at the end of the drama for a dramatic commercial with the same family cast taking part. So here they are, folks, their grief of $2 \mathrm{~min}$. ago forgotten, happily playing a parlor word game with not a care in the world other than to mention the sponsor's product frequently. Amos 'n' Andy did a better job when sometime ago the dramatic incident of the evening depicted Amos' wife as very ill. The final selling talk which closed the program was omitted to keep the program in harmony with the feelings of the listeners. 


\section{The Tempo of the Advertising Message}

Reference has already been made to the tempo of the commercial. Shall the wordage run 175 words per min., which can be handled safely (but rapidly) by a good announcer, or 135 or even 125 words, which more nearly approaches the rate of an average conversational delivery? If a long advertising message is necessary, it may be better to speed it up so that it does not seem so long to the listener. But except in these rare cases, a slower commercial is more effective; certainly the tempo should be no faster than a good platform speaker would talk or a good salesman would speak in an effective sales presentation. If the advertiser will keep in mind the suggestion already made, that the message is delivered in the privacy of the prospect's living room, he will adapt a conversational tone and rate of delivery fitted to the occasion.

It seems strange that an advertiser who would not think of crowding a half-page advertisement with all the words it can hold, will crowd a radio minute with as many words as an expert announcer can possibly rattle off. Figuratively, white space can often be used very effectively in a broadcasting announcement. Although a caution here, 2 sec. of silence may seem like 20 to the not-too-pleased listeners. When sound effects are used, they can save word time. It-should be noted that some stations in selling 1-min. spot announcements actually specify 100 words; also that Ted Husing in his interesting book "Ten Years before the Mike" credits sports announcing at times with a rate of 400 words a minute.

\section{Copy Technique}

Script writing in all its ramifications is a business in itself. No attempt is made here to cover it completely. It is enough to point out a few details in technique so that the advertising man can judge script or in an emergency write his own. Any piece of copy should be checked for its continuity of ideas, i.e., that one thought follows logically the one preceding, that the subject or the viewpoint is not shifted too often, that thought detours are avoided. Clearness, conciseness of expression, and emphasis should be checked. Have important points been placed in important positions and less important ideas subordinated to 
main ideas? As already stated a good book on copy writing covers all this.

As radio copy is to be spoken, there is no better check on the smoothness of radio script than to read it aloud. Some radio script writers dictate radio copy on the premise that in style and sequence it will more nearly approximate the spoken word.

Mechanical aids in advertising script writing should include a more generous use of commas, dashes, dots for pauses-even an occasional underline. But a caution here about underlining. The run-of-the-mine announcer may have a tendency to overemphasize underscored words, with the result that his delivery may sound artificial. Better to plan the sentence structure so that the emphasis falls naturally on the word or idea of importance.

It is almost needless to add that paragraphing is rarely used in commercial announcements. The paragraph is primarily a visual aid to readers.

\section{Writing the Spot Announcement}

In spot announcements more attention should be given to picking out the type of listener than in announcements which are part of a 15- or 30-min. program, where the assumption is that the type of listener has already been picked out by the type of program.

There is much value to the claim that the opening sentences in any advertising script should be dynamic enough to attract the attention of the listener and hold it. When one considers the mass of radio listeners who use the radio program as a background for other pursuits such as conversation, bridge, or reading, it can be readily seen that a dynamic opening sentence may politely call many a listener back to consciousness of the program. This, however, can be overdone. Such expressions as "Attention, radio listeners" or "Flash, flash" not only have been overdone but are annoying to many listeners. During the 1938 hurricane's visit to New England, when listeners were all attention to the news breaks over radio, one advertiser unwittingly used the standard expression "We interrupt the program at this point" to introduce his advertising message. He got attention, probably the best his radio advertising message had ever received, but it was far from favorable. 
Following is a 1-min. spot announcement for P \& G Soap in which is used the dramatic "predicament" situation for attention and to pick up the right type of listener. The dramatic approach is combined with the straight commercial.

\section{P \& G White Naphtha 1-min. Spot Announcement \#14}

1st Woman: Mary, I am so sick of washing greasy dishes I could scream!

2nd Woman: Polly, no wonder the grease sticks-your soap isn't giving you enough suds!

1st Woman: Well, greasy dishes for six people would flatten down any suds!

2nd Woman: Not if you'd try P \& G Naphtha Soap-you never saw such rich suds.

Announcer: Yes, ladies-P \& G does give richer suds! And better yet-it contains a special ingredient that cuts grease. Even heavy grease like lamb or mutton fat just melts away like magic. And $\mathrm{P} \& \mathrm{G}$ cuts down that sticky scum that often makes glass and china look streaky! So try $P \& G$ in your dishpan. See how every glass and plate just sparkles! Note that this white soap is easy on your hands too. P \& G now comes to you in an airtight, moistureproof wax wrapper that keeps this fine white soap fresh and quicksudsing.

Your dealer now has P \& G White Naphtha Soap in the new wax wrapper at special low prices. Ask for it today.

\section{Considering the Announcer}

That the efficient advertising script writer puts himself in the place of the announcer as well as of the listener accounts for much of our better script. A good script writer should thoroughly understand the problems of the announcer. As pointed out in Chap. V, adapting copy to the natural rate of delivery, style, and personality of a given announcer is almost a fine art. If the script writer will also picture himself actually delivering before the microphone the script as he has written it, there will be natural breaks for the announcer to do his breathing, fewer tongue twisters and cumbersome phrases, less blatant sales talk and insincere delivery. For it is a psychological fact that even the experienced announcer, if he is disgusted with 
his script will let creep into his voice an unnaturalness which the radio listener's ear is surprisingly quick to detect.

\section{Length of Commercials}

As to the time length of each commercial, there are no setfast rules. The criterion is the listener's attention. If an announcement is interesting, smooth, well delivered by a "voice with a personality," 2 min. may seem short to the listener. If it drags, is uninteresting, has a powerful sales talk, a single minute may seem like 5 . Tests made by Sales Management a few years ago among radio listeners showed that a goodly majority of listeners guessed the length of a commercial as 5 to $7 \mathrm{~min}$., when even at that time a $2 \frac{1}{2}-\mathrm{min}$. commercial was an exception. So far as the listener is concerned, the shorter the announcement is, the better. Certainly few should run much over a minute.

As to the total amount of advertising on a program, see Chap. XIII for maximum amount per program, as allowed by Columbia Broadcasting System and recommended by the 1939 code of ethics of the National Association of Broadcasters. Whether a broadcasting station has such a rule or not, these figures, which have been carefully worked out, should rarely be exceeded if listener approval is to be obtained.

Nothing in this chapter should be construed to mean that well-executed straight-selling commercials have no place on a program. More and more the listening public is beginning to realize that it is the advertising that makes the entertainment possible and, with the exception of the conscientious objector who is satisfied with nothing about radio advertising, the mass listening group will respect a straight-selling job, done in a dignified manner and effectively presented. 


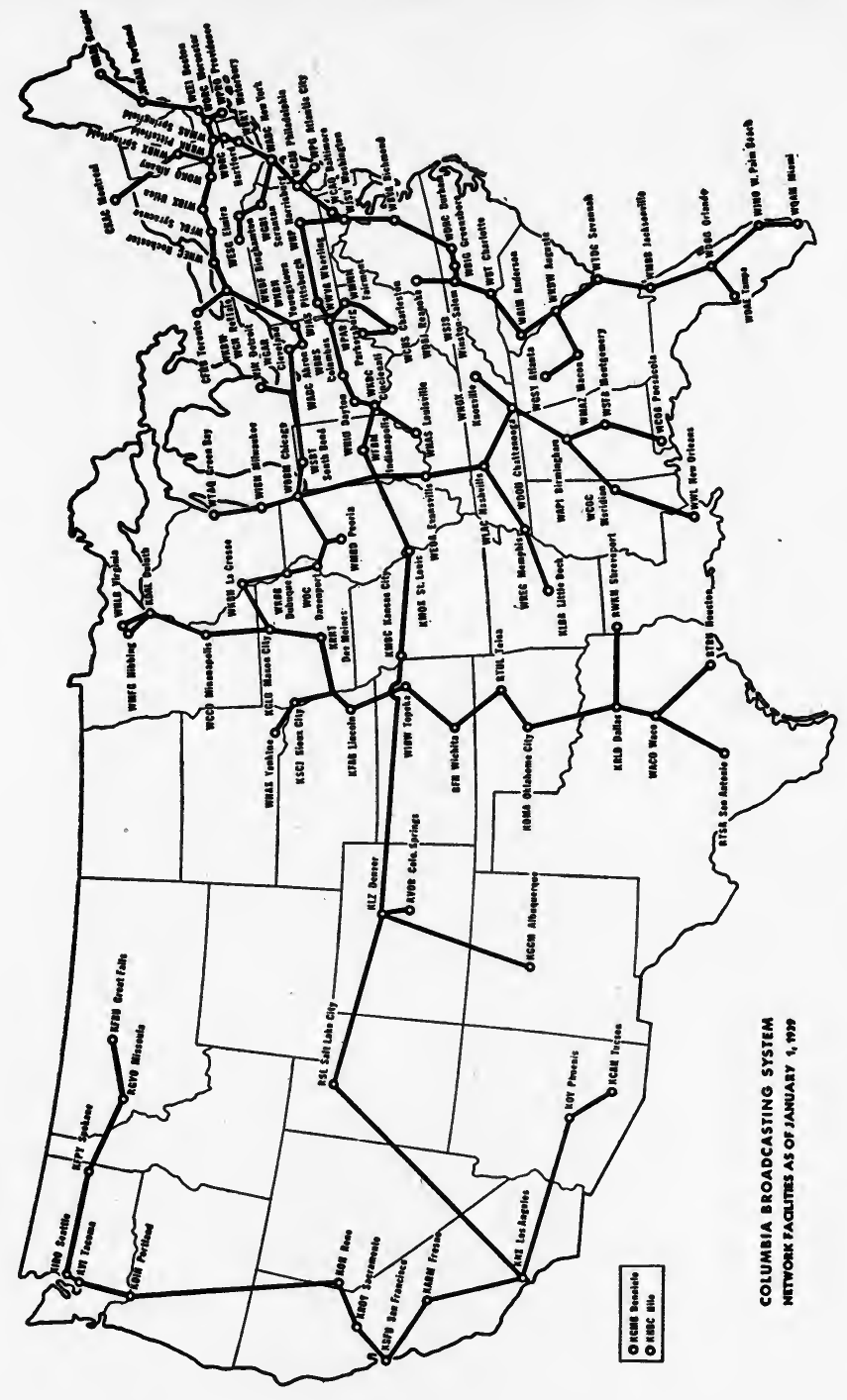




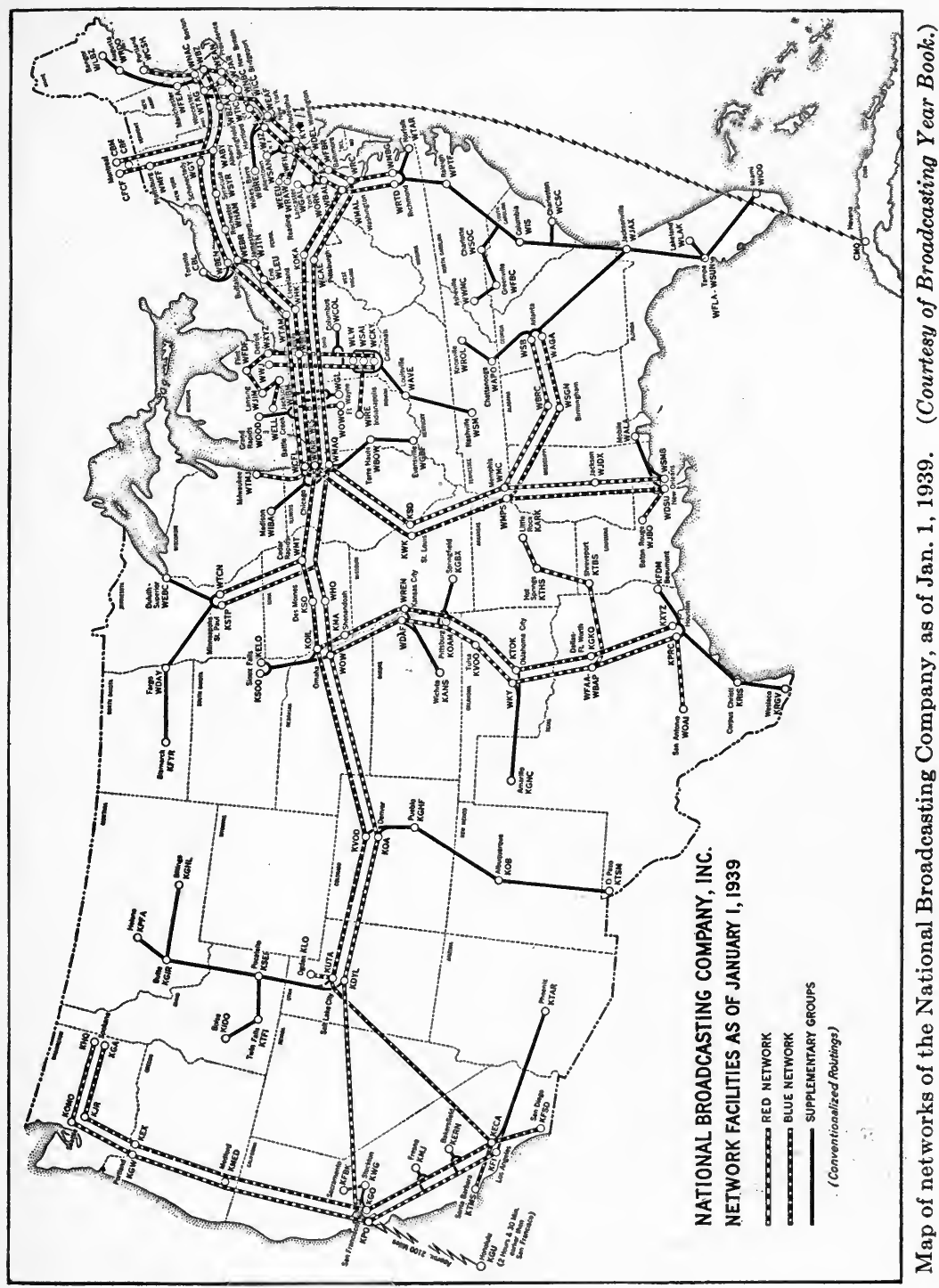




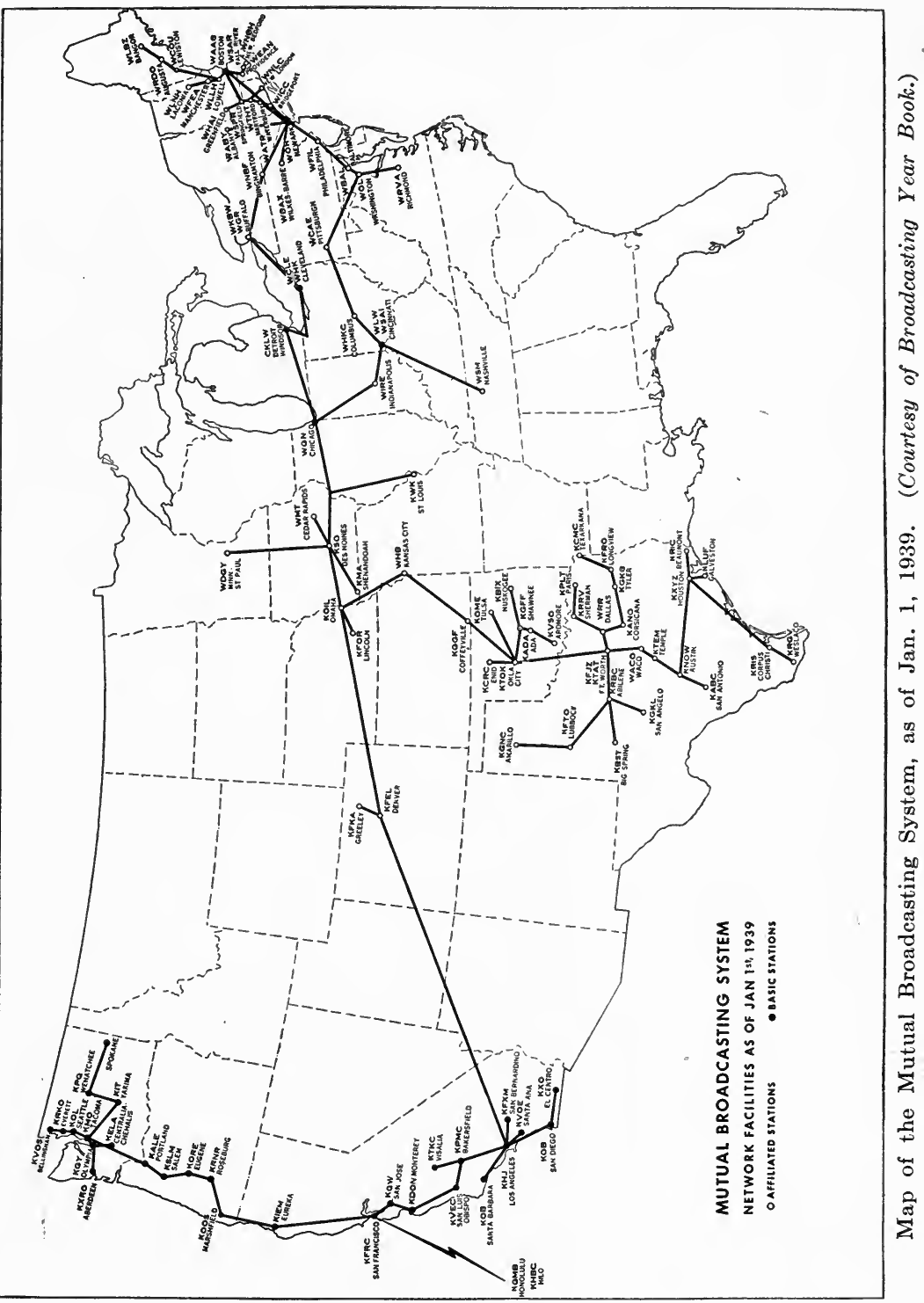




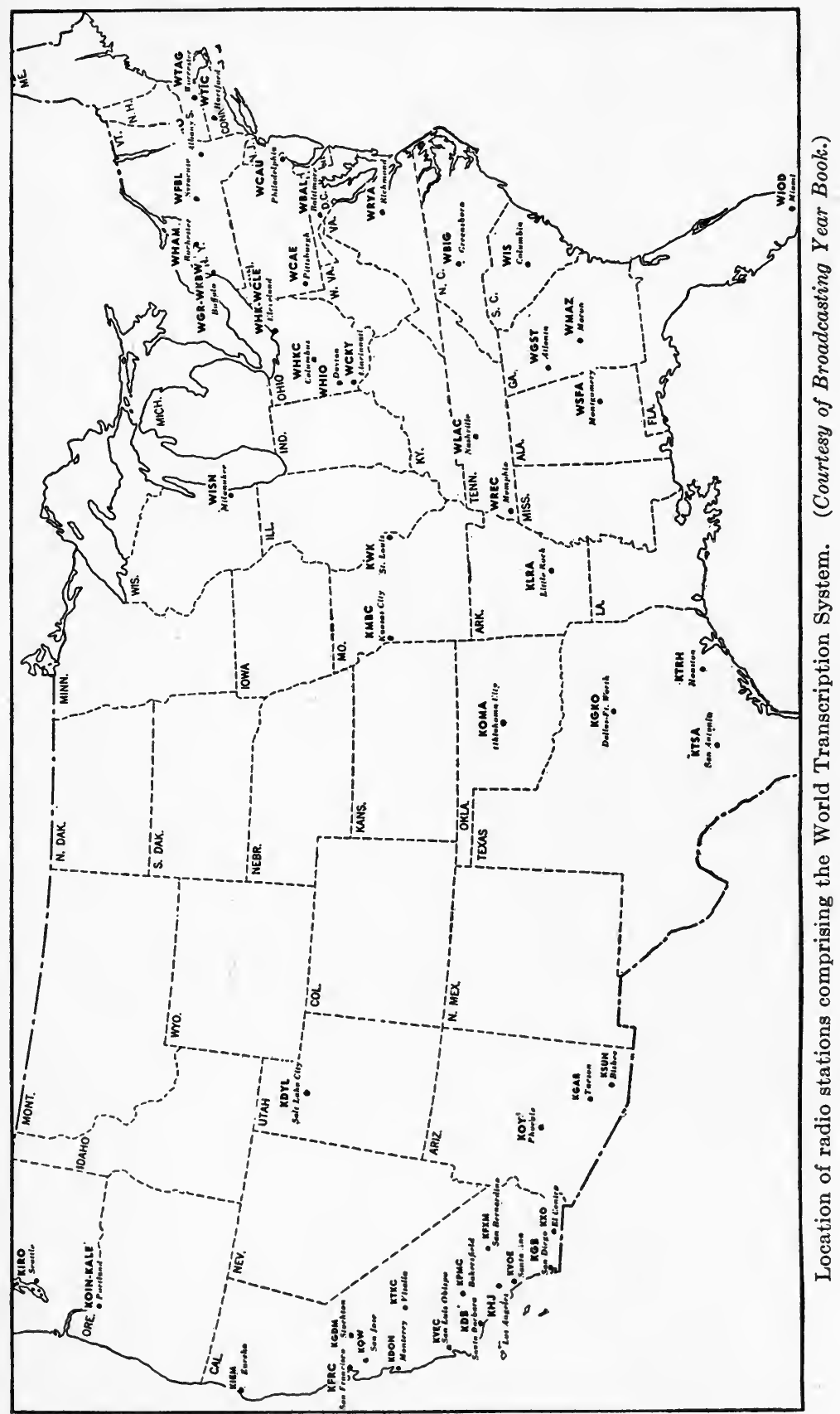




\section{CHAPTER XIII}

\section{CENSORSHIP-GOVERNMENTAL AND OTHERWISE}

So long as censorship can be interpreted in terms of benefits to the public, no advertiser should seriously object to it. The air belongs to the public. Even the broadcasting companies have only short-time leases on its use. They are required by law to serve "public interest, convenience, and necessity." Only so long as they do this, will they hold their license to use the public's air. Certainly the advertiser, because he buys 15 min. of it, cannot expect to romp through his time on the air with the same abandon he uses in his 32-page catalogue or his sales manual.

He will find in radio, as he does in most other advertising media, a formidable array of public interest's watchdogs who never share the advertiser's enthusiasm for his product. Statements of opinion and statements of fact must be plainly enough differentiated so that good old credulous John Q. Public will not mix them up. And sometimes John is a dull boy. And worse luck for the advertiser, there are penalties for overstepping. Penalties for the advertiser, and penalties for the station so lax as to give voice to questionable script. Many advertisers today let their lawyers put a final OK on radio script much to the disgust of the enthusiastic copy writer who is often more to be blamed for overstatement than the advertiser himself.

The advertiser will do well to consider the demands of radio censorship from the moment he begins thinking of his program idea to the time when he writes his advertising script. There are things besides questionable advertising that will not go over the air. This most intimate of all media, this fireside companion, cannot handle intimate products with the same frankness used by some of the other media. In some cases where any doubt of procedure may arise, the stations themselves, always fearful of losing their short-term licenses under the Federal Communications Act, will play safe and say "no" on the premise that it is better to be safe than to be sorry. 


\section{National Broadcasting Company's Censorship}

Thus the radio advertiser will find definite types of censorship which must be reckoned with. First, there is the station itself. The larger the station, the more rigid the censorship. National Broadcasting Company in a statement of program policies ${ }^{1}$ prefaces its "Thou shalt nots" with: "The NBC can best serve the true interests of its advertisers by pleasing first the interests of the public." Then follow such caution as: Unpleasant or gruesome statements should be avoided as more likely to offend than to instruct or entertain. Courtesy and good taste should govern the manner in which announcements are made. The advertising message should be in harmony with the rest of the program, should contain information of interest to the public, and should be prepared with brevity and skill. Statements which tend to undermine an industry by attributing to its products generally, faults and weaknesses true only of a few and statements which are derogatory to an individual, an institution, a group or an industry, should be avoided. Protection against libel and slander is as essential for the advertiser and his agency as for the National Broadcasting Company. Tiresome repetition or too much detail should be avoided. Offers made to the radio audience should be simple and easy to grasp quickly. Each program should be individual and distinctive and should not resemble too closely an adjoining program on the same network, etc.

Then follows the real "shall nots": The use of the Diety's name is acceptable only when used reverently or as a part of a standard classic work. Statements or suggestions which are offensive to religious views, racial traits, and the like must be avoided. False or questionable statements and all other forms of misrepresentation must be eliminated. Obscene and off-color songs or jokes, oaths, sacrilegious expressions, and all other language of doubtful propriety must be eliminated. Testimonials must reflect the genuine experience or opinion of a competent witness. Statements of prices and values must be confined to specific facts. Misleading price claims or comparisons must not be used. As a safeguard against misuse of broadcasting facilities for unfair competition, commercial programs shall not refer to any competitor, directly or indirectly, by

1 "NBC Program Policies," January, 1934. See also "Broadcasting in the Public Interest," NBC, 1939. 
comparing name, by individual name, or by brand name-regardless of whether such reference is derogatory or laudatory.

A reading of the Federal Communications Act will show that many of these same precautions are covered in the act itself.

National Broadcasting Company's program procedure, in common with most other networks, consists in having all continuities, including the words of all spoken lines as well as the wording of commercial announcements, submitted for approval at least one week in advance of the broadcast, except where the nature of the program does not so permit. The titles, composers, and copyright owners of music to be used on the program are also submitted in advance for the purpose of copyright clearance. Also submitted are any evidence of the right to use musical or literary material, and written releases for testimonials to be used on the program or, in the absence of these, an indemnification signed by the advertiser or his agent.

\section{Columbia Broadcasting System's Censorship}

Columbia Broadcasting System has parallel rules of censorship but has added one very definite one, i.e., the maximum advertising time allowance for each CBS program. In their statement of policies ${ }^{1}$ they give the following maximum time allowances for the sponsor's commercials and commercial announcements including contests and offers.

\section{Evening Programs after 6 P.m.}

Maximum Time

Full-hour programs.............. 6 min.

Three-quarter hour programs.......... 4 min., 30 sec.

Half-hour programs............... $3 \mathrm{~min}$.

Quarter-hour programs............2 min., 10 sec.

In CBS daytime programs, the time for the sponsor's commercials shall not be more than 15 per cent of the total boardcasting period, plus 40 sec. on a quarter-hour program.

Unpleasantly rapid delivery of the sales message to effect a crowding in of excess material will not be permitted.

Another censorship for which Columbia has specific rules has to do with the handling of children's programs. ${ }^{2}$ Some of

1 "New Policies," Columbia Broadcasting System, May 15, 1935.

${ }^{2}$ For NBC's policies on children's programs, see "Broadcasting in the Public interest," p. 47, NBC, 1939. 
the specific themes and dramatic treatments which are not permitted in broadcasts for children follow:

The exalting, as modern heroes, of gangsters, criminals, and racketeers will not be allowed.

Disrespect for either parental or other proper authority must not be glorified or encouraged.

Cruelty, greed, and selfishness must not be presented as worthy motivations.

Programs that arouse harmful nervous reactions in the child must not be presented.

Conceit, smugness, or an unwarranted sense of superiority over others less fortunate may not be presented as laudable.

Recklessness and abandon must not be falsely identified with a healthy spirit of adventure.

Unfair exploitation of others for personal gain must not be made praiseworthy.

Dishonesty and deceit are not to be made appealing or attractive to the child.

Columbia Broadcasting System also rules against proprietary products, the advertising of which discusses internal bodily functions, symptoms, and the like. Laxatives, depilatories, deodorants are specifically ruled out.

Other broadcasting systęms and many individual stations have adequate censorship rules. Occasionally a small station hard put to sell its advertising time will not be any too fussy about censorship.

\section{The Federal Communications Commission}

The censorship of most stations, as already pointed out, is patterned after the ruling of the Federal Communications Act. Advertisers will do well to have a copy of this act in their files and to be thoroughly familiar with its rulings. ${ }^{1}$

The Federal Communications Act of 1934 established the Federal Communications Commission, which was almost wholly taken over from the former Federal Radio Commission functioning under the Radio Act of 1927. Most of its power has to do with such matters as classifying stations, prescribing the nature of service, assigning frequencies and power, determining locations

1 "Federal Communications Act of 1934," Government Printing Office, Washington. (5 cents) 
and type of apparatus, and the like. There is little direct reference in the 1934 act to broadcast advertising as such. However, much of the authority given over communications can be applied to advertising. It should be noted that the Commission has not the power of censorship which would interfere with the right of free speech. The main censorship as such comes from the station owners, not from the Commission.

Three sections of the act which are of vital interest to the advertiser, however, follow:

\section{LotTeries and Other Similar Schemes}

Sec. 316: No person shall broadcast by means of any radio station for which a license is required by any law of the United States, and no person operating any such station shall knowingly permit the broadcasting of, any advertisement of or information concerning any lottery, gift enterprise, or similar scheme, offering prizes dependent in whole or in part upon lot or chance, or any list of the prizes drawn or awarded by means of any such lottery, gift enterprise, or scheme, whether said list contains any part or all of such prizes. Any person violating any provision of this section shall, upon conviction thereof, be fined not more than $\$ 1,000$ or imprisoned not more than one year, or both for each and every day during which such offense occurs.

\section{Announcement that Matter Is Paid For}

Sec. 317: All matter broadcast by any radio station for which service, money, or any other valuable consideration is directly or indirectly paid, or promised to or charged or accepted by, the station so broadcasting, from any person shall, at the time the same is so broadcast be announced as paid for or furnished, as the case may be, by such person.

\section{Censorship: Indecent Language}

Sec. 326: Nothing in this Act shall be understood or construed to give the Commission the power of censorship over the radio communications or signals transmitted by any radio station, and no regulation or condition shall be promulgated or fixed by the Commission which shall interfere with the right of free speech by means of radio communication. No person within the jurisdiction of the United States shall utter any obscene, indecent, or profane language by means of radio communication.

\section{The Federal Trade Commission}

Another Federal Commission which exerts a censorship over radio advertising is the Federal Trade Commission. The 
Commission was established in September, 1914, before radio was big enough to need censoring. The Federal Trade Commission Act empowered the Commission to prevent unfair methods of competition. A series of court decisions followed which held that false or misleading advertising constitutes an unfair method of competition. Since 1914, the Commission has put a "cease and desist" order on many questionable commercial ventures. As radio grew in stature and its advertising in enthusiasm for the sponsors' claims, the Federal Trade Commission added the censorship of this medium to its censorship of other media. The Commission has supervision over advertising script and may call on networks and stations to furnish advertising script used. In 1934 over $100,000^{1}$ pieces of script were examined by the Commission. Almost 90 per cent were filed as free from violation of the law. Advertisers are given an opportunity to justify their commercials and in some cases are able to do so. Where programs are found to contain false and misleading statements in violation of Section 5 of the Federal Trade Commission Act, the stations are communicated with and, generally speaking, the broadcasting companies and stations take the necessary steps to eliminate all objectionable matter.

\section{The United States Post Office}

If the radio advertiser is contemplating embarking in the contest and free-offer business or in any way making offers which will result in the use of the United States mails, he will do well to consider the United States Postal Regulations. This phase of censorship is discussed in detail in Chap. XVII.

To sum up the censorship situation, the advertiser will do well to study all federal, state, and even municipal laws relating to advertising and marketing, if he wants to feel reasonably safe about his radio program. Liquor advertising in particular not only is indirectly under the eye of the Federal Communications Commission but the Federal Alcohol Administration as well. Nor should the Food and Drug Act be overlooked.

The advertiser contemplating radio will notice that much of radio's censorship is the same as the censorship he finds existing for other advertising media. A safe advertisement in any other

1 "117,357 Radio Programs," Printers' Ink, Sept. 13, 1934; "Federal Trade Commission Looks at Copy," Printers' Ink, July 7, 1938. 
medium is generally a safe advertisement in radio, only excepting those which by poor taste violate the intimate home characteristics of the radio program.

\section{Danger of Lawsuits}

In spite of the broadcasting station's censorship precautions, its advertisers occasionally lay both station and themselves open to criticism, particularly from the listeners. In some cases legal action has been taken by listeners who feel they have been defamed. An example of this:

A few years ago two well-known comedians on a radio program burlesqued the activities of a small law office. The firm name used was Beagle, Shyster \& Beagle. An attorney in New York City named Beegel commenced suit, maintaining injury to his reputation as well as the unlawful use of his name. The case was later dismissed without formal opinion. Other cases are on record where both broadcasting company and advertiser have been subject to suit. This illustrates how careful the advertiser should be in planning the details of his broadcasts, not only the content but the character and manner of delivery as well.

Nor should the advertiser resent the care with which the broadcasting company checks his continuities. The procedure may save the advertiser from embarrassment and even from suit.

\section{Libel and Slander}

The question is often asked, does the law of libel or of slander apply to radio? Libel is the publication of a writing which exposes a person to hatred, contempt, ridicule, or obloquy or causes or tends to cause him to be shunned or avoided. Slander may be defined as oral defamation. Both give rise to causes of action for damages but libel, at common law and by statute in many states, also constitutes a crime. Broadcasting defamation is directed to the ear, as is slander, rather than to the eye, as is libel, yet in all probabilities the rules of libel will usually be applied in cases of defamation by radio. ${ }^{1}$

${ }^{1}$ Joseph A. McDonald and Ira L. Grimshaw, "Radio Defamation," National Broadcasting Company, 1937. 


\section{The National Association of Broadcasters}

Just as other advertising media have their associations for the general welfare and improvement of the medium and of the relations between its members, so radio has its association, the National Association of Broadcasters.

In 1935, this association adopted the following code of ethics for the broadcasting stations which were its members:

1. Recognizing that the radio audience includes persons of all ages and all types of political, social and religious belief, each member station will endeavor to prevent the broadcasting of any matter which would commonly be regarded as offensive.

2. When the facilities of a member station are used by others than the owner, the member shall ascertain the financial responsibility and character of such client, that no dishonest, fraudulent or dangerous person, firm or corporation may gain access to the radio audience.

3. Matter which is barred from the mails as fraudulent, deceptive or obscene shall not be broadcast by a member station.

4. Each member station shall refuse any advertising matter regarding products or services injurious to health.

5. Each member station shall maintain a public record of its current rates charged to advertisers for the use of broadcasting time together with all discounts, rebates, refunds and agency commissions which shall be allowed to the users of such time or to their recognized agents.

6. Each member station shall refuse to accept any business on a cost per inquiry, contingent, or percentage basis, or to accord free time for commercial use.

7. No member station shall permit the broadcasting of advertising statements or claims which he knows or believes to be false, deceptive or grossly exaggerated.

8. No member station shall defame or disparage a competitor, directly or indirectly, by words or acts which untruthfully call in question such competitor's business integrity, ability to perform contracts, credit standing or quality of service.

9. No member station shall claim for its service a character, scope or quality which cannot be substantiated, nor shall it claim as regular characteristics of its service features which it knows to be purely temporary or accidental.

10. Where charges of violation of any article of the code of ethics of the National Association of Broadcasters are filed in writing with the Managing Director, the Board of Directors shall investigate such charges, give opportunity for hearing and afterwards notify the station of its findings. 
This code of ethics, while too general in application, did much to improve radio. But it was not specific enough for so fast growing an industry. So at the 1939 annual convention of the National Association of Broadcasters the code committee, under the chairmanship of President Neville Miller, presented for acceptance a new and more stringent code for the industry's self-regulation. The new code meets squarely almost every program and fair-practice criticism leveled against radio since its beginning. ${ }^{1}$

The complete text of the NAB Code as proposed was not accepted, but it is given below and should give the prospective radio advertiser a safe code to follow if he wants to produce a program acceptable to everyone from broadcasting station to radio listeners. As a matter of record, the 1939 NAB Convention did adopt parts of the following text, particularly as it applied to children's programs, controversial public issues, educational broadcasts, news, religious broadcasts, and length of commercials (adopted without change). For full text of the adopted code, see Broadcasting, July 15, 1939.

\section{STANDARDS OF PRACTICE OF THE NAB}

(Code Interpretations for the Guidance of Member Stations)

(As Proposed at the 1939 NAB Convention)

\section{The Yardstick of Góod Taste}

1. Reference to the Deity shall be made only in a manner of respect and reverence.

2. Language used and subject matter discussed must be acceptable in mixed social groups.

3. Broadcasters will bar dialogue or statements which are, or which border on the obscene, sacrilegious, profane or vulgar, especially as these appertain to sex, bodily functions and expressions fraught with double meaning.

4. No unkind reference ridiculing racial or religious characteristics, or to physical imperfections such as lameness, blindness, deafness shall be permitted.

5. Where dramatic situations are based upon dramatizations of religious rites, such as baptism, marriage or funeral ceremonies, such shall be treated in a manner respectful and sympathetic.

${ }^{1}$ Broadcasting, June 15, 1939. 


\section{Religious Broadcasts}

1. It shall be the policy of stations, in broadcasting religious programs, to consider primarily the interests of the radio audience rather than those of any particular church or churches or religious groups, so that, over a period of time, stations may transmit a well balanced series of religious programs best suited to the spiritual needs of the community truly reflective of its religious complexion.

2. For reasons clearly stated in Section II of the Basic Code, religious broadcasts shall not contain any attack upon another religious faith or race and should be on a high spiritual and devotional plane.

3. Stations shall not be considered under obligation to accept religious programs on a commercial basis.

In fact, such a practice might give the station a tone and complexion entirely erroneous and disproportionate to the actual religious tone and denominational make-up of the community served.

Recognizing the constructive work which has been accomplished through non-sectarian, religious programs placed upon a commercial basis, it is felt, nevertheless, that the best service to religion and to the public will eventually lead to the elimination of commercial religious programs.

\section{The Broadcasting of Controversial Public Discussions}

Throughout the country there has grown up, of late, the practice of restoring something akin to the colonial "town hall" meetings, wherein the clash of opinions and ideals are broadcast in a radio-forum debate so that the greatest number of citizens may hear the issues, evaluate the different opinions advanced, and act upon them. Such forum practice is recommended.

\section{Fair Consideration to All}

1. Without prejudice, radio stations will consider, fairly, the request for time of every responsible individual or organization. Should time be secured for a speaker or program through the request of some group or organization, the identification of such group or organization shall be clearly stated before and after the broadcast period.

\section{Different Points of View}

2. In presenting discussions of a controversial public question, stations will make every effort to provide fair and equal opportunity for each responsible point of view to be heard. However, the failure of an opposition viewpoint to avail itself of this opportunity should not, in itself, preclude any discussion of a given question. 


\section{Handling of Discussions during Strikes}

3. No time may be sold for the discussion of issues arising from a strike. If time is given for such discussions, it will be given on a fair and equal basis to all interested parties. If time is denied, the broadcaster will determine in his own mind that he has attempted faithfully to serve the public interest in such an action.

\section{Political Broadcasts}

1. No dramatizations of political issues will be permitted. Such dramatizations would lift the campaign out of the realm of debate, and place it on a wholly emotional level, and might conceivably obscure real issues, or raise artificial ones.

For these reasons, both sides will be limited to logical exposition with whatever persuasive ability the speakers possess.

\section{News Broadcasts}

In the handling of news matter, radio news editors shall live up to the highest traditions of news integrity, fair play and accuracy. News programs shall be limited to a straight reporting of the news as received from accredited news sources. Any explanatory or background matter added by the news announcer shall be limited to relating current news with known facts, past or present. In no case shall the personal opinion of the announcer, news editor, or station management be reflected in any news matter broadcast.

\section{Commercial News Broadcasts}

News reports may be sponsored by commercial advertisers. The control of all news matter broadcast must remain in the hands of the station. In no case shall the opinion or viewpoint of the commercial sponsor be reflected in any news matter broadcast.

If a commercial sponsor wishes to introduce a news item about his own product or industry, he must qualify such news announcements so as to clearly differentiate between straight news matter and commercial news matter; viz., "Motor car news"; "News from the motor car world."

No date line may be used in conjunction with a commercial announcement.

Where news broadcasts are commercially sponsored, it must be clearly stated that the commercial sponsor is presenting news matter gathered and reported from accredited sources; viz., "Jones and Company present United Press news bulletins," or "Smith and Company bring you the news of the day as gathered by the International News Service." In no case may it be inferred that the news has been gathered and edited by Jones and Company or by Smith and Company, direct. 


\section{Commentators}

The primary service which a broadcasting station can render in the news field is to inform the public as to what is happening and to make as clear as possible the significance of events, rather than to express either its own approval or disapproval or to devote its time to the editorial opinions of some particular commentator.

If a broadcaster devotes a reasonable amount of time to fair and twosided discussion of controversial public issues, using representative speakers to give differing points of view, he is providing debate and the expression of opinion on controversial issues in a far more effective way than can possibly be provided by one or even a handful of commentators, regularly expressing personal points of view on every conceivable subject. However, should the interest of the listening audience so indicate, responsible and well qualified commentators may be engaged, provided it is clearly stated that such commentator expresses only his or her own views and not those of the station.

\section{Commercially Sponsored Commentators}

Commentators may be presented by commercial sponsors, provided it is clearly indicated that the commentator expresses only his or her views and not those of the commercial sponsor.

Where commentators include in their remarks comments on one side of a question which significantly affect the welfare or life of any substantial group, member stations will give the public an opportunity to hear the opposite side of the matter, presented by a representative spokesman thereof. Moreover, in sponsoring a commentator, the advertiser must agree that upon demand by a member station, time will be given for this purpose on his own program.

\section{Miscellaneous}

1. No restriction is intended herein that would prevent the factual reporting and factual interpreting of news by a news announcer in accordance with a style of technique or manner of delivery which he or she might develop, so long as the subject matter and interpretation thereof is presented in conformity with the letter and spirit of this Code.

2. Use of the word "flash," or the words "news flash," or "news bulletin" must be reserved for the announcement of special legitimate news bulletins and may not be used in such a way as to provoke confusion or misleading reaction.

3. Nothing in this Code shall be construed as denying the obligation or privilege of the individual broadcaster to arrange such "special events" broadcasts as he determines might be in the public interest. 
4. In the broadcasting of court proceedings, news about or comment upon individuals; or cases subject to court procedure, such shall be made with due consideration for the orderly administration of justice.

5. No participants in criminally morbid sensational news stories may appear on the air. Reference to such cases shall be limited to the reporting from legitimate news accounts thereof.

\section{Propaganda}

1. This Code clause relates likewise to commercial propaganda wherein under the guise of "public interest" may be found a hidden commercial interest. This may be found in paragraph 2 under Business Ethics.

\section{Educational Broadcasting}

1. Each NAB member station shall maintain a department or else shall appoint one responsible person on its staff through whom all time for educational purposes may be cleared, and to whom educational broadcasting groups may look for guidance, instruction and development. In line with its previous policy, NAB headquarters itself will continue to furnish educational studies and aids in printed form, available to teachers and educational broadcasting groups.

2. Should a demand for educational time from a multiplicity of educational institutions and interests threaten to absorb more time than consistent with proper program balance, the station management, in consultation with educational leaders, shall endeavor to determine those common denominators of chief educational and public concern which will most benefit the educational or public needs of the area served, and so place them on the air.

\section{Children's Programs}

It is worth noting that the literature for children which continues to find their favor through many generations, offers heroes worthy of the child's ready impulse to hero worship, and of his imitative urge to pattern himself after the hero model. Such literature, whether created 100 years ago or written today, succeeds in inspiring the child to socially useful and laudable ideals such as generosity, industry, kindness and respect for authority; it opens doors into wide worlds that may be reality or fantasy, but are in neither event ugly or repellent in aspect; it serves, in effect as a useful adjunct to that education which the growing and impressionable child is absorbing during every moment of his waking day.

Through the continuous studies and consultations as outlined in the Basic Code, it is our hope and purpose to stimulate the creation of a better standard in children's programs than has yet been achieved. 
Pending the outcome of these studies, the following additional requirements will be made of children's programs by member stations:

\section{Program Content}

1. Scripts must be based upon sound social concepts and must be especially written for the child audience.

2. Programs must reflect respect for parents, adult authority, law and order, clean living, high morals, fair play and honorable behavior.

3. Programs must not contain sequences involving horror, torture or suspense, or the use of the supernatural or superstitious in a way which might reasonably be regarded as likely to over-stimulate the child listener to a dangerous or unhealthy degree.

\section{Advertising Appeal}

1. No advertising appeal through the voice of a program character will be permitted.

2. No contest or offer which would encourage a child to enter strange places for the purpose of collecting wrappers, boxtops and other evidences of purchase will be allowed.

3. No premium that depends upon its "luck-bearing" powers or in any fashion appeals to superstition will be permitted.

4. No premium or gift may be offered which is harmful to life or property.

5. When promises are made as to the benefits to be derived from the use of the product advertised, it will be necessary for the advertiser to furnish member stations with adequate proof that such promises can be kept.

6. Full details concerning the formation of radio children's clubs must be approved by the member station before the announcement of such clubs may be broadcast.

IX. Acceptance of Commercial Programs and Announcements

\section{Miscellaneous .}

Member stations shall not accept for advertising:

1. Any product, the sale of which or the method of sale of which constitutes a violation of law.

2. Any product, the advertising of which would constitute a violation of good taste.

3. Any spiritous or "hard" liquor of any kind.

4. Any fortune-telling, mind-reading, palm-reading, or characterreading, by handwriting, numerology, or astrology, or advertising related thereto. 
5. Matter which is barred from the mails as fraudulent, deceptive or obscene.

6. Matrimonial agencies.

7. Schools that offer questionable or untrue promises of employment, as inducements for enrollment.

8. Offers of "homework" except by firms of unquestionable responsibility.

9. Any race track, "dopester," or tip-sheet publications.

10. All forms of speculative finance or real estate promotion. Before member stations may accept any financial advertising, it shall be fully ascertained that such advertising and such advertised properties or services comply with all federal, state and local laws.

\section{Medical}

Member stations shall not accept for advertising:

1. Medical products or remedies which do not meet every requirement of law and regulation.

2. Medicines which are habit-forming or dangerous to life.

3. Medicines, remedies or medical services which encourage the listener to postpone diagnosis by a licensed practitioner, of a likely dangerous condition.

4. Cures and products claiming to cure.

5. Products advertised as hair-restorers, hair-dyers, wrinkle removers.

6. Reducing agents as well as foods and beverages designed solely to perform that function.

7. So-called "scientific" talks on medical subjects, by any one other than by a graduate doctor holding a degree from a recognized institution.

\section{Editing of Commercial Copy}

Member stations shall not permit:

1. The broadcasting or advertising statements or claims it knows to be false, deceptive or grossly exaggerated.

2. The broadcasting of continuity which describes, repellently, any internal functions or symptomatic results of internal disturbances, or relief granted such internal disturbances through use of a medical product.

3. Testimonial or endorsement copy not fully and honestly substantiated.

4. Unfair attacks or reflections upon competitors, competing products, or upon industries, professions or institutions.

5. Misleading statements of price or value, or misleading comparisons of price or value. 
6. The broadcasting of copy written in the first person, which would give the impression of personal endorsement by the station management, staff announcer, or other staff employees.

7. Commercial statements, sound effects, or dramatizations that violate the accepted standard of good taste.

\section{Length of Commercial Copy}

Brief handling of commercial copy is recommended procedure at all times.

Member stations shall hold the length of commercial copy to the following number of minutes and seconds.

\section{Daytime}

Fifteen-minute programs............... 3:15

Thirty-minute programs.............. 4:30

Sixty-minute programs.............. 9:00

Nighttime

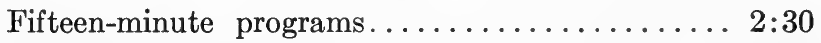

Thirty-minute programs........................ 3:00

Sixty-minute programs.............. 6:00

Exceptions:

The above limitations do not apply to participation programs, announcement programs, "musical clocks," shopper's guides and local programs falling within these general classifications.

\section{Average Number of Words per Minute}

Stations shall consider that the delivery of not more than 125 words per minute constitutes the best practice in the handling of commercial spot announcements.

\section{Diction of Announcers}

1. As radio station announcers speak, so will America. This is fundamental to radio.

It is mandatory upon all station announcers that they give a dictionary-approved pronunciation of every word spoken.

2. As radio brings the names of foreign countries, location, and statesmen into everyday American conversation, there devolves upon the announcer a duty that such names shall be given a correct pronunciation, acceptable and uniform. In the recruiting of new members for the station announcing staff, broadcasters shall give due consideration to such educational background of the applicant as may be indicative that such practices may be assured. 


\section{Handling of Accounts}

Member broadcasters shall protect the advertising rights and priorities of clients, permitting no infringement of original program ideas. This not only insures fundamental rights of "discovery," it makes also for a more diversified character of sponsored programs.

\section{Business Ethics}

1. Each member station shall maintain a public record of its current rates charged to advertisers for the use of broadcasting time together with all discounts, rebates, refunds and agency commissions which shall be allowed to the users of such time or to their recognized agents.

2. Each member station shall refuse to accept any business.

(a) on a cost per inquiry, contingent, or percentage basis, or to accord free time for commercial use.

(b) While the practice is discouraged, member stations may broadcast programs offered by outside program building organizations, either on a sustaining or commercial basis, so long as the commercial interest of the program building organization is restricted to one of identification, and so long as such indentification excludes direct selling copy for the product or service of the organization offering the program.

3. No member station shall defame or disparage a competitor, directly or indirectly, by words or acts which untruthfully call in question such competitor's business integrity, ability to perform contracts, credit standing or quality of service.

4. No member station shall claim for its service a character, scope or quality which cannot be substantiated, nor shall it claim as regular characteristics of its service features which it knows to be purely temporary or accidental. 


\section{CHAPTER XIV}

\section{AND NOW-TO TELL THE WORLD!}

One of radio's least understood oddities is this: The bestplanned radio show in the world must have its "ballyhoo." And "ballyhoo" in the show world is another word for "telling the world." This has been the showman's problem from the beginning of time. No show was ever opened, no movie ever played on Broadway or on Main Street, that did not have its "advance notices" and its advertising and exploitation. If an advertiser is spending $\$ 20,000$ or $\$ 5,000$ to put on his radio program, an added $\$ 2,000$ or an added $\$ 100$ may increase the "box office" many times over. In the show business, ballyhoo means box office; in the radio business it means extra listenersincreased circulation. An advertiser willingly pays for increased circulation in a magazine; he makes his own in radio-and either way, it costs money and effort.

To put the whole situation in advertising parlance and to quote a solid advertising authority, Mr. Ralph Starr Butler: "If your program is to sell your product, you must sell your program. . . A program is worthless without listeners."

\section{Word-of-mouth Publicity Not Enough}

To depend on the caprice of the dial shopper as many advertisers do, to depend on one satisfied listener's word-of-mouth praise of a program, will of course without one penny of extra expense eventually build a fine paying group of listeners. Some advertisers do it that way. Yet if they were asked to pay $\$ 20,000$ a week for an advertisement in a magazine that would have 20,000 circulation, on an average, for 13 weeks, then 90,000 for the next 13 weeks, and eventually millions of circulation, they would say that this had too much of the chance element to be a good purchase.

Telling the world, after all, is so simple a thing. It can cost as little or as much as the economic structure of the advertising campaign allows. It may be economically sound to spend very 
little on an inexpensive program which is planned to be kept on the air for a long time. But it is poor economy to let an expensive show build up slowly for the want of a few dollars spent in merchandising it.

So important to success do the broadcasting companies consider this phase of radio, that they have large press and merchandising departments organized to assist the advertiser along these lines.

It should be noted that radio itself uses the phrase "broadcast merchandising" to cover not only this phase of the work, but also two other important factors in radio success: telling the dealer and handling a sales-promoting idea that will help the program and the dealer sell the product. Whereas it is not necessary to put equal emphasis on all three of these phases in every type of program and because the procedure involved is so different, the author proposes to handle these three phases separately in this and the two following chapters.

\section{Advanced Radio Announcements}

Telling the world, then, is the simple procedure of advanced notice or continued notice, to obtain new listeners for a sponsored radio program. It may be done in several standard ways depending on the money available and the component parts of the program. Radio, itself, offers the first way: advanced notice of the program's opening given as spot announcements over the air. Broadcasting stations generally give the advertiser, in this case, a series of courtesy spot announcements for a week or 10 days preceding the opening of the program. No charge is made for this service. Or if the advertiser wants a really intensive advance campaign, he can buy spot announcements where available and do his own ballyhoo. These can be bought at spot broadcast rates, and spotted to cover different times of the day and different days of the week. Many stations use an off-period during the day to tell listeners of coming attractions both sponsored and sustaining. At no extra cost, the announcements of a worth-while program are included in this.

\section{Publicity}

Then there is that much-abused animal, publicity. If the stars on the program are well known, good publicity stories will 
be published. Fan magazines, radio columns, and other newspaper departments are not adverse to giving a boost to a star in the public eye. But note how rarely, if ever, a newspaper will tie in the star to the product by name; sometimes to the show itself, but rarely to the product. Good publicity stories written in reader-interest style will often, in part or whole, reach the printed word. News, real news, seldom goes begging.

But how few programs have any worth-while publicity material to offer! If you have nothing worth while, save your money and time and forget printed publicity. The author, a few years ago, was radio columnist for a well-known publication. Seventenths of the publicity material received from advertisers, agencies, and broadcasting stations would have caused his column to be dropped from the publication had it been published. A statement as purely selfish as "The Blank Company, makers of the famous Blanks, goes on the air next week featuring Billy Noname and his equally unknown orchestra-" is quite typical. The other three-tenths had possibilities: "Lucille Manners will replace Jessica Dragonnette on Cities Service Hour," "Eddie Cantor will switch from toothpaste to gasoline," and the like are news in any man's publication.

\section{The Newspaper Radio Listing}

Then there is the radio $\log$ of the newspaper. If the advertiser has selected a station important enough to be listed in the daily papers, here is "advanced and current notice" for the asking. But newspapers are not going to give the radio advertisers free advertising. And if they can possibly do it, they will make the $\log$ announcement as innocuous as possible. A service program may get no other announcement than "beauty talk," "food talk," and the like. Other types of sponsored shows may draw nothing better than "variety show," "talk, songs," "talk and music," "orchestra."

There are, fortunately, some rather fixed rules to get around this and make the radio $\log$ a real means of program identification. The first is to give your program an individual name (not containing the name of the product). Town Hall Tonight, Betty and Bob, Lum 'n' Abner, Hit Parade, Jack Armstrong, The Manhatters, are examples. Such titles may mean little to the new listener but they serve as identification to the lost 
listener who cannot remember where or when the next offering is to be on the air.

The second method is of use only if "big-name" material is on the program. Abe Lyman's Orchestra, Guy Lombardo, Charlie McCarthy (Edgar Bergen), George Burns and Gracie Allen, Lowell Thomas, and John Barrymore are names no sane newspaper would withhold from its radio fan readers. Such listings are attractions for both the new listener and the old. Such names too have an army of fans who will follow their idols from program to program, from product to product, from network to network.

\section{Newspaper Spotlight Advertisements}

Another method successfully used by many advertisers is the spotlight advertisement, a small newspaper advertisement, generally single column by 2 in., placed on the radio page if a
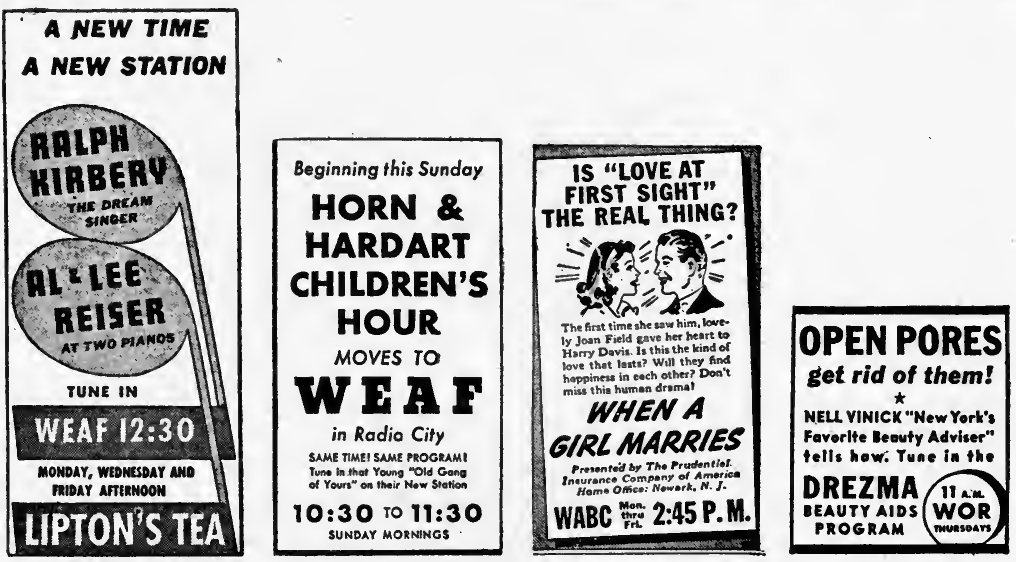

Typical newspaper "spotlight" advertisements. The Lipton's Tea advertisement not only guides regular listeners to a new station but also makes a bid for new listeners. The Horn \& Hardart advertisement is directed primarily to the program's regular listeners. The Prudential Insurance Company advertisement makes an appeal for new listeners and is written in typical show advertising form. The Drezma advertisement attempts to line up new listeners through the service, the product, and the program given.

newspaper has one or as near the radio listings as possible. Or occasionally, if nonradio fans are to be reached, placed elsewhere in the paper, for example, on the woman's page. NBC claims that at least "three-fourths of the vast army of radio listeners refer to the radio page when selecting the entertainment they 
wish to hear." 1 Even if one-quarter of the "vast army" follow their newspaper, a spotlight advertisement may be profitable. Note that these advertisements are really show advertisements and not product advertisements. They should contain the following basic elements: program title, names of stars (if any), sponsor's name, exact local time, local station call letters, and network if program is nationally presented. Human interest and new slants, as with other "show" advertisements, are most effective here. Whether such advertisements are to be used or not depends on the size of the program. A $\$ 20,000$-a-week show may justify a spotlight advertisement each week on the day of the show. For a national hookup of over 90 stations, the cost of such an advertisement in all 90 cities may run as high as $\$ 1,500$ a week. Few but big programs justify such an expense. Certainly a small special-appeal program has no place in this picture.

Another much-used method is to run spotlights only during the period when the show is building up its listening audience, the first 3 or 4 weeks or more. Even the smaller shows are justified under certain conditions in using this method to build up a listening audience.

Some advertisers use one advertisement, often a larger one, 5 in. by 2 columns, on the opening night. Only the size of the show justifies this procedure.

\section{Advertisements in Other Media}

A few years ago, when the Campbell Soup Company opened the famous Hollywood Hotel Show over a national hookup, they enlarged on this accepted method by taking a full page in color in The Saturday Evening Post to tell the world about the opening of their program. They wisely did not split the effectiveness of the advertisement by trying also to sell the magazine readers on the qualities of their soups. The small advertiser with limited means is simply outmaneuvered here.

Other advertisers have used their regular product advertisements in other media to sell their radio program, for example, a by-line at the end of the regular advertisement, "Listen to Blank Hour over Station Blank Tuesday evening at $7: 30$ P.M.,

1 "Broadcast Merchandising," p. 36, National Broadcasting Company, 1936. 
etc." This procedure, in the eyes of many veteran advertising men, is of doubtful value, except for new programs. A by-line is too small to be effective; a larger notice spoils the unity and effectiveness of the product advertising. Leading advertisers, such as the Campbell Soup Company, the Kellogg Company, the Liggett \& Myers Tobacco Company, and the Pepsodent Company, generally make no reference whatsoever to their radio offerings. Other advertisers go so far as even to include a radio announcement on their car cards.

\section{Direct Mail}

Where a specialized program is being put on the air and where a list of preferred listeners can be procured, direct-mail announcements may be used. A special announcement to music lovers upon the advent of a symphonic hour has possibilities, or an announcement to the advertiser's mailing list, if he uses it regularly for other direct-mail contact. Many advertisers have felt that an announcement to dealers is helpful. Better probably is a dealer broadside announcement which can be used for display in a dealer's store so that it may have a secondary reading by the customers.

The dealer's counters and windows should not be overlooked as a means of advanced notice of a show. Special attractive counter and window cards featuring the new show and tying in the product may lead many a reader to become a listener. (See Chap. XV.)

\section{Merchandising Stunts}

Direct advertising stunts have also been used to merchandise a new show. Anything in fact where the cost is in keeping with the possibilities of the number of new listeners contacted is worth trying. Not so many years ago, the Sheffield Farms Company wanted to get as many of their customers as possible to listen to one of the regular Liberty Magazine Radio Forum Hours on which Thomas H. McInnerney, President of the National Dairy Products Corporation, was to tell "why milk costs you what it does." On the morning of the broadcast, every bottle of Sheffield Milk delivered had a special red-and-white paper collar bearing the message "Flash! Important! Tune in 8:30 P.M. WABC Thursday night December 6th" and then 
followed on the inside of the collar a detailed list of the program offering. Another advertiser, sponsoring a national heavyweight championship bout, had tickets made up to approximate the regular admission tickets but plainly marked "An armchair seat at your Radio." These were distributed by the thousands through dealers and effectively tied the product to the event. It should be noted that in the case of events so well publicized as a national championship prizefight or a football game between leading colleges, the audience is assured and no great amount of money should be spent in acquainting listeners who already have made up their minds to listen to the event.

The basic principle to follow in deciding when and how much ballyhoo is to be used depends on the cost and the size of the program. Where the cost of the entire show including time charges is comparable with the cost of an effective advancednotice campaign, it may be cheaper to let the show build up its own listeners. This is particularly true if a popular hour is chosen. The number of dial shoppers who will check up at 8 P.M. on the well-known stations in a good-sized community is probably legion; given a good show, they will remain. Given a poor show, they or all the listeners who have been called in by expensive merchandising methods will leave.

\section{The Tailor-made Show}

There is one type of show that may need no merchandising, the sustaining program with a large following when it is purchased by an advertiser. Thus when the advertiser takes over a popular sustaining hour, a practice very much in use, he often effects quite a merchandising saving. Many broadcasting stations design their sustaining hours with an eye to selling them to an advertiser. Some go so far as even to make good-natured mention on the program itself that a sponsor would be welcome. When this type of show is in keeping with a product, when it has a proved following, it may often be an ideal purchase for the advertiser. Certainly it saves him two-thirds of all radio headaches caused by program planning, artist selection, and preliminary production work. The sponsoring of the "Information, Please" program by Canada Dry Ginger Ale, Inc., is an example of this. The show, as a sustaining feature, was said to have $5,000,000$ listeners. 


\section{CHAPTER XV \\ CONTACT-HOW TO GET IT}

A skeptical radio advertiser who was using several other media once said: "Sending out a radio program is like writing to someone who never answers letters. You never know whether the message was received, and if it was, you never know whether your instructions were followed." That he could actually contact his radio audience had never occurred to him.

There are today radio advertisers who do not want to contact their audience. They have faith enough in radio, as they have in other media, to know that a well-planned program is listened to. Many advertisers using good-will programs are in this class. If the sales are good, radio and the other advertising media used get their share of glory. This attitude is typical of the advertiser in Chap. I who calls his radio advertising the "icing on his advertising cake." Of course, if radio is the only advertising medium used, ultimate sales may be used as the criterion and no contact may be necessary.

\section{Getting the Listener's Reaction to a Program}

But the alert advertiser today wants to know his listeners' reactions. He demands contact. Such advertisers fall into two classes: (1) The advertiser who merely wants assurance that a fair number are listening, and (2) the advertiser who devises definite plans to make the listener act.

For the first, if he has a popular program, there are the popularity ratings referred to in Chap. XIX. If he has a small or local program, he will have to devise his own means for finding how many listen. This can be done by survey (telephone, letters, or interviews) in the territory covered, which is generally an expensive and often ineffective procedure for small programs. Or he may contact his audience, as many of his big brothers do, by fishing for an answer over the air. Shrewd choice of bait, 
of course, is important. Even so simple a question as "How many listeners like this program?" has brought in at least a fair "catch." An offer of a service booklet will bring results. Richardson \& Robbins in their Wednesday evening 15-min. program of music, The Revelers, offered a recipe book for making sauces to go on the $\mathrm{R} \& \mathrm{R}$ Plum Puddings mentioned in the program's commercials.

Note that offers of this type not only show evidence of listeners but also allow the advertiser to continue his selling talk in the booklet sent out. This method is almost standard procedure with many radio advertisers. The number of replies they get depends naturally on the number of listeners, but a more important factor is the attractiveness of the offer made in the announcement and the probable usefulness of the booklet to the listeners. Obviously "Send for our catalogue on indirect lamps," will not compare in results with "Here is a booklet that tells you how to have safer, more convenient lighting in your home and save money at the same time." It did not take radio to teach the advertiser this fundamental lesson in advertising.

\section{The Free Offer over the Air}

Another good bait in season is the free offer ${ }^{1}$ of a novelty which will appeal to the general listener. Here the returns will depend on the value of the novelty. If the offer is too good, the advertiser will hear not only from listeners, but from friends and neighbors of listeners who have been told by word of mouth about the Santa Claus of the air. Also Santa will hear several times from the same listener. Thus the very purpose of the novelty offer may be defeated. It is well then to keep the free offer down to something with no intrinsic value.

Columbia Broadcasting System, as already mentioned, in checking up on the number of listeners so that it could make its first coverage maps, offered an inexpensive radio game and a puzzle. Several offers at different times over the entire system brought in 400,000 requests. Recently Columbia repeated the offer. This time a map was offered in the evening, a simple game in the day. The average length of the spot announcements was 40 sec. Announcements were made at various times of

${ }^{1}$ For other types of offers and for contests over the air, see Chap. XVII. 
the day and evening for one week only. There was no advanced publicity, no ballyhoo, no build-up. A total of 520,155 families responded. ${ }^{1}$

A caution here to the advertiser with limited means. Weigh well the entire cost of such offers before trying them out. The offer itself, the packing, postage, clerks' time may amount to a formidable figure. And there is no way to tell whether the returns will be 40 or 40,000. Many advertisers have been embarrassed by having their stock of gifts run out. One advertiser who bought up a few thousand attractive novelties at a negligible price, and who had failed to limit his offer in his announcements, was financially embarrassed when he was called upon to deliver not a few thousand but many thousand of the novelties. The free novelty offer has been greatly overdone and is of doubtful economic value. Certainly, it has been overexploited by some advertising agencies which have felt that, if they could not show an advertiser some tangible results as to number of listeners, the advertiser would close out his program.

Free samples of the product have been used over the air as offers. The results both in cost and in effectiveness parallel such offers in other advertising media.

\section{The Actual Sale of Goods over the Air}

The second type of advertiser, he who decides to make the listener do more than merely prove he is listening, includes those who demand either part or full payment for their offerings or that the listener prove that he is a user of the product; or that he contacts the dealer. Economically these procedures are sound for they give evidence not only of listeners but better still that the listeners are familiar with and possibly using the product. Many advertisers who have popularity rating to prove the number of listeners, use their program to sell goods in this roundabout fashion.

Some advertisers seem to go so far as to forget the objective of their radio advertising and use the program as a bold and often distasteful counter to sell their goods. "Send three box tops

1 "Listeners and Dealers," p. 239, Vol. II, Columbia Broadcasting System, 1938. 
from X Health Food and receive, etc." is undisguised premium selling. Radio's misfortune is that certain advertisers who follow orthodox methods in their newspaper and magazine advertising become outlaws over the air, shamelessly commanding a 7-yearold child to procure one or more box tops for an overdescribed and often almost valueless gadget or trophy which disappoints the child the minute he sees it.

Such advertisers should know that surveys seem to show that products so introduced into a home rarely become repeat items. For repeat sales and good will, success comes to the advertiser who does not exploit the listener. This advertiser sells his goods on their own merits, not on their premium values. For its own protection radio might do well to add to its censorship rules, certain hard and fast regulations to control the advertiser who says in effect: "Never mind future good will; give me today's sales."

This does not mean that demanding money from the listener or even, upon the proper occasion, demanding box tops as the consideration should not be done. It merely means such offers should be tempered with good judgment and some conception of ethics.

\section{Novelty Offers}

Offers which pay for themselves can be safely used by the advertiser. A novelty for 10 cents, if that amount will cover also the cost of mailing, can do no harm. It may create good will; it certainly will give evidence of the number of listeners. A novelty-or a premium-depending on the sending in of one or more box tops also can well pay for itself. Advertisers have, however, as already pointed out, received much adverse criticism from the listening public because of this type of offer-particularly when made on a children's program. One Sunday newspaper devoted almost a page to a scathing criticism of the practice, entitling the article, "The Box Top Horrors."

In all these types of offers where the public must pay in part or in full, the advertiser will do well to check his plan carefully before putting it into operation. The Better Business Bureaus, the Federal Trade Commission, and the United States Post Office have quite definite rulings on what can and what cannot be done in this connection. 


\section{Analyzing Results of Offers}

Many advertisers prefer to have their offers handled through the dealers themselves. This has its advantages and disadvantages, as pointed out in the following chapter.

Radio offers many classic examples of response to offers over the air. The advertiser should not be carried away by such startling examples. In some cases, where the novelty offered was distributed by dealers, countless requests must have come from those hearing about the offer through friends and dealers rather than those actually hearing of the offer over the air. For instance, in 1935 the Sinclair Refining Company offered children a free stamp album and a series of colorful poster picture stamps. One evening announcement distributed over 1,000,000 sets in 48 hours at the dealers. As fine as this record is for radio, the $1,000,000$ should be discounted because of the dealer influence. Likewise in 1936, the Household Finance Corporation, from a single evening broadcast offer over 18 stations, received 250,000 requests for an Edgar Guest calendar.

So many factors have influenced the distribution of offers that past records should not be taken too seriously. A few of the 1938 records follow: ${ }^{1}$

Gilmore Oil Company. Gilmore "Mike," a radio publication. Announced 6 months over the air. 1,850,000 distributed at dealers.

Gallenkamp Stores Co. entry blank for contest announced over 4 Pacific stations. Procure at dealers. 500 to 600 letters per week.

Canada Dry Ginger Ale, Inc., "Information, Please" program. Send in questions for cash prizes. 10,000 letters received the first week.

To sum up, when it comes to contacting the listener over the air, the advertiser should realize that for every listener with energy enough to send in for the offer, there are many other listeners who, after all, just listen. Whether this proportion is 1 to 100 or 1 to 5,000 , is not so much the question as is this: even a few hundred inquiries is indicative of many, many more listeners. One advertising writer paralleling this to the printed media puts all readers into two classes, those who write and those who walk to the store and buy the product.

1 "NBC Radio Offers and Contests of 1938." 


\section{Importance of Cost}

A final caution on offers is that the advertiser should check and recheck his costs in planning such a move. Every possible expense should be allocated and a definite figure arrived at in terms of cost to contact a single listener or cost per 1,000 listeners. Then, the advertiser should say: "And suppose there are 100,000 listeners who write. Can I still 'afford to make this offer?" If not, he should either give up the idea or limit the offer to 10 days - or safer yet, to a specific number of units. 


\section{CHAPTER XVI}

\section{KEEPING THE DEALER INTERESTED}

Experienced advertisers have a little campaign slogan of their own: "As the dealer goes, so goes the campaign." The day of creating consumer demand without the cooperation of the dealer is fast passing. Radio, or any other medium, that is not keyed to the dealer (or the distributor) is not getting its advertiser even 50 cents on his advertising dollar.

\section{Dealer Merchandising Defined}

Much in the advertiser's bag of tricks which he has collected from experience in other media can be adapted to radio. But radio also has a bag of merchandising tricks all its own. Radio dealer merchandising is different basically in that its interests can seldom be bulked with the general dealer campaign. To be successful, radio merchandising must keep its identity. General merchandising sells the product; radio merchandising sells the program and ties in the product. This is reasonable when we consider that every new listener obtained (dealer or dealer's customer) is increased circulation for the program which, when it is listened to, does its own selling. Advertisers with house organs, i.e., little magazines of their own making, are up against the same problem. They must first build a reader following which, when it reads the house organ, is influenced by, the advertising and good will the house organ contains.

Another important difference. Radio has always been on the defensive when it comes to establishing close association between the product and the program identity. Advertisers are ever complaining. Tell me, they say, not how many listen to my program but how many who listen can identify the product. A good radio program is planned from the very start with this important feature in mind. Some admirable jobs have been done: Jack Benny and Jell-o; Charlie McCarthy and Chase \& Sanborn. But additional help is needed and dealer merchandis- 
ing offers it and explains why the shrewd advertiser in his dealer tie-ups goes to such pains to make a close association between his product and his show. The author is not implying that the radio program cannot complete its own association, but rather that with successful visual dealer helps, the job is easier.

Most authorities would probably point out the Jell-o program as one that had done most of its association work on the air. The Chase \& Sanborn program, on the other hand, depends for its association of program and product on the help of visual aids-a window card showing Charlie McCarthy lovingly holding a bag of Chase \& Sanborn Dated Coffee, Charlie's wooden face peering out from magazine advertisements. Maxwell House Coffee, too, have depended much on visual help for good productprogram association. One conclusion might well be drawn here: If the program is particularly well designed for productprogram association, extensive merchandising for association may not be necessary.

\section{Objectives of Radio Merchandising}

But product-program association after all is only a phase of radio dealer merchandising. The real objectives, and there are others, might be listed somewhat as follows:

1. Selling the program to the dealer to gain his good will.

2. Selling the program to the dealer's customers.

3. Helping the dealer to sell more of the product.

In deciding how far to go with each of these, caution should be used in exploiting the dealer for the advertiser's selfish ends. Picture the desirable dealer as a busy man, hard put to make a profit on his business. A favor to you that costs him time and effort, he will not do. He will ask himself: "What do I get out of this? Will the idea really sell more goods for me?" To ask him to distribute toy balloons free to children on a busy Saturday morning or to expect him to pass out literature or contest coupons, unless extra sales value is emphasized, will seldom work. A toy balloon with each loaf of bread sold, or a contest coupon when the dealer receives a special prize if his customer wins, that is a different story.

Also the cost of these different merchandising stunts must be considered. The small radio advertiser must choose more carefully among the wealth of merchandising ideas than the national 
advertiser. But even if the program is on a spot station and is small fry compared with the big shows, the advertiser will find some inexpensive merchandising helps which may mean the difference between the success or failure of the campaign.

\section{Selling the Program to the Dealer}

The first objective of dealer broadcast merchandising is the simple one of selling the program to the dealer. Any step to gain the dealer's good will may be included. "This program comes to you in the interest of 446,000 grocers whose duty it is to serve you and millions of others" is approximately the way the Best Foods, Inc., ${ }^{1}$ cover the good-will angle. The Bayer Aspirin program, American Album of Familiar Music, generally contains some such announcement as this: "If you have enjoyed this program sufficiently to thank someone for it, thank your druggist, etc." Or Ford's "Presented by the Ford Dealers of America."

Other methods used actually to sell the dealer on the program are (1) mailed announcements to the dealers telling them about the show, its stars, and pointing out the dealer's advantages in publicizing the news, (2) broadsides which can be hung up in the store, (3) broadcast tickets for the dealer and for distribution by the dealer, (4) announcements in trade-paper advertising. Anything in fact that shows the dealer that the program is functioning in his interest is useful in selling the dealer, subject always to the cost for such promotion. Obviously to send announcements to 446,000 grocers each week may cost the advertiser close to $\$ 10,000$. Better to have a preferred dealer list and even then announce only the opening of a new show to the dealer, or some outstanding feature at long intervals.

Sometimes the advertiser prefers to accomplish this contact with the dealer through the advertiser's salesmen. The salesmen are given special selling talks and information on the radio program which they in turn relay to the dealer. If salesman cooperation can be depended on, this is an inexpensive and effective method.

${ }^{1}$ It should be noted that Best Foods, Inc., and most other large radio advertisers do not consider this enough. Back of this simple statement Best Foods, Inc.; used a complete broadcast merchandising campaign. See “Broadcast Merchandising," National Broadcasting Company, 1936. 


\section{Reaching the Customers through the Dealer}

The plan of reaching the customers through the dealer, if well done, not only sells the dealer himself, but builds up an army of extra listeners and, as already pointed out, establishes a visual association in the mind of the customer between product and program. Window announcements, counter and window cards, counter literature, and novelties are in this class, anything in fact that the dealer can give or show to his customers.

Counter and window cards are subject to the same limitations found in general merchandising. They should fit the type of store, should be outstanding enough to be presented and not left to gather dust in the storeroom. Also, for radio they should be designed to feature the program and its stars and not to sell the product or the product's merits. The product and the sponsor should, of course, be displayed on the card. Where stars very much in the public eye are featured, the card is more likely to be displayed.

Novelties used in this connection should be close to the program and if possible close to the product as well, a difficult thing to do. Cutouts of the stars, if they are famous ones, and pictures of the radio cast, have been successfully used. Perhaps one of the closest tie-ins has been the Charlie McCarthy spoon. Charlie McCarthy for program tie-in; the spoon for Chase \& Sanborn coffee.

Distributing novelties through dealers has its objections. If the novelties have intrinsic value, many of them may get into the same hands. If their popularity becomes great, a burden may be worked on the dealer in taking care of them. Where the manufacturer controls or has close contact with his dealers, better cooperation can be obtained. The Sinclair Oil Company announcement over the air to drive into a Sinclair Service Station and ask for a free Dinosaur Poster Stamp Album plus 24 colorful poster stamps of prehistoric animals was mentioned in Chap. XV. The offer was aimed at children, who had to be accompanied by adults when calling at the station. Within 48 hours, 1,000,000 albums had been distributed. The "papa "Milquetoasts" who accompanied their children probably bought at least 5 gallons of Sinclair gas each, which impressed the dealer. Note that in this case fine dealer cooperation could be expected. 
The same offer through 446,000 grocers would have been next to impossible and decidedly costly.

Where novelties are offered for a consideration such as box tops or money, the general practice is for the advertiser to send the novelty direct. The Charlie McCarthy spoon and also an earlier Chase \& Sanborn offer, a 22-in. cutout of Charlie, were in this class.

\section{Helping the Dealer to Sell the Product}

This type of merchandising includes such helps as definitely assist the dealer to sell more goods. It may well be claimed that any merchandising help will sell goods. But many dealers in their simple reasoning want to see definite results. Thus a merchandising stunt that brings customers into the store will convince some dealers. Frigidaire, a few years ago when they were featuring Seth Parker on their radio program, offered an attractive colored print of the ship in which Parker was to travel around the world. To procure the print, the prospect had to call at a Frigidaire dealer's. This beyond a doubt offered certain worth-while contacts and the alert dealer was able to procure names and addresses in many cases. The offer of tickets to Ford broadcasts procurable at a Ford dealer's again offers the aggressive dealer a chance to make a contact.

On the other hand, an offer to pick up an inexpensive novelty at a drug or a grocery store will not be so effective because the amount of the possible sale is small and the merchant generally too busy to give much time to this type of prospect. Dealers of small-item merchandise prefer the plan that shows actual sales. All box-top offers or novelties with a sale of the product are more attractive for these dealers although even here, the merchant may not want to clutter up his store with the novelties. This is one reason why so many offers are a direct transaction between the advertiser and the customer. True, the customer must buy the product at the dealers, and the advertiser should see that the dealer associates these sales with the radio program.

Often the dealer can be sold on really cooperating with the radio tie-up, if he is sold on the possible results. The radio window display of radio-advertised products is one of these merchandising ideas Where the advertiser can offer actual attractive material for window dressing and where the display 
has an attention-getting value, this plan will be found effective. Radio advertisers, for example, may feature a special offer before hand on the idea that by displaying the goods in the windows it will bring in business.

Other media, particularly magazines, talk of dealer prestige; at least one large national weekly can offer proof that dealers prefer to have the manufacturers of goods they carry advertise in its pages. Radio has at least one survey which indicates that dealers prefer radio to other media. Radio is generally a weak second to magazines when dealer prestige is considered and this seems to be true because of the lack of permanence in the radio presentation. Until advertisers merchandise their dealers more thoroughly and show dealers results, radio can scarcely usurp first place from the magazine.

Much of the success of dealer merchandising depends on the originality and attractiveness of the presentation. Just another piece of radio merchandising will not do. Also haphazard hitand-miss merchandising has no place in successful radio advertising campaigns. Plan merchandising campaigns carefully and carry them through; see that they are coordinated with the radio program and timed properly; sell your own salesmen on the advantages so that they can pass your enthusiasm on to the dealers.

\section{Examples of Merchandising Campaigns}

The following examples of merchandising campaigns are given more to show the advertiser how extensively some manufacturers go into this type of work than to suggest that any other advertiser could use the same plan without first adapting it to his product, his marketing situation, and his pocketbook.

\section{Best Foods, Inc.}

1. Window announcement in the form of a combination broadside and window display.

2. Membership "Certificate" to the Merry Musical Grocers' Association presented to all grocers who verified the fact that they had heard the program.

3. Poster stamps 3 by 3 in. given to the dealer for distribution. Grocers used them on packages sent to customers and Best 
Foods pasted them on all correspondence to dealers and the general public.

4. Celluloid button to be worn by the grocer's clerk to remind him and his customers to tune in every Friday night. Between 30,000 and 40,000 were ordered to supply the demand.

5. Trade-paper advertisements showing the radio artists in costume of the program.

6. Radio party given the night of the broadcast by suburban stores. With Best Foods and local cooperation these parties were said to be a great success and decidedly inexpensive.

\section{Lehn \& Fink Merchandising, 1934}

1. Display cards distributed to 15,000 druggists before the initial broadcast, many being placed by the company's own salesmen.

2. Display cards for chain stores with special "Want List" pad and a picture of the star on each of the broadcasts for the entire series.

3. Four-page folders giving entire list of artists and program dates for over-the-counter distribution to customers.

4. Small stickers featuring the series prepared for pasting on correspondence.

5. Tie-in reference to programs on all current advertising.

6. Special tie-in in advertising to Drug Trade Press.

7. To 1,900 leading druggists a Jumbo Telegram signed by the radio star, sent out on the day of the opening of the program.

8. Personal letters to executives of leading chain, syndicate, and wholesale drugstores.

9. Newspaper spotlight advertisements.

10. In metropolitan area, broadcast tickets used to gain window display.

11. Photograph of star offered on first broadcast in return for a carton top of product.

12. Pair of night gloves offered to listeners on third broadcast in return for carton top.

13. Every 3 weeks, follow-up letters to drug organization buyers.

14. Salesmen of advertiser continually instructed to "talk up the program." 


\section{CHAPTER XVII \\ SHALL WE HAVE A CONTEST?}

When the reader has weighed the pros and cons of radio contests as discussed in this chapter, if he still is in doubt, the answer to the question "Shall we have a contest?" is definitely No. Probably more unexpected grief and extra costs have been dropped on the radio advertiser's doorstep from contests than from any other type of the radio "doubtfuls."

And yet contests have paid and paid nobly in some cases where every precaution was taken to anticipate every kind of trouble a contest can bring, and where the advertiser profited by every bit of experience and advice he could procure. Certainly when it comes to audience response, if that is all the advertiser wants, a contest cannot be excelled.

\section{Impossible to Limit Size of Contest}

But he should look before he leaps. More often than not a contest which actually sells 500,000 extra boxes of a product may bring with it extra expenses which will eat up that extra profit-and more. Never figure on having a little contest. Even a program with practically no audience mail may develop a blizzard of contest letters, enough to demand the full-time attention of a corps of extra clerks in a special office loft of their own and at a cost which may be out of all keeping with the profit - cash or publicity-which it brings. If the advertiser has anticipated this expense beforehand, no harm is done, but if he has not, the current year's earnings may show a startling drop.

Fortunately for the radio advertiser who is contest-minded, the broadcasting companies are keyed to advise intelligently on what may happen. Also in some of the big cities there are companies which make a business of promoting and handling all the details of contests. Some of them, through their vast experience, can carry the advertiser safely through this difficult 
and poorly charted channel. Successful contests there always have been and there always will be, but when all the votes are in probably the contest loses. Certainly the broadcasting companies themselves do not go out of their way to suggest contests.

\section{What a Radio Contest Can Accomplish}

Let us see what a radio contest can do for the advertiser. It probably cannot be excelled for quick response and if the sale of the product is directly tied to the contest it may not be excelled for quick sales as well. A contest then is admirable to launch a new product quickly or to reduce accumulated stocks on the dealers' shelves. Next, because more listeners are interested in contests than in the product, the advertiser can exploit this army of "contest hounds" for at least one try at his product. If the product is outstandingly good, they may become regular users. That is the hope of most contest advertisers. But surveys seem to show that a goodly percentage of these will not repeat. Their interest in the product is gone with the prize money they do not win.

And next, because the contestee once on the scent of prize money will eat, sleep, and talk the product, the advertiser probably will get much publicity for the brand name and for the product and its uses, especially if he ties this information into his contest plan. He can even encourage new users and discover undreamed-of uses, some of which may be well worth all the cost and headaches of any contest. The advertiser's name and his product may literally be on everyone's lips. Thousands of dollars in priceless publicity and word-of-mouth praise may be developed. This is the contest at its best, the goal which 10 advertisers strive for and only one reaches.

\section{For Every Winner, Ten Thousand Losers}

How about the other nine? What might happen to them and their contest? The experience of all nine will probably be different. It may be no worse than a severe case of ill will on the part of the contest losers, who may, however, number 10,000 for every one prize winner. Angry letters every contest advertiser will get. John Q. Public in the mass is a peculiar fellow. A dozen or even a hundred ill-will letters can always be 
expected; 10,000 is not an improbable number, especially if all the rules for conducting a successful contest are not followed. Monte W. Sohn, Vice-President of Picard-Sohn, Inc., gives a typical example ${ }^{1}$ of the lower mass-group reaction. Amusing when taken as one letter, but it may still reflect the reactions of the thousands who did not write:

\section{Gentlemen:}

I wouldn't buy one of the Kitchen Mechanic Mashines you make under no circumstances. My wife and myself worked of two weeks on your contest, and our answer should have entitled some kind of prize but no. You did not even tell us who got it. We know now, you dirty crooks because you were afraid it would show you got it. Probly some relatives got these prizes. I have told George Simpson from who I buy lumber as well as hardwear if he carries your lousy Mashine I will buy all my need from someone who don't.

\section{Yours}

(Signature)

Dear old John Q. does not seem to know that the Post Office, the Federal Trade Commission, and the Better Business Bureaus are watching his interests and that a radio contest of any great size could not be basically crooked even if the advertiser wanted it to be. But rather John Q. is skeptical and always a poor loser. Unless means are taken to offset this natural reaction, it would be far better not to run the contest at all.

\section{Objections to Radio Contests}

Other generally accepted objections to contests, besides the creating of ill will, are as follows:

1. There is likely to be too much emphasis on the contest and too little on the product and its merits.

2. The prestige of the advertiser and his product may be cheapened.

3. The impulse to purchase the product is not founded on genuine desire.

4. Contests do not build permanent additions to sales.

5. Uncertainty concerning the response makes it difficult to estimate the cost of the contest.

${ }^{1}$ Monte W. Sohn, “Radio Contest Blues," Printers' Ink Monthly, March, 1932. 


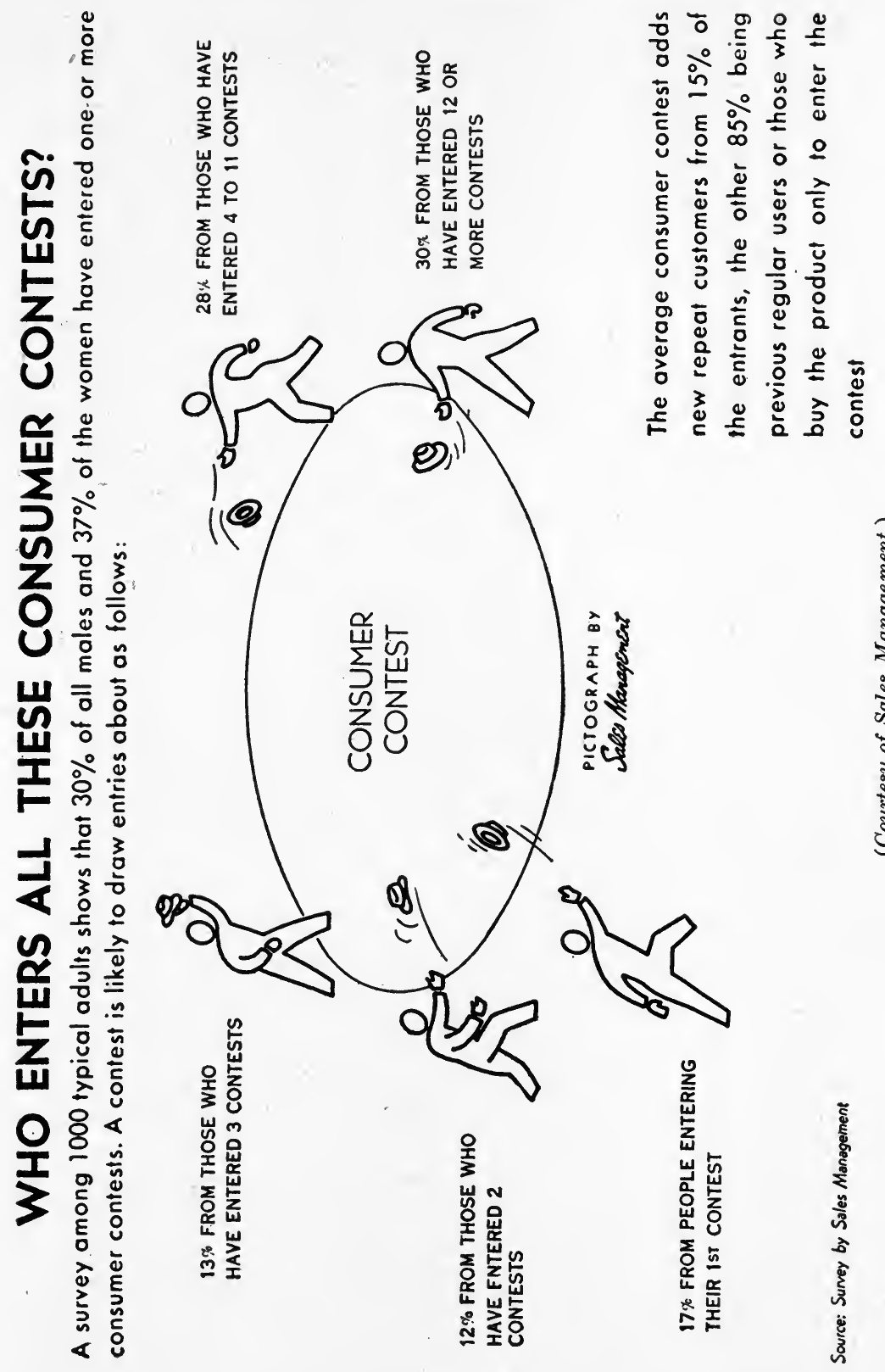


6. Skepticism on the part of the public as to whether its entries are read and whether judges' decisions are unbiased may create permanent ill will.

7. The number of professional contestants and racketeers who take advantage of an illegality in the contest procedure to sue for damages is increasing.

8. Dealers may be disinterested.

Many of these objections can be overcome by careful planning. Emphasis can be put on the product, as with contests offering prizes for new uses. Skepticism can be forestalled by acknowledging all entries, by emphasizing the fairness of the judges, by notifying all contestants of the winners. Dealers can be made to take an interest in a contest, if they are made an integral part of it, perhaps an extra prize offered to the dealers from whom the consumer prize winners get their contest blanks. One large. advertiser even included a worth-while money prize for the clerk. who handed out the coupon to the winner. There was a place for his signature as well as the dealer's on each coupon.

\section{The Law and Contests}

To be legal just how must a contest be conducted? Whereas any contest of size must use the United States mails, let us see what the Post Office has to say in this connection. Sec. 473, Federal Postal Laws and Regulations, reads in part:

No letter, package, postal card or circular concerning any lottery, gift enterprise, or similar scheme offering prizes dependent in whole or in part on lot or chance . . . shall be deposited in or carried by the mails of the United States. . . .

The Federal Communications Act of 1934 carries a similar warning. The fine is $\$ 1,000$ or imprisonment or both. Note first then that a contest cannot be a matter of mere chance winning. The word "luck" must not even be hinted at. But there is no law against a contest of skill. Therein lies the open path for the contest advertiser. The contest must be one of skill, even so simple a skill as writing a best essay or letter or digging out the number of words which can be built from the letters in the product's name.

Even here the authorities may not agree with the advertiser where skill begins and chance leaves off. Nor will the fact that a contest idea has been used before be a safe criterion. The 
Post Office considers each contest as a new case. Certainly their approval should be obtained in all matters pertaining to contests. Hershel Deutsch in discussing contests in an article ${ }^{1}$ says:

Under no conditions should an idea be prepared without official approval of the finished form. Regardless of how many competent lawyers have passed on it and how many other contests of identical nature have been used, this presentation for the postmaster's approval must not be omitted. The law is dangerously broad and the postmaster's interpretation is all that matters.

\section{Making the Instructions Clear}

Besides this, the contest must be as nearly foolproof as possible. If instructions are not clear enough for a 9-year-old boy to understand, the advertiser may have to answer thousands of unnecessary letters. He will have to answer enough anyway, for there are always a few enthusiastic contestants who will not try to understand the simplest instructions.

Then, too, if there can be any misinterpretation of the contest offer itself, more trouble may arise. One advertiser a few years ago made a modest contest offer in which he thought he was offering one or at the most three prizes. His offer, however, was ruled to offer the prize to all who got the correct answer. He gave out over 250 prizes. Fortunately, they were not large nor the contest a very popular one.

Then we have that shrewd class of contest followers who are looking for trouble. Suits have started, honestly and otherwise, over the interpretation of the offer. A lawyer, for example, entered a suit for $\$ 25,000$ damages on the following basis. The contest offered a prize for the most logically worded letter. The prize went to probably the best entry submitted but the lawyer claimed he could prove it was not as logically worded as his-and a lawyer ought to know. The advertiser here made two serious errors: one in using the word logical in his offer, and the other in publishing the winning letter. Announce the prize winners by all means, but seldom if ever give their answers verbatim to the public. A comparison of a winning entry with a losing one can bring nothing but dissatisfaction.

${ }^{1}$ Hershel Deutsch, "Keeping Your Contest within the Law," Advertising \& Selling, Dec. 9, 1931. 


\section{Free-entry Contests}

There is a big difference, too, between contests with free entry and contests with entries depending on the purchase of the article. Where entry is absolutely free, the consideration of chance does not necessarily make the contest a "lottery." Note that the purpose of this chapter is not to offer a guide to the contest-minded advertiser, but rather to impress on him the importance of seeking professional advice in this hazardous business.

Clowry Chapman ${ }^{1}$ says in this connection:

There is no law which prohibits the gratuitous distribution of one's property by a lot or chance. If the distribution is a prize, gift or bounty, and not in name or pretense merely, which is designed to evade the law; if it be entirely unsupported by any valuable consideration moving from the taker, there is nothing in this mode of conferring it which is violative of the policy of our statutes condemning lotteries or gaming.

\section{Choosing the Type of Contest}

It is claimed that contests, radio or otherwise, run in cycles, their peaks coinciding with periods of depression when people have not only time to work on them but added need for prize money. Contest incentives should be considered, then, in deciding on the type of contest. The incentives are (1) entertainment, (2) education, and (3) financial gain.

Contests in the first group would include puzzles, contests of skill governed mostly by the zest of winning. The second group would include word-building contests and those which add to the useful knowledge of the contestant. The third group would include those contests with large cash or merchandise prizes. There will always be a considerable number of listeners in each of these groups. The first and second groups will probably contain a better and more loyal type of prospect. The third group, working for financial gain, will have, on the average, scant respect and often little use for the product. Of course, the third group will yield the greatest number of contestants.

1 Clowry Chapman, "The Law of Advertising," p. 252, Harper \& Broṭers, 1929. 
From the advertiser's standpoint, there is another decision to make. Shall the contest be open to all or limited to the purchasers of the product? The first group will naturally have the more entrants and ordinarily can be offered smaller prizes. The second group, if the contest is to be popular, must be offered large enough prizes to make the gain well worth while. Less ill will probably will result from the free-entry contest.

Ill will can be lessened, if the requirements of the contest are easy. Much work to be done not only drives away entrants but makes the losers more disgruntled. To ask a listener to spend hours to prepare his material for the contest entry is obviously unfair, yet many advertisers make this mistake. Word-building contests and essays of any length are examples. Writing contests, by the way, automatically bar many of the worthy uneducated who are often the advertiser's best prospects.

A list of various types of contests used over the past few years follows. Many of these types were used by radio advertisers.

Essays (about product or general subjects)

New uses for the product

Limericks or poems

Slogans

Name for product

Word building

Puzzles

Advertisement writing

Answers to questions

Recipes and menus

Childrens' bright sayings

Snapshots (general or close to product)

Titles for pictures

It is well not to use a contest which requires valuable material from the listener, a snapshot, for example. The advertiser may specifically state that no material will be returned and yet he may find stamps enclosed and demands that the material be returned.

\section{Prize Money}

There will always be this unsettled question: Shall we give a large number of small prizes or a small number of large prizes? If the contest is on a financial-gain incentive alone, certainly 
large prizes will bring the most contestants. Yet for the other incentives, a large number of small prizes is probably more desirable.

\section{Suggestions for Conducting a Contest}

No list of rules for conducting a successful contest could ever be written. As already pointed out, there are unforeseen bugaboos which can spring out from the most carefully planned contest. However, there are certain fundamental suggestions which can help. To follow all of them can run the cost of the contest beyond economic limits. In a general way, the contest should require little work from the entrant, should be easy enough to appeal to as large a group as possible, should anticipate every possible thing which might lead to ill will.

It has been said, for instance, that nobody ever hears who wins a contest. A single announcement over the air or in newspapers never seems to reach even a fair percentage of the contestants. Listerine, in a prize contest given a few years ago, in order to be sure that every contestant should know the winners, actually sent a printed list of all winners to every contestant. The list contained several thousand names and addresses and undoubtedly convinced every contestant as to the fairness of the contest and thus allayed much ill will. Yet what a fine mailing list this made for mail-order advertisers.

The merchandising department of the National Broadcasting Company gives the following 15 suggestions for conducting a contest:

1. Make rules simple and specific.

2. If it is possible to put printed rules in the hands of each entrant so much the better.

3. Be definite as to where entries are to be sent.

4. Be definite about closing date of the contest.

5. Acknowledge each entry promptly.

6. Give large number of small prizes rather than small number of large prizes.

7. Give each contestant a souvenir or sample of product.

8. Give all an equal opportunity.

9. Announce winners promptly.

10. Publish names of winners.

11. Pick prominent judges. 
12. Make contest of short duration.

13. Protect names of contestants and use them carefully.

14. Answer special letters.

15. Sell the product in the contest.

Some of the outstanding radio contests of recent years with their results ${ }^{1}$ follow:

F. W. Fitch Company

(Hair preparations)

Contest: Listener to write verse.

Requirements: Send empty carton to nearest NBC Station.

Stations: 20 on Red network.

Time: Sundays, $7: 45$ to 8 P.M.

Duration: September, 1933, into 1934.

Results:

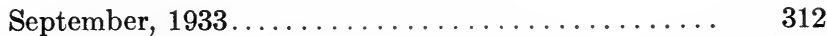

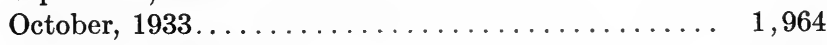

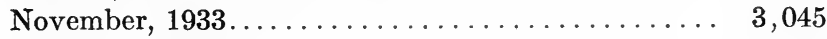

December, $1933 \ldots \ldots \ldots \ldots \ldots \ldots \ldots \ldots \ldots \ldots, 401$

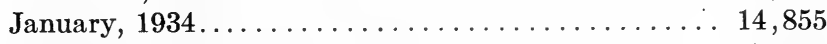

February, $1934 \ldots \ldots \ldots \ldots \ldots \ldots \ldots \ldots \ldots \ldots \ldots \ldots \ldots \ldots \ldots, 7,648$

\section{Great Atlantic \& Pacific Tea Company}

Contest: 35 words in answer to question.

Requirements: Coffee label.

Stations: 20 on Red, 9 on Blue network.

Time: Monday 9 to $9: 30$ A.M. Daily except Saturdays and Sundays 6 to 6.15 P.M.

Duration: March 28 to April 7, 1933.

Results: 57,329 .

\section{Borden Ice Cream Company}

Contest: Prize twisters.

Requirements: None.

Station: WMAQ.

Time: Friday 7:30 to 7:45 P.M.

Duration: February to December, 1933.

Results:

1 From "National Broadcasting Handbook on Offers and Contests," National Broadcasting Company, 1934. 


\begin{tabular}{|c|c|c|c|c|c|c|c|c|c|c|c|c|}
\hline \multirow{2}{*}{ CLIENT } & \multicolumn{12}{|c|}{1938} \\
\hline & JAN & FEB & MAR & APR & MAY & JUN & JUL & AUG & SEP & OCT & Nov & UEC \\
\hline Amer ican Tobacco Company & $\longmapsto$ & & & 4 & & & & & & & & \\
\hline Bristol-Myers Company & & & & & & & $\longmapsto$ & & & & & \\
\hline Brown \& Willianson Tobacco Corporation & $H$ & & & & & -1 & & & & & & \\
\hline Canada Dry Ginger Ale, Inc & & & & & & & & & & & $\longmapsto$ & \\
\hline Cities Service Company & 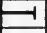 & & & & & & & & & & & \\
\hline Cummer Products Company (Energine) & & & & & & & & & $\longmapsto$ & & & \\
\hline$"$ " $"$ (Molle) & & & & & & & & & $\vdash$ & & & \\
\hline Fels and Company & & & & & & & & & & $\longmapsto$ & & \\
\hline F W Fiten Concany & & & & & & & & & $\mathrm{XX}$ & & & \\
\hline Gallenkamp Stores Company & & & & & & & & & & & & \\
\hline General Electric Company & & & & & $\longmapsto$ & 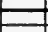 & 4 & & & & & \\
\hline General Foods Corporation (dell-0) & & & & & & & $\longmapsto$ & & $\longrightarrow$ & & & \\
\hline " " " (Naxwell House Coffee) & $\longrightarrow$ & & & & & & & & & & & \\
\hline " " (Post Bran Nlakes) & & $\mathrm{X}$ & & & & & & & & & & \\
\hline General Mills, Inc (Bisquick) & & & & & & & & & $H$ & & - & \\
\hline " " " (Wheaties) & & & & & & & & & & & -1 & \\
\hline Gilmore Oil Company & & & & & & & & & & & & \\
\hline S C Johnson \& Son, Inc & & & & & & $\underline{X}$ & & & & & & \\
\hline George W Luft Company & & & & & & & & & & $\longmapsto$ & & \\
\hline " " " " & & & & & & & & & & & & -1 \\
\hline Macfadden Publications, Inc & & & H & & & & & & & $\longmapsto$ & & \\
\hline Miles Laboratories, Inc & $\underline{X}$ & & & & $H$ & & & & & & & \\
\hline C F Mueller Company & & & & $=$ & $\longrightarrow$ & & & & & & & \\
\hline National Association of Ice Industries & & & & $=$ & -1 & & & & & & & \\
\hline Neni, Inc & & & $\longmapsto$ & Z & & & & & 4 & & & \\
\hline Nestles Milk Products, Inc & & & & & & & & & & $\longmapsto$ & & \\
\hline Oxo, Ltd & & 4 & & & & & & & & & & \\
\hline Penn Tobacco Company & & & & & & & & & & & $\underline{X}$ & \\
\hline Princess Pat, Ltd & & & & & 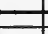 & 4 & & & & & & \\
\hline Procter and Gamble Company (Camay) & & & 4 & $\square$ & 4 & & & $\longmapsto$ & $\longrightarrow$ & & & \\
\hline " " " " (Chipso) & & & & 3 & & & & & & & 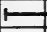 & $\rightarrow$ \\
\hline$" \quad " \quad " \quad($ Crisco) & & & 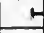 & - & 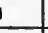 & & & & & 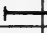 & -1 & \\
\hline$" \quad " \quad "$ (Drene) & & & & & & & & & $\mathrm{X}$ & & & \\
\hline$" \quad " \quad "$ (Ivory) & $H$ & & 4 & & & $\longmapsto$ & H & & & & & \\
\hline (oxydol) & 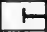 & -1 & & & & & & $F$ & 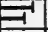 & & & \\
\hline " " " "Naphtha) & $\mathrm{X}$ & & & & $\longmapsto$ & - & 4 & & & & & \\
\hline Radio Corporation of America & & & & & & & & & & 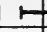 & & 4 \\
\hline$S$ \& W Fine Foods, Inc & H & $\longmapsto$ & & -1 & & & & & & & & \\
\hline Seal test, inc & 4 & & & & & & & & & $\longmapsto$ & 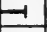 & \\
\hline Sperry Flour Company & & & & & & & $\mathrm{X}$ & & & & & \\
\hline Stewart-Marner Corporation & & $\mapsto$ & & -1 & & & $\longrightarrow$ & & & & & \\
\hline Tillamook County Creacery Associat ion & & $x$ & & $\mathrm{X}$ & $\mathrm{X}$ & & & & & & & $\therefore$ \\
\hline The Wander Company & & & $\mathrm{X}$ & & & & & & & F & & $\mathbf{x x}$ \\
\hline Ward Baking Company & & & & & & & & & & & & $\underline{X}$ \\
\hline G Washington Coffee Refining Company & & & & & & & & & & & & \\
\hline J B Williams Company & & & & & & & 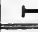 & 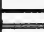 & & & & \\
\hline & 17 & 15 & 17 & 17 & 17 & 13 & 13 & 11 & 17 & 17 & 23 & 18 \\
\hline
\end{tabular}

Chart showing the timing and duration of NBC contests during 1938. (Courtesy of National Broadcasting Company.) 


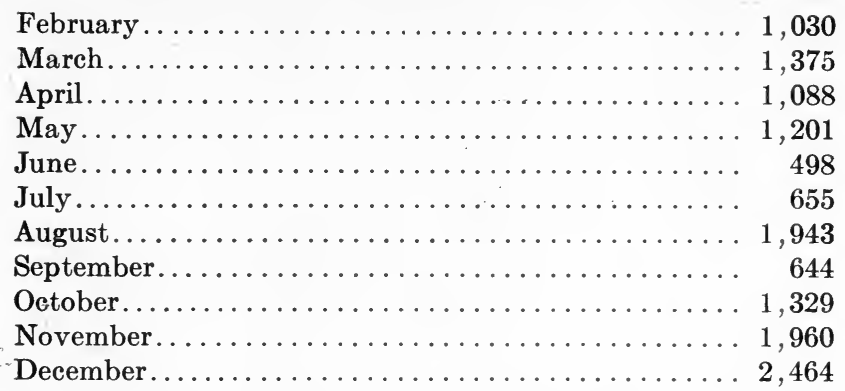

Gertainly, where a box top or label was the entry fee, these contests resulted in acceptable sales. It is unfortunate, however, that actual cost data are not available to determine just what the net profit of the transaction might have been. Also it would be interesting to the contest-minded radio advertiser to know just how many of this great contest army became regular users. Certainly not the great army of professional contesteers, nor even the enthusiastic contest amateur who like the busy bee rarely comes back to the same flower for his honey.

\section{Duration of Radio Contests}

A series contest, where a prize is given each week, may be conducted over a long period of time; just as long as a profitable number of entries materialize. A contest where the prizes are delivered at the end of the contest should be short, for the public's interest is short-lived. A study of many contests conducted in 1938 showed that the length of these contests was from 4 to 6 weeks. A few with high prize offers and unusual interest ran for longer periods.

\section{Entry Requirements for Contests}

A study of radio contests ${ }^{1}$ during 1938 showed a surprisingly large number of radio advertisers requiring no purchase of the product to enter the contest. Other advertisers asked one or more cartons, box tops, labels, etc., for entry. Some of the advertisers used both types of requirements; the Procter \& Gamble Company, for example, required no entry for their White Naptha Soap Contest, two wrappers for their Ivory Soap contest, and three wrappers for their Oxydol contest.

1 "NBC Radio Offers and Contests," National Broadcasting Company, 1938. 


\section{CHAPTER XVIII}

\section{TRIAL AND ERROR TESTING}

When show producers on Broadway put on a new production with their fingers crossed and when dramatic critics, who are supposed to know what the public wants, guess wrong more than occasionally, how is the poor radio advertiser going to be sure his $\$ 20,000$-a-week investment isn't going to “flop" on radio's Great White Way?

Anticipating what the public will like, whether it be books, magazines, theatrical productions, styles, or radio shows, always has been and always will be one of the most hazardous parts of marketing. The continued stress put on research and scientific forecasting by marketing and advertising authorities is saving the manufacturer millions of dollars annually.

\section{Value of Program Testing}

The pathetic thing is that some advertisers who follow this advice carefully in their business and media problems, throw all their knowledge to the wind when they enter the spangled portals of the radio show business. There have been cases of otherwise shrewd advertisers who have spent thousands of dollars to check their market, their copy appeal, and even their radio coverage, but when it came to the radio show itself, have been content to take the word of those who created it that it "should 'wow' the public." The opinion of experienced showmen and advertising executives is invaluable and in the case of radio shows featuring famous comedians and nationally known orchestras, according to a mass-appeal pattern similar to the current popular radio shows, their opinion may be as good as a hundred surveys. Eddie Cantor, Guy Lombardo, Paul Whiteman, to mention but a few of the many top-ranking radio artists, are names that would keep practically any mass-appeal show from "flopping." 


\section{Need for Testing the Special-appeal Show}

It is rather the special-appeal shows and the original-idea shows of radio that need checking up for possibilities, that need to give the advertiser some evidence that he is not gambling his advertising appropriation. Here no showman nor radio authority, no matter how great, can forecast even as well as the weatherman. One of the most interesting examples of this in present current radio shows is "Information, Please," originally a sustaining show on the NBC Blue network and now sponsored by Canada Dry Ginger Ale, Inc., over the same network.

When Dan Golenpaul, the originator of this program, first approached radio and advertising executives with the plan, he was met with grave doubts. Over the typical radio listener's head, uninteresting, etc., was their comment. And the best Mr. Golenpaul could get was a tryout as a sustaining program. At the present writing, "Information, Please" has a high popularity rating. Some 10,000 letters a week are received from enthusiastic listeners; over 1,000,000 questions have been submitted. The show is generally credited with some 5,000,000 listeners. ${ }^{1}$ Advertisers who, a year ago, would have turned it down without a moment's hesitancy, today would buy it up at a premium. Probably before this book is off the press, the show will have enough imitators to spoil the field not only for the original program but every similar one as well.

\section{Danger of Imitating Current Programs}

This matter of imitating popular radio shows does give the shrewd forecaster data which no survey can furnish. Book and magazine publishers and theatrical producers have used such data for a long time. When a book on a given subject goes over well, you will find it followed by another book on the same subject. When a magazine such as Life or Look gets public acclaim, others spring up to ride to fame on the public interest created by the originator. For the radio advertiser this can be summed up in this advice: watch the trends in popular radio shows. When a new-idea radio show "catches on" to the public's fancy, as "Information, Please" or Major Bowes'

${ }^{1}$ Henry Morton Robinson, "Information, Please," The Reader's Digest, December, 1938. 
Original Amateur Hour, when its popularity ratings run high, another show well done and in similar interest is bound to succeed.

But not six others. Note this carefully! There are rising and falling trends in radio shows. The information type, i.e., questions and answers, has been on a rising trend for over a year. It probably right now is close to its peak. A few more of the type added to the already startling number on the air will mark the downward trend, for the public, easily tired, will be receiving more than it can absorb. Information and question programs will go the way of the amateur hours. Only a fewand sometimes none-will remain popular. Popularity ratings show this almost every day. Today's fine shows unless backed by superior showmanship gradually slide down the popularity rating scale.

Whether the advertiser draws a profitable conclusion from studying trends will depend on his good judgment and a complete study of a trend over a period of one or more years. This can be summed up for the advertiser, thus: "Be not the last to jump on the trend band wagon."

\section{How to Make Tests}

In any case, what the advertiser wants to know is: Will the show have enough listeners to justify the investment? And one way to find out is actually to test the program. Give it a place on two or more spot stations before tying up thousands of dollars in a network contract. This is an old story to advertisers in other media. A copy slant may be tested in the newspapers of a few typical towns before it is used as the keynote idea for a national magazine campaign. So the radio advertiser can take a few spot stations, if they are typical of his national listening audience, and make a similar test.

As response is the criterion, the program must be designed to get it. Premiums, free offers, requests to send for attractive service booklets, direct requests for suggestions and criticism, anything in fact that will give, first, indication that there are listeners; and second, that they like the program. Or an actual listener survey can be made in the areas covered by the spot stations used in the test. Most research companies of any size have contacts in all cities and will make a special listener survey at reasonable rates. Or a program can be run for 13 
weeks on the spot station, and the increase in the fan mail over that obtained by the station's average programs used in figuring the new show's popularity.

\section{Examples of Program Testing}

The Lum and Abner show sponsored by Horlick's Malted Milk was first tested for popularity on spot stations. Several different independent stations were used where the product distribution was good, and results in audience response and in sales were watched carefully. When all test stations in different parts of the country showed a good listener reaction, then and only then was the program put on nationally.

Results justified the original tests. Other examples of pretested programs are: Kay Kyser's College of Musical Knowledge, "Information, Please," Professor Quiz, and Adam Hats' Sports program.

\section{Pretested Programs}

In the methods thus far referred to, the advertiser pays the testing bill. But when the advertiser takes over a sustaining program with a proved following, which is a method that is becoming more and more popular, the broadcasting station pays the testing bill. "Information, Please," already referred to, is a program of this type. The Orson Welles Campbell Playhouse is another.

Most sustaining programs, but not all, are designed by the broadcasting station with an eye to procuring a sponsor. A careful record is kept of audience mail and often the broadcasting company can assure the prospective sponsor that an actual listening audience exists. It is surprising how loyal the listeners are to some of the sustaining programs. One orchestra leader on a sustaining program started a title-guessing contest with no prizes offered. A large number of entries resulted with no other reward in sight than that the orchestra leader would send a correct list of the titles to all who wrote in.

The Orson Welles program, already referred to, continued after its sponsoring by the Campbell Soup Company, to show the listeners' keen interest in the program. The first commercial broadcast had a rather heavy lot of commercials. As one listener said, the program actually dripped Campbell's Soup. If there 
had been no really interested listeners, this would have made no difference. But there were many listeners who resented this too-heavy dose of advertising and promptly complained. So many of them there were, that the next week's program not only had fewer and better placed commercials but contained a veiled apology to the "regular" listeners as well.

\section{How to Handle the Advertising on a Pretested Program}

The trend among advertisers seems to be toward these pretested sustaining programs and advertisers may do well to consider them, especially when they can show a goodly audience response and when they are adaptable to the product advertised. There is one caution, however. The loyal listeners may resent the arrival of the sponsor with his commercials, for they have been doing very well without them. This objection can be overcome by using discretion in the introduction of commercials. Start with modest commercials free from the hammer-and-tongs selling message. Work up to stronger commercials gradually, only after the listener has become accustomed to the presence of the sponsor. Failure to do this seems to be the reason why the commercials in the Campbell Playhouse program received so much criticism.

It should be kept in mind, too, that the broadcasting company itself does not keep even a sustaining program on the air if it does not give evidence of pleasing the listeners. The writer recalls such a program put on locally in the New York metropolitan area, featuring a well-known news columnist. From the start, the possibility of a sponsor was foremost in mind. During the first week, there were approximately 23 answers to a direct appeal for audience mail. At the end of a month not over 80 replies had been received and audience response decreased instead of increased. No sponsor would be impressed with this showing. The program was shortly taken off the air and the columnist probably never thought of blaming himself or the one who built his program for the failure of the idea.

\section{Continued Testing Necessary}

The methods thus far emphasized have referred to preliminary tests. The advertiser who wants to keep his show in top place or even near it, should continue his testing as long as 
the program is on the air. Special surveys, special offers over the air, the popularity ratings discussed in the next chapter, all these are invaluable to the radio advertiser. Sometimes a great program begins to slip before those responsible for its success realize it. To know when-and not after-the program slips, may save the show.

Not so long ago, a popular program had a comedy team in one of its lesser comedy spots. Surveys made by the radio classes of New York University showed considerable reaction against the spot by radio listeners. That the sponsor was also getting reactions seemed to be evident. The comedy team was changed for a new one. Continued survey by the students showed that the second team was less popular than the first. At the present writing, survey evidence shows the popularity rating of this show dropping in spite of much good material in it. Can the lesser spot comedy act have a bearing on it? To know the answer to this question now might save this sponsor hundreds of thousands of listeners. To know it when the lost listeners are happily following some other program appearing at the same hour is merely to know that "the victim died." He cannot be brought to life again, nor can the program.

\section{Pretesting before the Program Goes on the Air}

The author is indebted to John J. Karol, Director of Market Research, Columbia Broadcasting System, for the following account of how one advertiser pretested, by the consumer-jury method, several programs for the purpose of finding a new daytime program.

Several proposed programs under consideration were studio rehearsed and electrically transcribed. These, with electrical transcriptions of the other shows of known popularity, were used for the consumer-jury test. Halls were hired in different sections of the country and women were invited, by house to house calls, to attend the preaudition. The invitations were properly proportioned to give a representative cross section of all economic classes; approximately 200 persons attended each audition.

After hearing each recorded program, the members of the listening group were asked to express their individual opinions of the show on a secret ballot. The first question was: "What 
is your favorite daytime program?" and then "What is your opinion of X program: exceptional ——, very good good ——, fair — , poor — , very poor ——?" After this information was obtained, the listener was asked how the $\mathrm{X}$ program compared with her favorite daytime program.

The same questions were asked for each program, and following the auditions, the listeners were asked to check the programs in which they would most like to hear the next episode and why.

The analysis of the votes for these programs indicated that certain of the newly prepared shows were significantly superior in the opinion of the groups and one or two were definitely preferred to the well-established regular programs which were included in the tests. It also brought out the fact that certain component parts of the new programs were more popular than others. The result was that the advertiser decided on a composite program which included a popular narrator from one program and the plot of another show, both of which had received unstinted praise from the assembled consumer's jury. As a matter of record, this program is one of the popular daytime radio shows. 


\section{CHAPTER XIX \\ POPULARITY RATINGS}

If the radio advertiser will keep in mind that popularity ratings are an indication of the number of listeners, not the number of product purchasers, he can get much of value from them. If he mistakes popularity for sales appeal, he may let popularity ratings lull him into a position of false security.

The advertiser should consider this phase of radio advertising only after he has reasoned the matter out something like this. What is the objective in my radio advertising? If it be mere good will, the popularity of the program means everything. If it be actual sales, the popularity of the program may mean next to nothing. For popularity as given by these ratings means popularity of the show itself - not the sponsor nor his advertising. Advertising per se will never be popular on the radio.

If the advertiser wants proof of sales, there is only one way to get it and that is to check sales. We have at present no regular surveys for this important part of radio advertising. If a manufacturer wants this information, he must get out and dig for itand pay out of his own pocket. He can make sales area checkups; he can make dealer surveys, and the so-called pantry surveys by going to the consumer direct. If radio is his only medium of advertising, he has but to watch his sales curve; if radio is merely one of a half-dozen advertising media, an actual check on radio results may be almost impossible.

However, it seems a fair premise to start with that if a program is popular, there are just that many more people to listen to the sales message. And this indeed should be the basis of the so-called popularity rating when viewed from an advertising standpoint.

\section{Popularity Ratings Tell Half the Advertising Story}

From the show standpoint, popularity ratings are box-office results. To produce a radio show that will attract listeners is after all the showman's first duty. He, like the magazine and 
newspaper, should be held to circulation results. 'How much goods the show or the magazine will sell depends on another factor; i.e., how well and how effectively the advertising is handled. Admittedly the ideal modern radio showman, and there are many, combines these two factors and builds a show in which advertising and entertainment are integral. To him popularity ratings tell half the story. To many other showmen popularity ratings tell the whole story; this may be misleading.

Not that popularity ratings are not a valuable adjunct to radio; on the contrary, they are well-nigh essential. They are the barometer that warns the advertiser and program stars of changing conditions. If a sponsored radio show has a top rating and that rating drops continuously, one thing is certain, listeners are walking out. Any sane advertiser may well want to know why. Is the show slipping? Is a competing program drawing its listeners from the program's following? Are some of the expensive stars not so effective as their managers and the advertiser's radio advisers led him to believe?

Many advertising authorities claim that the sponsor takes his rating too seriously. Some advertising agencies are on record as saying that the advertiser wants to know how much goods the program sells, not how many people listen. Obviously, if an advertiser has his show keyed to too popular an appeal for a conservative product, a high popularity rating would tell him that the appeal of his show is slipping for he is getting mass interest instead of class. Such advertisers actually shudder if their rating zooms too suddenly or too high.

\section{Cost of Ratings}

But to most advertisers, particularly the large ones (ratings of small shows are not often given), the popularity rating is more than worth its salt. So popular has the rating idea become that several reliable research concerns have found it profitable to make these surveys for all programs and charge any advertiser who wants to subscribe to the service, a fee, varying from $\$ 480$ to $\$ 3,600$ annually, for biweekly reports. In many cases advertisers desiring special information about their own shows can contract with these research companies to procure just about any information imaginable and in any city, town, or hamlet specified. 
Of the several companies making such surveys, the Cooperative Analysis of Broadcasting (CAB) and C. E. Hooper, Inc., are outstanding. These are discussed in detail because the radio advertiser is often confused when he cannot make their different ratings agree. Both of the services work on a relative basis. The rating shows the percentage of listeners among the number of homes interviewed. The premise seems sound that if the sample is large enough and typical enough, the same percentage applies to all radio homes in areas covered by the programs rated.

\section{Rural vs. Urban Popularity Ratings}

There is a fallacy here which the research companies themselves admit, and that is that most samples have not taken into consideration the difference in listening habits between city and rural communities. Until recently, the surveys were made in fairly large key cities because the cost of interviewing listeners was low. If the farmer has different listening habits, the city survey cannot be conclusive. A case in point is the Seth Parker program sponsored by Vick Chemical Company. The appeal would seem to be more interesting to small-town and rural audiences than to sophisticated city audiences. The annual CAB Rural vs. City Ratings does not give this program but it would seem reasonable that a survey among small-town and rural audiences would give this show a higher rating than would a survey among city audiences.

The caution here then seems to be this: If the product advertised has its greatest sale possibilities in cities, the popularity rating can be taken as indicative. If the farm market or even the small-town market is the field of greatest sales possibilities, a high rating merely shows that city people like the show but gives no guarantee that the country people are of the same opinion. There seems to be little doubt that mass-appeal programs such as Jack Benny's Jell-o and Charlie McCarthy's Chase \& Sanborn programs appeal both to city and country markets. The CAB ratings quoted in Chap. VII show this.

\section{Methods Used in Making Ratings}

Much has been said about the various methods used by the research companies. Some authorities even claim that because most of these surveys are made over the telephone, they cannot be typical of the radio audience because there are $26,500,000$ 
radio homes and only $13,500,000$ telephone homes. C. E. Hooper, Inc., recognize this and recommend that studies to supplement their reports be made to determine methods of establishing trustworthy listening differences existing between telephone and nontelephone homes. The Cooperative Analysis of Broadcasting select their telephone calls by income groups, thus reaching the typical radio audience. Other authorities like to compare the relative values of coincidental telephone surveys (those made while the program is on the air) and recall surveys (those made several hours after the program is on the air). The latter may be either assisted or unassisted recall.

\section{Coincidental Method}

This method is exemplified by the C. E. Hooper, Inc., popularity ratings which give the advertiser the popularity rating of his program determined by coincidental telephone interviewing in 30 cities representing 67 per cent of total $A$ market population and 64 per cent of the total United States retail sales volume. All have both NBC and CBS radio outlets. Both coincidental and immediate-recall methods are used throughout the period of interview, the first referring to the current 15-min. period and the second to the last previous 15-min. unit. Maximum size of sample is: Evening 7 to 10:30 P.M. Eastern time, 4,800 per hour; daytimes 9 A.M. to 7 P.M. Eastern time, 24,000 per hour. The typical Hooper Radio Report gives a relative figure for the radio audience, the program audience, and the sponsor identification.

The radio audience is an expression of the size of the audience of all programs, or the percentage of radio sets listening to anything or everything during a particular period. This percentage, when related to a particular program, is based on interviewing conducted in every checking point to which the program is broadcast. The change, plus or minus in the size of the radio audience from the last report, is also shown.

Program audience is an expression of the size of the audience of a particular program, or the per cent of total radio sets listening to that program.

Audience radio is an expression of the per cent of the total audience that is listening to the particular program. If half of all the radio audience is listening to a specific program, the audience ratio is 50 per cent. 
AND A LITTLE DUMMY SHALL LEAD THEM

PER CENT OF RADIO LISTENERS TUNED TO CHARLIE MC CARTHY PROGRAM
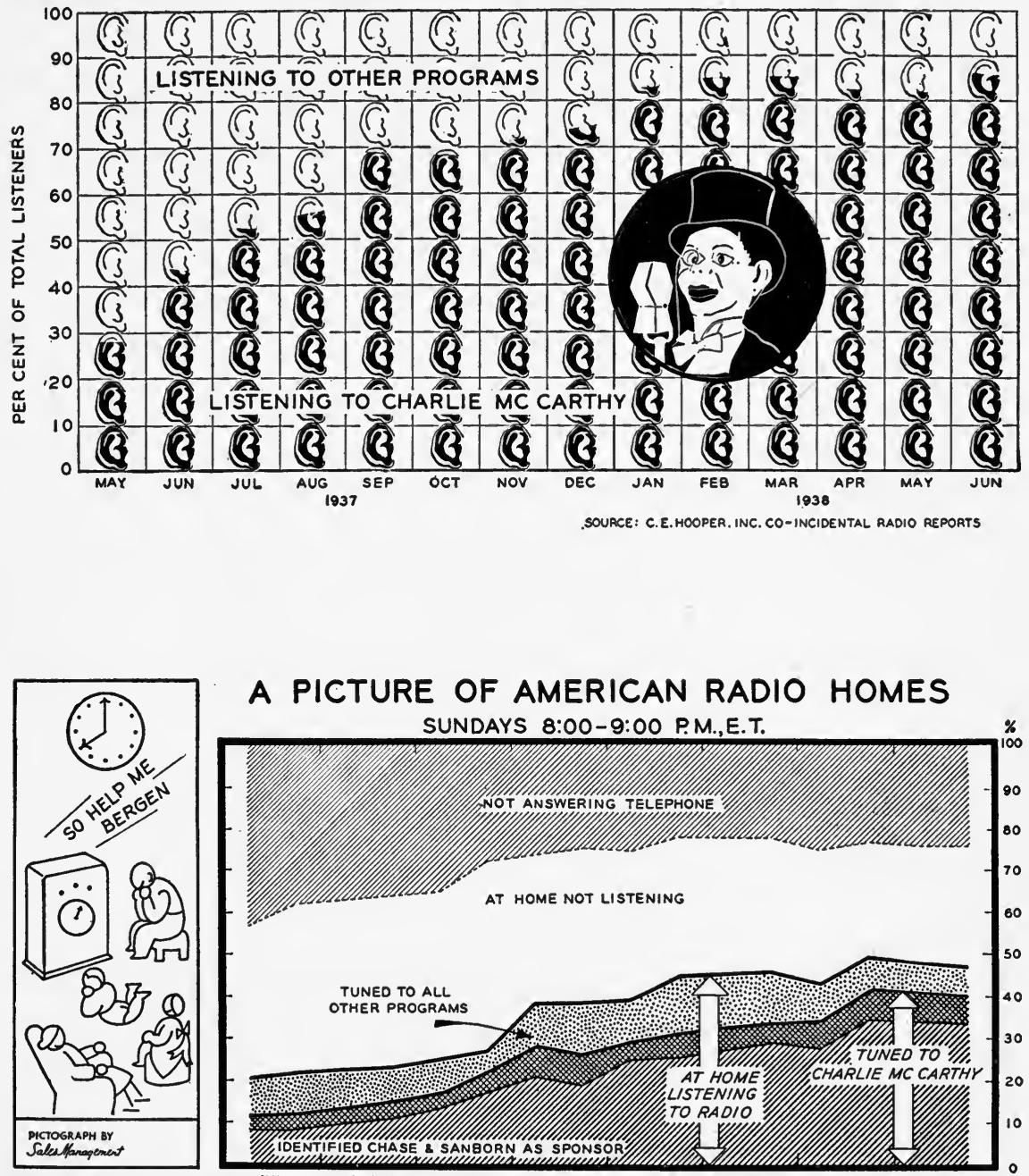

A PICTURE OF AMERICAN RADIO HOMES

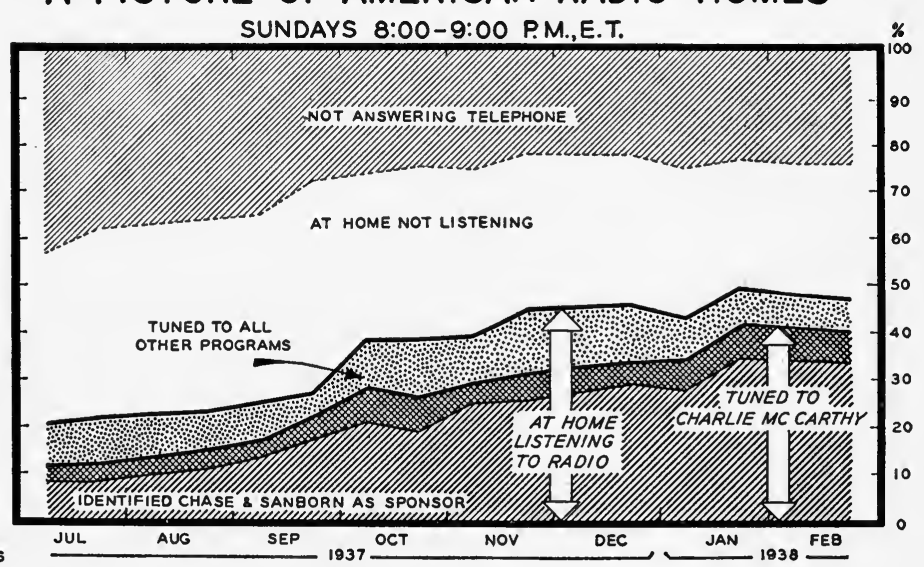

A graphic presentation of the listener situation at 8:00-9:00, Eastern Time on Sunday evenings. (Courtesy of Sales Management.)

Sponsor indentification during the broadcast is determined by asking persons who are listening to a specific program to name the product advertised or the advertiser sponsoring the program. 
It is reported as a percentage based on listeners to the program. After the broadcast, sponsor identification is determined by asking persons who were listening to a specific program during the past previous quarter-hour unit of broadcasting, to recall the product which was advertised or the advertiser who sponsored the program. It is reported as a percentage based on those previously listening. Reports are given for large cities and small, combined or separately. Other types of Hooper reports show per cent not at home, per cent at home not listening, and per cent of radio audience. Considering the total radio audience as 100 per cent, these are further broken down to show competitive pulling power between programs concurrently broadcasted in those areas where network program competition is uniform. Thus the 100 per cent might be broken down to show Red NBC 30 per cent, CBS 30 per cent, Blue NBC 30 per cent, and others 10 per cent.

Typical Hooper Radio Reports covering both these types of survey are shown on pages 200 and 201 .

\section{Recall Method}

The recall method, as exemplified by the Cooperative Analysis of Broadcasting, gives the advertiser the popularity of his show determined by telephone interviewing conducted after the programs are broadcasted.

The Cooperative Analysis of Broadcasting, whose ratings are popularly called the $\mathrm{CAB}$ ratings, is an outgrowth of the 1929 activities of the Association of National Advertisers' Radio Committee. It is a mutual and nonprofit organization operating under the supervision of a governing committee, two members of which are appointed by the president of the American Association of Advertising Agencies, and three members by the president of the A.N.A. The present governing committee consists of Dr. D. P. Smelser, in charge of Market Research Department of Procter \& Gamble, Chairman; Dr. George Gallup, of Young \& Rubicam, Inc., Treasurer; Chester H. Lang, of General Motors; Dr. L. E. D. H. Weld, of McCann Erickson, Inc.; and A. Wells Wilbot, of General Mills, Inc. A. H. Lehman is General Manager. The field work is conducted by Crossley, Inc., a private research organization on a contract basis. The subscribers comprise radio advertisers, agencies, and networks. The cost is spread 


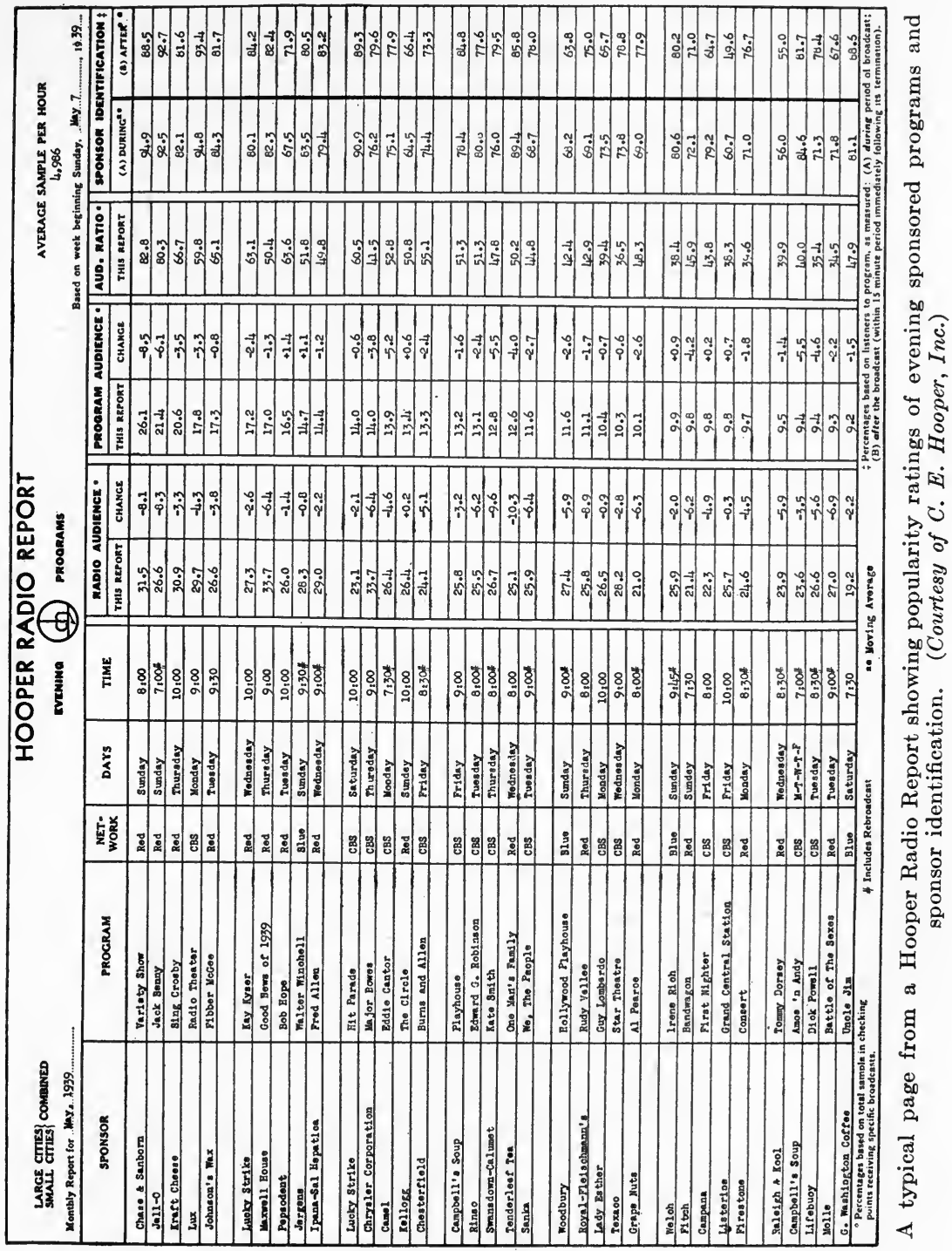




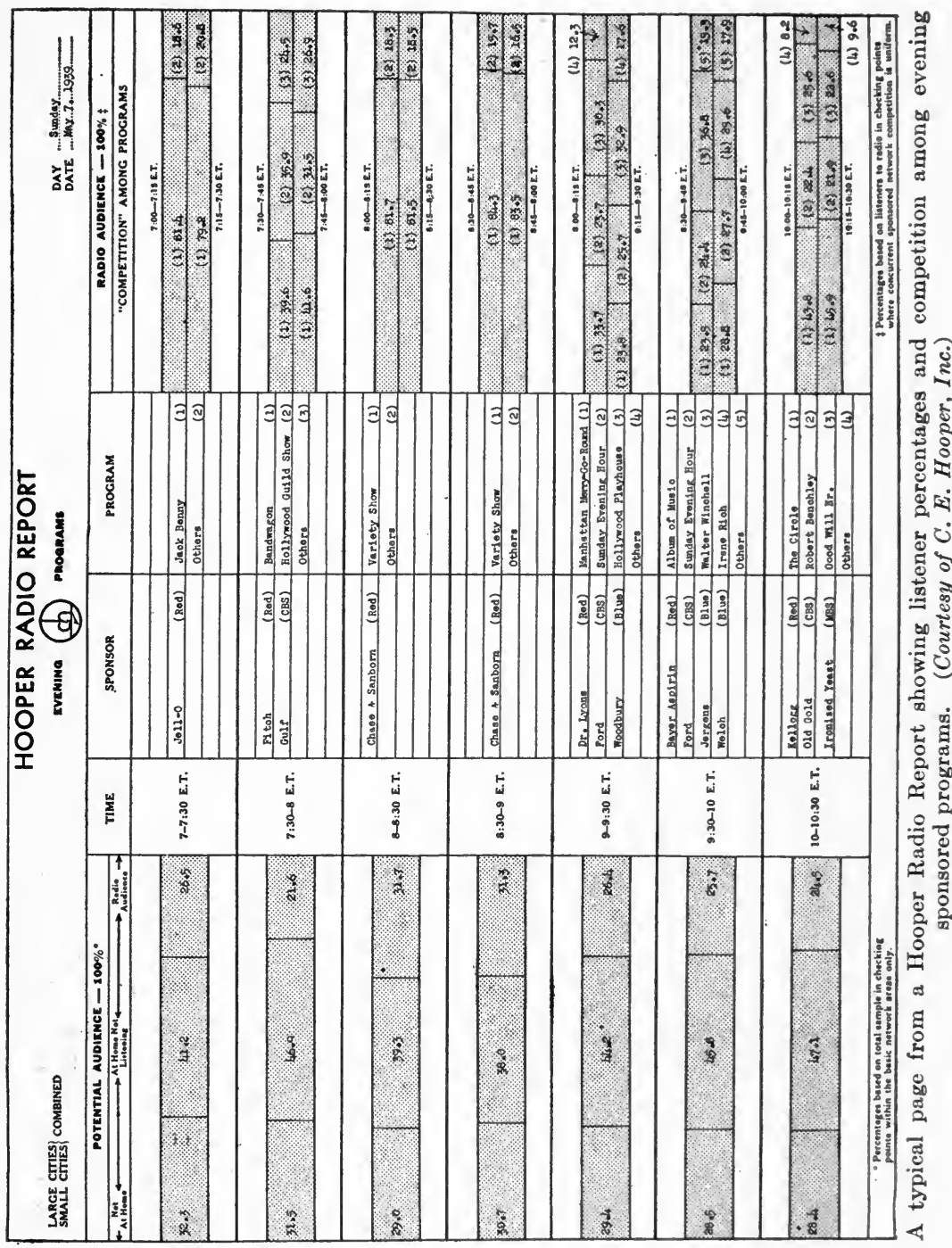


among them according to their respective interests in radio advertising.

Ratings on practically all commercial network programs, daytime and evening, are reported to subscribers in 24 semimonthly and several more comprehensive reports which analyze programs by geographical sections, income levels, etc. Over $2,000,000$ interviews have been made by the $\mathrm{CAB}$ since its founding in March, 1930. During the past 2 years the CAB has made two comprehensive studies of rural listening habits (quoted in Chap. VII). Each of these surveys consisted of over 20,000 interviews with set owners-8,000 among farmers, 10,700 among residents of small towns, the population of which averaged about 700 to a town. In addition to the regular CAB service, special analyses on specified transcribed and sustaining programs, listening habits, talent ratings, etc., are furnished subscribers.

For the standard $\mathrm{CAB}$ popularity ratings, over a half million calls are made annually by 53 investigators in 33 cities. The calls are carefully distributed by income levels to parallel the distribution of radio sets among economic groups, and by geographical sections to correspond closely to the distribution of radio homes.

The CAB popularity ratings, like the Hooper ratings, are reported as a percentage. The CAB rating for a given program is the percentage of set owners called in a given area, who are listening to a given program. Thus, if out of each 100 set owners who are called in the area covered by a given program, 20 report that they heard it, then the rating which appears in the report is 20. The percentage is not a percentage of the listening audience, but a percentage of set owners interviewed.

The standard CAB reports contain a description of the method used, the time of interviews (four times a day after the program is off the air), a detailed list of the cities in which the calls are made, and a percentage rating of audience trends for both evening and day sponsored programs. Separate lists are given for hour, half-hour, and quarter-hour shows. The quarter-hour shows are separately listed as given (1) five times a week, (2) two to three times a week, and (3) once a week. Daily variations are also given. 
QUARTER HOUR DAYTIME FOUR FIVE TIKES WEETLY

- 11 -

Quarter-Hour Programs

The arerage (median) of all quarter-hour programs broadcast 4 or 5 times a weak is 5.3

Program

\begin{tabular}{|c|c|c|c|c|c|}
\hline 半 & $\begin{array}{l}\text { Rat } \\
\# 1\end{array}$ & $\begin{array}{l}\text { s for } \\
\text { Polnts } \\
\text { Change }\end{array}$ & port & \#23 & $\begin{array}{c}\text { Dally } \\
\text { Variation }\end{array}$ \\
\hline 5.5 & 5.6 & & 5.5 & 5.8 & \\
\hline
\end{tabular}

\section{Ma Perkins}

Procter \& Gemble Co.

\section{$3: 15 R$}

Also transcription
$+0.0$

8.8

Son. 8.7

Tue. 8.8

Fied. 10.1

Thu. 10.2

Fr1. 8.9

The Guiding Light

Procter \& Gamble Co.

$3: 45 R$

$9.1 \quad 8.9$

$+0.2$

$8.4 \quad 7.8$

Mon. 8.8

Tue. 9.0

T.T. 9.0

Thu. 9.7

Fr1. 8.7

Popper Young's Family

Prooter \& Gamble co

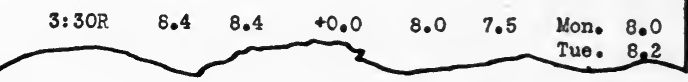

\section{HALF HOUR इVENIIG}

$-2-$

30-linute Programs

The average (median) of all 30-minute programs is 10.0

Program

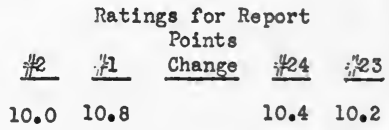

Medians

Jack Benny

Jell-0

Big Town

Lever Bros.

Cantor's Camel Caravan

R. J. Reynolds Tobacco Co.

Burns and Allen

Liggett \& lyers Co.

Diok Powell

Lever Bros. $\begin{array}{lllllll}7: 00 R & \text { SUI } & 38.4 & 38.0 & +0.4 & 36.7 & 38.9\end{array}$

$11: 30$ rejroadcast

8:00C TUS $27.0 \quad 21.8 \quad+0.2 \quad 22.5 \quad 21.1$

$11: 30$ rebroadcast

$\begin{array}{lllllll}7: 30 \mathrm{C} & \text { MON } & 21.6 & 21.8 & -0.2 & 20.6 & 20.5\end{array}$ 10:30 rebroadcast

$\begin{array}{lllllll}8: 30 \mathrm{C} & \text { FRI } & 21.6 & 19.6 & +2.0 & 20.7 & 22.5\end{array}$

11:30 rebrcadcast

$8: 300$ TUE $20.1 * 20.9 \quad-0.8 \quad 20.4 \quad 20.5$ $12: 00$ rebroadcast

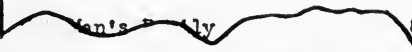

8:00R
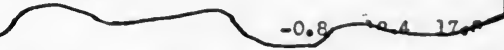

Part of typical pages from a Cooperative Analysis of Broadcasting (CAB) Report; showing popularity ratings of evening and daytime sponsored programs. (Courtesy of Cooperative Analysis of Broadcasting.) 
An average (median) for each time group is also given, as well as the change in ratings from the last report.

Typical CAB reports are shown on page 203.

\section{Factors Affecting Popularity Ratings}

Whether the $\mathrm{CAB}$ or the Hooper ratings are used, certain factors should be considered in studying the trends of the ratings. Naturally a startling drop in a single rating may not be serious. A bad thunderstorm or an emergency news broadcast may have caused it. The next report may show the rating back to normal. A cumulative drop in rating, however, is a serious matter. Here all factors should be considered before blame for the lost audience is placed entirely on the members of the cast.

A. H. Lehman, Manager of the Cooperative Analysis of Broadcasting, has kindly furnished the author with the following list of factors influencing popularity ratings.

1. The adding of several stations to the network. An advertiser might add several supplementary stations to a basic network. His rating may jump from 15 to 18 . This is due to the fact that in the basic area, generally speaking, three network programs are being broadcast simultaneously; in the nonbasic area, there are generally two. Therefore, other things being equal, a greater percentage of the radio audience in the supplementary areas will listen to a given program than in the basic area.

2. Variations in degree of acceptance of the program among people in different income levels and in different sizes of communities.

3. General popularity and the geographic coverage of the individual stations carrying the program.

4. Direct competition. One or two extremely popular programs opposite a given program will reduce considerably its "naturally expected" audience.

5. Program position. This may benefit or harm a given program. Following an extremely popular program on the same chain, the given program will find its listening audience greatly increased. Following an extremely popular program on a competing network the given program will find its audience reduced, for many tuned into the other station will not change their dial unless the next program annoys them.

6. Emergency competition. Special events such as the World's Series, prizefights, special news broadcasts, simultaneously presented on other stations will draw regular listeners from a given program.

7. The hour of the day, the day of the week, and the season of the year. 
8. The weather.

9. Frequency. Certain types of programs must appear more frequently than once a week to maintain or increase their audience. On the other hand, there are types which would lose their popularity if presented daily.

10. Age of program. A program which is at least fairly acceptable will increase its audience as its age increases. However, there comes a time when senility takes its toll. A check of rating reports would show at least a score of such cases.

C. E. Hooper of C. E. Hooper, Inc., gives six variables that may have an effect on the popularity ratings of a radio program. They are

1. Inherent appeal to people.

2. Competition of simultaneously broadcast programs.

3. Time of reception.

4. Program preceding or following.

5. Survey points selected.

6. Lapse of time between broadcast and interview.

Four of these factors, illustrated by specific program ratings, are shown on pages 206 and 207.

\section{The Audimeter Survey}

Another type of popularity survey which has definite limitations but also certain advantages is the audimeter survey. This is a strictly mechanical survey made possible by the audimeter, an instrument which when attached to a radio set makes a continuous record of the times when a set is turned on and of the stations to which it is tuned.

The audimeter was designed by Professors Robert F. Elder and L. F. Woodruff of the Massachusetts Institute of Technology. It is about the size of a lunch box and can be placed in any radio, uses little extra current, and by means of a telechron clock, a roll of graph paper, and a marking indicator connected to the dial of the radio set actually shows a 2 weeks' record of what stations were tuned in, how long they were tuned in, and how often. The claim for the method is that the type of radio home can be definitely determined and the listening habits of that type definitely recorded. Thus 2,000 audimeters in Class A homes within a given market area would give an intimate picture of that type of home. Obviously how many are listening to 


\section{II "COMPETITION"}

AFFECTS THE SIZE OF THE PROGRAM" "RATING"

PROGRAM

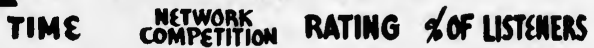

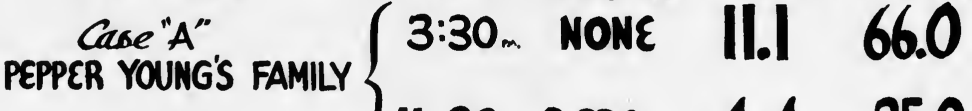
11: 30 . 2 PRO. $4.4 \quad 25.0$

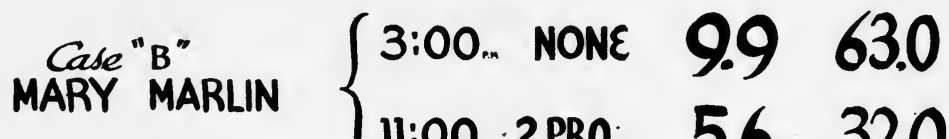
111:00 2PRO: $\quad 5.6 \quad 32.0$

Case "C" ROAD OF LIFE

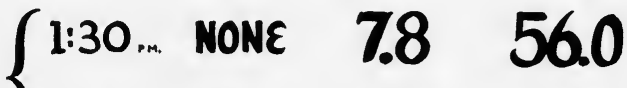 11:45... 2 PRO. $6.7 \quad 41.0$}

\section{III "RECEPTION TIME"}

AFFECTS THE SIZE OF THE PROGRAM "RATING"*

TIME ZONE LOCAL TIME AUDIENCE AUDIENCE LIOFTENERS

PROGRAM"A" EASTERN 10:15-10:30 A... $15.85 .5 * 34.8$

" " CENTRAL 9:15-9:30 A.m. 14.8 7.8* 53.0

" " PACIFIC I:I5-I:30 r.m. $20.65 .6 * 27.3$

PROGRAM"B" EASTERN 10-10:30

" " CENTRAL 9-9:30 30.4 14.3* 47.0

" " PACIFIC 7-7.30 $27.314 .6^{*} 53.5$

The results of a Hooper survey of current sponsored programs to show how competition and reception time affect popularity ratings. (Data furnished by C. E. Hooper, Inc.) 


\section{PROGRAM "PRECEDING" OR "FOLLOWING" AFFECTS THE SIZE OF THE PROGRAM "RATING"}

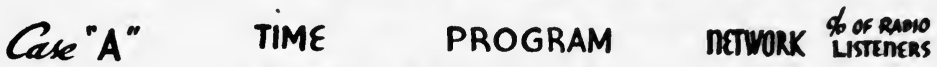

MARCH $1939\{7-7: 15$ AMOS ' $n$ ' ANDY RED 55.5

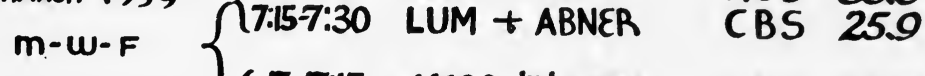

APRIL $1939 \begin{cases}7-7: 15 & \text { AMOS ' } n \text { ' ANDY CBS } 53.9 \\ 7: 15-730 & \end{cases}$

77:15-7:30 LUM $\$$ ABNER CBS 34.6

Case"B" $\quad$ 7:30-7:45 BANDWAGON RED 39.8

sun $\quad 8$ BNDWAON RED 46.8

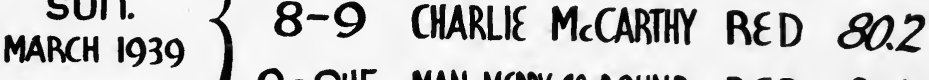

9-9:15 MAN. MERRY-60-ROUND RED 30.7

9:15-9.30 MAN.MERYY-GO-ROUND RED 24.0

\section{I "SURVEY POINTS SELECTED" AFFECTS THE SIZE OF THE PROGRAM"RATING" \\ Distance from station city}

Cincinnati STATION CITY

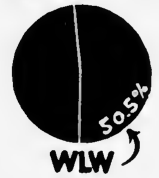

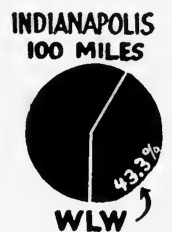

TOLEDO OHIO

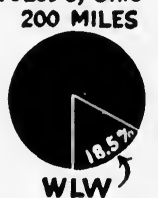

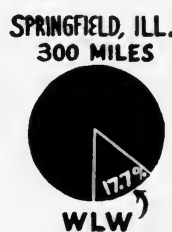

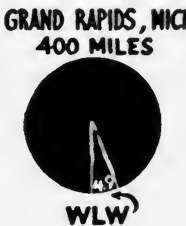

The results of a Hooper survey of current sponsored programs to show how programs preceding and following and survey points selected affect popularity ratings. (Data furnished by C. E. Hooper, Inc.) 
each audimeter equipped set, whether they really are listening, whether they can identify the sponsor or his product, are things this automatic survey cannot determine. Nor can one be sure whether Mr. and Mrs. "Class A" are listening or their servants.

Certain listening habits in general, however, can be observed. The number of dial shoppers, the number having favorite stations to which they tune first, and also the holding value of an individual program, can often be determined.

For example, in the present Chase \& Sanborn program, if a goodly percentage tuned out at 8:15 approximately, it would show Charlie McCarthy and Charlie McCarthy only-to be the drawing card. If listeners stayed until after the dramatic production at approximately the halfway point in the program, its holding power would be known. If many tuned out immediately after that, it would show that the attractions on the balance of the program had little holding power. If many tuned out exactly on the half hour, it might show a competing program of greater magnitude or that a half-hour program of this type is all the average listener cares to contract for. The author believes that the possibilities of the audimeter in this connection are worth exploring, particularly for checking the holding power of different types of entertainment and different stars on a single program. 


\section{CHAPTER XX}

\section{THE ADVERTISING AGENCY AND RADIO}

Ten years ago no advertising agency, nor anyone else for that matter, knew much if anything about this new advertising medium, radio. But they were perfectly willing to learn and many of them did with the advertiser paying the experience bill. Unfortunately there are still today a few agencies with this same pioneering spirit. They see their regular clients adding radio to their list of media and rather than lose the business, they and their client learn radio together-just as 40 years ago agencies and advertisers learned advertising together with the client paying the tuition fees.

In fairness to some of these late-comers in the radio field, it must be said to the average advertising expert's credit that his past experience in mastering new problems and solving unusual market setups often enables him to do his first radio job fairly well But he generally does it leaning heavily on the broadcasting companies' efficient service departments.

These service departments are the outgrowth of a medium which at first grew too fast for the advertising agencies to keep pace with it In those early days advertisers often preferred to place their accounts direct, feeling that if anyone should know the oddities of this new medium, it should be the medium itself.

\section{How Agencies Have Helped Radio}

Today, however, we have advertising agencies whose superiority in radio rivals the broadcasting company's own expert knowledge. We have a few, in fact, who the broadcasting companies feel are too cocksure of themselves in an industry where yesterday's tricks will not sell today's goods; those who know the most about radio will tell you that nobody knows all about this still-new medium. Certainly much of radio's success ean be claimed by the progressive advertising agencies. Many 
of them have a radio department equipped to create the basic program idea, write the script, both dramatic and advertising, select and rehearse the cast, arrange the merchandising tie-up, and deliver the show to the broadcasting station all ready for the air.

\section{The Ideal Radio Advertising Agency Should Know Other Media}

Most advertising agencies have added radio to their regular and long-standing advertising experience. This is a very desirable qualification from the businessman's standpoint. An agency's recommendation of radio as a carrier of the advertising message should be based on a complete knowledge of and experience in other media. There are certain advertising problems that have no place on the radio. Magazines, newspapers, outdoor advertising, may be able to do the job more effectively and more cheaply. Or possibly to be most effective, the radio advertising must be coordinated with other media. The agency that handles all media can seldom be accused of favoring radio. Its recommendation is made-or should be made only after a careful consideration of the possibilities of other media. This type of agency will seldom ask radio to do the impossible.

Then there is the station and coverage situation, a media problem best solved by professional media experts schooled in media selection in other fields.

\section{Comparison of Agency Facilities with Those of Broadcasting Companies}

In looking for the ideal advertising agency setup for radio, let us see what departments the broadcasting networks themselves feel are necessary for the success of the radio advertiser. There will be found, in the organization chart of most of these companies, the following departments upon which the advertiser or his agency can lean if necessary: the program department, which is equipped to originate program ideas and write the continuity for them; the music department, which may have a director of music, a library of music, a card index of talent and orchestras, and arrangers of music; the production department, with its production manager, assistants, and announcers to rehearse and carry through the ideas originating in the program department; the merchandising department, with its staff of 
merchandising men to give advice on "over the air offers," premiums, contests, dealer tie-ups, and the like; the research department, ready to check by survey and research the listener's habits, both radio and buying; and the publicity department, keyed to send out to every newspaper, magazine, and trade paper, news stories about radio, about the program's stars, special events, and the like.

Many of the large leading advertising agencies specializing in radio can lay claim to covering this same ground and, as already pointed out, can do everything the broadcasting station can do. It seems reasonable to assume that some of the agencies that cannot do all this, but use the station's facilities to augment their own, can still be classed as effective radio agencies. Sometimes the small radio advertiser whose account these great agencies are not keyed to handle profitably, may find the smaller agency, if basically efficient, the only entry to radio advertising. Whether an advertiser is going to spend $\$ 1,000$ or $\$ 500,000$ changes the agency picture. The author has had in his radio classes at New York University executives from many of the smaller agencies who have diligently learned all they could about radio and, coupled with their general experience, have handled fair-sized radio accounts with marked success.

\section{Importance of Performance Records}

The really big radio advertiser, however, can well dictate his own terms in selecting his advertising agency. So far as radio is concerned, a present-not past-record of successful shows on the air is a good sign. Study the shows on the air today, the ones that "click," that run smoothly, hold your interest, make a good job of the advertising, that have high popularity ratings, and you will find back of most of them an agency that has in its radio department not only advertising men but men from the show world, men from the stage, and dramatic writers of known value. It is no wonder that agencies of this type can say, as one recently did, that per dollar spent, they can deliver 30 per cent more listeners who know the product advertised and who can identify the sponsor than the average of all other radio sponsored programs.

While mere bigness is no criterion of radio effectiveness, it is interesting to note that 30 large agencies place over $\$ 60,000,000$ 
worth of radio business a year, the top-ranking agency for 1938 placing $\$ 9,093,125$ during the year.

As already pointed out, however, the prospective radio advertiser should be cautious about selecting an agency on mere big radio accounts alone or solely on the popularity ratings of its radio programs. It is results that the advertiser must have and it is sensible enough that he should demand from his prospective agency that it produce sales evidence for some of these highly rated shows. Many an advertiser, to his later regret, has been too well impressed by the jargon of the show business, the cleverness of a presentation of claims rather than proved results.

\section{Factors in Agency Selection}

Nor should the radio advertiser overlook in his selection of a radio agency those basic characteristics checked by keen advertisers in other fields. These factors vary in value according to the product, the amount of service required, and the particular advertising problem, but they can be stated basically somewhat as follows: ${ }^{1}$

1. Age and recognition of the agency.

2. Advertising experience of the entire staff. (No agency can be better than the men who comprise its organization.)

3. Number of accounts handled and their standing, size, and the length of time they have been with the agency.

4. The turnover of accounts, i.e., the number of accounts lost within a year.

5. Opinions of clients and of different media.

6. Whether the account will be handled by an experienced executive. (Often small accounts are turned over to so-called "cub" account executives, who may be clever enough, but who cannot boast the experience of handling an account safely and economically.)

7. Financial standing of the agency.

8. Size of its organization. (It need not be large but it must be big enough to give the type of service necessary to the advertiser's success.)

In addition to the above, one should consider, particularly in radio, the broadmindedness of the agency and its experience in all media. If 90 per cent of its accounts are majoring in radio,

${ }^{1}$ W. B. Dygert, "Advertising Principles and Practice," Longmans, Green \& Company, 1936. 
the agency may be so close to radio as to have lost its perspective. It may have forgotten (if it ever knew) that there are other media capable of doing a good advertising job and in some cases of doing an equally good job at a smaller cost. As already pointed out, radio is not a panacea for all marketing ills. There are certain types of products, certain campaign objectives, which lend themselves better to other media.

When the advertiser has selected an agency that has directed its clients to the most suitable medium for the task to be done, that is, placing advertising intelligently in all media, then can that advertiser feel a sense of security in the agency's selection of radio. For the advertiser will feel that all possible media were carefully considered before the agency recommended radio.

Some advertisers use more than one advertising agency, often splitting their account because one agency may specialize in a given medium. There is no harm in this provided the advertiser has executives of his own experienced enough in advertising procedure to coordinate the work of the two agencies, to see, in other words, that neither horse runs away with his advertising wagon. 


\section{CHAPTER XXI}

\section{CAN RADIO DO IT ALL?}

What advertising medium cannot tell a success story? And produce the figures to prove it! Only the closeness of advertisers, who do not want their competition to know when they have found an ideal media setup, keeps the media salesmen from having a portfolio of proved success stories to show prospective advertisers.

Radio, like magazines, newspapers, and outdoor advertising, has an abundance of these success stories. The caution in being sold on them, as it is with all media success stories, is to see that your problem, objective, and market situation is the same as that of the hero in the success story.

\section{Early Radio, a Good-will Medium}

There was a time not so long ago when radio confined its success stories to secondary glory. Advertising authorities were wont to wag their authoritative finger and say: "Radio is a supplementary medium; it should supplement the advertising in other media." It was a very nice gesture and radio believed its own story. But some of the shrewd advertisers did not. Radio will sell goods, they said, and they set out to prove it. Stories of companies that were letting radio do it all began to reach the advertising trade papers. Obviously when the selling was too ardent, good will was lost, but goods were sold. One of the first classic examples was an advertiser in the Middle West who was selling products to farmers. He must have put a lot of his personality into his radio talks; although the program had no brass bands or movie stars, it sold goods-several carloads in fact.

Other advertisers tried this new plan of selling goods and while many made a mess of the job, many others succeeded. Lady Esther, Ltd., invited Wayne King and his popular music to put the listeners in the mood so that a female voice impersonating 
Lady Esther could deliver a 21/2-min. straight-from-the-shoulder sales talk clothed thinly in a beauty-hint approach. Surveys showed that many people objected.

Some said they listened to Wayne King's soothing music and turned off the long commercials. And yet, with practically no other media helping out, at that time at least, Lady Esther sales mounted. Grant that progressive merchandising and shrewd sales strategy helped, but grant that, from an advertising standpoint at least, radio did it all. For every three listeners who harped about ill will, two other listeners bought. Probably one of the three who harped also bought.

\section{Radio Now Sells Goods}

And then the broadcasting companies woke up and began saying, "Radio does sell goods." WSM took a two-column advertisement in Tide to tell of a nursery in Osage, Iowa, which offered in a 15-min. weekly program a complete assortment of plants, shrubs, and seeds for $\$ 1$. The program consisted of music and a friendly voice, the Master Gardener, who talked of seedtime and planting and invited the listeners to order. Dollar orders received, ran something like this:

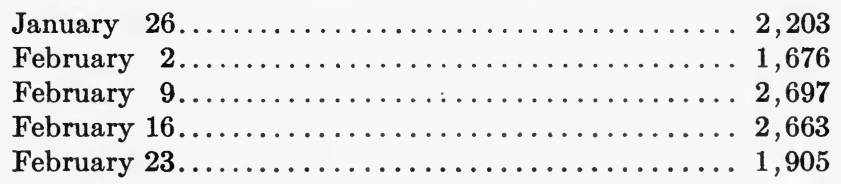

At what profit these goods were sold may be another story, but radio did sell the goods.

Captain Tim's Adventures, three times a week, 6:15 to 6:30 P.M. for Ivory Soap, gathered from 1934 to 1936, 2,700,000 members into the Ivory Stamp Club, according to the New York Sun. During that time some 800,000 stamp albums and over 400,000,000 stamps were mailed out to listeners-and not free. Two Ivory Soap wrappers were required for the album, and two for each packet of stamps, plus 5, 10, or 20 cents, according to the richness of the collector's appetite.

So radio could go on, as any other media could do, relating success stories. They do not prove that Blank's Soap could duplicate Ivory's record or that every nursery in the land could sell $\$ 1$ assortments over the air at the rate of 2,000 a week. 
But they do prove that radio-all by itself-can sell goods and no longer need be considered a secondary advertising medium depending upon other media for the main selling effort.

But there seems no doubt that radio is at its best as a secondary medium ${ }^{2}$ as a good-will medium to back up the strong sales talk in newspapers and magazines. Survey after survey shows that advertising, as such, is less popular with listeners than with readers. One seldom hears these days of magazine readers tearing out the advertisements in rage but one does hear often enough of a listener tuning out the advertising message, particularly if it is a long one. The big advertiser will probably accomplish more by leaning toward good will in his radio program and using other media to pound the public into prospects. The small advertiser, however, who cannot afford this effective plan, must and can do his selling over the air. The caution is: Do not overdo it.

\section{The Good-will Program}

There are various degrees of good-will programs: those, like the Ford Sunday Evening Hour, that make practically no attempt to advertise and those, like the former Carborundum Broadcast, that call themselves good-will programs but in a quiet, dignified way use conservative advertising. Sales are secured by suggestion rather than direct command.

A classic example of this second type is the Carborundum Broadcast. Back in 1934, in a speech before the Convention of the American Federation of Advertisers, Francis D. Bowman, advertising manager for the Carborundum Company, presented figures to show that radio can accomplish direct results, even with a good-will program.

Mr. Bowman told how their program started on a single Buffalo station, then added another, then moved to a western New York hookup, then onto the Columbia network stations. He told, too, how it sold goods. For example, a kitchen knife sharpener during 6 months of radio featuring increased its sales 283.5 per cent over the preceding 6 months. Another example was a safety blade hone which, under the same conditions, showed a sales increase of $\mathbf{1 6 0 . 4}$ per cent. Radio was the

${ }^{1}$ Agnew and Dygert, "Advertising Media," p. 303, McGraw-Hill Book Company, Inc., 1938. 
only consumer advertising used. A week's fan mail for this program came from as many as 2,700 different cities and towns, and toward the end of the program's run, averaged 34,445 per week. The week's high was 96,546 .

\section{Coordination with Other Media}

Coordination with other media may mean (1) using other media to sell the radio program, or (2) simply coordinating the radio advertising with the advertising message in other media. The first includes, as already pointed out, the program spotlight advertisement in newspapers, which seems fundamentally sound. It also includes the by-lines in the general advertising calling attention to the radio program. Many advertisers object to this latter plan. "Who ever heard of using a car card or a billboard to ask the reader to refer to our advertisement in next week's The Saturday Evening Post?" they ask. "Let radio stand on its own feet; if it is an advertising medium, let it be independent like other advertising media." Sensible comment in many cases. It is a fundamental sales principle that one cannot sell two articles at once. If an advertisement is to sell goods, let it do it wholeheartedly. If it is to sell a radio program, charge it up to merchandising, to getting more circulation for radio, and use the whole advertisement for that purpose.

One of the outstanding illustrations of advertising to sell a radio program, as already pointed out, was when the Campbell Soup Company opened its Hollywood Hotel program a few years ago; a full page in color was used in The Saturday Enening Post on the opening week of the show. This was plain and simple broadcast merchandising. Nothing was said about the talking points of Campbell Soups. Another accepted example is the merchandising done in the dealer trade papers. It was fundamentally sound to take a full page in the trade magazine Meat, as Swift \& Company did, to sell the dealer on the radio program which this company was offering the public in the interest of the dealer.

Direct advertising and occasional direct-mail advertising will always be a legitimate part of radio advertising. The service booklets, the pamphlets, the direct-mail follow-up of radio inquirers, if well done and well organized, simply add to 
the effectiveness of radio advertising as they do in many cases to the effectiveness of advertising in other media.

The second class of coordination, the radio advertising message coordinated with that in other media, merely places the radio advertising as an integral part of the general advertising campaign. Selecting radio to reinforce a newspaper or outdoor advertising campaign in key cities or a national magazine campaign is an example. Which of the media in this case is primary and which supplementary depends on the objective of the campaign.

Radio, too, may find an effective use in bolstering up weak spots in other campaigns. For example, a spot radio campaign may be advantageously used in a city where, in spite of the regular campaign in other media, sales are not comparable with 'sales in other cities; or a spot radio campaign may be used in sections of the country where a national magazine campaign's coverage may be a little thin.

Strangely enough radio may bolster up or supplement itself. The advertiser may feel that an evening program over a national hookup is at its best with little sales talk. He may decide to take a morning program at the same time to do a little more intensive selling to the housewife. On the strength of a good-will program the night before, she may not object to an increased pressure on the sales angle the following morning.

An advertiser may feel that one program at any time is not enough to reach all classes and types of his prospects. $\mathrm{He}$ may therefore use more than one network program as Camel Cigarettes do with Benny Goodman's orchestra on Tuesday nights on one network and Eddie Cantor on Monday nights on another network. Some advertisers have several programs on the air during the same week at different hours. Sometimes the appeal is basically different to get different classes of prospects. More often, the idea is merely to reach listeners whose habits make it impossible to listen to a program placed entirely at the will of the advertiser. 


\section{CHAPTER XXII}

\section{TESTS AND SURVEYS BY BROADCASTERS}

Much emphasis has been placed in this volume on the necessity for showmanship in radio. One might wish radio showed less of it in presenting its own test and surveys. The businessman should look at all tests and surveys, for radio or any other medium, with a critical eye. If ever he needs keen judgment and critical understanding, it is in studying a survey made by any medium. There are so many legitimate, ethical ways of interpreting figures. And what medium would pocket its enthusiasm or its showmanship in presenting a favorable survey? Rest assured it would not be presented at all if it were not favorable. One suspects that filed away in the private archives of radio, and magazines, and newspapers, are some very damning surveys that just did not bear out the hunch of the media that made them.

\section{Check List for Studying Surveys}

If optimism and imagination are the handmaids of advertising managers, they should be laid off when the advertising man studies his tests and surveys. Suspicion and pessimism should take their place. Was the sample, i.e., number of people interviewed, large enough? Was it typical of the group being analyzed? Are the conclusions drawn from the data perfectly logical? Isn't there something hiding between the lines that will make the survey a farce? A leading question? A wrong premise? Make a survey prove every step of its way. Remember, if an advertising medium made it, it was to put the medium in a better light. Don't believe a word of it until you have to.

But if you have to, if the survey holds up under the most exacting acid tests, then, and then only, be convinced. Radio, like other media, has made some very unconvincing tests and surveys. Honest, of course, but weak in both their premises and conclusions, though so well presented that the average adver- 
tising man has accepted them, with probably no great harm done. But radio has done some very fine jobs too. Unlike other media, radio has been on the defensive from the start. It has had to fight every step of its way when it wanted to compare its effectiveness with that of other media. And in most cases it has done a fine job, especially where reliable and unprejudiced outside research companies have been employed. But even here, the businessman must be on his guard. A survey may be made by outside research companies, may be verified by them, and the figures absolutely beyond reproach. But the conclusions may have been drawn by the broadcasting company and who should blame them if their enthusiasm trips up their logic.

\section{Weakness of Present Coverage Surveys}

The implication included in some of the coverage propaganda of the broadcasting companies seems a case in point. It seems reasonable to believe that there are now $26,600,000$ radio homes in the United States. The methods used in arriving at this conclusion seem fair and unbiased. And it is reasonable to believe that a single great broadcasting station has $3,000,000$ or 4,000,000 radio homes in its area. But to imply or even hint that the advertiser can reach all this magnificent circulation just by going on the air is as sensible as to believe a newspaper can claim all the people in its city who know how to read. Even the good circulation work done by the Joint Committee on Radio Research, so long as it is based on this strange idea, can hardly be expected to be comparable to that of the Audit Bureau of Circulation for publications or the Traffic Audit Bureau's evaluation of circulation for outdoor advertising. It would seem to the author that radio circulation can never go on a comparable basis with other media and should not attempt to.

Give the advertiser a guarantee that all the coverage maps made by broadcasting companies are made by the same method. Audit them. Tell the advertiser the number of radio homes in such areas and caution him that he could not contact every home with his program even if he were an earthquake. How many of these homes he does contact will always depend on his program and any proof of circulation for his program does not prove that a similar program will have the same possibilities. Nor does it prove that his program's circulation of this Sunday 
night will be the same as the circulation for the same hour on Sunday night a month later. Actual listeners to a program should be the advertiser's problem just as actual readers of a given advertisement have always been.

\section{Worth-while Surveys}

Within the past several years, radio has presented along with the usual run-of-mill surveys, a number of really worth-while surveys that have assisted all interested in radio. Both the advertiser who wants to sell his product to the listeners and the educational uplifter who wants to sell his pet theories have. profited. Some of these surveys have been made at great expense and the broadcasting industry should be given credit for their presentation. Some of them have helped the advertiser to get a better picture of the radio listener and to build programs that please rather than antagonize. Surveys of listener preference for types of programs are an example.

Some of these surveys that seem to be generally accepted as to accuracy are worthy of mentioning. One, conducted by CBS continuously since 1933, covers the characteristics of various radio homes. ${ }^{1}$ It includes among other things:

1. U. S. radio ownership by income levels:

Radio Coverage,

Per Cent

Homes with incomes over $\$ 5,000 \ldots \ldots \ldots \ldots \ldots \ldots . . .69$

Homes with incomes $\$ 2,000$ to $\$ 5,000 \ldots \ldots \ldots \ldots . \ldots 96.3$

Homes with incomes under $\$ 2,000 \ldots \ldots \ldots \ldots \ldots . \ldots .1$

2. U. S. radio ownership by city size:

Radio Coverage,

Per Cent

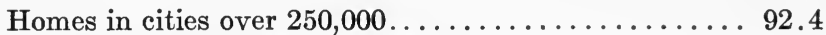

Homes in cities 25,000 to $250,000 \ldots \ldots \ldots \ldots \ldots \ldots 9.8$

Homes in cities 10,000 to $25,000 \ldots \ldots \ldots \ldots \ldots \ldots 9 . \ldots \ldots$

Homes in cities 2,500 to $10,000 \ldots \ldots \ldots \ldots \ldots \ldots 8.8 \ldots \ldots$

3. Interlocking markets:

95.0 per cent of urban automobile homes own radios

66.1 per cent of urban radio homes own automobiles

95.7 per cent of urban telephone homes own radios

I "Radio in 1937," Columbia Broadcasting System. 
cent listened while driving in the evening. One helpful questionnaire answerer scribbled a note on his questionnaire: "I find it helpful in reducing the amount of back-seat driving." Another lord and master of his household added: "When the family in the house wants one program and I don't want to listen to it, I turn on the radio in the car in the garage and listen to my favorite program out there."

\section{Station Promotion Surveys}

These surveys just discussed give information for the good of the entire industry. Another type of survey includes those made for the good of the individual station making the survey. These are legion in number. Some are obviously prejudiced, others perfectly fair. Most of them are useless except to prove a selling point for the station making them. An example of this type recently made by WOR at least shows ingenuity.

On Tuesday, Dec. 20, 1938, the station had seven full-time research interviewers of the Hooper-Holmes Bureau look into 5,850 cars parked in paid-space parking lots and garages in Manhattan, Brooklyn, Queens, Bronx-Westchester (N. Y.), and in Newark, N. J. They found that 40 per cent of the automobiles investigated were equipped with radio sets. (The national average for passenger cars is 35 per cent.) They found 35 per cent more automobile radio dials set at WOR's frequency than at the frequency of New York's other 50,000-watt stations. The figures were: WOR 23 per cent, Station B 17 per cent, Station C 13 per cent, Station D 10 per cent. Advertisers with statistical minds can, of course, tear down such a survey. But it makes a nice little "space seller's" story.

But surveys, big or little, conducted by independent research companies or broadcasting companies themselves will come and go. Many of them are good only for station promotional literature. A few may make radio history. As good as they are, they should be considered only when they are fresh. Six months in radio can see startling changes in the listener's preferences-and sometimes even in his listening habits. Today's radio facts may be misleading tomorrow. 


\section{CHAPTER XXIII}

\section{GETTING THE BEST OUT OF THE SMALL STATION}

Approximately 65 per cent of the commercial stations in the United States have less than 1,000 watts power. At the present, writing, only about 10 per cent of these small stations have national network affiliation.

There is a school of advertising men who say: "Beware of the small station unless it has national affiliation. Results are uniformly poor." But the facts do not bear this out. A small station well operated may be a gold mine to the advertiser, particularly to the local merchant, who may find the small station the only thing he can afford.

\section{The Doubtful Small Stations}

Today, with electrically transcribed music and drama so well handled by many of the small stations, the listener trend is toward the small station-if it has good programs. But unfortunately not all small stations are good stations. Shop the dial and see for yourself. One will find particularly a type of small station which is run with no more intelligence than a 10-year-old schoolboy would use; sometimes with less. No balancing of the day's offering, no fixed proportion of advertising to entertainment, no consideration whatsoever for the listener who does not have to listen to such a station-and who generally does not. A tiresome 3-min. commercial about Blank the Clothier at 327 Main Street, who is offering two pairs of pants with a $\$ 12$ suit and tossing in an overcoat for another $\$ 3.50$, is typical of the commercials offered by this type of station. Or a monotonous unbalanced offering of carelessly presented electrically transcribed musical numbers may be carefully alternated with an equal, or greater, amount of poorly prepared advertising material. Or worse, the local fireman's male quartette, with the tenor a half note off pitch may sing pieces that even the local choral society buried 10 years ago. There is no excuse for the existence 
of such stations and any advertiser who cares to spend a few hours in a listening checkup can easily avoid them. There ought to be a law against their cluttering up the air and giving a black eye to the really good small stations.

\section{The Good Small Stations}

And there are really good small stations; good small stations are like the good small country newspaper with an owner who ties his institution into local interests. The good small station takes pride in creating interesting material for its listeners. This type of station will have a worth-while collection of electrical transcriptions and the program director (he may also be announcer, salesman, and bookkeeper) will give some thought to coordinating the selections he offers. $\mathrm{He}$ will have separate programs for symphony and for swing music. He will write himself and his personality into the script. He will give a certain humanness to the station's offerings which will result in a loyal local listener following, a following who may desert for the big shows of the air but who will return often enough each day to make the station a profitable one for the advertiser. This station will make every reasonable effort to soften the tedious long-winded commercials so popular with the local merchant. Nor will this station allow over a certain percentage of advertising to each quarter hour. In other words, this small station will conduct its programs on the same principles, if not with the same skill, as the big networks. There will be developed a loyalty and confidence on the part of the listener which can be easily transferred to the advertiser who uses the station.

\section{Small Station Results}

That such stations exist and that advertisers find their listeners profitable prospects can easily be proved by a look at the records. Even the big national advertisers use them in addition to regular network offerings. Daytime programs, in particular, free from serious national competition are favorites. Transcribed dramatic strip shows (an episode a day) are popular and even 1-min. transcribed dramatic commercials when well done seem to bring results. Such programs are in favorite use by Procter \& Gamble Company. At the present writing they have spot announce- 
ments and spot dramatic programs on many of the small stations of the country.

On these stations, electrical transcriptions, because they are practically foolproof, are the rule. Complicated live shows requiring local actors and rehearsals are a risk. Simple live shows which can be built around the announcer are a possibility. Generally these small stations have at least one announcer who is passably good. Some of the smaller stations have really fine announcers. If these announcers have personality, the advertiser can with the proper arrangements use them as a kind of master of ceremonies for a live show, especially if the script is written by clever experienced script writers. For example, with the immense amount of news releases sent out by Hollywood, a newsy movie gossip script might be written and delivered creditably by the local announcer under the radio name of the "Movie Newscaster" or "Hollywood News." A checkup should be made, of course, to see that the title was not already being used by some other station or advertiser.

Health talks, fashion hints, home economics, interior decorating, and the like all have possibilities as small-station topics, if the subjects are near enough to the advertiser's products. Copies of the script could be spotted on such stations as fit into the advertiser's market campaigns. There is no reason why a good musical variety $15 \mathrm{~min}$. or even $30 \mathrm{~min}$. could not be worked out by supplementing the announcer's efforts with well-chosen electrical transcriptions. The small station probably suffers most from not having a good program planner. If the advertiser with expert assistance plans a good show, writes good script around the local announcer, a program can result comparable to some of the offerings by the big stations.

\section{How One Large Advertiser Ứses Small Stations}

An outstanding example of successful use of the small station by a national advertiser is the Esso News Reporter program familiar probably to millions of radio fans, which appears for 5 min. three times a day, on many large and small stations, This is a live program and the company's advertising agency, Marschalk \& Pratt, go to great pains to see that the program, whether on large or small stations, is presented acceptably to the 
radio listener. The news is condensed from the regular press news service but is chosen to fit the interests of the section of the country in which it is presented. The advertising script is carefully written to be close to the news and again is selected to fit the weather conditions in different parts of the country.

To be assured that the news will be presented in an acceptable manner, this sponsor makes a careful checkup of the station's announcer before it selects a station on this nationwide spot program. Records are made of the announcer's delivery; records from the air are also made, when the announcer does not know he is being checked. If he passes the tests and the station is selected, the regular prepared news and advertising script is furnished him on a regular schedule. This type of program is particularly appropriate for this sponsor because it can be woven smoothly into the advertising message and also because news is news on any station large or small and is bound to develop a more or less loyal following.

Other advertisers interested only in the live spot announcement on smaller stations (i.e., 1-min. commercial talks without entertainment) have worked out means to assure them that their announcements will be uniform and acceptable. The Scholl Company at one time sent to each spot station carefully prepared electrical transcriptions of several of their short spot announcements. The transcriptions were not to be given over the air, for the company preferred live announcements. The transcriptions were merely to be used as a guide for announcers to note the delivery, styles, and stress which the company wanted in its announcements.

These examples are given merely to show the advertiser that the possibilities of small stations have not as yet been fully exploited. A clever advertiser rather than imitate existing programs should set about developing something new. If he will put to work the same experts who develop his network programs, he should have an effective program which with modifications may be successfully used on hundreds of these small but good stations. Add the total potential circulation of the small stations, consider the small cost of program preparation, and add up the time rates and you may have a program that, when figured on a cost per thousand listener basis, may cost far less than a network presentation. 


\section{Check List for Small Stations}

In considering small stations, the basic principles involved seem to be: Do the operators of the station have the local interests of the community at heart? Are their sustaining features carefully enough prepared to create listener acceptance? Is their advertising censorship severe enough to keep undesirable advertisers off that station? Is the station entirely free from the influence of a given creed, cult, society, and the like?

It should be noted, too, that many of the small stations which are affiliated with the big networks take over a percentage of the network's sustaining and sponsored programs but operate a good part of the day on a local basis. Some of these network stations as well as independent stations have availed themselves of transcribed program service furnished by such companies as RCA Victor and World Broadcasting System. The Thesaurus Service, furnished by RCA Victor, gives stations transcriptions of the better type of music and orchestras and, with the proper arrangement, a program-planning service which can do much to improve the local offerings. 


\section{CHAPTER XXIV}

\section{FOREIGN BROADCASTING}

Far pastures always seem greener and many an advertiser has looked toward foreign markets before he has cropped all the choice green tufts in the domestic pasture. Other advertisers find that foreign markets have a really necessary place in their sales plans. A discussion of foreign markets and foreign advertising procedure has no place in a volume such as this. A discussion of foreign broadcasting per se has. To the advertiser who has not yet employed expert counsel and who may be asking himself, in an elementary way, "How about foreign broadcasting?" the following may serve as a kindergarten course.

\section{Basic Differences between Foreign and Domestic Broadcasting}

First, a few of the basic differences between foreign and domestic broadcasting. From the advertiser's standpoint, the first is that some countries do not permit broadcast advertising as we know it here in America. Outstanding of these is Great Britain, with approximately 17 stations, operated by the British Broadcasting Corporation, a division of the British Post Office system. No broadcast advertising is permitted, as will be pointed out later in this chapter, but there is a legitimate, if not ethical, way to deliver the advertising message to Great Britain's 8,347,800 radio homes. Some of the other countries prohibiting broadcast advertising are Germany, Soviet Russia, Sweden, and Japan. France's government radio stations accept no paid advertising but France's privately owned stations do. There are more than ten of these, five of which have over 10,000 watts power. One has 90,000 watts.

Other countries, for example, Belgium, Italy, Norway, Australia, Canada, Mexico, all the South American Republics, do accept broadcast advertising. ${ }^{1}$

${ }^{1}$ See "Broadcasting Year Book, 1939" for complete lists. 
Another feature of foreign broadcasting is that many of the countries have a radio tax. In Great Britain the fee is 10 shillings per set per year. Australia has an annual license fee of 1 pound, 1 shilling; Belgium, 60 francs; France, 50 to 200 francs.

Nor is coverage as great in foreign countries as it is in the United States; it is more class coverage and less mass. United Kingdom has approximately 10 per cent coverage; Canada claims 92 per cent coverage in Ontario, 58 per cent in Quebec, 55 per cent in Nova Scotia, and 42 per cent radio home coverage in New Brunswick. Mexico has 7 per cent coverage, Argentina 30 per cent, Brazil 4 per cent.

Many stations in South America are very small and poorly operated. It is said that South America is 10 years behind the United States in broadcast procedure and program presentationand 10 years in United States radio has covered a startling number of basic improvements.

Standard radio data are given on the following pages for a few of the countries in which the American advertiser might be interested.

\section{Broadcasting in Canada}

So close in broadcast advertising procedure is Canada to the United States that some Canadian coverage can be reached through Canadian stations affiliated with the large networks of the United States. The National Broadcasting Company in its rate card 25, dated Dec. 1, 1938, lists stations in Toronto and Montreal, including CBF at Montreal which is a French Language Station. The Columbia Broadcasting System in its rate card 24, dated Apr. 1, 1938, also lists affiliated stations in Toronto and Montreal. Of course, many of the large United States stations along the border cover much worth-while Canadian territory.

For the rest of Canada, for all of Canada for that matter, the Canadian Broadcasting Corporation offers an advertising service comparable with the service offered by United States networks. The Canadian Broadcasting Corporation offers 51 stations in 8 national network divisions. Six French network stations are also offered. On the CBC basic network of 34 stations, 1 hour costs $\$ 2,193$; $1 / 2$ hour, $\$ 1,316$; and $1 / 4$ hour, $\$ 877$. 
As already pointed out, in Chap. I, the Canadian Broadcasting Corporation has similar rulings to our own covering advertising, except that it limits both the number and wordage of the straight spot advertising announcements.

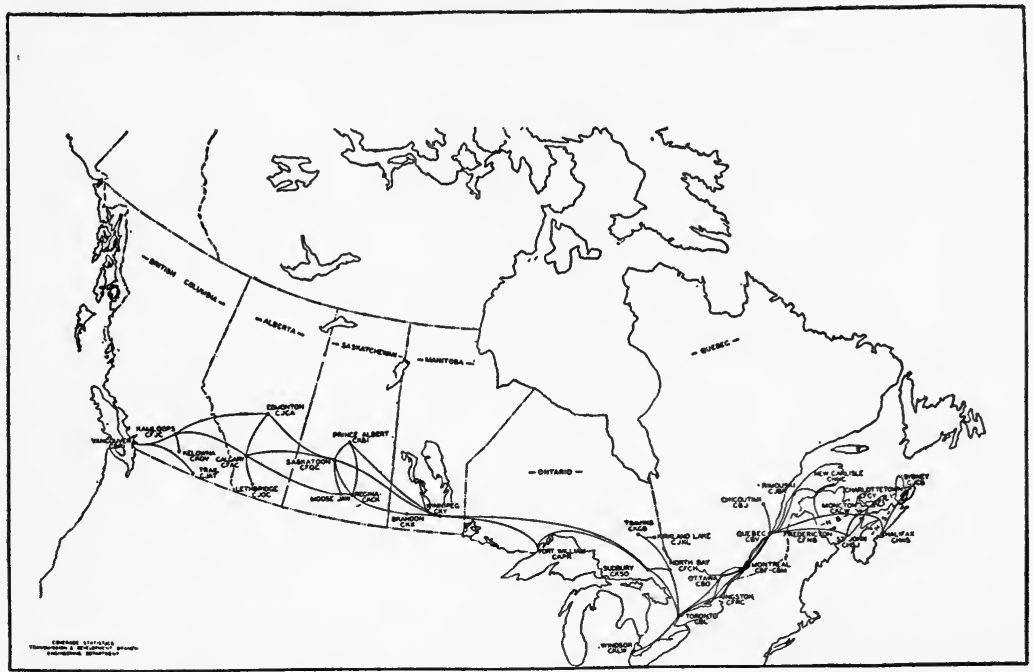

Map showing the location of stations of the Canadian Broadcasting Corporation's National and Regional Basic Networks. (Courtesy of Broadcasting.)

Canada's Largest Stations

\begin{tabular}{|c|c|c|}
\hline Location & Station & $\begin{array}{c}\text { Power, } \\
\text { watts }\end{array}$ \\
\hline Calgary. & CFCN & 10,000 \\
\hline Vancouver... & CBR & 5,000 \\
\hline Toronto........ & CBL & 50,000 \\
\hline Toronto..... & CFRB & 10,000 \\
\hline Montreal. . & $\mathrm{CBF}$ & 50,000 \\
\hline
\end{tabular}

\section{Broadcasting in Central and South America}

Mexico's broadcasting stations, numbering almost 100, accept advertising, with the exception of cultural and official stations. ${ }^{1}$ The power of the stations varies from 12 watts, XEFT at Vera Cruz, to 250,000 watts, XERA at Villa Acuna. There are about 300,000 to 350,000 radio sets in Mexico.

1 "Broadcasting Year Book, 1939," p. 344. 
Cuba's 88 broadcasting stations accept advertising. The largest station has a power of 25,000 watts, the smallest 200 watts. There are approximately 150,000 receiving sets in Cuba.

Argentine has approximately 50 stations which accept advertising. Power - varies from 500 watts to 50,000 (LRI at Buenos Aires). There are approximately $1,100,000$ radio sets in Argentine.

Brazil has approximately 60 broadcasting stations that accept advertising. Power varies from 250 to 25,000 watts. There are approximately 420,000 receiving sets in Brazil.

\section{The British Broadcasting Corporation}

It has already been said that Great Britain does not allow broadcast advertising. The shrewd advertisers of other countries who have wanted to reach the British radio ear have worked out ways to overcome this in part. Approximately one-half the British radio tax goes to maintain broadcasting and the rest to general governmental maintenance. This restricted radio budget has limited the amount of "flash" shows so generously paid for by radio advertisers in some of the other countries. In addition, the British Broadcasting Corporation has been very earnest in giving the British Public, not what they want, but what is good for them. On Sunday in particular, British broadcasting is what Sunday broadcasting might have been in Puritan 1870 - if we had had radio at that time. Religious services dominate the day's offerings. While this may be an admirable arrangement for the public good, the British public even as the American public would resent it and promptly turn to continental stations such as Luxemburg, Radio Normandy, and Post Parisien, Paris. These stations accept advertising and seem to have no such high ideals as to what is best for the public uplift. Thus do many radio advertisers reach the British market.

It has often been pointed out that the British Broadcasting Corporation has not succeeded in keeping broadcast advertising off the air waves of British, but merely off the British broadcasting stations. A recent nationwide survey conducted in Great Britain showed that 69 per cent of English radio owners were dialing sponsored shows coming from the continent. A 
similar survey in 1935 , showed 60 per cent of the radio homes were listening to commercial programs. ${ }^{1}$

Both British and American advertisers make use of this condition. Many large American advertising agencies have London branches which are said to place more than 50 per cent of all the advertising contracts for these continental stations.

Some of the American advertisers that thus enter Britain are: Ford Motor Co., Ltd., B. R. Goodrich Rubber Co., Colgate Dental Cream, Hind's Honey \& Almond Cream, Outdoor Girl Cosmetics, Palmolive, Thomas Cook \& Son, Ltd.

\section{Radio. Luxemburg}

Typical of the continental stations claiming both continental and British Isles coverage is Radio Luxemburg, a 200,000-watt

\begin{tabular}{|l|r|r|r|}
\hline \multicolumn{3}{|c|}{ NUMBER OF RADIO SETS IIN USE VERSUS POPULATION } \\
\hline \multicolumn{1}{|c|}{ COUNTRY } & POPULATION & RADIOS IN USE & \multicolumn{1}{|c|}{ RATIO } \\
\hline UNITED STATES & $130,000,000$ & $37,000,000$ & $1-31 / 2$ \\
Sweden & $6,233,000$ & $1,026,000$ & 1.6 \\
Denmark & $3,706,000$ & 673,000 & $1-6$ \\
Germany & $66,000,000$ & $8,000,000$ & $1-8$ \\
France & $41,834,000$ & $3,916,000$ & $1-101 / 2$ \\
Argentina & $12,561,000$ & $1,000,000$ & $1-121 / 2$ \\
Japan & $70,000,000$ & $2,593,000$ & $1-28$ \\
British Empire & $486,726,000$ & $10,000,000$ & $1-48$ \\
Italy & $42,527,000$ & 800,000 & $1-53$ \\
Mexico & $16,552,000$ & 250,000 & $1-64$ \\
Brazil & $45,000,000$ & 400,000 & $1-100$ \\
Russia & $165,000,000$ & 350,000 & $1-470$ \\
\hline
\end{tabular}

Note that the figures given in this table are for radios in use, not for radio homes. In the United States many of the $26,600,000$ radio homes contain two radios and a few boast of several. In the other countries listed, one radio to a radio home is quite standard. (Courtesy of Radio and Television Retailing.)

station located in the Grand Duchy of Luxemburg. It uses both live and electrically transcribed programs; it limits com-

${ }_{1}$ Advertising Age, Dec. 7, 1936. 
mercials to 40 words and commercial continuities to not over 190 words in 1 hour, nor 160 in $1 / 2$ hour, nor 95 in $1 / 4$ hour. Commercials may be given in as many as three languages for an extra consideration. The station broadcasts all day Sunday and every evening in English. Daytime, except Sundays, is reserved for Italian, French, German, and Dutch.

Coverage is claimed for Great Britain, Germany, France, Italy, Belgium, in fact for most of the European continent to the border of Soviet Russia.

It is assumed, of course, that any American manufacturer contemplating foreign broadcasting will appreciate the value of expert advice in making his plans, and expert advice on the radio habits and general likes and dislikes of each particular foreign market in which he is interested. He can generally in entering the foreign field multiply his American marketing headaches by three. Some who have tried it will say by ten. 


\section{CHAPTER XXV}

\section{TELEVISION, FACSIMILE, AND ULTRA HIGH-FREQUENCY BROADCASTING}

Should the advertiser begin to study the possibilities of television? A television broadcasting station, according to the Federal Communications Commission's rulings effective Sept. 15,1936 , is for "research and experimentation." Also the same source specifically states concerning rebroadcast of sponsored programs:

All commercial announcements not a part of the entertainment shall be eliminated from the television broadcast except the mere statement of the name of the sponsor or product or the televisioning of the trademark, symbol, slogan or product of the sponsor . . . . .

No licensee of any other broadcast station or network shall make any additional charge, directly or indirectly, for the simultaneous transmission of the aural or visual program by a television broadcast station, nor shall commercial accounts be solicited by the television broadcast station nor shall commercial accounts be solicited by the licensee of another broadcast station or network or by others acting in their behalf upon the presentation that the commercial program will also be transmitted by a television broadcasting station.

In short, the door to the generous advertising dollars that have built broadcasting to its present greatness are closed to television at the present writing. But in preparation for the day when the ruling may be changed, the progressive advertiser should be weighing television's possibilities as an advertising medium. As an entertainment and educational medium; television is very much here, although far more people have read about television than have ever seen a television broadcast. As'an advertising medium (when and if) it seems to have more disadvantages than advantages.

\section{The Mechanics of Television}

But first let us see just what television is and how it operates. It like motion pictures, owes its beginning to the principle of 
persistence of vision; i.e., if a number of separate spots of light are presented to the vision in rapid succession, the eye will see a continuous image. Motion pictures use 16 separate pictures per second. Television can produce about 30 complete pictures per second. For a 441-line picture, this means 13,230 lines of light per second. At first a rapidly revolving scanning disk having a series of small holes that allowed light from the object to reach photoelectric cells was used. The cells picked up each flash and transformed it into electrical impulses. These electrical impulses could be broadcast one dot at a time and the picture reconstructed again and presented to the viewer at a distance as a succession of small dots so rapidly delivered that the viewer saw continous pictures rather than the succession of lines of dots.

The principle of the dots in a half tone, with which the advertiser is familiar, is a parallel example. Put a magnifying glass on any newspaper or magazine half tone and the dots are plainly distinguishable. A greatly magnified slow motion of a television presentation under present conditions would show the same thing, except here the dots would at the original'speed be changing in character at the rate of 30 per second to give motion.

The first television sets were expensive, cumbersome, and every dot had to be wired to receive its succession of electrical impulses, 2,500 wires leading to 2,500 connections on the neon grid.

Today in the modern television set all this is changed. A pickup camera, the iconoscope, has a plate of photoelectrically sensitive particles upon which the lense of the camera focuses the scene. The stored-up electrical charges on the plate are then released one by one by a rapidly acting cathode-ray beam which directs a stream of electrons at the plate according to a pattern similar to the scanning in the original method. Each little charge is released one at a time. This is still called scanning. These charges are separately televisioned all at a rapid speed, broadcast, picked up in the home receiver, by similar but reversed method reassembled on the rounded end of a cathode-ray tube called the kinescope. These completed pictures changing at the rate of 30 per second, as already stated, are reflected in a mirror on the lid of the receiver. The kinescope tube most frequently used at present will provide a picture approximately 

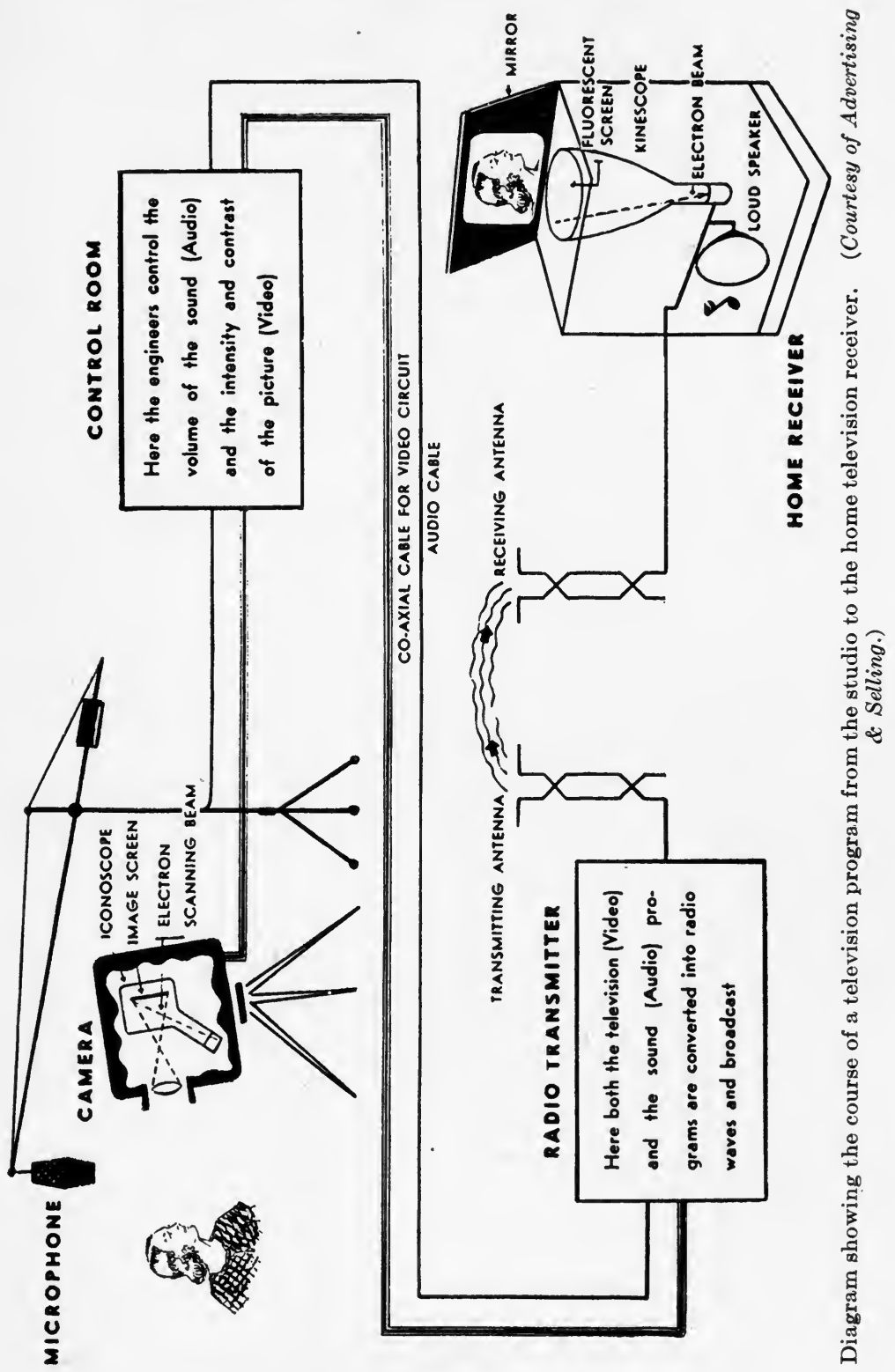
$71 / 2$ by $10 \mathrm{in}$. It is now claimed that several companies are prepared to make these new-type receiving sets at prices ranging from $\$ 200$ to $\$ 600$. To this sum should be added a very indeterminate amount to select a site and place for the home receiving antenna. A case is on record where it took two men 3 days to find the proper spot for successful reception.

The sending stations are highly expensive. NBC's television station with tele-aerial atop the Empire State Building in New York and CBS's station on the Chrysler Building are said to have cost $\$ 500,000$ each. And these stations are claiming only a coverage of 50 miles, 8,000 square miles and some 3,700,000 homes in the New York metropolitan area. If the advertiser were allowed to enter this picture, he would eventually be expected to liquidate a goodly part of this investment for the broadcasting company.

\section{Circulation}

The advertiser talks in terms of circulation-mass or class. He will pay several times more per thousand for class than for mass circulation and if he has a class-appeal product the extra cost is justified. Certainly, television will be a class circulation for some years to come and if the number of American television owners grows no faster than the number of British television owners has grown, it will be a long time before this circulation is a profitable buy for advertisers. In England, during the first year of television only 1,350 receiver sets were in use. Add to this the fact that with rapid strides in improved sending and receiving, present television sets might soon be obsolete, and we probably will find the days of profitable advertising circulation for television far in the future.

Mr. Sayre M. Ramsdell, Vice-President of Philco Radio \& Television Corporation, in a printed interview said recently:

It would cost $\$ 100,000,000$ to spread even a limited number of [television] stations over the United States. This cost would have to be borne by the industry in order to create a market for television sets. As there is no commercial value to the stations until advertising possibilities have been demonstrated and there must be a sale of receivers to justify the erection of stations . . . television is likely, for sometime to come, to be not so much of an industry as a headache. 
The radio manufacturers to a great extent paid the bill for radio broadcasting until its circulation was large enough to interest advertisers. There seems no reason why televisionset manufacturers, assisted by the great broadcasting chains, may not be able to do the same thing for television. It is absurd, however, to expect them to do the same thing in the same period of time used to build up radio.

\section{Television "Listening" Habits}

Will television eventually replace radio? The largest national networks are on record as saying $N o$ to this.

Lenox R. Lohr, President of the National Broadcasting Company, says: "Television will never supplant sound broadcasting. You can't watch television while you are eating, dressing, playing bridge, or doing odd jobs about the house."

William S. Paley, President of Columbia Broadcasting System says: "It will not, I believe, undermine or replace present broadcasting."

Motion-picture authorities said the same thing when asked if the sound movies would entirely replace the silent movies. But they did. However, the prophecy of Mr. Lohr and Mr. Paley seems far safer in the case of television. When one tries to forecast the listening habits of the future television owner, the basis for their prediction is evident. It is said man uses his ears three times more than his eyes. To use both intensively as would probably be done in television reception would put a nerve strain on the average listener too heavy to be borne more than an hour or two a day-especially after the novelty of television had worn off. The average radio listening per home at last report was close to 5 hours per day. After the first few months of novelty wears off, 5 hours of television broadcasting per day would be next to impossible for the average listener, who today listens as he works, eats, and plays. Television viewers in order to keep full sequence of the show will have to give full attention to the broadcast. No playing bridge, washing dishes, reading the newspaper, while a television program is on. By its very definition it demands both eye and ear and more concentration, a thing which the average John Q. Public is extremely short on today. 
Let us assume then that not only will the circulation of television be smaller, but the actual hours of listening fewer. All of which mean less satisfactory results for the advertiser.

\section{Cost of Television Shows}

But far more serious from an advertising standpoint will be the cost and preparation of television sponsored shows. Television will require a complete new technique, similar but not the same as that of motion-picture production. No seripts can be read, but must be memorized as on the stage. Some of our finest radio stars who were not brought up on the stage have never learned to memorize. For them, television may be impossible. Certainly, the price of actors must be raised. Also there can be no doubling of actors. Today a radio sketch calling for seven characters may be well handled by four or even three actors, for to change voice and character is part of an actor's business. With television no such happy situation can exist, because the eagle eye of the viewer will ever be on the stage.

Stage settings, too, must be complete in television and cannot be used over and over again like the local "opera house" street scene in Manhattan. In fact, in television whole costly scenes will have to be reproduced accurately and satisfactorily, whereas in radio a few well-chosen sound effects suffice. Compare the cost of a 15-min. "across the board" serial, now played with one or two actors, no setting, and little rehearsing, with the cost of a similar television presentation of four or five shows a week, parts letter perfect, stage directions and gestures well planned, scenery accurate and pleasing to the eye. To pay a sponsor, this show would have to sell more breakfast food per day than there are stomachs to hold it. Certainly a sponsored television show well done will be costly.

Television, in a way, has part of the answer to this. We shall reproduce movie film, replay or give premières of scenes from the latest Hollywood motion-picture productions, just as today radio is giving scenes from the same great productions. We shall go in for the unusual, a presentation of what one sees under the powerful microscope or equally interesting telescope. Street scenes, football games, special events, all these will make interesting and inexpensive sponsored shows. But today radio prepares thousands of shows a year. NBC claims to have built and 
produced more than 56,000 shows for its two networks in a single year, 1938. In credit to the producers there has been an infinite variety to the presentations of these radio programs. Can television entertainment do likewise?

Those who are given to prophesy say that television for some time to come will at best broadcast not more than an hour or two each day. And the avid radio listener of today is demanding 16 hours or even 24 hours a day from the present networks.

In emphasizing these disadvantages, the author in no way feels they are unsurmountable. He does believe, however, that it will take time-and a long time at that-to overcome them. In other words, while television is here, television advertising is not even around the corner.

\section{Advertising Advantages of Television}

From the advertiser's standpoint, television does offer the ideal in advertising-vision and motion. See a product, see its style, its line, its color (in time). See it in action! Here is a trade-mark, a package just as the prospect will see it on the dealer's shelves. All this has possibilities and will, when properly worked out, knock the last prop out from under the printed media's best talking point. Many food companies today, for example, spend large sums to get visitors to go through their plants, to see for themselves how sanitary the kitchen, how carefully prepared the product, how fine the ingredients. Anyone, for instance, who has been on one of the famous Heinz tours will vouch for the careful preparation of Heinz products. What a fine educational and advertising program this could be if made for television, yet one showing on television and the offering is old. It would be good for only one broadcast just as a Jell-o or a Chase \& Sanborn program, as interesting as it is, will not bear repeating next month or next year.

Another advantage of television is that, because the programs will require full concentration on the part of the listener-viewer, the advertising will be more carefully listened to and will be more likely to be favorably acted upon.

It has been said by those who feel television will replace radio as we know it today, that television programs will not necessarily require the full attention of the listener-viewer, and that in musical offering and even in sketches, he can if he chooses, 
listen and not look. Try shutting your eyes at the next motionpicture show you attend! It is bad enough trying to follow the action even now in listening to radio shows where the actors play to the studio audience. We have too many "sight jokes" on our radio programs as it is.

The very premise of television dramatic presentation will be that of the stage, the careful coordination of sight and sound. If a television show is designed so that it can be listened to and not seen, it is after all a radio show. But in spite of all this, sponsored television is something to be reckoned with. If and when it does come, let us not have the years of stumbling and experimenting with the advertiser's dollars that radio has hadnor a race so fast that no one has a chance to think over a show before presenting it. Radio grew so fast that no one had time to think; things were just done and done none too well and with little thought, but done on the moment because they had to be.

The more careful thought given to television by producers, actors, showmen, and advertising men before television is here in a big way, the better the shows, the better the advertising returns, and the fewer the headaches when it does arrive. An advertising man recently in writing for one of the trade papers said in substance: Do your planning now, be ready to act effectively when the time for sponsored television does come. Study the movie presentations, study stage productions. Ask yourself how could this be done in television. Can I improve it? What obstacles will arise?

Anyone following this procedure will be miles ahead of the last-minute boys when (and if) sponsored television becomes a fact.

\section{Television Coverage}

At the present writing television can be broadcast from specially equipped television studios as live shows, from standard motion-picture film, or under favorable conditions from such outside scenes as baseball or football games, fires or other catastrophes-from practically any scene that a motion-picture camera can pick up. These broadcasts are delivered to the home television sets in black-and-white pictures, comparable to a motion picture. Technicolor has not arrived yet, although experiments show it to be possible. 
These television programs are carried to the transmitter by a coaxial cable, or special wire line, developed in the Bell Laboratories. This cable costs about $\$ 1$ a ft., thus any long lines of it are economically impractical. This means that television as a network presentation is at present impossible. Probably for years to come, television will have coverage only in large cities.

In the advent of television advertising programs, television will not only be class rather than mass advertising, as already pointed out, but also confined to large cities and intense coverage.

\section{Television Advertising Presentation}

In anticipation of the coming of advertising to television, the large broadcasting companies already have special observers whose task it is to watch and chart the development in reaction to its possibilities as an advertising medium. These men have developed exhaustive files ${ }^{1}$ of information on all phases of television as an advertising medium and have explored its possibilities from the economic and from the practical advertising standpoints, have laid preliminary plans for the maintenance of proper statistical records, the measurement of reception conditions, and a study of the psychological aspects of television advertising. They are also carefully studying the application of television program technique to such problems as packagedesign commercial announcements, and dramatizations of the uses of products.

Thus those who are nearest to television are optimistic about the place advertising is to play in this coming field.

\section{Facsimile}

Here is more food for thought for the advertiser. Facsimile reproduction of pictures, type matter, and the like by ultra high-frequency transmission is not new by any means. For years facsimile systems have been in commercial use. RCA and the news syndicates have brought us pictures from abroad. Commercially, pictures, proofs, and the like have been transmitted from city to city by wire. A picture is presented in New York, and a few hours later in Chicago a facsimile is repro-

1 "Television in Advertising," National Broadcasting Company, March, 1939. 
duced. Now the broadcasting stations, under license for experimental work, are beginning to reproduce pictures and printed matter over the air, so that a home in their area equipped with a special receiving set would receive the facsimile in permanent form. Stations WHO, at Des Moines, Iowa, KSTP, at St. Paul and Minneapolis, Minn., WGH, at Newport News, Va., WOR, Mutual Broadcasting Key Station in Newark, N. J., have been delivering a morning newssheet, so to speak, to those chosen few who have facsimile receiving sets in their homes. WOR broadcasts news and pictures nightly at 2 A.M. after the regular broadcasting is off the air, and the next morning Mr. John Q. Public goes to his set and picks out his little newspaper which his set has made for him during the night, thanks to WOR.

This is an advertising book and the mechanical wonders of such reproduction have no place in it. As yet the F.C.C. has seen fit to bar advertising from facsimile broadcast as it has from television. If the ruling is revised, then again along comes a new possibility for the advertisers. As with television, the advertiser can ask himself the usual questions and be more or less prepared to do a good advertising job when and if the occasion arises. Certainly here again is a class medium with limited circulation.

\section{Ultra High Frequency}

At present the Federal Communications Commission has allocated for educational purposes purely as an experimental venture, a specific wave band in the ultra high-frequency range. It is claimed for this wave band that interference is little or none and that an inexpensive 100 - to 250 -watt station can cover effectively a territory of approximately 40 miles radius. The average radio set cannot pick up this high frequency and a special device must be added to make such a set effective. Television sets can pick up these ultra high-frequency broadcasts and as the stations become more plentiful, it is assumed that the new commercial sets will extend their receiving bands to cover such broadcasts.

At the present writing, the New York Board of Education has such a station in New York City and is sending out daily educational programs to the present limited audiences. It is 
doubtful if these bands will be opened to advertising. If they are, the broadcasting procedure will be no different from the present popular band presentations. There is no way at present to hook up ultra high-frequency stations for network broadcasts and their use for a long time to come will be for purely spot broadcasts. Of course, studio productions can be sent for any distance by special wire to the transmitters of these ultra highfrequency broadcasting stations, and it is to be assumed that, as with present short-wave broadcasting, many worth-while sustaining shows from the national networks will find their way to the ultra high-frequency stations as fillers.

\section{Short-wave Broadcast}

Short-wave broadcast offers no problem to the advertiser because paid-for advertising is barred and probably always will be. Its advantage is that it can carry farther than broadcasting in the popular bands. Broadcasts from abroad are sent by short wave, picked up here by short-wave receivers, and rebroadcasted over the popular wave bands. The interference and static are still very much short wave's problem, which again makes it an undesirable medium for advertising purposes. Short wave has been successfully used in sponsored broadcast presentations where wire facilities for transportation of the program were not available, such as following a golf champion in a national tournament. Also, a few years ago Admiral Byrd broadcasted by short wave from the South Pole for rebroadcast for the Ruppert Beer program. Broadcasts from airplanes, moving trains, boats, etc., have been picked up and handed to the great listening public by rebroadcast on a wave length that could be picked up by their sets. All too often the apology "conditions beyond our control" coming over the air has shown the average listener-and it should show the advertiser-that short-wave transmission cannot always be depended upon.

It is possible that eventually short-wave stations may accept advertising programs at advertising rates for international broadcasting. Already the Alka-Seltzer National Barn Dance Hour has been transmitted by short-wave to South America. But the station sending it was not allowed to charge the advertiser for this service. 
$\because 4$ 


\section{INDEX}

A

Across the board, 81, 101, 240

Actors, advantage of radio-trained, 70

microphone technique, 53

playing more than one part, 70

reaction, to air performance, 119

to studio audience, 67

stage or radio-trained, 69,70

Adam Hats' Sports program, 190

Advertiser, problem of small, 107

showman, 13-21

showman point of view, 13, 14

viewpoint, weakness of, 14

Advertisers, radio's big, 6

Advertising, amount per program, total, 133

comparison with printed media, 10 coordinating with other media, 33,74

expenditures in five media, 7

newspaper spotlight, 158

placing, 118

principles for radio, new, 10, 11

procedure, radio compared with

other media, 49

purpose of, in radio, 1

radio's annual income, 6

reaction of class group to, 118

types suitable to class group, 118 , 119

unsupported, weakness of, 9

use of cue scene, to introduce, 118

Advertising agencies, 209-213

business placed by, 211, 212

facilities for handling radio, 54, 117,210

factors in selecting, 212,213

history of, in radio, 209
Advertising agencies, importance of performance records in radio, 211

radio helped by, 209, 210

talent bureaus, 66

use of more than one, 213

Advertising message, cost of, 55

objection to, by listener, 15

placing, 129

tempo of, 130

words per minute, 130

Advertising script, approval of, by stations, 140

compared with advertising copy, 123

copy technique, 130

dictating, 131

examined by F. C. C., 143

mechanical aids in writing, 131

package identification on, 124

rules for writing, 124

simplicity, need for, 124

style in presentation, 125

tone of, 127

writers' need to know announcing, 132

writing, 123-133

Advertisements, characteristics of, 159

cost of, 159

examples of, 158

spotlight, 158-159

when to use, 159

Advertising \& Selling, 180, 237

Agencies, theatrical, 66

Agnew, H. E., 216

Allen, Fred, 18

Ambassador of good will, 3

Ameche, Don, 55

American Album of Familiar Music, 170 
American Home Products Corporation, annual radio expenditure, 18

American Society of Composers, Authors, and Publishers (ASCAP), 96, 97

Amos 'n' Andy, 70, 101, 108, 129

Amplifiers, 50, 52

Announcements, advanced radio, 156

closing, use for advertising, 125

courtesy, 156

opening, use for advertising, 125

spot, by electrical transcription, 61

examples of, 128

how sold, 101

importance of opening, 131

one-minute and five-minute, 101

use on small stations, 227

writing, 131

Announcers, diction of, 153

duties of, 54,55

furnished by advertising agencies, 55

history of, 55,56

men vs. women, 58

qualifications of, 57

sales message, and convincing, 57 selection of, 55

on small stations, 226,227

star, 55

women, when used, 58

words per minute, 130

Announcing, danger, of falling inflections, 56

of incorrect breathing, 56

of provincialisms, 56

definition of good, 57

qualifications for good, 56

rate of, 56

Applause, studio, cost of, 4

Argentine, broadcasting in, 230

number of radio stations, 232

number of sets, 232

Arrangements, musical, requirements for, 95,96
Artists, classification of vocal, 92 managers of, 66 publicity value of, 92 selection of, 92,93 service bureaus for, 66

ASCAP, 96, 97

Associating program with product, 168,169

Audience, loyalty of, 73

percentage, of night and day, 222 not at home, 37

not listening, 37

radio, 197

size affected by distance from station, 207

studio (see Studio audience)

Audimeter, 205, 206

Audio circuit, 237

Audit Bureau of Circulation, 220

Automobiles, radio equipped, number of, 28

survey of, 222,223

use of, $37 n$.

Ayer, N. W. \& Son, Inc., 10

B

Baker, Phil, 18

Balance, in program presentation, 120

showmanship and advertising, 18

Ballyhoo, 155, 161 .

Barnum, P. T., 117

Batten, Barton, Durstine \& Osborn, 57

Bell Laboratories, 243

Benny, Jack, 18, 118, 125, 168

Best Foods, Inc., 170

merchandising campaign, 173, 174

Better Business Bureaus, 165, 177

Blue network, NBC, 135

Bond Bread Reporters' Club, results of offer on, 80

Borden, Robert, 56

Borden Ice Cream Company, results of radio contest, 184, 186

Bowes, Major, 17, 18, 110

Original Amateur Hour of, 189 
Bowman, Francis D., 216

Box office, definition of radio, 155

Box-top jitters, 80

Brazil, broadcasting in, 230

number of sets in, 232

number and size of stations, 232

British Broadcasting Corporation, 229

operation of, 232, 233

Broadcast merchandising, $155-168$

(See also Merchandising)

Broadcasting, 71n., 78n., 146n.

Broadcasting, advertising facilities, 49-63

facsimile, 243,244

foreign (see Foreign broadcasting)

short wave, 245

studio layout, 51

television, 235-243

ultra high frequency, 244, 245

Broadcasting companies, facilities

for handling programs, 210

Broadcasting Year Book, 16n., $229 n ., 231 n$.

Broadcasts, of educational programs, 150

of news, 148

of political speeches, 148

of religious talks, 147

Broadsides to dealers, 160

Bulova Watch Company, 10

Burns and Allen, 18

Business men, how to reach, 29

Busse, Professor Alvin C., 56

Butler, Ralph Starr, 155

Buyers vs. listeners, 4

Byrd, Admiral, expedition, 245

\section{C}

Campaign, advertising, use of network and spot stations, 106.

examples of merchandising, 173, 174

Campbell Soup Company, 108, 160, 217

Canada, radio coverage, 230, 231

Canada Dry Ginger Ale, Inc., $161,166,188$
Canadian Broadcasting Corporation, advertising service of, 230

cost of time, 230

location of stations, 231

number of stations, 230

Canadian coverage by U. S. networks, 230

Cantor, Eddie, 17, 18, 68, 187, 218

Captain Tim's Adventures, program results, 215

Carborundum Broadcast, 216

Carrier wave, 52

Cathode-ray tube, 236

Censorship, 138-154

of children's programs, 140, 141

by Columbia Broadcasting System, 140

by Federal Communications Commission, 142

by National Broadcasting Company, 139, 140

radio, compared with other media, 143,144

testimonials of, 139

Chapman, Clowry, 181

Chase \& Sanborn, 83, 109, 110, 112 program of, 4, 55, 73, 208

cost per 1,000 listeners, 38

Chevrolet Motor Company, 60

Children, age groups of listeners, 80 exploitation by advertisers, 165

Children's programs, approval by parents, 80

censorship of, 140, 141

National Association of Broadcasters' proposed code on, 150,151

selection of, 77

Circulation, 35-48

actual vs. potential, 35,36

class, 11, 238

compared with other media, 8 11,36

effect of time zones on, 46

factors affecting, 44, 45

potential, 35,36

divisions of, 36,37

television, 238 
Clocking rehearsal, 53

Co-axial cable, 237, 243

Code of Ethics, National Association of Broadcasters, 145, 146

Columbia Broadcasting System, 43, 44, 108, 163, 192, 221, 239

"CBS Radio in 1936," $29 n$. censorship, 140

"Listeners and Dealers", 1938, 43n. "Listening Areas, Day and Night," $1935,43 n$.

map of network, 134

minimum stations purchasable, 103

number of stations, 45

television station, 238

Collier's, $97 n$.

Commentators, commercial, sponsored, 149

objections to, 6

Commercial, dramatic, example of, 127

placing, 126

example of, 128

leading up to, 129

length of, 133

CBS ruling, 140

NAB ruling, 153

objections to long, 33

straight, 126

use, of long, 74

of sound effects, 130

writing, 123-137

Commercial programs, types not acceptable, 151,152

Commissions, advertising agency, 107

on talent, 66

Competition, 37, 109-114, 201, 204, 206

effect of, 109

examples of, 206

among the evening programs, 201

mass vs. class programs, 113

on popularity ratings, 204

program, long range, 114

use of surveys to check on, 114
Consumer-jury, method of program testing, 192

Consumers, reaching through dealer, 171,172

Contact, how to get, 162-167

Contests, 143, 175-186

announcing winners, 183

choosing type of, 181, 182

danger of lawsuits, 180

duration of, 185,186

entry requirements, 186

Federal regulation of, 179, 180

free entry, 181

ill will, overcoming, 179, 182

importance of consulting Post

Office, 180

incentives to enter, 181

limited to purchase of product, 182

luck vs. skill, 179

making instructions clear, 180

objections to, 177, 179

prizes, size of, 182,183

reactions of losers, 176, 177

results from, 176, 184, 186

size of, 175

suggestions for-conducting, 183, 184

types of, 182

types of entrants, 178

Contracts, actors', 66

Control Console, 50

Control room, 49, 50, 54

engineer, 50, 52

master, 52

television, 237

Cooperative Analysis of Broadcasting (CAB), 37, 113, 196, 197, 199, 202, 203

history of, 199

rating, method of determining, 202

reports, typical pages from, 203

Coordinating radio with other media, 217,218

Copy technique, 130

Copyright, clearing musical, 97

duration of musical, 97 
Counter cards, 160

radio requirements for, 171

Counter literature, 171

Coverage, by city size, 221

comparison with other media, 38

day and night, 41,43

domestic and foreign, 230, 233

by income levels, 221

maps, use of, 220, 221

market, 39

national, 38,39

station, by power, 44,45

concentric circle method, 39, 40

controlled response method, 42

cumulative mail method, 42

field strength method, 40, 41

television, 242, 243

urban and rural compared, 105, 106

Cross, Milton, 55

Crossley, Inc., 29, 199

Cuba, sets in, 232

stations in, 232

$\mathrm{D}$

Damrosch, Dr. Walter, 87

Daytime hours, popularity of, 100

Dead spots in programs, danger of, 121,122

Dealers, distributing novelties through, 171

helping, to sell product, 172, 173

importance to radio, 168

keeping, interested, 168-174

merchandising, 173

prestige with radio, 173

selling the program to, 170

Deutsch, Hershal, 180

Dial shoppers, 208

divisions of, 2

popularity of, 2

Direct advertising, 217

Direct-mail advertising, 160, 217, 218

principles applied to radio, 73

Discounts, 107, 108

Doubling in brass, 70, 118
Dramatic commercial (see Commercial, dramatic)

Drezma, newspaper advertising of program, 158

Durstine, Roy S., 34, 57

$\mathrm{E}$

Educational broadcasting, NAB proposed code on, 150

Elder, Professor Robert F., 205

Electrical transcriptions, cost of, 62 description of, 58

designing programs for, 122

F. C. C. ruling on, 59,90

method, of making acetate, 60 wax, 59

Millerfilm, 60

payment of song copyright fee, 98

on small stations, $47,62,82,225$, 226

speed of, 59

use of, 61,62

Electrical waves, speed of, 53

Engineer, sound, 62

Equipment, remote control, 45

Erwin, Wasey \& Company, 15, 24

Esso News Reporter, 226, 227

Ethics, business, recommended by $\mathrm{NAB}, 154$

code of NAB, 145

Etude, The, $87 n$.

Evening hours, precentage of set owners listening, 30

popularity of, 100

Expedition, Admiral Byrd, 54

\section{F}

Facsimile, 243, 244

Families, radio, at home, not listening, 111

location of, by cities, 104, 105 by income groups, 104, 105

by geographic divisions, 104, 105

not at home, 111

Fan mail, danger of, 17 
Farmer, occupation affecting listening, 28

reaching, 19, 20

Federal Alcohol Administration, 143

Federal Communications Act of 1934, 138, 140, 141, 179

Federal Communications Commission, 141, 142, 244

index of program trends, 78

ruling, based on public approval, $15 n$.

on television, 235

Federal postal laws and regulations affecting contests, 179

Federal Trade Commission, 142, 143, 165, 177

Fitch, F. W. Company, contest results, 184

Fitch's Bandwagon, 109, 118

Food and Drug Act, 143

Ford Motor Company, 11

Ford Sunday Evening Hour, 16, $89,119,216$

Foreign broadcasting, 229-234

American companies using, 232

Argentine, 230, 232

Brazil, 230, 232

Canada, 230, 231

compared with domestic, 229, 230

Cuba, 232

difficulties of, 233

France, 229

Great Britain, 229

Luxemburg, 233, 234

Mexico, 230, 231

Foreign language stations, 11

Free-lance ideas, 116

Free offers (see Offers, free)

Frequency, of program, effect on listening, 205

Frigidaire, 172

\section{G}

Gallenkamp Stores Company, response to offer, 166

Gallup, Dr. George, 199

Gannon, Charles F., 15
General Foods Corporation, radio appropriation, 6,18

Gilmore Oil Company, response to offer, 166

Golenpaul, Dan, 188

Good taste, in program presentation, 120

NAB proposed code for, 146

Good will, radio as medium of, 214

Good-will program, 216, 217

Goode, Kenneth, 31, 81

Goodman, Benny, 218

Great Atlantic \& Pacific Tea Company, results of contest, 184

Great Britain, radio homes in, 229 stations in, 229

television, 238

Greene, Rosaline, 69

Grimshaw, Ira L., 144n.

Gulf's Passing Parade, 109

$\mathrm{H}$

Harlow, R. L., $71 n$.

Haws, R. Calvert, 120

Hecker's program, 24

Heidt, Horace, 117

Herbert, Victor, $96 n$.

Hettinger, Herman S., $34 n$.

Hobbies, use of, for program idea, 117

Hobby Lobby, 62

Hollywood Hotel, Campbell's, 110, 217

Homes, radio, number in U. S., 30, 104, 105

Hooper, C. E., Inc., 37, 109n., 113, 196-202, 205-207

Hooper-Holmes Bureau, 223

Hooper Radio Report, typical pages from, 200, 201

Horlick's Malted Milk, 190

Horn \& Hardart's Children's Hour, newspaper advertising of, 158

Hotchkiss, George B., $127 n$.

Hour of Charm, 87

House bands, use of, 94

House organs, 168 
Household Finance Corporation, air offers, 166

Housewife, occupations of, in radio homes, 24-27

reaching, 29

selecting program to suit, 77

Human interest, in programs, 20

Husing, Ted, 130

I

Iconoscope, 236, 237

Ideas, free-lance, danger of, 116 program, 117

Identification, sponsor, 198, 199

Identity of program, 168, 169

Indecent language, F.C.C. ruling on, 142

"Information, Please," 161, 188, 190

International broadcasting by short wave, 245

Ionosphere, 40

Ivory Stamp Club, 215

J

Jell-o, 38, 83, 125

program, 118, 169

Joint Committee on Radio Research, $28,36,220$

Juvenile clubs of air, 80

\section{K}

Karol, John J., 192

Kay Kyser's College of Musical Knowledge, 94, 190

KDKA, 16

Kinescope, 236, 237

King, Wayne, 214, 215

Kraft Music Hall, 110

L

Lady Esther, Ltd., 33, 58, 214, 215 sales success, 7

Lady Esther Serenade, 34

Lang, Chester H., 196
Lawsuits, in contests, 180 danger of, 144 over ownership of ideas, 116

Lawyers, checking script, 138

Lehman, A. H., 199, 204

Lehn \& Fink, merchandising campaign, 174

Length of program, doubling, effect on sales, 8

Lever Brothers Company, results of air offer, 81

Libel, 144

Liberty Magazine Radio Forum, 160

Liggett \& Myers Tobacco Company, 160

Lipton's Tea, newspaper advertising of program, 158

Listener, adapting copy to, 124

as buyer, 4

children, size of market, 79

curiosity, value of, 23

definition of, 22, 23

exploiting, 165

habits of, 24,81

intelligent, reaction to commercial, 34

interest groups, 73

juvenile, age of, 24

program preferences, 29

marginal, 112, 113

mood of, 22,23

number, at home, 30

listening to popular programs, 110,112

occupations affecting listening, 24

program preference, 114

reaction of, 162

to advertising, 190, 191

to contests, 176, 177

to end of program, 121

to sales talk, 33

and reader, compared, 67

replies from, 164

selecting programs to reach, 116

tying interests to program, 72

types of, 71

typical Sunday, 198 
Listener, use of newspaper listings to reach, 158,159 woman, 32

Listening, in city, 222 daily, average, 222 effect of competition, 206 of program preceding or following, 207

effective time for, 206, 222

habits, 29, 31, 32

television, 239

income levels, 222

limitation of, 110 mass vs. class, 32 popular hours, 29 reading habits compared, 22,23

Listings, newspaper, 157 planning successful, 157

Log, radio, 157

Lohr, Lenox R., 239

Lombardo, Guy, 34, 117, 187

Longines, Wittnauer Time Signals, 10

Lotteries, 181

F.C.C. ruling against, 142

Lucky Strike, 54

Lum and Abner, 190

Luxemburg, coverage of, 233, 244 radio, $232-234$

\section{M}

McCann Erickson, Inc., 199

McCarthy, Charlie, 113, 168, 198

McDonald, Joseph A., 144n.

McInnerney, Thomas H., 160

Magazines, advertisements featuring program, 159

advertising reinforced by radio, 218

March of Time, 115

Market Research Corporation, 24

Markets, geographic divisions of radio, 104, 105

by income groups, 104

interlocking with radio, 221

located by cities, 104

urban and rural, 105
Marschalk \& Pratt, 226

Mass-appeal program, expensive, 73 use of, 73

Massachusetts Institute of Technology, 205

Master of ceremony, 4, 11, 54, 55, 129

Maxwell House, 110, 169

Meat, 217

Media, coordination with radio, 217,218

Merchandising, broadcast, 155-174

campaigns, 173, 174

dealer, 168-174

NBC department of, 183

objectives of, 169, 170

Mexico, broadcasting in, 230 sets in, 231

Microphone, placing of, 49, 53 technique at, 53

Millerfilm, 60

Modernism in music, 96

Modulator, 52

Monitoring, 52

Movies, effect on radio listening, 100

Music, 86-98

artists, selection of, 92, 93

arrangements, length of, 96 requirements for, 95,96

ASCAP, 96, 98 register of theme songs, 97

background, as, 86

balance in programs, 92

bands, furnished by stations, 93 selecting, 93

bridges, 86,87

class appeal, 89

classification, of female voices, 93 of male voices, 92

copyright clearing, 97, 140 duration of, 97

dance orchestras, selecting, 93

electrical transcriptions, 90

feeling tone, 91

house bands, 94

instrumental combinations, 94

lovers, classes of, 86,87

mass appeal, 87, 94 
Music, modernism, danger of, 96 orchestras, selection of, $\mathbf{9 3}$ percentage on various programs, 86

presentation of, 91

rhythm in, 87

selection for programs, $86,90,94$, 95

songs, best sellers, 88,89

folk, 89

light symphonic, 95

new, danger of, 95

noncopyright, 88

old vs. new, 89

plugging, 95

selection of, 90

singers, 93

tempo, 91,94

theme songs, $86,87,96$

type of program, 94

unauthorized performance of, 97

use of, in programs, 90, 91

Music Publishers' Protective Association, 98

Musical director, 92

Muisical Moments, 60

Musical programs, planning, 86, 87, 92

popularity by types, 77,78

signatures on, 97

uses, in factories, 87

weakness of, 79, 87

Mutual Broadcasting Company, map of network, 136

number of stations, 45

\section{$\mathrm{N}$}

Name bands, value of, 66

Name stars, value of, 66

Nash-Kelvinator Corporation, 64

"Nationwide Survey of Listening Habits," NBC, $24 n$.

National Association of Broadcasters, Code of Ethics, 145, 146 proposed 1939 code, 146-154

National Barn Dance Hour, 245
National Broadcasting Company, $43,44,108,139,140,158,184 n$, $185,186 n ., 239$

basic networks, 103

"Coverage Areas, 1935," $43 n$.

how stations are sold, 45, 103

map of Red and Blue networks, 135

number of stations, 45

television station, 238

National Farm and Home Hour, 19

Nemo broadcast, 54

Networks, advantage in using, 45

basic, number of stations, 103

map of CBS, 134

Mutual Broadcasting System, 136

NBC, 135

vs. spot stations, 45

New York Board of Education, 244

New York University, 56, 192, 211

News broadcasts, NAB recommendations, 148

service, 227

Newspaper advertising, radio $\log , 67$ reinforced by radio, 218

Novelties, 163

distributed through dealer, 171

offers of, 165

public's appreciation of, 67

tied to program, 171

Noxzema Chemical Company, 64

\section{$\mathrm{O}$}

Offers, box-top, 172

cost of, 167

free, over air, 43, 163, 164

for program testing, 162, 163

results of, $80,81,163,164$ analyzed, 166

Orson Welles Campbell Playhouse, 190

\section{$\mathbf{P}$}

Package identification, in radio script, 124

in television, 241 
Paley, William S., 239

Parker, Seth, 172

Penner, Joe, 18

Pepsodent Company, 160

Personality, voice, 133

Philco Radio \& Television Corporation, 238

Photoelectric cells, 236

Pillsbury, example of commercial, 128

Pinoleum, example of commercial, 128

Political broadcast, NAB recommendations, 148

Popularity, holding, 11, 12 ratings (see Ratings, popularity)

Post Office, U. S., 143, 165, 177

Post Parisien, Paris, 232

Premiums, 165

for program testing, 189

Presentation of programs, television, 242

Pretested programs, 190

Printers' Ink, $7 n ., 143 n$., $177 n$.

Prizes, size of, contest, 182

Procter \& Gamble, 125

radio appropriation, 6,18

small station, use of, 225,226

spot announcement, sample of, 132

Product, actual sales over air, 164 fitting program to, 6

Professor Quiz, 64, 190

Programs, action-getting, 116 age of, affecting popularity, 205 children's, CBS censorship of, 140,141

$\mathrm{NAB}$ recommendations, 150, 151

planning of, 79, 80

selected to fit age group, 80

commercial types of, not accept-

able, 151, 152

competition in, 102

constructive criticism, value of, 119

course of, from microphone to home, 50
Programs, director, duties of, 91

selection of, 65

educational, weakness of, 21

essentials for effective, 120, 121

fifteen minute, use of, 101

free-lance ideas, danger of, 116

good-will, 33, 116

description of, 73,74

half-hour, 102

identity, 168, 169

imitation of, 77

information type, 76, 189

length of, determining, 101, 102, 116

mass appeal, 32, 33, 73

merchandising, 115

musical, types of, 76

natural, 71, 77

news, types of, 76

novelty, 75

one-hour, weakness of, 102

when necessary, 102

participation, 76

preliminary planning, 115

presentation, 115-122, 204, 207

balance, 120

form, 120

good taste in, 120

length, 121

progression, 120

tempo, 121

variety, 120

pretested, 190, 193

remote control, 54

rural vs. urban preference, 83

sales action on, 73,74

selection, 64, 115, 116

of basic idea, 117

by interest groups, 77

by types of listeners, 77

selling the dealer, 170

service type of, 76

small station, live, 226, 227

originating on, 115

procedure, 224-227

special appeal, 32

need for testing, 188 
Programs, special events, 76

special interest, examples of, 72

sponsored, why some fail, 2

straight dramatic, 76

strip, $101 n$.

successful small time, 4

sustaining, purchase of, 190

tailor-made, 161

talks, types of, 76

television, cost of, 240

source of material for, 240, 241

testing, 187-193

by consumer-jury, 192

examples of, 190

necessity for continued, 191, 192

time, last 3 minutes, 121

trends, 12, 77, 189

F.C.C., index of, 78

types, 71-76

appealing to women, 81

light symphonic, 95

percentages of, on air, 79

daytime, 75

evening, 74

F.C.C. index, 78

recognized, by broadcasting stations, 75

by CAB, 75, 76

selecting, 76,77

small stations, for, 81,82

for sponsoring, 76

use of more than one program,

218

variety, 33

Proprietary products, CBS censorship of, 141

objections to, on radio, 16

Prudential Insurance Company, spotlight advertising, 158

Public disapproval, danger of, 15

Public interest, convenience and necessity, 138

Publicity, 156-157

how to get, 67

word-of-mouth, 155
$\mathbf{R}$

Radio Act of 1927, 141

Radio Art, $69 n$.

Radio Corporation of America, 56

Radio Voice Technique Committee, 56

Radio City, master control desk, 52

Radio families, number and distribution of, 36, 104, 105

Radio sets, in foreign countries, 233 number of, 5

owned by income group, 222

with phonograph attachments, 31

Ramsdell, Sayre, M., 238

Ratings, popularity, 194-208

CAB method of, 199, 202

caution in using, 196

coincidental method, 197, 199

cost of, 195

distance from station, factor of, 207

evening and daytime, examples of, $200,201,203$

factors affecting, 204, 205

Hooper method of, 197

importance of, 113, 114

limits of, 194, 195

methods used, 196, 197

purpose of, 194

radio audience as used on, 197

recall method, 199

rural vs. urban, 84, 85, 196

use of, 195

RCA Victor, 62, 228

Reader vs. listener reactions, 67

Readers Digest, $188 n$.

Reading and listening habits compared, 22, 23

Recall method of popularity rating, 199

Reception time, effect on listening, 206

Red network, NBC, 135

Regional Advertisers, Inc., results of radio offers, 81 
Rehearsing, 119

duration of, 53

final, 118

Religious broadcasts, NAB recommendations, 147

Research, 187

Research companies, 189, 220 making popularity surveys, 195, 196

Rhythm, in music, 87 in script, 124

Richardson \& Robbins, 163

Ringle, Fred J., $97 n$.

Robinson, Henry Morton, $188 n$.

Rothafel, S. L. (Roxy), 95

Rural, adult male audience available to radio, 28

listeners, types of programs preferred, 83

listening hours, most popular, 100 listening surveys, 114

popularity ratings, 196

preferences, daytime programs, 85 evening programs, 84

\section{$\mathrm{S}$}

Sales Management, 34, 58, 133, 178, 198

Sales results, 215, 216

from Carborundum Broadcast, 216

Sales talk, objection to harsh, 3

Salesmen, using company, to sell program, 170

Samples, free, offered over air, 164

Scanning disc, 236

Schaefer Brewing Company, 38

Scholl Company, 227

Script, 119

(See also Advertising script)

Selby Shoe Company, 120

Selling, of products over air, 164 on radio, examples of, 214-216

Service departments, of broadcasting companies, 209

Sheffield Farms Company, 160

Short wave, 245

use of, in sponsored programs, 54
Show business, 19

politics in, 65

vs. showmanship, 19

Showman, 19, 112, 187, 195

characteristics of, 13

how radio got its, 16

importance of, 14

point of view, 13, 14

types of, 17

vs. advertiser, 13-21

Showmanship, examples of, 19

Shows, supercolossal, 7, 8 traveling, 82

Sign language, 53

Sinclair Refining Company, free offer, 166, 171

Slander, 144

Small stations (see Stations, small)

Smelser, Dr. D. P., 199

Smith, Kate, 18

Sohn, Monte W., 177

Song plugging, 95

Sound effects, examples of, 127

how produced, 63

script instructions, 63

use in commercials, 62, 130

Sound engineer, 62

Sound waves, speed of, 53

South America, broadcasting in, 230

Special interest programs, examples, 72

Spitalny, Phil, 87

Spoken programs, advantage of, 79

Sponsor, F.C.C. rulings concerning, 142

Hooper ratings of, 200

identity of, 31

Sponsor indentification, 198, 199

Sponsor's booth, 2, 54

Sponsored program, history of, 16 purpose of, 15

Spot stations, advantages of using, 46

announcement, CBC ruling, 10

example of, 132

length of, 9

vs. network, 45 
Spotlight advertisements, examples of, 158

in newspapers, 158

Standard Rate and Data Service, 107

Stars, method of checking their popularity on program, 208

Statement, of fact, 138 of opinion, 138

Stations, ASCAP fees from, 98 how many to use, 103

large vs. small, 46,47

musical staffs of, 93

personnel, 45

popularity, 45

small, 224-228

advantages of, 225

announcers on, 226

check list for selecting, 228

number of, 224

originality on, 64

possibilities of, 227

results, 225

weakness of, 224, 225

television, 238

time-selling, 101

Straight commercial, placing, 126

(See also Commercial)

Studio audience, advantages and disadvantages of, 67-69

capacities of studios for, 68

compared with listening audience, 17

merchandising, 68

reactions of, 68

studying, 2

tickets for, 68

when not needed, 69

Studio control room, 53

description of, 49

procedure in, 53

Stunts, examples of, 160, 161

merchandising, 169

Summer, effect of, on listening, 28

radio during, objections to, 28

Surveys, by audimeter method, 205, 206

broadcasters, 219-223
Surveys, check list for studying, 219, 220

coincidental telephone, 197, 199

coverage, weakness of, 220,221

danger in accepting, 223

listeners in Great Britain, 232

station promotion, 223

telephone, results of, 111

value of, 32

for testing program, 12

Sustaining programs, 10

purchase of, 190

Swift \& Company, 217

Junior Nurse Corps, result of offer, 80

\section{$\mathrm{T}$}

Tact, need for, in script writer, 124

Talent, cost of, 18, 61

procuring, 66

sources of, 66

types furnished by spot stations, 77

Talent scouts, 66

Tasteyeast, 96

Telephone, homes, number of, 197

use in survey (see Surveys)

Television, 235-243

advertising, advantages, 241, 242

presentation (when authorized by F.C.C.), 243

antenna, 237, 238

audio circuit, 237

cathode-ray tube, 236

circulation, 238

co-axial cable, 237,243

control room, 237

coverage, 242,243

diagram, program from studio to home, 237

disadvantages of, 239-241

iconoscope, 236, 237

kinescope, 236, 237

listener-viewer, habits, 241, 242

listening habits, 239

mechanics of, 235-238

photoelectric cells, 236 
Television, program, cost of, 240 presentation, 242

settings for, 240

source of material, 240, 241

scanning beam, 237

scanning disk, 236

sets, cost of, 238

suggestions for study of, 242

technicolor, 242

transmitter, 237

video circuit, 237

Tempo, advertising message, 130

musical programs, 91, 94

program presentation, 121

"Ten Years before the Mike," 130

Testimonials, 140

censorship of, 139

Testing procedure, 189, 190

Testing programs, 187-193

examples of, 190

special appeal, 188

value of, 187

Tests, value of, 12

Theme songs, ASCAP register of, 97 selection of, 96

Thesaurus Service, 228

Time of day, factors in selecting, 100

Time radio, advertiser's use of, 108

agency commission on, 107

buying procedure, 99-102

cancellation clause, 103

contracts, length of, 102

cost comparison with magazines and newspapers, 107

discounts, 107, 108

evening hours, cost of, 99 value of, 99

factors in selecting, 110, 112

Time schedules, how used, 53

importance of, 119

Time zones, difference in, 46

effect on circulation, 46

Timing, split-second, 52, 53

Tipper, Hotchkiss, Hollesworth, Parsons, 8n.

Today's Children, 128

Transcriptions (see Electrical transcriptions)
Transmitter, 52

television, 237

Transmitting, by facsimile, 243

by special wire, 54

Transmitting station, 53

Trends, in programs, 12, 77, 189

Traffic Audit Bureau, 220

U

Ultra high frequency, 244

Urban preferences, for leading daytime programs, 85

for leading evening programs, 84

U. S. Post Office, 143, 165, 177

\section{V}

Vallee, Rudy, 18

Variety, 24n., 29n., 93n.

Vick's Open House (Seth Parker), 109

Video circuit, 237

Visible audience, playing to, 69

Voice, personality, 56

qualifications for announcers, 55

Von Zell, Harry, 55

W

Wallington, James, 55

Waltz Time, Phillip's Milk of Magnesia, 112

War of the Worlds, 113

Waring, Fred, 18

Weather, effect on listening, 205

Weld, Dr. L. E. D. H., 199

Welles, Orson, 112

Wells, H. G., 113

WENR-WMAQ, 93

WGH, 244

Whiteman, Paul, 117, 187

Wilson, Don, 55

Winchell, Walter, 18

Window cards, 160

radio requirements for, 171

Window displays, in radio, 172, 173

WJZ, 62

WKY, 51

WLW, 45

WMAQ, coverage map, 42 
Woodruff, Professor L. F., 205

WOR, 62, 93, 223, 244

facsimile, 244

Millerfilm, use of, 60

Word-of-mouth publicity, 155, 176

Word pictures, necessity of, in radio script, 124

Work sheet, use of, 119

World Broadcasting System, 48, 62, 228

location of stations, 137
WQXR, 91

Writers, script, 117, 118

Writing advertising, 123-133

WSM, 215

WTHT, 93

WWNC, coverage map, 41

Y

Young, John S., 55

Young \& Rubicam, Inc., 10 




8. (1) 30 .

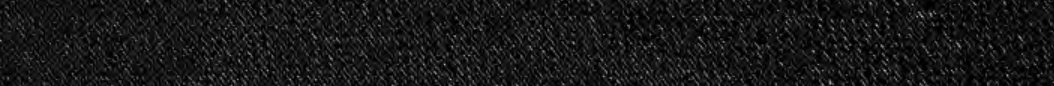

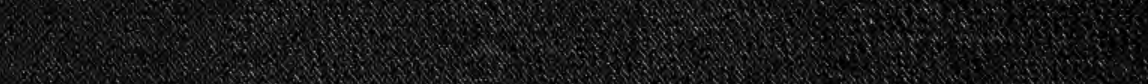
(1)

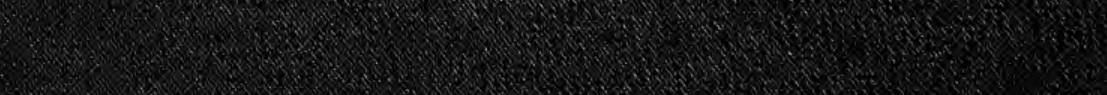
1. 